Sabine Klotz, Heiner Bielefeldt,

Martina Schmidhuber,

Andreas Frewer (eds.)

\title{
Healthcare as a Human Rights Issue
}

Normative Profile, Conflicts and Implementation 
Sabine Klotz, Heiner Bielefeldt,

Martina Schmidhuber, Andreas Frewer (eds.)

Healthcare as a Human Rights Issue

Menschenrechte in der Medizin | Human Rights in Healthcare | Volume 4 edited by Prof. Dr. Dr. Heiner Bielefeldt and Prof. Dr. Andreas Frewer, M.A. 


\begin{abstract}
This book deals with various facets of the human right to health: it's normative profile as a universal right, current political and legal conflicts and contextualized implementation in different healthcare systems. The authors come from different countries and disciplines - law, political science, ethics, medicine etc. - and bring together a broad variety of academic and practical perspectives. The volume contains selected contributions of the international conference »The Right to Health - an Empty Promise?« held in September 20I5 in Berlin and organized by the Emerging Field Initiative Project »Human Rights in Healthcare« (University of Erlangen-Nürnberg).
\end{abstract}


Sabine Klotz, Heiner Bielefeldt,

Martina Schmidhuber, Andreas Frewer (eds.)

\section{Healthcare as a Human Rights Issue}

Normative Profile, Conflicts and Implementation

[transcript] 


\section{(c) $)(i)(9)$}

This work is licensed under the Creative Commons Attribution-NonCommercial-NoDerivs 4.0 (BY-NC-ND) which means that the text may be used for noncommercial purposes, provided credit is given to the author. For details go to http://creativecommons.org/licenses/by-nc-nd/4.o/.

To create an adaptation, translation, or derivative of the original work and for commercial use, further permission is required and can be obtained by contacting rights@transcript-verlag.de

\section{(C) 2017 transcript Verlag, Bielefeld}

\section{Bibliographic information published by the Deutsche Nationalbibliothek}

The Deutsche Nationalbibliothek lists this publication in the Deutsche Nationalbibliografie; detailed bibliographic data are available in the Internet at http://dnb.d-nb.de

Cover concept: Kordula Röckenhaus, Bielefeld

Printed by Majuskel Medienproduktion GmbH, Wetzlar

Print-ISBN 978-3-8376-4054-0

PDF-ISBN 978-3-8394-4054-4 


\section{Table of Contents}

Healthcare in the Spectrum of Human Rights. An Introduction

Heiner Bielefeldt, Sabine Klotz, Martina Schmidhuber, Andreas Frewer $\mid 9$

\section{Normative Profile of the Right to Health}

The Human Right to Health.

Fundamentals of a Complex Right

Michael Krennerich | 23

The Minimum Core Approach to the Right to Health.

Progress and Remaining Challenges

Amrei Müller | 55

Conceptualising Minimum Core Obligations under the Right to Health. How Should We Define and Implement the sMorality of the Depthsı?

Lisa Forman, Luljeta Caraoshi,

Audrey R. Chapman, Everaldo Lamprea | 95

The Right to Health and the Global Rise of Non-Communicable Diseases

Brigit Toebes | 123

The Human Right to Health and Primary Health Care (PHC) Policies

Walter Bruchhausen | 145 


\section{EMPIRICAL VULNERABILITIES AND CONFLICTS}

Using EquiFrame and EquIPP to Support and Evaluate the Implementation of the Sustainable Development Goals

Tessy Huss, Malcolm MacLachlan | 169

Conscientious Objection in the Medical Sector.

Towards a Holistic Human Rights Approach

Heiner Bielefeldt | 201

The Implications of the Right to Health for Border Management. Emergency Assistance and Medical Screenings in the Context of Forced Migration

Veronika Flegar, Marie-Noëlle Veys $\mid 227$

Prevention of Torture and Cruel or Inhuman and Degrading Treatment in Healthcare

Adriaan van Es $\mid 263$

\section{Implementation in Healthcare Systems}

The Right to Health and the Post-2015 Health and Sustainable Development Goal Agenda. Jonathan Mann's 1997 Call for a Paradigm Shift Remains Imperative

Claire E. Brolan | 293

Mapping Constitutional Commitments on Sexual and Reproductive Health and Rights.

A Global Survey

Lucía Berro Pizzarossa, Katrina S. Perehudoff | 321

Emergency Treatment after Potential HIV-Exposure.

A Neglected Right to Healthcare?

Mathias Wirth | 347 
The Case Law on the Right to Health as an Example and as a Problem.

The Distortive Effects of Litigation Reconsidered

Laura Clérico, Leticia Vita $\mid 365$

IV. THERAPISTS AS AdVocates. THE EXAMPLE OF HELEN BAMBER

Human Rights in Practice.

Life and Work of Helen Bamber

Rachel Witkin | 395

Therapists as Advocates.

A Conversation with Helen Bamber

Freihart Regner, Rachel Witkin | 403

Authors $\mid 421$ 



\title{
Healthcare in the Spectrum of Human Rights. An Introduction
}

\author{
Heiner Bielefeldt, SABine Klotz, \\ MARTINA SCHMIDHUBER, ANDREAS FREWER
}

The human right to the highest attainable standard of health ${ }^{1}$ frequently evokes skeptical reactions. After all, human rights differ from moral postulates in that they impose binding obligations on the state, which under international law figures as the formal guarantor of the rights of those living under its jurisdiction. If that is true, however, how can a certain standard of health become a legally binding entitlement? Obviously, efficient and comprehensive healthcare presupposes an expensive infrastructure, which not every state can afford. ${ }^{2}$ Even affluent states face the problem of increasing healthcare expenses, which they may feel unable fully to shoulder in the long run. For economically impoverished states in the global south, the situation is much more dramatic; scarcity of resources may even hamper the development of a minimum healthcare infrastructure. In the light of such obvious contingencies, how can the state "guarantee« a right to health for everyone? If the state promises what is beyond its control, such a promise

1 For an overview on the right to health see Mann et al. (1999); Toebes (1999); Riedel (2009); Tobin (2012); Wolff (2012); Saul et al. (2014). For basic issues regarding the right to health see WHO (2008); Clapham (2009); Grodin et al. (2012); San Giorgi (2012); Toebes et al. (2014); Kavanagh (2016); Yamin (2017).

2 See Campbell et al. (1986); Beyrer/Pizer (2007); Gostin (2014); Harris et al. (2014); Cruft et al. (2015). 
does not seem to be fully reliable. Do we have to conclude that the proclaimed human right to health is illusionary? Is it but an empty promise? ${ }^{3}$

Radical critics of the right to health go a step farther by contending that the semantics of a right to health might in the long run weaken the validity claims of international human rights in general. ${ }^{4}$ Human rights are a particularly strong category of norms. Based on due respect for »the inherent dignity [...] of all members of the human family «, ${ }^{5}$ they have the elevated status of »inalienable rights «. Accordingly, human rights claim priority over other legal norms. Now, by inserting an entitlement that in practice depends on the availability of adequate resources and other socio-economic contingencies, the framework of human rights may eventually lose much of its stability and reliability. This at least is what skeptical commentators have objected. ${ }^{6}$

Such criticism has a long tradition, it sometimes culminates in a general juxtaposition of civil and political rights (CP rights), on the one hand, and economic, social and cultural rights (ESC rights), on the other. While CP rights, like freedom of conscience, freedom of religion, freedom of expression etc. claim unconditional validity, ESC rights, like the rights to education, housing or health remain merely conditional, given their resourcedependency. This in turn implies that ESC rights do not have the same elevated normative status as the »classical« $\mathrm{CP}$ rights - or so the critics would argue. They may go on to declare that $\mathrm{CP}$ rights chiefly impose negative duties on the state. For example, in order to do justice to freedom of expression or freedom of religion what the state has to do is merely refrain from exercising censorship or from harassing religious minorities, respectively. Not to do the wrong thing seems to be enough. By contrast, ESC rights require expensive infrastructural investments in schooling, housing or healthcare etc. They thus impose positive duties upon the state. This difference between negative and positive duties manifests itself also in the lan-

3 »The Right to Health - an Empty Promise? « was the title of our conference at the Berlin-Brandenburg Academy of Sciences and Humanities (September 2015).

4 See Wolf (2012) for an overview on the human right to health and its critics.

5 Universal Declaration of Human Rights (1948), first sentence of the preamble.

6 See Campbell et al. (1986); Beyrer/Pizer (2007); Harris et al. (2014); Cruft et al. (2015). 
guage of »obligations to respect« versus »obligations to fulfil«. Whereas $\mathrm{CP}$ rights call for respect by the state, ESC rights postulate far-reaching state activities - or so is the assumption. Finally, by carving out a sphere free from undue state inferences, CP rights are rights to freedom. Many of those rights - like freedom of expression or freedom of assembly - actually carry »freedom « in their titles. By contrast, the heading of ESC rights is less clear. Assuming that they inter alia rectify the consequences of social inequalities, they sometimes figure under the title of rights to equality.

The juxtaposition of CP rights and ESC rights may thus lead to the impression that these two categories of rights are essentially different, perhaps even antagonistic, as illustrated in the following table:

\section{Table 1: Juxtaposition of CP rights and ESC rights}

\begin{tabular}{|l|l|}
\hline \multicolumn{1}{|c|}{ CP rights } & \multicolumn{1}{c|}{ ESC rights } \\
\hline unconditional validity & merely conditional validity \\
negative state obligation & positive state obligations \\
(to respect) & (to fulfil) \\
rights to freedom & rights to equality \\
& \\
\hline
\end{tabular}

The consequences drawn from such an antagonistic conceptualization can be different. While radical critics of ESC rights reserve the title of human rights to $\mathrm{CP}$ rights, moderate critics push ESC rights to the margins of the human rights debate in order to keep the priority of the »classical« $\mathrm{CP}$ rights in place. This also manifests itself in different degrees of skepticism towards the right to health.

However, the antagonistic conceptualization of CP versus ESC rights has come under increased pressure in recent decades. It no longer represents the state of the international debate. ${ }^{7}$ The UN committee in charge of monitoring the 1966 International Covenant on Economic, Social and Cultural Rights (ICESCR) played a leading role in the ongoing effort to develop a more comprehensive normative framework. An important part of the work undertaken by the Committee was carving out »core elements« of the various ESC rights, including the right to health. ${ }^{8}$ It has become obvious

7 See Krennerich (2016).

8 See Tobin (2012); Müller (2016). 
that not all the elements of those rights are equally resource-dependent. Take the example of non-discrimination. Even an economically less developed country with a poor schooling infrastructure cannot give boys privileged access to schools, to the detriment of girls. This would be a flagrant case of discrimination and a clear violation of the right to education. Invoking limited resources would not justify such discrimination. Likewise, a country with scarce resources in healthcare cannot distribute those resources in a discriminatory fashion, for instance, by prioritizing members of a particular ethnic group or social class. This is an obvious problem also in rich Western countries, as illustrated by the inevitable competition over scarce organs, which must meet criteria of transparency, fairness and nondiscrimination. With regard to such »formal« criteria, however, countries like Norway and Burkina Faso are ultimately on the same page. This is an important insight. In other words, the focus on core elements of ESC rights has contributed to the awareness that not all aspects of these rights are entirely dependent on resources. Of course, the right to health covers many other aspects as well. It also includes an obligation for the state pro-actively to develop an appropriate health infrastructure, which naturally is a longterm project. While core elements have an immediate obligatory nature, other aspects of the right to health accommodate more leeway. With regard to the latter aspects, the state has a broader degree of discretion for implementing the right in a step-by-step fashion (progressive realization). ${ }^{9}$

When looking again at the $\mathrm{CP}$ rights, we may realize that things are not entirely different there. Without denying remaining conceptual differences, $\mathrm{CP}$ rights, too, cover various aspects, which likewise can be differentiated according to the logic of core elements and broader areas. Take the example of freedom of religion or belief. While the forum internum, i.e. the inner nucleus of a person's faith formation, even enjoys absolute protection, ${ }^{10} \mathrm{ex}-$ ternal manifestations of one's religious convictions can be limited, provided that all the criteria for such limitations are fully satisfied. Moreover, although issues like the treatment of religious diversity in the school curricu-

9 For an overview on state obligations and progressive realization see De Schutter (2014).

10 See Article 18(2) ICCPR (International Covenant on Civil and Political Rights). There are only few absolute norms in international human rights law. Examples include the probation of torture and prohibition of slavery. 
lum have an impact on the general atmosphere in a society and thus fall within the scope of freedom of religion or belief, human rights law does not specify any detailed rules, which the state is supposed to follow in this field.

Generally speaking, every human right - whether categorized as $\mathrm{CP}$ or as ESC right - is internally differentiated. While some aspects are immediately obligatory, other aspects allow for more leeway. Admitting this, however, must have consequences. It means to replace the antagonism of »unconditional« rights versus »conditional« rights by a more nuanced language. The question where exactly to draw the line between unconditional and conditional elements of human rights guarantees runs across the entire spectrum of CP and ESC rights. At any rate, to assume a neatly ordered bifurcation, like in table 1 , fails to capture the complexity of the problem.

The same is true for the distinction between "negative« and "positive« state obligations. Let us start with CP rights. Not to do the wrong thing would certainly not be enough for a state to discharge its human rights obligations. In order to realize freedom of expression, for example, the state has to provide effective protection to journalists under threat. NGOs promoting freedom of expression have furthermore demanded that the state facilitate the development of community radios for ethnic minorities and indigenous peoples, which requires far-reaching infrastructural investments. Likewise, to be able to enjoy their freedom of religion or belief, religious minorities may need an appropriate status position as a collective legal entity, which presupposes legislative efforts for that purpose. Finally, one should not forget human rights in general presuppose a functioning and independent judiciary, which one cannot take for granted. These examples may suffice to demonstrate that $\mathrm{CP}$ rights demand manifold state activities way beyond the proverbial »negative« duties of non-censorship and nonoppression.

Just as CP rights imply positive state obligations, i.e. obligations to protect and fulfil, ESC rights inter alia require of the state an attitude of respect. The state cannot implement the right to food without respecting people's dietary customs, including dietary rules based on moral or religious convictions. This is part of the right to food itself. To give another example, the right to education presupposes respect for specific needs and vulnerabilities of students from minorities and their parents. The right to health, in 
turn, requires a respectful attitude towards patients. As the ESC Committee points out in its General Comment No. 14 (2000) on the right to health:

»All health facilities, goods and services must be respectful of medical ethics and culturally appropriate, i.e. respectful of the culture of individuals, minorities, peoples and communities, sensitive to gender and life-cycle requirements, as well as being designed to respect confidentiality [...].«

These are very clear words. Many violations of ESC rights follow from a lack of due respect. ${ }^{11}$

Again, the neatly applied differentiation between negative and positive duties and their location in the CP and ESC camps, as illustrated in table 1, fails to do justice to the complex tasks ahead. Since the late 1990s, the ESC Committee and other UN bodies have in fact used a more adequate scheme. It has become customary to distinguish between three main state obligations, i.e. obligations to respect, to protect and to fulfil. ${ }^{12}$ The decisive point is that these obligations apply to all human rights, across the whole range of CP and ESC rights. In other words, not a single right would flourish without due respect, without efficient protection and without a workable infrastructure provided by the state. In this regard, CP rights and ESC rights are again on the same page.

Finally, one has also to overcome the ideological bifurcation of rights to freedom versus rights to equality. This opposition fails to make any sense. In the context of human rights, freedom and equality are two closely interwoven principles. Neither can exist without the other. Without a due account of equal implementation, freedom would end up as the privilege of the happy few, and without the spirit of freedom, equality could easily be mistaken for sameness, uniformity or homogeneity. Human rights in general are rights of equal freedom specified for the various aspects of human life. ${ }^{13}$ Take, for example, the right to marry a spouse of one's choice, which usually figures as a CP rights. It applies equally to men and women. Moreover, the equality principle has recently led to an opening up for same-sex couples as well. Freedom of religion or belief likewise has an equality dimension, because it challenges discriminatory practices and structures

11 E/C.12/2000/4, 11. August 2000, para. 12.

12 See Krennerich (2016).

13 See Bielefeldt (1998). 
based on people's religious or non-religious convictions. The right to fair trial - again a CP right - would amount to a mockery of human rights unless it is effectively open for everyone equally, including economically impoverished people. Indeed, no CP right can count as a human right unless it remains within a systematic framework of equality and non-discrimination.

When turning back to ESC rights, we can correspondingly find the principle of freedom in all of them. Take the example of the right to housing. It inter alia serves as one of the most important safeguards of personal privacy (which itself counts as a CP right). »My home is my castle« is an early-modern slogan demanding respect for privacy. Moreover, without adequate housing family life can hardly flourish in freedom. To give another example, the right to work includes the prohibition of forced labour, thus also contributing to the guarantees of human freedom. Finally, the right to health presupposes respect for the autonomy of patients. ${ }^{14}$ To quote again from the General Comment issued by the ESC Committee:

»The freedoms [as contained in the right to health] include the right to control one's health and body, including sexual and reproductive freedom, and the right to be free from interference, such as the right to be free from torture, non-consensual medical treatment and experimentation. ${ }^{15}$

Informed consent of patients, which specifies the principle of autonomy, has become an international standard without which the right to health would be inconceivable. Incidentally, healthcare professionals, too, should experience respect for their rights to freedom, including their freedom of conscience. $^{16}$

We thus have good arguments to replace the bifurcation of CP and ESC rights, as contained in table 1 by a holistic paradigm, in which $\mathrm{CP}$ and $\mathrm{ESC}$ rights mutually reinforce each other, as illustrated in the following scheme:

14 See Weisstub et al. (2008).

15 E/C.12/2000/4, 11. August 2000, para. 8.

16 Bielefeldt (2016). 
Table 2: CPESC-rights (mutually reinforcing rights)

\section{CPESC-rights}

Unconditional core elements + broader areas

State obligations to respect, protect and fulfil

Freedom and equality together defining the human rights approach

The new paradigm is important for the interpretation of all human rights. It also provides guidance for the understanding of the right to health. This has a number of implications. It underlines the need of carving out core elements of the right to health, in particular core obligations falling upon the state. Some articles in this volume are dedicated to further clarifying this important task. While resource-dependency remains an undeniable feature of the right to health, even in rich countries, the human rights nature much rests on the possibility of identifying core elements that apply universally. Another important consequence is the obligation to respect, which deserves more attention. It is understandable that much academic work currently undertaken deals with the obligation to fulfil, since this seems to be the area, where the right to health receives its practical contours. However, without due reflection on the obligation to respect, policies of implementing ESC rights could easily end up in mere cost analyses and utilitarian calculations of benefit distribution. It is worth highlighting in this regard that respect is more than a »negative duty« narrowly understood as merely refraining from doing harm. Respect presupposes a positive attitude of appreciating every human being as always »an end in itself«, to say it in Kantian terms. This respect also demands treating human beings as self-responsible subjects, which in turn requests rights to freedom for everyone equally.

The articles put together in this volume stem from a conference held in September 2015 in Berlin. Its original title was »The Right to Health - an Empty Promise? « It took place as part of the »Emerging Fields Initiative« (EFI) Project »Human Rights in Healthcare« supported by the FriedrichAlexander-University (FAU) Erlangen-Nürnberg. This includes Prof. Dr. Markus Krajewski (Centre of Human Rights Erlangen-Nürnberg, CHREN), who spontaneously supported the conference in various ways. We would like to thank all those who have contributed to the conference. We are also indebted to the FAU, Prof. Dr.-Ing. Joachim Hornegger, president of the 
FAU, and the team of the Emerging Fields Office (EFO) for the important support during our project »Human Rights in Healthcare« (2014-2017).

We want to thank Silvia Krönig, Frauke Scheller, M.A., Kerstin Wagner, M.A., Anja Koberg, M.A. and Cornelia Geisler, B.A. for their important editorial help. Many thanks to Diplom-Übersetzerin Carolyn Kenny and Francis Henry for parts of the translations.

We are particularly indebted to the authors of this volume who have submitted valuable results of their intellectual investments concerning the right to health. The articles contained in this volume originate from presentations first made in the above mentioned conference at the Berlin-Brandenburg Academy of Sciences and Humanities. We would like to see this volume as part of an ongoing cooperation across the boundaries of various disciplines.

\section{REFERENCES}

Beyrer, Chris/Pizer, Hank F. (2007): Public Health and Human Rights. Evidence-based Approaches, Baltimore: Johns Hopkins University Press.

Bielefeldt, Heiner (1998): Philosophie der Menschenrechte, Darmstadt: Primus.

Bielefeldt, Heiner (2016): »Conscientious Objection in Healthcare«, in: Frewer et al. (2016), 319-342.

Campbell, Tom/Goldberg, David/McLean, Sheila (Eds.) (1986): Human Rights. From Rhetoric to Reality, New York: Basil Blackwell.

Clapham, Andrew/Robinson, Mary (Eds.) (2009): Realizing the Right to Health, Swiss Human Rights Book, Vol. 3, Zürich: Rüffer \& Rub.

Cruft, Rowan/Liao, Matthew/Renzo, Massimo (Eds.) (2015): Philosophical Foundations of Human Rights, Oxford: Oxford University Press.

De Schutter, Oliver (2014): International Human Rights Law. Cases, Materials, Commentary, Cambridge: Cambridge University Press.

Frewer, Andreas/Bergemann, Lutz/Jäger, Christian (Eds.) (2016): Interessen und Gewissen. Moralische Zielkonflikte in der Medizin, Würzburg: Könighausen \& Neumann. 
Frewer, Andreas/Bielefeldt, Heiner (Eds.) (2016): Das Menschenrecht auf Gesundheit. Normative Grundlagen und aktuelle Diskurse, Bielefeld: transcript.

Gostin, Lawrence (2014): Global Health Law, Cambridge: Harvard University Press.

Grodin, Michael A./Tarantola, Daniel/Annas, George J./Gruskin, Sofia (Eds.) (2013): Health and Human Rights in a Changing World, New York: Routledge.

Harris, David/O'Boyle, Michael/Bates, Edward/Buckley, Carla (2014): The Law of the European Convention on Human Rights, Oxford: Oxford University Press [3rd edn.].

Kavanagh, Matthew M. (2016): »The Right to Health. Institutional effects of constitutional provisions on health outcomes«, in: Studies in comparative international development 51, 3 (2016), 328-364.

Krennerich, Michael (2016): »Das Menschenrecht auf Gesundheit. Grundzüge eines komplexen Rechts«, in: Frewer/Bielefeldt (2016), 57-92.

Mann, Jonathan Max/Gruskin, Sofia/Grodin, Michael A./Annas, George J. (Eds.) (1999): Health and human rights. A reader, New York: Routledge.

Müller, Amrei (2016): »Die Konkretisierung von Kernbereichen des Menschenrechts auf Gesundheit. Internationale Debatten $\mathrm{zu}>$ Minimum Core Obligations «, in: Frewer/Bielefeldt (2016), 125-168.

Riedel, Eibe (2009): »The Human Right to Health: Conceptual Foundations«, in: Clapham/Robinson (2009), 21-39.

Salomon, Margot/Seiderman, Ian (2012): »Commentary to the Maastricht Principles on Extraterritorial Obligations of States in the Area of Economic, Social and Cultural Rights«, in: Human Rights Quarterly 34, 4 (2012), 1084-1169.

San Giorgi, Maite (2012): The Human Right to Equal Access to Health Care, Antwerp: Intersentia.

Saul, Ben/Kinley, David/Mowbray, Jacqueline (Eds.) (2014): The International Covenant on Economic, Social and Cultural Rights, Oxford: Oxford University Press.

Tobin, John (2012): The Right to Health in International Law, Oxford: Oxford University Press.

Toebes, Brigit C. A. (1999): The Right to Health as a Human Right in International Law. Antwerp: Intersentia. 
Toebes, Brigit C. A./Ferguson, Rhonda/Markovic, Milan M./Nnamuchi, Obiajulu (Eds.) (2014): The Right to Health. A Multi-Country Study of Law, Policy and Practice, The Hague: TMC Asser Press/Springer.

Weisstub, David N./Díaz Pintos, Guillermo (Eds.) (2008): Autonomy and Human Rights in Health Care. An International Perspective. International Library of Ethics, Law, and the New Medicine, Volume 36, Dordrecht: Springer.

WHO (2008): »Commission on the Social Determinants of Health (CSDH), Closing the gap in a generation: health equity through action on the social determinants of health «, Final Report of the Commission on Social Determinants of Health, Online: http:/www.who.int/socialdeterminants /thecommission/finalreport/en/index.html [15.06.2017].

Wolff, Jonathan (2012): The Human Right to Health, New York: Norton Company Inc.

Yamin, Alicia Ely (2017): »Taking the right to health seriously. Implications for health systems, courts, and achieving universal health coverage «, in: Human rights quarterly 39, 2 (2017), 341-368. 



\section{Normative Profile OF THE Right to HEALTH}





\section{The Human Right to Health}

\section{Fundamentals of a Complex Right}

MICHAEL KRENNERICH ${ }^{1}$

\section{INTRODUCTION}

Human rights as they are enshrined in public international law concern primarily the relationship between the individuals as right holders and the state as the primary duty bearer. The underlying idea behind such a human right to health is that the state refrains from compromising the health of the people, protects them against interference, and undertakes measures to ensure that healthy living and working conditions are available to the people and above all that they have access to appropriate healthcare.

\section{EnSHRining the Human Right to Health IN INTERNATIONAL HUMAN RIGHTS LAW}

The article commences by embarking on a short trek through the jungle of international law documents and treaties in which the human right to health is set down. The starting point is the second half of the 1940s when following the Second World War, building on corresponding historical forerun-

1 This contribution is a slightly modified translation of a German article first published in: Zeitschrift für Menschenrechte (Journal for Human Rights) 9, 2 (2015). Furthermore, see Krennerich (2016). 
ners and contemporary preparatory work, modern-day human rights protection came into existence and the human right to health was incorporated within the United Nations framework.

The World Health Organization (WHO) set out already in the preamble to its 1946 constitution that each individual person has a fundamental right to the »enjoyment of the highest attainable standard of health «. In doing so the WHO defined health in a comprehensive and ambitious way as a »state of complete physical, mental and social wellbeing and not merely the absence of disease or infirmity ${ }^{2}{ }^{2}$ The WHO thereby detached itself from a purely biomedical understanding (and most everyday notions) of health as being the freedom from physical and mental illnesses and impairments ${ }^{3}$ and ignited a lively expert debate, and not only among medical professionals. On the one hand, the concept of health as complete wellbeing ${ }^{4}$ was often criticised as utopian, ${ }^{5}$ on the other hand it remained heavily disputed what exactly such wellbeing consisted of. ${ }^{6}$

Although due to its non-binding character the WHO preamble does not strictly speaking amount to a source of law for the right to health, ${ }^{7}$ the WHO definition is frequently used in human rights discourse. ${ }^{8}$ Interesting issues arise not only because this approach emphasises the interconnectedness of physical, mental-psychological and social aspects of health. Also the subjective components of health inherent to wellbeing are emphasised. Understood in this way, defining health as wellbeing is no longer just a matter for experts. Nevertheless, not every person who feels well is healthy from a medical point of view, and not everybody who is feeling unwell is sick. As such the danger exists that the biomedical profile of health, which is imperative for healthcare in the strict sense (and which the WHO does not completely abandon) will become less selective.

2 Constitution of the World Health Organization: www.who.int/governance/eb/ who_constitution_en.pdf [01.03.2017].

3 Franke (2006), 32.

4 It would possibly make more sense to understand »complete wellbeing « in the sense of a »comprehensive« rather than »total« wellbeing.

5 Instead of many: Venkatapuram (2011), 66.

6 For example Dodge et al. (2012).

7 Hestermeyer (2007), 113.

8 For example UNICEF (2002), 344; Freeman et al. (2012), 315. 
As it is »only« a declaration of the UN General Assembly, also the Universal Declaration of Human Rights (UDHR) from 1948 was originally not binding in public international law. However, in the course of time the UDHR, which has been translated into over 300 languages, has developed a large moral, political and at least indirectly a legal importance. Its legal effect is due to the fact that it contains general legal principles and human rights norms recognised by customary international law. Well justified is also the belief that the UDHR substantiates the purpose of the UN Charter which is binding on all UN Member States - to promote and strengthen respect and observance of human rights and fundamental freedoms for all people without discrimination. ${ }^{9}$

The human right to health cannot, however, be found in the UDHR in a separate article as would be expected and as was discussed in the Human Rights Commission. ${ }^{10}$ Instead, in order to keep the UDHR short and concise, it was enshrined as part of the right to an adequate standard of living which guarantees everyone health and wellbeing, including food, clothing, housing and medical care and necessary social services (Article 25, para. 1). Contrary to the preamble of the WHO constitution, the UDHR differentiates in its wording between health and wellbeing, makes clear, however, that both are closely related. With regard to the right to health, which in the UDHR is not clearly differentiated from the other components of the right to an adequate standard of living, it should be noted that the UDHR identifies medical care as a central but not the only element of this right. Also social security, especially in cases of illness and invalidity, as well as access to healthy living conditions (food, housing, etc.) play an important role.

The right to health was later enshrined separately and with binding effect in international (treaty) law in the International Covenant on Economic, Social and Cultural Rights (ICESCR) from 1966 and which came into force in 1976. The ICESCR is the fundamental UN Human Rights Convention on Economic, Social and Cultural rights (ESC rights) including the right to health. In the convention, the now 165 State Parties (as of

9 On the legal nature of the UDHR see, e.g. Nettelsheim (2009).

10 Morsink (1999), 192-199. See also the collection of documents by Schabas (2013). 
25.07.2017) recognise the right of everyone to the enjoyment of the highest attainable standard of physical and mental health (Article 12, para. 1).

Two aspects need to be emphasised here. Firstly, the ICESCR moves away from the notion of a right to be healthy. ${ }^{11}$ Such a right appears to still be laid down in the preamble to the WHO constitution which talks about a state of complete physical, mental and social wellbeing. Secondly, in the ICESCR the highest attainable standard refers only to physical and mental health but not, for example, to »social wellbeing " (as intended in the original draft of the commission) or even to "moral wellbeing " (as the delegations from Afghanistan and the Philippines suggested at the time when the convention was being drawn up). ${ }^{12}$ The social conditions are consequently rather determinants for health than their defining component.

Also, the measures stated in the non-conclusive list in the ICESCR for the realisation of the right focus on physical (and mental) health, naturally taking account of contextual conditions which can promote or impair health. The measures are aimed at reducing stillbirths and infant mortality, the healthy development of the child, environmental and industrial hygiene, the prevention, treatment and control of epidemic, endemic, occupational and other diseases, as well as people's access to medical facilities and medical attention (Article 12, para. 2). There are overlaps with the right to just and favourable working conditions and the right to social security, both of which are enshrined in separate articles.

Further UN human rights conventions also include the right to health or individual aspects of it in respect of particular problem areas or especially disadvantaged or needy population groups. The International Convention on the Elimination of All Forms of Racial Discrimination (ICERD) from 1966 (in force since 1969) enshrines the non-discriminatory right to public health, medical care, social security and social services (Article 5).

The UN Convention on the Elimination of All Forms of Discrimination against Women (CEDAW) from 1979 (in force since 1981), which until today 189 states have ratified provides in various parts of the convention for numerous measures to realise the right to health without discrimination, not only in the area of healthcare (Article 12), but also in the area of healthrelated education, in the workplace, in relation to family planning, in rural

11 See E/C.12/2000/4, 11th August 2000, paras. 4 and 8.

12 Saul et al. (2014), 980. See also Tobin (2012), 125. 
areas and during pregnancy, when giving birth and whilst breastfeeding. ${ }^{13}$ Several other rights concern social determinants of health. ${ }^{14}$ By pointing out the gender dimensions of health, the convention enables human rights violations to be identified that would perhaps otherwise have remained undiscovered and to demand human rights policy measures which would possibly otherwise never have been taken (as comprehensively). This includes, for example, measures relating to reproductive and sexual health. ${ }^{15}$

The UN Convention on the Rights of the Child from 1989 (in force since 1990), which now has 196 state parties and - with the exception of the USA - has been ratified by all states worldwide recognises the right of the child to the highest attainable standard of health and to facilities for the treatment of illness and rehabilitation of health (Article 24, para. 1). The convention names (not exhaustively) various measures for securing the complete realisation of the right to health, amongst other things the reduction of child and infant mortality, the securing of medical assistance and healthcare for children, the combatting of undernourishment and malnutrition, healthcare for mothers as well as various aspects of health education, hygiene, breastfeeding, accident prevention and family planning (Article 24). At the same time the UN Convention on the Rights of the Child provides for protective measures against the health-damaging economic exploitation of children and against the use of addictive drugs by children (Article 32, para. 1; Article 33). Particular obligations to protect arise in connection with the state accommodation of physically and/or mentally ill children (Article 25). Furthermore, the convention refers to the particular needs of children with disabilities, to whom the access to healthcare services must be ensured (Article 23).

The rights of persons with disabilities, including the right to health, were substantiated and differentiated in the UN Convention on the Rights of Persons with Disabilities from 2006 (in force since 2008). With this convention now 174 state parties recognise the right of persons with disabilities to the highest attainable standard of health without discrimination due to their disabilities. Also, the convention names - again non-exhaustively -

13 CEDAW, Article 10(h), Article 11, para. 1(f) and para. 2(d), Article 14, para. 2(b).

14 CEDAW A/54/38/REV I., 2nd February 1999; see also WHO (2008).

15 Freeman et al. (2012), 320-323. 
numerous measures for the complete realisation of the right. These seek to remove discrimination when it comes to access to healthcare and also to health and life insurance - something which is often overlooked - and aims to take into consideration the specific health needs of people with disabilities (Article 25). By taking a »diversity approach« which sees physical and mental disability as a part of normal human life, and by aiming at the »removal of barriers « for those people who are confronted with various social barriers, the UN Convention on the Rights of Persons with Disabilities impressively overcomes a purely medical »deficit approach« to disability. At the same time it takes physical and mental impairments seriously enough to constitute a particular need for action for an assisted autonomy ${ }^{16}$ in the area of health and in other areas of life. No other convention is as strongly characterised by the understanding of health as »capability« as the UN Disability Rights Convention. ${ }^{17}$

The conventions mentioned so far do not differentiate in their wording between persons of different nationalities. The practice of the respective states is, however, that foreigners sometimes do not enjoy the same entitlement to healthcare as nationals. The problem becomes clear in the $U N$ Convention on the Protection of the Rights of All Migrant Workers and Members of their Families from 1990 (in force since 2003), notwithstanding the fact that it has been ratified by only 51 mainly African and LatinAmerican states, which deals with the rights of migrant workers and contains corresponding restrictions.

The treatment as equal to the citizens of the respective state is limited here to urgent medical treatment:

»Migrant workers and members of their families shall have the right to receive any medical care that is urgently required for the preservation of their life or the avoidance of irreparable harm to their health on the basis of equality of treatment with nationals of the State concerned (Article 28, sentence 1).«

16 On the concept of »assisted freedom« see the study by Graumann (2011).

17 A capabilities approach, a view held, for example, by Venkatapuram inspired by Amartya Sen with regard to health conceptualizes health as »a meta-capability, the capability to achieve a cluster of basis capabilities to be and do things that reflect a life worthy of equal human dignity.« Cf. Venkatapuram (2011), 71. 
Pursuant to the convention, migrant workers may not be denied urgent treatment even if there is any »irregularity« with regard to their stay or employment in the country (Article 28, sentence 2). Equal, general access to social and healthcare services is enjoyed by migrant workers and their families only "provided that the requirements for participation in the respective schemes are met« (Article 43[e]). As such, the Migrant Workers Convention is an ambivalent document: on the one hand, it emphasises the important entitlement to the right of migrant workers to basic medical care, on the other hand it remains rooted in a legal practice, which makes comprehensive medical treatment dependent on residence status.

What remains to be mentioned is the fact that also different regional human rights conventions contain the right to health. Within the scope of the Council of Europe, in particular the European Social Charter in its original (1961/1965) and revised (1996/1998) versions should be named, and which seeks to guarantee an effective exercising of the right to the protection of health (Article 11). The supplementary protocol to the American Human Rights Convention (Protocol of San Salvador) from 1988, in force since 1999, also contains the right to health which in terms of the WHO is defined there as the highest level of physical, mental and social well-being (Article 10, para. 1). The African Charter on Human and Peoples' Rights (Banjul Charter) from 1981, which came into force in 1986, guarantees the best attainable state of physical and mental health (Article 16), whereas, for example, the African Charter on the Rights and Welfare of the Child from 1990, which came into force in 1999 provides for the right to »best attainable state of physical, mental and spiritual health» (Article 14, para. 1).

\section{Fundamental Aspects of the Right to Health}

In light of the many sources of law, a general interpretation of the right to health is no easy task. A suitable starting point to record the fundamentals of this right is the CESCR which is the fundamental UN human rights covenant on economic, social and cultural rights and is therefore the focal point of this article. Helpful in this respect are the comments from the UN Committee on Economic, Social and Cultural Rights founded in 1988, and which oversees the realisation of the CESCR. In 2000, the Committee 
published a »General Comment« on the right to health ${ }^{18}$ and it regularly offers its views on the realisation of social human rights by the signatory member states within the framework of the state reporting procedures. Comments and recommendations by the Committee are of course not legally binding; they do, however, provide widely recognised guidance on the up-to-date interpretation of individual ESC rights. Also, other UN human rights treaty bodies as well as $\mathrm{UN}$ special rapporteurs refer to them. ${ }^{19}$

The human right to health as it is enshrined in the CESCR entitles every person to enjoy the highest attainable standard of physical and mental health in order to lead a life in human dignity. As already mentioned, this is not simply understood as being a legal guarantee to be healthy. No state could possibly provide such a guarantee on the grounds alone that health is dependent on factors which the state is unable to control or which it should not be controlling for good human rights reasons. An example here might be people's genetic predisposition. Although the technical possibilities are already available to enable disease-preventing genetic correction, the (state) manipulation of genetic material has so far been taboo. Even a healthy life style can not be imposed on people, at least not in a way that takes account of human dignity and thereby also freedoms. Nevertheless, the state does have possibilities to shape the political, socio-economic and ecological conditions of health. In that sense, the human right to health stresses that people's health is not adversely affected. On the other hand, the preconditions must be created to allow everybody access to an appropriate level of healthcare and the ability to autonomously live and work healthily. This also includes information and education on matters relevant to health.

The right to health incudes first of all the freedom to make decisions relating to one's own health and body as well as the right to be free of interference with one's health. Here obvious overlaps come about with, amongst other things, the right to life, ${ }^{20}$ as well as with the prohibition of torture and

18 E/C.12/2000/4, 11th August 2000.

19 The corresponding documents are all available in the human rights portal of the UN High Commission for Human Rights: cf. www.ohchr.org [01.10.2015].

20 Following the decisions of the ECHR the right to privacy also encompasses physical and psychological integrity as well as individual self-determination as regards the right of disposition in respect of a person's own body; cf. Kälin/ Künzli (2008), 437-439. 
inhuman or degrading treatment or punishment. At the same time a number of problem areas in healthcare stand out: what, for example is the situation as regards - from a medical or the state's point of view - necessary compulsory treatment against the patient's will? Or: what could the - where necessary assisted - self-determination of those people be, who are significantly restricted when it comes to making decisions and expressing their will, for example those suffering with the later stages of dementia? ${ }^{21}$ The concept of autonomy is central to the discussion here. ${ }^{22}$

The right to health further requires that conditions are established or maintained such that people can lead a healthy life. According to the UN Committee for ESC Rights this includes, for example, access to safe and potable water and adequate sanitation, an adequate supply of safe food, nutrition and housing, healthy occupational and environmental conditions, and access to health-related education and information, including on sexual and reproductive health, as well as the participation of the population in health-related decision-making. ${ }^{23}$ Whilst there is an overlap in this respect, amongst other things with the rights to adequate food and nutrition, safe and potable water and adequate working conditions, the right to health additionally includes the entitlement to preventive, curative and palliative ${ }^{24}$ healthcare. Healthcare that should enable everybody to enjoy the highest attainable standard of physical and mental health. With regard to healthcare and medical care, the UN Committee for ESC Rights uses - similarly to other social human rights - the categories availability, accessibility, acceptability and quality in order to substantiate the right. ${ }^{25}$ Availability means the provision of functioning healthcare facilities and medical care. Although the actual conditions of these are dependent on many factors - in particular on the level of development and resources in the country - certain minimum conditions are necessary, for example safe and potable water and

21 For example Schmidhuber (2013) and (2014).

22 See also Bielefeldt (2016).

23 E/C.12/2000/4, 11th August 2000, para. 11.

24 The concept of palliative healthcare cannot yet be found in the CESCR. It is, however, to be seen as part of a comprehensive, also alleviating medical treatment. However, in General Comment No. 14, E/C.12/2000/4, 11 th August 2000, para. 34.

25 E/C.12/2000/4, 11th August 2000, para. 12. 
sanitation, hospitals and other healthcare facilities, trained and adequately remunerated personnel, as well as a basic supply of essential medicines in accordance with WHO standards. Everybody must also have access to medical facilities and treatment - in several respects:

- without discrimination, also and in particular in the case of population groups which are especially in need of protection and marginalised.

- physically, i.e. within easy reach and accessible - in particular to women, children, older people and people with chronic diseases or disabilities;

- economically - in such a way that public or private medical facilities and treatments are affordable for everybody, including poor and socially disadvantaged people;

- informed - in the sense that the people have the right to seek, receive and pass on health-relevant information as long as in doing so the personal protection of legitimate expectations is not affected.

Acceptability means that medical facilities and medical care should be provided in accordance with the principles of medical ethics, in confidence and with the aim of improving the health of those concerned. The cultural backgrounds of the individuals, but also of minorities and communities are to be respected and gender or age-related characteristics are to be specifically taken into account. Furthermore, it is required that medical facilities and medical care are appropriate and of an adequate quality from a scientific and medical point of view. The medical care must be provided by trained personnel and conform to medical standards for medicines, equipment, facilities and hygiene.

\section{State Obligations}

From an international law perspective, the main responsibility for the realisation of human rights lies with the states. According to of international human rights conventions, the states are obliged to respect, protect and fulfil the human rights of individuals under their jurisdiction. ${ }^{26}$ From an

26 I will briefly mention extra-territorial obligations later. 
international law perspective, ${ }^{27}$ the human rights are binding on all state powers, organs and institutions, irrespective of whether these are at the state, regional or local level or whether they are superordinate or subordinate authorities. The obligation of states also extends to such private actors who have been tasked with carrying out public duties or who are acting on behalf of, on instruction of or under the control of the state. ${ }^{28}$ As a result of more recent dogmatic international law developments, the human rights thereby establish obligations to respect, protect and fulfil.

\subsection{State Obligations to Respect}

Obligations to respect form the core of a liberal human rights theory which protects the freedom of individuals from intervention by the state and in doing so places the defensive nature of human rights at the forefront. They oblige the states to not hinder individuals, either directly or indirectly, in the exercising of their human rights - and where they do so to remedy such interventions. This concerns above all obligations of omission.

With regard to our topic, the obligations to respect require the states to refrain from infringing the right to health themselves. The states may not therefore undertake any actions which run contrary to the right to health and $»$ which can result in bodily harm, unnecessary morbidity and preventable mortality «. ${ }^{29}$ What could such actions be? With regard to healthcare this encompasses generally all state actions which impede the availability, access to or adequateness and quality of healthcare to such an extent that the health of the people is endangered or harmed.

The UN Committee introduces in its General Comment as a key example the denial of medical treatment, and thereby focuses on a non-discriminatory, open access to healthcare. Here it needs to be examined whether laws, regulations or just the practice in public health facilities deny or hinder open access to specific population groups or individuals. This could be, for example ethnic groups or national minorities, persons with disabilities, the psychologically ill or women, but also foreign nationals,

27 Nothing is said about the question of how the responsibilities, jurisdiction and competences are divided in national law.

28 Kälin/Künzli (2008), 92.

29 CESCR E/C.12/2000/4, 11th August 2000, para. 50. 
refugees, »irregular « migrants or prisoners. Also sometimes problematic is the organisation of healthcare for lesbians, gays, bi-, trans-, and intersexuals (in short: LGBTI persons) in particular where they must fear criminal sanctions, as is the case in many countries.

However, also the way in which people are treated in state healthcare facilities is relevant with regard to the obligations to respect. Not only denied, but also incorrect or abusive treatments can amount to violations of the right to health. In this respect we are dealing here with the appropriateness and quality of healthcare. It must be examined, for example, whether the available treatment possibilities are being exhausted and the medical standards are being adhered to. This is by no means always the case. ${ }^{30}$ At the same time there are enough past and present examples of specific actions in state healthcare facilities which are harmful to health: these range from medical experiments with patients who have not given their consent ${ }^{31}$ to »inappropriate institutionalization of persons with mental disabilities in psychiatric hospitals ${ }^{32}$ (or also, as is the case in China, for example, the misuse of psychiatric facilities as a place of custody for political dissidents) to the forced sterilisation of people with disabilities ${ }^{33}$ or women. In Peru, for example, during Alberto Fujimoris' term in office (1990-2000), around 300,000 women and approximately 22,000 men - above all indigenes and farmers - were subjected to forced sterilisation as part of birth control without their consent and without explanation. ${ }^{34}$ Until today there have been hardly any criminal prosecutions as demanded by those concerned. ${ }^{35}$

Specifically, the state obligations to respect in healthcare throw up many questions, the already mentioned problem of discrimination to name just one example. Apart from the fact that medical care needs to be adapted to the individual patients, the question arises as to what health services the

30 For example the discussion surrounding mistakes and ethics in medicine, e.g. in Frewer et al. (2013).

31 Relevant in this context are also the cross-border trials by western pharmaceutical companies in the GDR. cf. Erices et al. (2015).

32 E/CN.4/2005/51, 11th February 2005, para.. 9.

33 For example: www.enil.eu/news/sterilization-of-women-and-girls-with-disabil ities-a-briefing-paper-november-2011/ [25.07.2017].

34 See on this Jaichand/O'Donnell (2010).

35 For example the press reports by Anliker (2014); Cordier (2015). 
human rights entitlement to equal treatment without discrimination refers to. Surely not only to the minimum provision! But what about our Asylum Seekers Benefits Act (AsylbLG) in Germany? As long as refugees, asylum seekers and people with precarious residence status obtain healthcare services on the basis of the Asylum Seekers Benefits Act, ${ }^{36}$ the corresponding service entitlement is limited to healthcare in cases of acute illnesses and pain, to the medical and nursing care of mothers and those who have recently given birth, as well as to officially recommended vaccinations and medically necessary preventive examinations (section 4 AsylbLG). This excludes - at least in principle - the treatment of chronic illnesses, insofar as they are not linked to conditions of pain, ${ }^{37}$ often with serious consequences for the persons concerned. The provision of dental care is completely inadequate as well. ${ }^{38}$ Also the psycho-social care of refugees has proven to be problematic - even before the enormous increase in the number of refugees in $2015 .^{39}$

Even in light of legitimate regulatory interests of the state, the de jure and de facto unequal treatment of people in the health sector dependent on their nationality or residence status is to be viewed critically from a human rights point of view, especially when the resulting healthcare provision is clearly insufficient and even emergency care is hindered due to bureaucratic hurdles. ${ }^{40}$ This is also true when it comes to migrants who are in the country »irregularly«. In principle, these people have a right to access healthcare services; in Germany, for example, by virtue of the Asylum Seekers Benefits Act. However, despite all the national peculiarities and isolated positive examples, Heinz-Jochen Zenker has determined that »everywhere there are people without papers at the lower end of access to ap-

36 Up until the law reform which came into force on 1st March 2015, this applied for a period of 48 months following entry. The reform of the law saw this period reduced to 15 months' residence in Germany.

37 Kaltenborn (2015).

38 Lindner (2015), 81.

39 BAfF (2015).

40 Cf. Lindner (2015); Misbach (2015). The federal government, however, considers the provision of healthcare to be adequate, cf. Bundestag printed paper 18/4758, 27th April 2015. Informative is also the plenary debate in the Bundestag, 115th meeting, 2nd July 2015, 11078-11093. 
propriate medical care and this is inconsistent with the human rights conventions and the European Social Charter «. ${ }^{41}$ What is more, the practice of tracing, reporting and detaining people often effectively discourages many undocumented persons from making use of healthcare services. ${ }^{42}$

Acts of states which are harmful and dangerous to health can also affect those parameters which influence people's health outside of the healthcare system. As already explained, the UN Committee for ESC Rights explicitly lists access to clean and potable water, adequate sanitation, safe food and accommodation, healthy working and environmental conditions and healthrelated information. Against this background it must be assessed to what extent health risks and health damage arise from state measures in the different policy areas (economy, energy, defence, etc.) - for example in the form of human rights impact assessments. It is also possible for state-run businesses or public infrastructure measures to infringe the right to health if health protection is neglected in the workplace or if the environment is contaminated. Joint responsibility may also arise as a result of cooperations with private companies. A landmark decision concerning this matter was passed by the African Human Rights Commission against the former military regime in Nigeria. Together with a large oil company, in the course of the national oil extraction, it had caused considerable environmental and health damage in the Niger Delta. The Commission concluded that the rights to health and to an appropriate - here: healthy - environment guaranteed by the Banjul Charter had been infringed. ${ }^{43}$

Also the retention or misrepresentation of health-related information can amount to a breach of state obligations to respect. The state may not hold back or falsify important or vital health information relating to the prevention of infection or epidemics or environmental disasters. From the perspective of the right to health, it was criticised, for example, that for a long time the government of Zimbabwe denied the outbreak of the cholera epidemic in 2008 and declared that it was over too early. ${ }^{44}$ Justified human

41 Zenker (2011), 96.

42 For example Fundamental Rights Agency (2012); Mylius/Frewer (2015).

43 Communication No. 155/2001, SERAC and CESR v Nigeria (2001), 15th Annual Activity Report of ACHPR: 2000-2002. The case is also well-documented in the secondary literature, see for example Keetharuth (2009); Nolan (2009).

44 Zimbabwe Human Rights NGO Forum (2009). 
rights criticism was also directed at the South African government under Thabo Mbeki (1999-2008) which trivialised the risk of infection from HIV and for a time even denied there was a link between HIV and AIDS. ${ }^{45}$ Conversely, measures to contain epidemics such as mandatory quarantine in the case of Ebola patients in Sierra Leone, Guinea and Liberia in 2014 can lead to interventions in the freedom and participation rights of those concerned. It can be discussed to what extent such interventions are justified, for example, by means of the »Siracusa Principles« which deal with limitations or the derogation of civil and political rights in the case of such public emergencies. ${ }^{46}$

\subsection{State Obligations to Protect}

Obligations to protect consist of the state obligation to protect individuals from actual or impending infringements of their human rights by third party, normally private actors. Obligations to protect are not prohibitions to act but requirements to act. State decision-makers, however, have a widereaching margin of discretion and freedom when it comes to the form of such measures. As such it is not always easy to determine possible infringements of state obligations to protect. The can arise, for example, through a state's omission to act where

- public authorities have knowledge of a current or impending risk or could have done had they taken the necessary care,

- despite having such knowledge, they fail to take appropriate protective measures within the scope of the means available to them and

- at the same time countermeasures in conformity with human rights would have been possible. $^{47}$

With healthcare, such infringements can occur, for example, when the state allows private healthcare facilities to breach medical standards or when it fails to do something to prevent harmful or ineffective medicines being in

45 See in this context the measures of the »Treatment Action Campaign«; Heywood (2009).

46 E/CN.4/1985/4, Annex (1985).

47 Kälin/Künzli (2008), 126. 
circulation (as is the case in several countries). In terms of the obligations to protect, the state must adequately regulate and control private healthcare facilities, services and products to ensure that people actually obtain medical assistance and that their health is not harmed. Here the same defects can arise in principle as with state-run healthcare facilities (see above), the difference being that here the harm originates from private actors. The state obligation to protect becomes particularly evident when avoidable deaths occur in private healthcare facilities and at the same time the state has failed to fulfil its monitoring and control obligations. In this regard, there is a series of relevant decisions, for example by the Inter-American Court of Human Rights ${ }^{48}$ or within the complaints procedure of the CEDAW. ${ }^{49}$

Of great significance in terms of human rights is also the question how open the access to private healthcare services must be. It is largely undisputed that also private healthcare facilities may not deny emergency treatment to anybody, but access to private services which go beyond this is commonly not possible or affordable for everybody. This is a problem particularly when at the same time there is no comprehensive public healthcare sector or where this is of a poor quality. In this case the state must ensure that a qualitatively adequate healthcare provision is accessible to everybody, either by way of respective regulation of private providers or by expanding the public healthcare sector, something which already refers to the obligations to fulfil (to be dealt with later).

Just like the obligations to respect, the obligations to protect are not limited to healthcare provision in the narrow sense, but take in also working and living conditions which also determine people's health. Here the obligations to protect refer on the one hand to an appropriate regulation and control of health protection in the workplace and on the other hand they are concerned with the protection of an intact and healthy environment against private (economic) interferences, which is crucial for people's health. Around the world harmful working conditions and cases of environmental pollution by private enterprises have been documented, be it the degradation of natural resources, in agriculture or in the manufacturing industry. Harmful working conditions in the textile industry in Southern Asia which

48 Ximenes-Lopes v. Brasil, Series C 149, 2006; see also Nolan (2009).

49 Alyne Silva Pimentel v. Brazil, CEDAW, communication No. 17/2008, judgment from 25th July 2011. 
attracted public attention following the fires and factory collapses in Bangladesh and Pakistan come to mind here. ${ }^{50}$ The problem is especially evident in developing countries and emerging markets. To make matters worse, largely informal employment relationships prevail there.

State obligations to protect for the prevention of occupational accidents and illnesses and environmental pollution can be found not only in Article 12, para. 2 (b) CESCR but also in conventions of the International Labour Organization (ILO). Within the scope of the Council of Europe, also a claim based on an infringement of the European Social Charter can be asserted. In the case of collective complaints against Greece, for example, the European Social Committee determined that the right to health had been infringed as - considering the scope for discretion and action allowed - the national authorities had done too little to protect residents from water and air pollution by private companies. ${ }^{51}$ A separate problem is the oftenprivatised waste disposal. $^{52}$

Furthermore, the health protection of consumers is significant. The state must prevent the distribution of consumer goods which are heavily polluted or harmful to health. At the same time in the past few years smoking bans and demands for measures to combat alcohol and drug consumption have been justified with the right to health. Demands for protection against excess weight $^{53}$ or for a »Global Convention to Protect and Promote Healthy Diets« go even further. The latter of these demands was made by the then Special Rapporteur for the right to food, Olivier de Schutter, and justified

50 Background information on the working conditions in the textile industry can be found, amongst other places, on the websites of »Clean Clothes Campaign« (www.cleanclothes.org), »Christliche Initiative Romero« (www.ci-romero.de), ECCHR (www.ecchr.eu), »medico international« (www.medico.de) and the »Fair Wear Foundation« (www.fairwear.org); see also Burckhardt (2014).

51 See the judgments on the complaints No. 30/2005 and No. 72/2011.

52 In the Southern Italian provinces of Naples and Caserta, for example, the criminal, illegal disposal of hazardous and poisonous waste was proven to have caused damage to the population's health. Cf. Camera dei deputati: D.L. 136/2013: Emergenze ambientali e industriali, 6th February 2014; Emergenze rifiuti, 21.11.2014; available at www.camera.it [01.06.2015].

53 For example the demand of the UN Committee for ESC Rights directed at Sweden: E/C.12/SWE/CO/5, 18th November 2008, para. 23. 
on the basis that unhealthy diets amount to an even greater health risk than tobacco. ${ }^{54} \mathrm{Up}$ to now hardly any state obligations have been derived from the right to health as regards eating habits and healthy diets. There would certainly be a need for in-depth discussion as to whether and to what extent intervention in the freedoms and sphere of responsibility of individuals above and beyond the information and education obligations is possible and desirable.

The situation is different in the case of physical acts of violence. Here the UN Committee for ESC Rights obliges states - on the basis of the right to health - to combat private violence, in particular also domestic violence, and to prosecute offenders. ${ }^{55}$ The Committee emphasises time and again the obligation to protect women and girls from sexual or other violence in very different risk situations and also makes use of other human rights: on the way to school or work or in the workplace, in search of water or sanitary facilities or also in makeshift shelters and refugee camps. In addition, the state is obliged to prevent cultural practices harmful to health, above all female genital mutilation (in short FGM). Both the UN Committee for ESC Rights and the CEDAW Committee have identified female genital mutilation as a human rights violation, although not always on the basis of the right to health. ${ }^{56}$

\subsection{State Obligations to Fulfil}

Obligations to fulfil are strictly speaking "positive rights«. They oblige the states to enable the most comprehensive exercising of human rights possible by way of active state action. It is about creating the prerequisites for the realisation of the right to health through respective statutes, institutions and procedures as well as by way of state provisions in the form of money, goods or services.

54 E.g., on 19th May 2014 in Geneva; cf. also his report on this topic: $\mathrm{A} / \mathrm{HRC} / 19 / 59,26.12 .2011$.

55 E/C.12/2000/4, 11th August 2000, para. 51.

56 Cf. here for example the »Concluding remark« on Chad: E/C.12/TCD/CO/3, 16th December 2009, para. 19; CEDAW/C/TCD/CO/1-4, 21st October 2011, paras. 22-23. See generally on FGM also Graf (2013). 
As stated at the beginning of the article, the respective human rights conventions already provide for a variety of steps to realise the right to health. ${ }^{57}$ Accordingly, the obligations to fulfil in the area of health are diverse. They comprise initially the establishing and maintenance of medical and health-relevant infrastructures, whereby the states must ensure that necessary medical institutions, services and programmes with well-trained staff are available, accessible to everybody and that the people have access to adequate food and nutrition, accommodation, sanitation, drinking water and essential medicines. Furthermore, the human rights conventions provide for specific steps to be taken by the states to improve the health situation of the population in general and that of individual, particularly needy or vulnerable groups, for example children, mothers, the elderly or people with disabilities. It is normally not sufficient in this respect to only ensure access to medical provision. Often the socio-economic and socio-cultural conditions must be changed, which co-determine the state of health, for example poverty or social marginalisation and exclusion.

The form of the healthcare systems, whether public and/or private, as well as specific health-related policy measures lie principally within the discretion of the respective states, at least as long as they respect these human rights principles (such as transparency, participation, non-discrimination) and guarantee the general availability, accessibility, acceptability and quality of the healthcare provision. ${ }^{58}$ Privatised or contractually outsourced healthcare services do not, however, relieve the states of their obligation to ensure this. The governments must, for example, prevent qualitatively appropriate healthcare provision from being available only to those patients who can afford it. However, according to the WHO, 100 million people are driven into poverty every year because they have to pay

57 The various human rights-related measures in the area of healthcare are not mentioned here in detail. See on this the reports and recommendations of the $\mathrm{UN}$ human rights organs based on the charter and the convention which can be found on the website www.ohchr.org. It is also worth reading the WHO documents which deal with the human right to health: www.who.int/ topics/human_rights/en/ [01.03.2017].

58 For example Hunt/Backman (2013). 
for healthcare services themselves (out-of-pocket payments). ${ }^{59}$ This not only points to a strong link between the right to health and the right to social security, ${ }^{60}$ but also often to the problem of abominable public healthcare provision. For this reason, as is, for example, reported from India, sometimes even poor people opt for fee-based private healthcare services rather than free treatment in state-run hospitals, at the same time running up enormous debts. ${ }^{61}$

As in the case of the right to health the realisation of the obligations to fulfil is linked with high costs, the realisation sees many countries reaching their limits. In particular, many developing countries have significant difficulties when it comes to ensuring a comprehensive provision of medical care and overcoming the partly serious defects in the healthcare system. Let alone can they afford such a comprehensive and expensive healthcare system as the developed countries. This does not though relieve developing countries of their obligation to take measures to realise the right to health progressively based on their available resources. ${ }^{62}$

The obligation to progressively realise the right progressively as provided for by the CESCR (Article 2, para. 1) takes account of the fact that faced with social problems that are difficult to overcome and scarce resources the social human rights cannot be realised overnight, especially those components of the right which require for their realisation extensive provisions of the state and long-term actions. With regard to the right to health (and other ESC rights), this applies especially to the obligations to fulfil.

However, the obligation to undertake a progressive realisation cannot serve as an excuse for failing to act at all. On the contrary, the state has the procedural obligation to draft specific and effective policies and to undertake measures, the result of which should be the goal to realise the right to health. As such, the states are obliged to develop a comprehensive national

59 See http://www.who.int/features/factfiles/universal_health_coverage/en/ [25.07. 2017]. See also Heinicke et al. (2016).

60 Krennerich (2014).

61 Shankar/Mehta (2008), 155.

62 The German translation is based on a comprehensive concept of resources which is not limited to just financial resources, but includes all kinds of resources; cf. also Klee (2000), 122-129; Engbruch (2008), 108. 
health strategy without delay by way of a participatory and transparent process in order to address the existing (and to be identified) healthcare problems in the respective country.

Additionally, as far as possible, several core obligations must be realised immediately. ${ }^{63}$ According to the UN Commission for ESC Rights this at least includes access to medical institutions and medical care without discrimination as well as access to a minimum amount of basic nutrition, to accommodation, sanitation and safe drinking water and provision of basic medicines. On top of this there is a fair distribution of medical facilities and medical care, with the particular problem of deficits in rural areas being the focus here. ${ }^{64}$ The Committee views the following aspects as having a similar priority: healthcare in relation to reproductive health, motherhood and children, vaccinations against infectious diseases, measures to prevent, treat and combat epidemic and endemic illnesses, education and information about essential health programmes in the community and an adequate training of healthcare personnel. ${ }^{65}$

Building on this, measures must be taken to realise the right to health continually and comprehensively. The obligation of a progressive realisation - at the time enshrined with a considerable amount of progressoriented optimism - is not in conformity with an absolute prohibition of regression, however, unavoidable setbacks are in need of explanation. Ultimately it is of vital importance that the state actually uses its resources - and thereby an appropriate proportion of the state's shares and possible international aid - for the realisation of the right to health. The view of the UN Committee for ESC Rights is that a state that is not willing to do this violates its obligations under Article 12 CESCR. ${ }^{66}$

Of course it must always be established what constitutes appropriate resources. The wording of the CESCR which obliges the respective state to exhaust the »maximum of its available resources« is not particularly helpful. It is clear that a state cannot utilise all of its resources for the realisation of individual human rights, however important these may be. The obligation to exhaust all resources exists based on the premise that the state is left

63 Müller (2016).

64 E/C.12/2000/4, 11th August 2000, para. 43.

65 Ibid., para. 44.

66 Ibid., para. 47. 
with sufficient means to undertake its various tasks (and also for the realisation of other human rights). Accordingly we are concerned here with the weighting of goals as well as the distribution and use of available resources. ${ }^{67}$

In practice, it quickly becomes apparent that the political setting of priorities and the spending policy of many states urgently need human rights corrections. To put it casually, if we look at what the states spend money on whilst at the same times millions of people are dying of avoidable and treatable illnesses it is not difficult to see that from a human rights point of view many resources are being wrongly distributed, not used, and certainly not exhausted. There is much potential for criticism in the demand to make use of a maximum of available resources as faced with continuing social problems it obliges the states to mobilise more resources for the realisation of social human rights. Significantly, within the scope of the reporting procedures on the CESCR, the UN Committee for ESC Rights regularly requests states to make more resources available for health care provision. These discussions can be made more objective by way of national human rights budgeting and systematic country comparisons, even though the use of considerable means alone does not guarantee an appropriate realisation of the human right to health.

The UN Committee for ESC Rights does not give a conclusive answer to the question at what point the human right to health has been completely realised. The demand for the "highest attainable level of health « leaves many questions unanswered. Since the health of an individual person is dependent on a variety of contingents and therefore factors which can be influenced, the conditions for a healthy life can, in principle, always be further improved. Pragmatically, one must therefore view the realisation of the human right to health as a continuous process which is based on the respective medical and health standards which are determined and further developed on a national or international level. It is, however, evident that the human right to health is not limited to basic levels of care. The right of every person to attain the highest level of health possible therefore serves as

67 The problem of »Prioritization of health interventions and respect of human rights « was addressed amongst other things by the UN Special Rapporteur on the right to food in his report to the UN General Assembly from 8th August 2007. A/62/214, paras. 11-32. 
a critical corrective so that comprehensive medical care and healthy working and living conditions are not reserved for certain groups within society.

\subsection{The International Dimensions of the Right to Health}

The realisation of the right to health within the respective states is heavily influenced on an international level - both positively and negatively. On the one hand, there are various endeavours in international health policy, in development cooperation and within the framework of humanitarian aid cooperation to improve the provision of healthcare to people particularly in developing countries and disaster areas. The CESCR in fact obliges the states to cooperate in this way. On the other hand, international policy and legal provisions can also affect the realisation of the right to health, for example in the form of credit terms or trade and patent regulations. The UN Committee for ESC Rights explicitly points to the international obligation of states to not compromise the right to health in other countries in the course of bilateral and multilateral cooperation. The states are therefore also obliged to duly acknowledge the right to health when signing international treaties and as members of international organisations.

Legal requirements in respect of patents within the framework of the World Trade Organisation's so-called TRIPS Agreement have, for example, often been criticised in the past. For instance, Holger Hestermeyer stated that the legal entitlement to "access to medicine $\ll$ is a component of the human right to health and life; that patent regulations - which WTO members are obliged to adhere to - have led to higher prices for new medicines; that higher prices have made it more difficult for poorer population groups in particular in developing countries to gain access to medicines, therefore amounting also to a human rights infringement; that such an intervention cannot be sufficiently justified, not even by way of the protection of moral and material interests of the authors of scientific works (within the meaning of Article 15, para. 1 CESCR), as this does not protect the patents of pharmaceutical companies. ${ }^{68}$ Corresponding flexible TRIPS regulations

68 Hestermeyer (2007). The UN Committee for ECS Rights has already clarified in its General Comment No. 17 on Article 15(1)c) of the CESCR that such patent rights are not human rights and that the state has an obligation to protect people 
in the form of compulsory licenses and parallel imports in order to solve such conflicts (»health safeguards «) are effectively thwarted. ${ }^{69}$

Also the subject of criticism are some savings measures by international lenders, as regarding the right to health cutbacks in the health and social sectors as foreseen by the internationally effected austerity programme in the 1980s and 1990s in Latin America and other world regions can seriously violate the »do not harm principle« and thereby also the lenders' extraterritorial obligations to respect. The main responsibility for the states' financial misery commonly lies with the national governments which ultimately also decide how much will be saved and in what areas; in many places, however, pressure from international lenders has aggravated the misery in the area of health. If the public healthcare system collapses altogether then urgent countermeasures must be taken.

Whilst the extra-territorial obligations to respect already throw up a number of questions, it is disputed to what extent the states are obliged above and beyond these to support other states in realising the human right to health (and other social human rights). Even governments which are heavily involved in development co-operations do not want to be obliged to do so under international law. We can therefore be curious as to what significance the Maastricht Principles on Extraterritorial Obligations of States in the Area of Economic, Social and Cultural Rights will take on, that were formulated by around 40 experts on international law and human rights from all over the world on $28^{\text {th }}$ September 2011 at the University of Maastricht. $^{70}$ The principles take up guidelines which UN committees and UN Special Rapporteurs have already formulated without binding effect and acknowledge comprehensive extraterritorial obligations on the part of states to respect, protect and fulfil. ${ }^{71}$ Further reaching are calls for $»$ global

from excessive prices for essential medicines; cf. E/C.12/GC/17, 12th January 2006. See also Schneider (2006), 162-170.

69 See for example People's Health Movement et al. (2014), 288-299.

70 The German translation can be found in Zeitschrift für Menschenrechte 6, 2 (2009), 184-195.

71 Also Coomans/Künnemann (2012); de Schutter et al. (2012); Krennerich (2013), 124-128. 
social rights« which should regulate international and transnational relations. $^{72}$

\section{OUtLOOK}

If human rights are to have an effect, they have to be actively claimed. For this reason, human rights empowerment is necessary. This denotes a process, in the course of which the right holders acquire the capacity to claim and assert human rights for themselves and others effectively. The main recipient of human rights claims are the respective states which are the primary duty bearers. Their readiness and ability to realise the human rights must be claimed and enhanced. However, also non-state actors such as commercial enterprises are noticeably being made accountable for human rights. Those concerned and their support groups generally have a wide range of possibilities to act available to them when it comes to asserting their human rights claims in the face of resistance.

From a legal point of view the right is especially characterised by the fact that it can be asserted through the courts. With an increasing recognition of the for a long time contested justiciability of social human rights, ${ }^{73}$ in the past few years an increasing number of possibilities to claim have become available. The amount of case law on social human rights in general and in particular on the right to health has grown considerably. By now there are numerous judgments and decisions which either directly or indirectly concern the right to health. ${ }^{74}$ Interestingly, these refer not only to obvious discrimination situations and the infringement of obligations to respect and protect, but sometimes also to the benefits entitlements of those concerned. ${ }^{75}$ Empirically it must also be examined who actually takes re-

72 For example Fischer-Lescano/Möller (2012).

73 Krennerich (2013), 116-123.

74 Cf. the databases at www.globalhealthrights.org and www.escr-net.org. See also Gauri/Brinks (2008); Langford (2009); Yamin/Gloppen (2011); Hogerzeil et al. (2013) and the work with three volumes by Clérico et al. (2013).

75 The German Federal Government is, however, sticking to the legal interpretation that no guarantee claims to specific benefits can be derived from the CESCR; cf. Bundestag printed paper 18/4758, 27th April 2015. 
course to the courts, how the courts decide and whether the corresponding judgments are acted on appropriately and result in sustainable effects.

It is almost as important that the human right to health is claimed and asserted by way of political means, for example through protests and campaigns or through lobbying and advocacy work. Without underestimating the significance of influential landmark judgments, fundamental, structural reforms with the goal of achieving a better and more comprehensive respect, protection and guarantee for the social human rights such as the right to health are primarily secured politically, and here it is mostly about conflicts of power and distribution. Ideally the (quasi-) judicial and the political enforceability of the right to health should complement each other. On the one hand, political demands to realise human rights gain in legitimacy and force as a result of the legal entitlements being positively enshrined in law and possibly subject to claims in the courts. ${ }^{76}$ For this, as a rule, an active civil society is of great significance.

To what extent the possibilities of demanding and claiming the right to health are used depends first of all on the organisational potential and capacity to act of civic groups and social movements, however, also constitutional structures and civic freedoms are necessary. Many governments restrict the scope of activity of the civil society and attempt to suppress human rights entitlements. The spectrum here ranges from complete repression to co-optation. Between these there are open and subtle forms of obstruction, for example legal and administrative restrictions on the freedom of assembly, association and opinion or also the targeted diffamation, stigmatisation or criminalisation of persons and groups who promote human rights (in UN jargon: human rights defenders). ${ }^{77}$

As such it is all the more important to organise and support civic commitment and human rights empowerment with solidarity, which is why

76 The already mentioned Treatment Action Campaign (TAC) in der Republic of South Africa demonstrates impressively how political and legal measures can complement each other in order to assert the right to a medical and medicinal treatment of HIV/AIDS patients despite considerable resistance; Heywood (2009).

77 Forum Menschenrechte (2012) and the reports of the previous special rapporteurs on human rights defenders, available from the human rights portal: www.ohchr.org [01.07.2015]. 
great significance is attached to transnational human rights networks which provide a link between the local and global levels. With regard to the right to health, for example the People's Health Movement is one such global network. ${ }^{78}$ It is not, however, about »exporting « supposed western human rights into »foreign countries«. The starting point and point of reference for solidary support is always the struggles of the people locally and protest against injustice, oppression, exploitation and hardship they have suffered, and who - implicitly or explicitly - point to their right to live a humane, liberal and autonomous life in community with others. The human right to health is most certainly a part of this.

\section{REFERENCES}

Ach, Johann S. (Ed.) (2013): Grenzen der Selbstbestimmung in der Medizin, Münster: mentis.

Anliker, Nicole (2014): »Nie mehr Mutter sein. Zwangssterilisierungen in Peru«, in: Neue Zürcher Zeitung, 26. Dezember 2014.

BAfF (Bundesweite Arbeitsgemeinschaft der psychosozialen Zentren für Flüchtlinge und Folteropfer) (2015): Versorgungsbericht. Zur psychosozialen Versorgung von Flüchtlingen und Folteropfern in Deutschland, Berlin: BAfF.

Bielefeldt, Heiner (2016): »Der Menschenrechtsansatz im Gesundheitswesen. Einige Grundsatzüberlegungen«, in: Frewer/Bielefeldt (2016), 1956.

Bösl, Anton/Disecho, Joseph (Eds.) (2009): Human Rights in Africa, Windhoek: Konrad Adenauer Foundation.

Brot für die Welt/Misereor/ECCHR (2011): Transnationale Unternehmen in Lateinamerika: Gefahr für die Menschenrechte?, Stuttgart u.a.: BfdW u.a.

Burckhardt, Gisela (2014): Todschick. Edle Labels, billige Moden - unmenschlich produziert, München: Heyne.

Clérico, Laura/Ronconi, Liliana/Aldao, Martín (Eds.) (2013): Tratado de Derecho a la Salud, Tres tomos, Buenos Aires: Abeledo Perrot.

78 For example Turiano/Smith (2008);www.phmovement.org [25.07.2017]. 
Coomans, Fons/Künnemann, Rolf (Eds.) (2012): Cases and Concepts on Extraterritorial Obligations in the Area of Economic, Social and Cultural Rights, Cambridge u.a.: Intersentia.

Cordier, Valeska (2015): »Zwangssterilisationen in Peru sollen strafrechtlich verfolgt werden «, in: Amerika 21. Nachrichten und Analysen aus Lateinamerika, 19. Februar 2015. Online: https://amerika21.de/2015 /02/112618/zwangssterilisationen-fujimori [25.07.2017.

De Schutter, Oliver/Eide, Asbjørn/Khalfan, Ashfaq/Orellana, Marcos/Salomon, Margot E./Seiderman Ian (2012): „Commentary to the Maastricht Principles on Extraterritorial Obligations of States in the Area of Economic, Social and Cultural Rights«, in: Human Rights Quarterly 34, 4 (2012), 1084-1169.

Deutsches Institut für Menschenrechte (Ed.) (2005): Die »General Comments " $z$ u den VN-Menschenrechtsverträgen, Baden-Baden: Nomos.

Dodge, Rachel/Daly, Annette P./Huyton, Jan/Sanders, Lalage D. (2012): »The challenge of defining wellbeing «, in: International Journal of Wellbeing 2, 3 (2012), 222-235.

Engbruch, Katharina (2008): Das Menschenrecht auf einen angemessenen Lebensstandard, Frankfurt/M. u.a.: Lang.

Erices, Rainer/Frewer, Andreas/Gumz, Antje (2015): „Versuchsfeld DDR. Klinische Prüfungen westlicher Pharmafirmen hinter dem Eisernen Vorhang«, in: Frewer/Erices (2015), 129-143.

Fischer-Lescano, Andreas/Möller, Kolja (2012): Der Kampf um globale soziale Rechte, Berlin: Wagenbach.

Forum Menschenrechte (Ed.) (2012): Protect instead of Persecute »The difficult situation facing defenders of economic, social and cultural human rights «, Berlin: Forum Menschenrechte.

Franke, Alexa (2006): Modelle von Gesundheit und Krankheit, Bern: Huber.

Freeman, Marsha A./Chinkin, Christine/Rudolf, Beate (Eds.) (2012): The UN Convention on the Elimination of All Forms of Discrimination Against Women. A Commentary, Oxford: Oxford University Press.

Frewer, Andreas/Erices, Rainer (Eds.) (2015): Medizinethik in der DDR. Moralische und menschenrechtliche Fragen im Gesundheitswesen, Geschichte und Philosophie der Medizin, Bd. 13, Stuttgart: Steiner. 
Frewer, Andreas/Bielefeldt, Heiner (Eds.) (2016): Das Menschenrecht auf Gesundheit. Normative Grundlagen und aktuelle Diskurse, Bielefeld: transcript.

Frewer, Andreas/Schmidt, Kurt W./Bergemann, Lutz (Eds.) (2013): Fehler und Ethik in der Medizin. Neue Wege für Patientenrechte, Jahrbuch Ethik in der Klinik, Bd. 6, Würzburg: Königshausen \& Neumann.

Fundamental Rights Agency (2012): Ungleichbehandlung und Mehrfachdiskriminierung im Gesundheitsbereich, Wien: FRA.

Gauri, Varun/Brinks, Daniel M. (Eds.) (2008): Courting Social Justice. Judicial Enforcement of Social and Economic Rights in the Developing World, Cambridge: Cambridge University Press.

Graf, Janna (2013): Weibliche Genitalverstümmelung aus Sicht der Medizinethik. Hintergründe - ärztliche Erfahrungen - Praxis in Deutschland. Mit einem Geleitwort von H. Bielefeldt und A. Frewer. Medizin und Menschenrechte, Bd. 6, Göttingen: V\&R unipress.

Graumann, Sigrid (2011): Assistierte Freiheit. Von einer Behindertenpolitik der Wohltätigkeit zu einer Politik der Menschenrechte, Frankfurt/M. u.a.: Campus.

Grodin, Michael A./Tarantola, Daniel/Annas, George J./Gruskin, Sofia (Eds.) (2013): Health and Human Rights in a Changing World, New York/London: Routledge.

Heinicke, Christina/Eriksson, Lotta/Saxena, Abha/Reis, Andreas (2016): »Universelle Gesundheitssicherung. Konzeptionelle Grundlagen und der Beitrag Nationaler Ethikräte«, in: Frewer/Bielefeldt (2016), 169194.

Hestermeyer, Holger (2007): Human Rights and the WTO. The Case of Patents and Access to Medicines, Oxford: Oxford University Press.

Heywood, Mark (2009): »South Africa's Treatment Action Campaign. Combining Law and Social Mobilization to Realize the Right to Health«, in: Journal of Human Rights Practice 1, 1 (2009), 14-31.

Hogerzeil, Hans V./Samson, Melanie/Vidal Casanovas, Jaime/RahmaniOcora, Ladan (2013): »Is Access to Essential Medicines as Part of the Fulfillment of the Right to Health Enforcable through the Courts«, in: Grodin et al. (2013), 139-150.

Hunt, Paul/Backman, Gunilla (2013): »Health Systems and the Right to the Highest Attainable Standard of Health«, in: Grodin et al. (2013), 62-76. 
Jaichand, Vinodh/O'Donnell, Ciara (2010): »Bringing it home: The InterAmerican System and State Obligations Using a Gender Approach Regionally to Adress Women's Rights «, in: Inter-American and European Human Rights Journal 3, 1-2 (2010), 49-69.

Kälin, Walter/Künzli, Jörg (2008): Universeller Menschenrechtsschutz, 2. Aufl., Basel: Helbing Lichtenhahn Verlag.

Kaltenborn, Markus (2015): »Die Neufassung des Asylbewerberleistungsgesetzes und das Recht auf Gesundheit«, in: Neue Zeitschrift für Sozialrecht 24, 5 (2015), 161-166.

Keetharuth, Sheila B. (2009): »Major African Legal Instruments«, in: Bösl et al. (2009), 163-231.

Klee, Kristina (2000): Die progressive Verwirklichung wirtschaftlicher, sozialer und kultureller Menschenrechte, Stuttgart u.a.: Boorberg.

Krennerich, Michael (2013): Soziale Menschenrechte - zwischen Recht und Politik, Schwalbach/Ts.: Wochenschau Verlag.

Krennerich, Michael (2014): »Social Security - Just as much as a Human Right in Developing Countries and Emerging Markets«, in: Verfassung und Recht in Übersee 47, 1 (2014), 105-123.

Krennerich, Michael (2015): »Das Menschenrecht auf Gesundheit«, in: Zeitschrift für Menschenrechte 9, 2 (2015), 8-35.

Krennerich, Michael (2016): »Das Menschenrecht auf Gesundheit. Grundzüge eines komplexen Rechts«, in: Frewer/Bielefeldt (2016), 57-92.

Langford, Malcolm (Ed.) (2009): Social Rights Jurisprudence: Emerging Trends in International and Comparative Law, Cambridge: Cambridge University Press.

Lindner, Katja (2015): »Die gesundheitliche Versorgung von Asylsuchenden in Deutschland. Aktuelle politische Entwicklungen «, in: Migration und Soziale Arbeit, 1 (2015), 1-8.

Merten, Detlef/Papier, Hans-Jürgen (Eds.): Handbuch der Grundrechte in Deutschland und Europa, Band VI/2: Europäische Grundrechte II, Universelle Menschenrechte, Heidelberg: C.F. Müller.

Misbach, Elène (2015): »)Sich für die Gesundheit stark machen < - Solidarische Flüchtlingsarbeit als gemeinsamer sozialer Kampf um Rechte«, in: Zeitschrift für Menschenrechte 9, 2 (2015), 122-135.

Morsink, Johannes (1999): The Universal Declaration of Human Rights. Origins, Drafting and Intent, Philadelphia: University of Pennsylvania Press. 
Müller, Amrei (2016): »Die Konkretisierung von Kernbereichen des Menschenrechts auf Gesundheit. Internationale Debatten $\mathrm{zu}>$ Minimum Core Obligations ««, in: Frewer/Bielefeldt (2016), 125-168.

Mylius, Maren/Bornschlegl, Wiebke/Frewer, Andreas (Eds.) (2011): Medizin für »Menschen ohne Papiere«, Menschenrechte und Ethik in der Praxis des Gesundheitssystems. Medizin und Menschenrechte, Bd. 5. Göttingen: V\&R unipress.

Mylius, Maren/Frewer, Andreas (2015): »Zugang zu medizinischer Versorgung von MigrantInnen ohne legalen Aufenthaltsstatus«, in: Zeitschrift für Menschenrechte 9, 2 (2015), 102-120.

Nettelsheim, Martin (2009): »Die Allgemeine Erklärung der Menschenrechte und ihre Rechtsnatur«, in: Merten et al. (2009), 191-236.

Nolan, Aife (2009): »Addressing Economic and Social Rights Violations by Non-State-Actors through the State: A Comparison of Regional Approaches to the >Obligation to Protect««, in: Human Rights Law Review 9, 2 (2009), 225-255.

People's Health Movement/Medact/Global Equity Gauge Alliance (2014): Global Health Watch 4. An Alternative World Health Report, London: Zed Books.

Saul, Ben/Kinley, David/Mowbray, Jacqueline (2014): The International Covenant on Economic, Social and Cultural Rights. Commentary, Cases and Materials, Oxford: Oxford University Press.

Schabas, William A. (Ed.) (2013): The Universal Declaration of Human Rights. The travoux préparatoires, 3 volumes, Cambridge: Cambridge University Press.

Schmidhuber, Martina (2013): »Überlegungen zu den Grenzen der Patientenverfügung für die Selbstbestimmung von Demenzbetroffenen im Anschluss an die Dworkin-Dresser-Debatte $\ll$, in: Ach (2013), 317-334.

Schmidhuber, Martina (2014): »Zum Personenstatus von Menschen mit Demenz«, in: Salzburger Jahrbuch für Philosophie LIV, 171-180.

Schneider, Jakob (2006): Menschenrechtlicher Schutz geistigen Eigentums, Stuttgart u.a.: Boorberg.

Shankar, Shyasri/Mehta, Pratap Bhanu (2008): „Courts and Socioeconomic Rights in India«, in: Gauri et al. (2008), 146-182.

Tobin, John (2012): The Right to Health in International Law, Oxford: Oxford University Press. 
Turiano, Laura/Smith, Lanny (2008): »The catalytic synergy of health and human rights: The People's Health Movement and the Right to Health and Health Care Campaign«, in: Health and Human Rights 10, 1 (2008), 137-147.

UNICEF (2002): Realisation Handbook for the Convention on the Rights of the Child, Fully Revised Edition, Geneva: United Nations Publications.

Venkatapuram, Sridhar (2011): Health Justice. An Argument from the Capabilities Approach, Cambridge/Malden, MA: Polity Press.

WHO (2008): »Closing the Gap in a Generation: Health Equity through Action on the Social Determinants of Health«, Final Report of the Commission on Social Determinants of Health, Online: www.who.int/ social_determinants/final_report/csdh_finalreport_2008.pdf [25.07.2017].

Yamin, Alicia Ely/Gloppen, Siri (Eds.) (2011): Litigating Health Rights: Can Courts Bring More Justice to Health? Cambridge, MA: Harvard University Press.

Zenker, Heinz-Jochen (2011): »Europäische Strukturen der Gesundheitsversorgung von irregulären Migrantinnen und Migranten«, in: Mylius et al. (2011), 83-99.

Zimbabwe Human Rights NGO Forum (2009): »The right to health in Zimbabwe«, in: Human Rights Bulletin 41 (2009), Harare. 


\section{The Minimum Core Approach to the Right to Health}

\section{Progress and Remaining Challenges}

AMREI MÜLLER ${ }^{1}$

\section{INTRODUCTION}

The editors of this volume raise the question of whether the human right to the highest attainable standard of physical and mental health (the right to health) set out in Article 12 of the International Covenant on Economic, Social and Cultural Rights (ICESCR or Covenant) remains an empty promise for a large majority of the world's population. A 2015 joint World Health Organization (WHO) and World Bank Group report measuring the world population's access to essential health services in 2013 concluded that »at least 400 million people do not have access to one or more essential health service and $6 \%$ of people in low- and middle-income countries are tipped into or pushed further into extreme poverty because of health spending. $\ll^{2}$ This indicates that for these people, even the so-called minimum core right to health - a right to access essential health goods and services - indeed remains an empty promise. Many old and new, national and universal threats to the human right to health remain to be addressed through legal and other measures.

1 Parts of this chapter build on and develop the author's previous work: Müller (2013), chapter 4 and Müller (2016a).

2 WHO/World Bank Group (2015). 
In this chapter, I would however like to present progress that has been made in conceptualising health as a human right, the implementation of which is increasingly monitored by domestic and international courts and quasi-judicial bodies. I would like to argue that international and national human rights law scholarship and practice has contributed greatly to clarifying the content of the right to health, as well as states' dynamic obligations flowing from this right. In doing so, important steps have been taken to ensure that international and domestic law can effectively protect the fundamental human interest underlying the core right to health - the interest to access at least essential health goods and services that enable human beings to lead a "good« life. The analysis focuses in particular on the contribution of the minimum core approach to the right to health that has been introduced by the UN Committee on Economic, Social and Cultural Rights' (CESCR) General Comment No. 14 on the Right to Health in 2000. It assesses how far human rights law scholarship and practice have come in developing the minimum core approach so that it can achieve its designated purpose. It also discusses the next steps that should be taken towards this aim in light of the continuing challenges to securing everyone's fundamental interest to have access to essential health goods and services through the effective implementation of the core right to health.

To achieve this, part 2 sets out the purpose and potential of the minimum core approach to the right to health and human rights in general. Part 3 examines some of the open questions about the minimum core approach originating from the CESCR's unclear and sometimes contradictory statements about this approach; and briefly summarises the critique of the core approach in existing human rights (legal) literature. Part 4 then shows that some of the open questions have been answered and criticism voiced has been addressed through the collective practice of (democratic) states interpreting and applying the right to health. The Committee could consolidate this practice further in an (updated) statement about the universal minimum core content of the right to health. This process has inter alia been facilitated by the clarification of procedural obligations under the ICESCR. In addition, political philosophers have helped to justify the internationally-defined minimum core content of the right to health, and the absolute character of this and other core human rights. Part 5 turns to discuss whether the minimum core approach can help to meet one of the main challenges that we are facing with the realization of the minimum core right to health, 
in particular in low-income countries: the fact that some states of jurisdiction are unable to secure even the minimum core right to health of their population because the threats to the interests protected by this right originate from outside their jurisdiction and/or because they do not have sufficient resources and capacities to realize minimum core rights. To address this, I tentatively examine how the minimum core approach could potentially help with the further specification and allocation of states' and international organisations' territorial or extra-territorial duties and responsibilities to cooperate and assist under the ICESCR, as well as with a better coordination of the implementation of these duties and responsibilities. The concluding remarks (part 6) summarise the main findings.

The method followed is that of legal interpretation of Articles 2(1) and 12 ICESCR in light of subsequent state practice (including domestic court decisions) and the interpretation offered by the CESCR and other UN treaty bodies and organizations, as well as regional human rights courts and bodies. Occasionally, the analysis will rely on arguments of political philosophers to tentatively justify the understanding of the minimum core approach to the right to health advocated here.

\section{The purpose of the Minimum Core Approach to the Right to Health IDENTIFIED BY THE CESCR}

At the start, the purpose of the minimum core approach to the right to health shall be recalled. What were the main reasons for the CESCR to adopt this approach to help interpreting the right to health in particular and economic, social and cultural rights (ESC rights) more generally? To answer this question, we have to look at the Committee's General Comment No. 3 of 1991. The Committee pronounced that the notion of »progressive realization « in accordance with »maximum available resources« set out in Article 2(1) ICESCR:

»should not be misinterpreted as depriving the obligation of all meaningful content. [...] the phrase must be read in the light of the overall objective, indeed the raison d'être, of the Covenant which is to establish clear obligations for States parties in respect of the full realization of the rights in question." 
It went on to observe that:

»minimum core obligations to ensure the satisfaction of, at the very least, minimum essential levels of each of the rights is incumbent upon every State party. Thus, for example, a State party in which any significant number of individuals is deprived of essential foodstuffs, of essential primary health care, of basic shelter or housing, or of the most basic form of education is, prima facie, failing to discharge its obligations under the Covenant. If the Covenant were to be read in such a way as not to establish such a minimum core obligation, it would be largely deprived of its raison d'être. $\ll^{3}$

This, together with the CESCR's pronouncements in its General Comment No. $14^{4}$ that will be discussed in more detail below, indicates that the Committee's main reason for adopting the minimum core approach was to give the notion of »progressive realization $«$ a clearer direction. ${ }^{5}$ It did so by defining a minimum quantitative and qualitative threshold of enjoyment of the right to health that should be guaranteed to everyone in all circumstances as a matter of top priority, ${ }^{6}$ and by defining relatively detailed corresponding (negative and positive) core obligations. It can strongly be assumed that the Committee wished to counter the constantly repeated traditional arguments of some states and influential academic writers ${ }^{7}$ that the right to health and other ESC rights are not individual rights (despite the fact that they are recognised as such in the ICESCR, in other international and regional human rights treaties, as well as in domestic human rights law) but only general guidelines to lead domestic policies. Consequently, these states and academics argued that ESC rights do not give rise to concrete and legally binding obligations, primarily due to the notion of »progressive

3 E/1991/23, 14 December 1990, paras. 9 and 10.

4 E/C.12/2000/4, 11 August 2000, paras. 43-44.

5 See the reference to the raison d'être of the ICESCR in the quotes. See also: van Bueren (1999) 57; Wesson (2004), 299-300.

6 See E/1991/23, 14 December 1990, para. 10; E/C.12/2002/11, 20 January 2003, para. 6; E/C.12/GC/19, 4 February 2008, para. 60; E/C.12/2000/4, 11 August 2000, para. 47; E/C.12/1999/5, 12 May 1999, para. 17.

7 For an overview of relevant literature, a summary and critical discussion of the main arguments, see De Schutter (2010), 740-751. 
realization« in accordance with »maximum available resources $«{ }^{8}$ These arguments have for very long undermined the effective protection of the right to health (and sometimes still do so ${ }^{9}$ ).

Further reasons for the CESCR's adoption of the minimum core approach can be inferred from other statements of the Committee. First, the minimum core approach promises to direct resources to where they are most needed, i.e. towards the implementation of ESC rights at a minimum level, benefitting those who have nothing or very little ${ }^{10}$ - in the words of the Committee to the realization of ESC rights of »marginalized and disadvantaged groups and individuals «. ${ }^{11}$ Second, the Committee has used the minimum core approach to comment on states' individual and collective (as members of international organisations) activities outside their own borders that can pose threats to the fundamental interests protected by minimum core rights, and that allegedly violate (negative) responsibilities to respect at least minimum core human rights outside their own territories. It has done so for example in the context of global trade and development poli$\operatorname{cies}^{12}$ as well as security regimes. ${ }^{13}$ At the same time, in its Statement on Poverty and the ICESCR, the CESCR observed that minimum »core obligations [rather: rights] give rise to [...] international responsibilities for developed States $«{ }^{14}$ to provide $»$ international assistance and cooperation, especially economic and technical to enable developing countries to fulfil

8 E/1991/23, 14 December 1990, para. 9.

9 E.g. E/C.12/GBR/CO/5, 12 June 2009, para. 13; and the strong reluctance of the US to ratify the ICESCR or back UN resolutions referring to ESC rights as human rights.

10 E.g. Scott/Macklem (1992), 77; Bilchitz (2007), 189; Liebenberg (2002), 174.

11 E/C.12/GC/19, 4 February 2008, para. 59(e); E/C.12/2002/11, 20 January 2003, paras. 37(b) and (f); E/C.12/2000/4, 11 August 2000, paras. 43(a) and (f); E/C.12/1999/5, 12 May 1999, para. 28.

12 E.g. E/C.12/GC/19, 4 February 2008, para. 61; E/C.12/GC/18, 6 February 2006, para. 30; E/C.12/2002/11, 20 January 2003, para. 38; E/C.12/2000/4, 11 August 2000, para. 45; E/C.12/2001/10, 10 May 2001, paras. 16-17.

13 E.g. E/C.12/1997/8, 12 December 1997, para. 7; E/C.12/2002/11, 20 January 2003, para. 32; E/C.12/1999/5, 12 May 1999, para. 37.

14 E/C.12/2001/10, 10 May 2001, para. 16. 
their core obligations. $\ll^{15}$ In other words, core rights also seem to trigger states' (positive) responsibilities beyond their own territories to a particular degree. Thus, the minimum core approach promises to help delineating (national) obligations and (international) responsibilities for the implementation of the core right to health and other core human rights. This is based on the recognition that often the realization of even these core rights remains difficult in countries lacking relevant capacities and resources without international assistance. This issue will be explored further in part 5 .

However, the usefulness of the minimum core approach has been questioned by some legal analysists ${ }^{16}$ and domestic courts, ${ }^{17}$ and the CESCR did not articulate and justify its understanding of the minimum core approach very clearly. The discussion now turns to some of the conceptual questions that have been raised about and criticism voiced of the minimum core approach.

\section{Open Questions About and Critique OF Minimum CoRE APPROACH TO THE RIGHT TO HEALTH}

The main open questions about the minimum core approach are about the actual feasibility of determining a realistic minimum core content of the right to health, and at what level this content should be defined - the national or the international. These issues are related to the question of whether minimum core rights are absolute or relative, i.e. whether they are subject to progressive realization in accordance with maximum resources available to a particular state, or whether it is assumed that they are per se affordable for all countries and therefore not conditional on progressive re-

15 E/C.12/2001/10, 10 May 2001, para. 16.

16 E.g. Lehmann (2006); Kende (2003/2004); Porter (2005), 48-55. Note that this contribution cannot discuss political philosophy literature on socio-economic rights in detail.

17 First and foremost by the South African Constitutional Court; see e.g. Minister of Health v. Treatment Action Campaign (TAC), Judgement of 5 July 2002. 
alization. It is also unclear whether limitations to or retrogressive measures touching upon the minimum core right to health are permitted. ${ }^{18}$

\subsection{Questions Left Open by the CESCR}

The Committee's position on these questions remains unclear. For example, in one statement the CESCR has held that »any assessment as to whether a state has discharged its minimum core obligations must take into account the resource constraints applying within a country concerned «. ${ }^{19}$ This is only explicable if one assumes that states only violate the minimum core right to health when they fail to take measures which could be expected given their available resources, and that therefore the minimum core content of the right to health and corresponding obligations are relative, are determined at the domestic level and are subject to progressive realization. Additionally, the Committee hardly ever finds violations of minimum core rights in its concluding observations, even in states where people starve and lack the most basic form of health care; nor does it rigorously ask states to prove that they did all they could, as a matter of priority, to remedy the situation. $^{20}$ This seems to indicate that minimum core obligations are statespecific and their scope contingent upon available resources.

Conversely, other statements of the Committee suggest that it understands the minimum core right to health as an absolute internationallydefined bottom-line, below which no individual should find him/herself, and which must be implemented regardless of a state party's level of economic development. For instance, in its General Comment No. 14 on the Right to Health, it held that "a state party cannot, under any circumstances whatsoever, justify its non-compliance with the core obligations [...]« [em-

18 This question will not be discussed here in detail, but see Müller (2009).

19 E/1991/23, 14 December 1990, para. 10.

20 E.g. E/C.12/1/Add.48, 1 September 2000, para. 25; similarly, E/C.12/1/Add.95, 12 December 2003. Notable exceptions are E/C.12/COD/CO/4, 20 November 2009, para. 16, where the Committee refers to >serious breaches` of Article 2(1) ICESCR; and E/C.12/LKA/CO/2-4, 9 December 2010, para. 28. 
phasis added, A.M. ${ }^{21}$ flowing from the minimum core content of the right to health that it had defined in the same General Comment.

\subsection{The Academic Debate of the Core Approach}

Human rights law scholarship has engaged with these questions and brought forward arguments for either defining relative state-specific minimum cores that are subject to progressive realization; or absolute international minimum cores the implementation of which is presumed to be per se affordable for all states, even low-income countries.

The main arguments of those supporting a nationally-defined minimum core right to health are first that it is unrealistic to require all states to implement the same minimum core, given the vast differences in levels of development around the world. ${ }^{22}$ Low-income countries may not command sufficient resources to satisfy minimum essential levels of the right to health as defined in the CESCR general comments for everyone under their jurisdiction. ${ }^{23}$ This argument gains force with a glance at the Committee's rather broad definition of the minimum core content of the right to health that comprises the provision of primary healthcare services, minimum essential foodstuffs, safe drinking water, adequate sanitation, essential drugs (as defined by the WHO), reproductive, maternal and child healthcare, immunisation against major infectious diseases and basic health education. ${ }^{24}$ For high-income countries on the other hand, a universally-defined mini-

21 E/C.12/2000/4, 11 August 2000, para. 47. The Committee seems to express this absolute understanding of minimum core rights also in: E/C.12/1999/5, 12 May 1999, para. 6; E/C.12/2002/11, 20 January 2003, paras. 40, 42 and 44(c); E/C.12/GC/19, 4 February 2008, para. 65.

22 Craven (1995), 141; and Scott/Alston (2000), 250.

23 The South African Constitutional Court has rejected the minimum core approach on that basis. It found that it would be impossible for the state to provide core services immediately, e.g. in Minister of Health v. Treatment Action Campaign (TAC), Judgement of 5 July 2002, paras. 34-37; see also Kende (2003/2004), 622; Chapman/Russell (2002), 10, who also recognise this danger.

24 E/C.12/2000/4, 11 August 2000, paras. 43-44. 
mum core right to health may become a reason for inertia, as these countries could in fact implement more far-reaching obligations. ${ }^{25}$

Second, a state-specific minimum core right to health is required because an internationally-defined minimum core would inevitably be abstract, inflexible and a-contextual, dividing right to health theory from the real-life experience of individuals whose right to health remains unimplemented. This may result in the exclusion of some individuals from the protection of the right to health whose contextual experiences did not reflect an international standard. ${ }^{26}$

Third, more support for the definition of a country-specific minimum core right comes from doubts over whether it is at all possible to determine a truly universal minimum core right to health, given that no convincing criteria have been developed that might distinguish elements of the right belonging to the minimum core from those belonging to the non-core, and that would justify a prioritisation of the former. Young, for example, reviewed the shared values or needs that have been suggested as a basis for the minimum cores of socio-economic rights (including the right to health), and concluded that there $>$ are no axioms that can deliver an uncontested minimum core ${ }^{27}$

Referring to various attempts to determine an essential minimum core through normative argument, she concludes that »the minimum core will look different to an advocate of human flourishing in comparison with an

25 Noted e.g. by van Bueren (1999), 59; Chapman/Russel (2002), 9; Ssenyonjo (2009), 66-67; Craven (1995), 144, who voiced the concern that when the CESCR focuses too much on minimum core obligations, it will necessarily direct its attention to developing countries, which might open it to criticism.

26 Porter (2005), 52. While Porter points to this danger in particular in the context of focusing adjudication of ESC rights on a universally-defined minimum core, it might be equally relevant for the development and adoption of other measures that aim at the implementation of minimum core obligations; see also Lehmann (2006), 188-189; this difficulty is also recognised by Liebenberg (2006), 31; Pieterse (2006), 491.

27 Young (2008), 138. She reviews different needs-based (life, survival and basic needs) and value-based (dignity, equality and freedom) approaches that aim to determine the content of a universal minimum core. See also Kende (2003/2004), 624; Lehmann (2006), 191. 
advocate of basic survival, just as the core will look different in various instantiations of both survival and dignity ${ }^{28}{ }^{28}$

Other scholars argue that defining a minimum core of the right to health (and human rights in general) would only make sense if it were defined as an universal, absolute standard that has to be implemented in all states, independent of their level of development. ${ }^{29}$ First, they hold that only an international standard can fulfil the promise to bring a degree of determinacy in the notion of progressive realization. ${ }^{30}$ There would be no difference between an obligation to define a minimum core nationally and the general obligation under Article 2(1) ICESCR to progressively realize ESC rights, as the scope of both would be dependent on available resources, and both would give states an excuse to postpone the implementation of ESC rights indefinitely.

Second, most elements of minimum core contents of socio-economic rights defined by the CESCR in its general comments can be linked to survival interests of individuals that exist regardless of the availability of resources, ${ }^{31}$ fulfilment of which is an essential precondition for human existence and development. ${ }^{32}$ This holds true also for the alleged minimum core content of the right to health - a right to access essential health goods and services. The implementation of minimum core rights should be part of

28 Young (2008); even Bilchitz (2007), 224, a strong advocate of a universal minimum core approach based on essential human interests (above all the interest to survive), submits that the survival interest is not suitable as a basis for determining a universal minimum core of the right to health.

29 E.g. Bueren (2002), 184; Coomans (2002), 167; Bilchitz (2007), chapter 6; Arambulo (1999), 130-135; Scott/Alston (2000), 250; Scott/Macklem (1992), 77; Ssenyonjo (2009), 66; Toebes (1999), 224; the Limburg Principles on the Implementation of the ICESCR, June 1986, para. 25.

30 Among others, van Bueren (2002), 184-185; Wesson (2004), 299.

31 E.g. Bilchitz (2007), 222.

32 This has been pointed out in a decision of the Swiss Federal Court, $V$ v. Einwohnergemeinde X und Regierungsrat des Kantons Bern, BGE/ATF 121 I 367, 27 October 1995, Erwägung 2, para. (b): »Satisfying elementary human needs, such as food, clothing and shelter is a precondition for human existence and development« [author's translation]; see also Liebenberg (2005), 22; Bilchitz (2007), 187. 
fundamental governmental functions in all countries, ${ }^{33}$ and states - even poor states - »have to begin somewhere ${ }^{34}{ }^{34}$ It is thus justified to assume that the implementation of universal minimum core rights is affordable even for low-income countries, if necessary through international cooperation and assistance. ${ }^{35}$ Related to the last observation, advocates of an internationally-defined minimum core content of the right to health and other ESC rights thirdly note that only an internationally-defined minimum core right to health holds promise for delineating national obligations and international responsibilities under the right to health, and for coordinating their implementation.

The summarised scholarly debate about these different understandings of the minimum core approach to the right to health has reached an impasse, and the CESCR's more recent statements have not contributed to a clarification of the Committee's understanding of the approach. ${ }^{36}$ To move forward in the process of developing the core approach further so that it can fulfil its purpose mentioned in part 2, the following section suggests to change perspective, utilising insights from the fast-growing field of comparative international human rights law: ${ }^{37}$ to focus on (democratic) states' practice (unilateral and multilateral practice, the latter as members of international organisations) on the right to health to determine whether an international consensus can be established on the minimum core right to health, its (abstract) content and the (abstract) obligations flowing from it. ${ }^{38}$ This perspective recognises that international human rights law is best understood together with domestic human rights law qua »transnational constitu-

33 Noted by Chapman/Russell (2002), 11-12; see also Paschim Banga Khet Majoor Samity v. State of West Bengal, Supreme Court of India, para. 16, reflecting the opinion that what is constitutionally necessary (in this case, the provision of emergency health services to the Indian population) has to be done, regardless of limited resources.

34 As pointed out by COHRE (2003), 119; similarly, Wesson (2004), 299.

35 See e.g. Ssenyonjo (2009), 68.

36 E.g. E/C.12/2016/1, 24 June 2016.

37 See e.g. Roberts et al. (2015) and other contributions to the Volume 109(3) of the American Journal of International Law.

38 For a similar suggestion to proceed in this way, see Forman et al. (2013), 7-8. 
tional law $\ll ;^{39}$ and that international human rights comparison has become one of the main methods of interpretation in human rights practice. ${ }^{40}$ This can be observed in international human rights courts and bodies which compare the practice of domestic courts and other authorities to establish the content of a common transnational standard and based on that, determine an international minimum human rights standard. ${ }^{41}$ And it can also be observed in domestic courts which often discuss and take on other states' practice and common transnational human rights standards when they interpret and apply international human rights treaties.

It shall be argued that an initial search for such an international consensus on the minimum core approach firstly indicates that this consensus tentatively defines the international minimum core content of the right to health as a right to access essential health goods and services; and secondly, that this (and the core of other human rights) is to be understood as an absolute standard (4.1). Moreover, it is argued that such an understanding of the minimum core is confirmed by the procedural obligations flowing from the ICESCR, which guide domestic authorities when translating the abstract international core content of the right to health into a concrete domestic content and concrete obligations. The existence of these procedural obligations will in addition help to address many of the reasonable objections raised against an understanding of the minimum core as an universally-defined absolute standard that were summarised above (4.2).

39 For the full argument see Besson (2015a), 280-299.

40 As analysed in many contributions to Müller (2017).

41 This is most prominent in the ECtHR's »European consensus « approach; but it is also clear from the CESCR's statements, see e.g. E/1991/23, 14 December 1990, para. 10. The practice is also in line with Article 31(3) of the Vienna Convention on the Law of Treaties concerning the use of »subsequent practice« in the interpretation of treaties; and public international methods for determining customary law through analysing state practice and opinio iuris. 


\section{Advocating a Universal and Absolute Minimum CoRe Right to HeALTH: A RIGHT TO ACCESS ESSENTIAL HeALTH Goods AND SERvices}

\subsection{International Consensus}

There are many domestic courts which assume the existence of minimum core contents of socio-economic and other human rights in their jurisprudence. To name but a few examples, the Colombian Constitutional Court has defined «minimum conditions for a dignified life« based on the rights to life, health, work and social security that are part of the extensive fundamental rights catalogue of the Colombian Constitution. ${ }^{42}$ If this standard is not met through government social policy measures, Colombian courts intervene to order the immediate enforcement of relevant minimum core rights to remedy the situation, even if this results in a duty to give an individual access to certain services, goods or programmes and even if this has resource implications. ${ }^{43}$ Similar jurisprudence is known from among others Argentina, ${ }^{44}$ Brazil, $^{45}$ Finland, ${ }^{46}$ Germany, ${ }^{47}$ India, ${ }^{48}$ Portugal $^{49}$ and Swit-

42 Langford (2008), 22; Sepulveda (2008), 147-148; Landau (2014).

43 Sepulveda (2008) cites many cases of the Colombian Constitutional Court. With regard to the right to health, the court has e.g. ordered state or private entities to provide individuals (in particular children) with medication or medical treatment necessary for the immediate protection of their right to health. It does so when this is necessary for the protection of the right to life, personal integrity, dignity or the minimum conditions for a dignified life of the person in question.

44 The Argentine Supreme Court has for instance held that: »in light of the human right to health guaranteed by the [Argentine] Constitution and international human rights treaties, statutory regulations granting access to medical services should be read as requiring health care givers to fully provide essential medical services in case of need «; cited in: International Commission of Jurists (2008), 25; similarly Courtis (2008), 163-181.

45 International Commission of Jurists (2008), 25.

46 Scheinin (2001), 51-53.

47 In its Article 19(2), the German Constitution includes a direct reference to the inviolable core of all fundamental rights protected by it. In regard to the protec- 
zerland. ${ }^{50}$ This trend in domestic courts' socio-economic rights jurisprudence is confirmed by comparative law literature. Drawing conclusions from a study of ESC rights jurisprudence of 13 domestic courts, Langford established that »in broad brush terms, many adjudicators tend to enforce [...] the implicit obligation to immediately achieve a minimum level of realization [of ESC rights] «. ${ }^{51}$ States have also expressed their support for the minimum core approach during the drafting process of the Optional Protocol to the ICESCR. ${ }^{52}$ In addition, regional human rights courts and bodies have endorsed the minimum core approach, even if not as explicitly as the CESCR and some domestic courts. The pronouncements of the European Committee of Social Rights (ECSR) indicate that it supports the idea of a minimum core of each socio-economic right protected in the (Revised) Eu-

tion of the core of socio-economic rights, see in particular, the decisions of the German Constitutional Court (BVerfG), 1 BvL 1/09 of 9 February 2010 and 1 BvL 10/10 of 18 July 2012 in which the Constitutional Court formulated in clear terms that the state has an obligation, deriving from the Article 1(1) (human dignity) read in conjunction with the »welfare-state principle« of Article 20(1) German Basic Law, to ensure that those in need have, as a minimum, their material needs secured that are necessary for maintaining physical well-being and for enjoying minimal participation in the country's social, cultural and political life (defining a minimum subsistence level). The German Constitutional Court's jurisprudence is also discussed by O'Cinneide (2014), 175-176.

48 See e.g. Paschim Banga Khet Majoor Samity v. State of West Bengal, Supreme Court of India, Judgment of 6 May 1996 (on minimum core right to health); and People's Union for Civil Liberties v. Union of India, Writ Petition (Civil) No. 196 of 2001, Interim Order of 2 May 2003, where the Indian Supreme Court held that the right to access government food supplies of those in danger of starvation forms part of the minimum core right to food; see also Muralidhar (2008), 117-118.

49 See the analysis by O'Cinneide (2014), 176.

50 Article 12 of the Swiss Constitution; and the discussion in Häfelin et al. (2012), 294-296.

51 Langford (2008), 22; similarly, see O'Cinneide (2014), 175.

52 Report of the Open-ended Working Group to Consider Options Regarding the Elaboration of an Optional Protocol to the ICESCR on its Third Session, E/CN.4/2006/47, 14 March 2006. 
ropean Social Charter ([R]ESC); ${ }^{53}$ as do the pronouncements of the InterAmerican Commission of/Court on Human Rights; ${ }^{54}$ and also the European Court of Human Rights (ECtHR) refers to the minimum core or essence of rights set out in the European Convention on Human Rights (ECHR). ${ }^{55}$ Koch notices in addition that certain statements by the ECtHR can be interpreted as recognising the notion of a minimum core right to basic health services ${ }^{56}$ and social cash benefits ${ }^{57}$ under the ECHR.

53 For more details see Mikkola (2010) at 316-317; and ECSR, European Roma Rights Centre (ERRC) v. Bulgaria, complaint 48/2008, decision on the merits of 18 February 2009, paras. 37-38; European Roma Rights Centre (ERRC) v. Greece, decision on complaint 15/2003, para. 42: »a significant number of Roma are living in conditions that fail to meet minimum standards« in Greece »in breach of the obligation to promote the right of families to adequate housing laid down in Article 16« [emphasis added, A. M.].

54 See the analysis by Shelton (2010), 211 et seq. (referring to minimum thresholds that have to be guaranteed in every state regardless of the level of economic development).

55 E.g. Gorzelik and Others v. Poland, judgment (Grand Chamber), appl. no. 44158/98, 17 February 2004, para. 105; John Murray v. UK, judgment (Grand Chamber), appl.no. 18731/91, 8 February 1996, para. 49; Ashingdane v. UK, judgment (Chamber), appl.no. 8225/78, 28 May 1985, para. 57; several dissenting opinions criticising majority opinions for accepting limitations to rights that affect the core/essence of these rights, e.g.: dissenting opinion of judge Loucaides to McElhinney v. Ireland, judgement (Grand Chamber), appl. no. 31253/96, 21 November 2001; and joint dissenting opinion of judges Wildhaber, Sir Nicolas Bratza, Bonello, Loucaides, Cabral Barreto, Tulkens and Pellonpää to Odievre v. France, judgment (Grand Chamber), appl. no. 42326/98, 13 February 2003, para. 11.

56 Koch (2009), 63-64.

57 Ibid., chapter 8. See also Clements/Simmons (2008), 426, concluding that »[I]n relation to complaints that disclose gross failures of the most basic socio-economic support, the Court's [ECtHR] starting point is now an unequivocal acceptance of the view that the Convention protects a core irreducible set of such rights«. This was confirmed in more recent judgments, such as MSS v. Belgium and Greece, judgment (Grand Chamber), appl.no. 30696/09, 21 January 2011, para. 263. However, the ECtHR remains reluctant to expand its jurispru- 
When it comes to the content of an internationally-defined minimum core right to health, developments point into the direction of accepting the right to access to essential health goods and services, also referred to as access to primary healthcare, as the minimum core content of the right to health. Leaving aside the so-called "underlying determinants of health «, ${ }^{58}$ the following health goods and services seem to make up the international core content of the right to health:

- Access to reproductive, maternal (pre-natal as well as post-natal) and child healthcare;

- Access to immunisation against the major infectious diseases occurring in the community;

- Access to services for the prevention, treatment and control of most prevalent epidemic and endemic diseases;

- Access to essential drugs, as from time to time defined under the WHO Action Programme on Essential Drugs; and

- Access to education and information concerning the main health problems in the community, including methods of preventing and controlling them.

An emerging consensus reflecting this is based on a number of international declarations, among them the Declaration of Alma-Ata, ${ }^{59}$ the Programme of Action of the International Conference on Population and Development (ICPD) ${ }^{60}$ which are both referred to in the CESCR's General Comment

dence further into the socio-economic field, see e.g. Koufaki and Adedy v. Greece, decision (Chamber), appl. nos. 576657/12 and 557657/12, 7 May 2013.

$58 \mathrm{E} / \mathrm{C} .12 / 2000 / 4,11$ August 2000, denotes that these underlying determinants are part of the minimum core content of the right to health (para. 43). The present author thinks that these »underlying determinants of health « are protected by the minimum core content of other human rights, e.g. the rights to food, water, housing, a clean environment and work-related rights. They should therefore not form part of the minimum core content of the right to health.

59 Declaration of Alma-Ata, 6-12 September 1978, section VII (3).

60 Programme of Action of the International Conference on Population and Development, contained in the Report of the International Conference on Population 
No. 14; and the more recent initiative of the International Labour Organization (ILO) on National Floors of Social Protection, among which is the access to essential healthcare; ${ }^{61}$ as well as domestic practice commented on by the CESCR, ${ }^{62}$ and the CESCR's General Comment No. $14 .{ }^{63}$ The WHO has also refocused its work on supporting the provision of primary healthcare, likely to reflect a consensus of its member states. ${ }^{64}$ A more systematic analysis of domestically defined minimum core contents of the right to health, e.g. in domestic law and in national courts' jurisprudence, could help to confirm (or refute) a consensus on the suggested international content of the minimum core right to health. Such a comparative analysis could be conducted by the CESCR in its review of domestic practice which it is presented with in the state reporting process. The Committee could more explicitly consolidate this practice into an updated statement on the minimum core content of the internationally-defined minimum core right to health. ${ }^{65}$ The CESCR could also rely on possible regional consensuses on the minimum core content of the right to health. ${ }^{66}$ The Committee's determination of an abstract universally-defined minimum core right to health based on domestic human rights practice and regional consensuses would

and Development, Cairo, 5-13 September 1994, A/CONF.171/13, Chapter VIII, paras. 8.4 and 8.5 .

61 International Labour Conference, Recommendation 202 Concerning National Floors of Social Protection, 14 June 2012, paras. 4 and 5(a). See also the summary of the wide-ranging consensus on social protection floor in ILO (2011), 16-18.

62 See the review conducted by San Giorgio (2012), 25-28.

63 E/C.12/2000/4, 11 August 2000, paras. 43 and 44; Declaration of Alma-Ata, 6-12 September 1978, VII (3).

64 See e.g. WHO (2008) and (2013).

65 By doing this, the CESCR might also address criticism to the CESCR's current definition of the minimum core right to health set out in its General Comment No. 14, which has been criticised for its broadness and the unclear distinction it draws between »core obligations « (para. 43) and »obligations of comparable priority« (para. 44).

66 For an innovative discussion of the role of regional consensuses, see Besson (2017); Neuman (2008). 
also ensure the practicality ${ }^{67}$ of this internationally-defined core right as a guideline for its implementation in particular domestic circumstances. ${ }^{68}$

Understanding the minimum core right to health as a right to access essential health goods and services (primary healthcare) is also supported by strong normative arguments. As noted above, the interest shared by every human being to have access to at least essential health goods and services is inherently connected to the particularly urgent broader human interest to survive. ${ }^{69}$ However, due to the nature of the right to health, using the interest to survive as a basis for the minimum core content of this right in particular raises problems. Securing the interest to survive of every individual would require individualised minimum cores, given the differing health conditions of many people; and some individuals might require access to services that are hugely expensive to ensure their survival. ${ }^{70}$ Therefore,

67 States' have recognised the CESCR's unique overview of ESC rights implementation in different countries around the world. More recently they named the Committee's expertise as one of the reasons why the CESCR should receive the mandate to review individual complaints under the Optional Protocol to the ICESCR. See the Report of the Open-ended Working Group to Consider Options Regarding the Elaboration of an Optional Protocol to the ICESCR on its Third Session, E/CN.4/2006/47, 14 March 2006, para. 91.

68 The need to specify minimum core duties flowing from the (abstractly) defined international minimum core right to health in light of particular domestic contexts is discussed in more detail in section 4.2 below.

69 For the full argument see Bilchitz (2007), 222, linking minimum core socioeconomic rights to the essential human interest to survive and to enjoy a minimum level of well-being which are essential preconditions for human beings to have positive experiences and to pursue their purposes. See also Pogge (2002), who refers to preconditions to lead a $»$ flourishing life $\ll$.

70 This difficulty is also recognised by Bilchitz (2007), 220-225. It should be noted that access to (expensive) secondary and primary health services are not excluded from the scope of the right to health. However, they will regularly be part of the non-core content of the right and their availability will thus be dependent on resources. Moreover, states are obliged under the ICESCR to also plan the progressive extension of health services to non-core services. For details on the relationship between core and non-core obligations flowing from the right to health, see Müller (2013), 96-99. 
identifying a universal minimum core right to health in a reality of limited resources and capacities that will have practical relevance also for lowincome countries will necessarily involve some utilitarian considerations and contain the basic health goods and services that will enable the vast majority of individuals to have their basic survival interest secured through such access. ${ }^{71}$ Understanding the international minimum core content of the right to health as a right to access primary health goods and services seems justified on this basis.

Last but not least, there are indications in state practice as well as in international declarations that minimum cores constitute absolute minimum thresholds of each human right that must be respected, protected and fulfilled at all times. ${ }^{72}$ In the drafting process of the OP-ICESCR, delegations participating in the consultations were of the opinion that allocating sufficient resources to the implementation of minimum core rights is an immediate obligation on states under the ICESCR; ${ }^{73}$ and an introduction to the 2012 ILO strategy paper »Social Security for All - Building Social Protection Floors and Comprehensive Social Security Systems" indicates a consensus on the assumption that the implementation of these protection floors, including access to essential healthcare, is affordable for every country. ${ }^{74}$ As will be elaborated further below, the resources for the immediate realization of minimum core rights can be made available as a result of international cooperation and assistance. ${ }^{75}$ Domestic human rights jurisprudence also points towards the understanding of the minimum core of human rights

71 As highlighted in particular by Lehmann (2006), 190.

72 Some core rights can still be derogated from temporarily »in time of war or other public emergency threatening the life of the nation« (see e.g. Article 15 ECHR; Article 4 ICCPR).

73 Report of the Open-ended Working Group, first session, E/CN.4/2004/44, 15 March 2004, para. 56. The report does not, however, reveal how many delegations shared this opinion.

74 ILO (2012).

75 See the pronouncements of the CESCR in that regard in its General Comments cited, infra ns. 112 and 119. 
as an absolute standard ${ }^{76}$ which has also been called the »limits of limits ${ }^{77}$ to human rights, i.e. a brake to a balancing of different rights or a right against a public interest that result in the complete extinction of a human right. ${ }^{78}$ This understanding of the absolute character of the »essence« of a human right also seems to underlie ECtHR jurisprudence when the Court observes that »limitations applied must not restrict or reduce the [right to] access [in this case: to a court] left to the individual in such a way or to such an extent that the very essence of the right is impaired «. ${ }^{79}$ The absolute character of the minimum core right to health and other socioeconomic rights is moreover strengthened by the above-mentioned urgent survival interest that underlies this right: its implementation (securing everyone's access to basic health goods and services) is urgent to avoid widespread tragic consequences.

Furthermore, not understanding the minimum core of each human right as an absolute standard would undermine the function that human rights should have in a democracy. Human rights function as egalitarian limits on democracy. Together with non-discrimination rights, the minimum core of each human right protects the basic equality of individuals against restrictions through democratic decisions. ${ }^{80}$ This recognition also implies that the right to access essential health goods and services as the minimum core content of the right to health should be protected against governmental claims of resource scarcity, even claims of democratically elected governments. As mentioned by the supporters of a universally-defined minimum core right to health, the implementation of minimum core rights should be

76 E.g. the jurisprudence of the German Constitutional Court points into this direction, see the analysis by Schaks (2015); see also, for the context of Switzerland, the discussion in Häfelin et al. (2012), 296.

77 Örücü (1986), 36-59.

78 On this, see Müller (2009).

79 ECtHR, Ashingdane v. UK, judgment (Chamber), appl.no. 8225/78, 28 May 1985, para. 57. The Court has also argued this in the context of other rights protected by the ECHR. See the judgments cited supra $\mathrm{n}$. 55 .

80 For a full analysis of the inherent relationship between human rights, equality and democracy that also justifies the understanding of the minimum core of each human right as absolute, see the work of Samantha Besson, in particular: Besson (2011) and (2012a). 
part of fundamental governmental functions in all countries. ${ }^{81}$ This also fits with the overarching obligation to fulfil human rights that requires the building of (democratic) institutions which are able to discharge the many negative and positive human rights duties flowing from international treaties, including institutions that can devise and implement health policies required for the implementation of the minimum core right to health. ${ }^{82}$

\subsection{Domestic Specification of the Minimum Core Right to Health and the Importance of Procedural Obligations}

Understanding the international minimum core content of the right to health as the right to access essential health goods and services, and understanding this core as an absolute right, does not yet address all the above-summarised objections that have been raised against the adoption of the minimum core approach. To do this, the discussion now turns to some of the procedural obligations that flow from the minimum core right to health in particular and the ICESCR in general.

One of the aforementioned main objections against the minimum core approach is that an internationally-defined minimum core right to health, e.g. in the shape set out under 4.1, would inevitably be abstract and inflexible. It would not cover the vastly differing health experiences of individuals around the world, and would thus be ineffective in changing the life to the better of human beings whose individual experiences do not resonate with the internationally-defined minimum core right to health.

Addressing this objection, it can be recalled that international human rights and corresponding obligations are regularly phrased in the abstract. Practically, in its interpretation of the international minimum core right to health and other ESC rights, the CESCR can neither cover the experiences

81 See supra ns. 33-34.

82 In practice, this implies the building of an effective health system that provides at least basic health goods and services to everyone under the jurisdiction of the state. See the report of the UN Special Rapporteur on the Right to Health, Paul Hunt, A/HRC/7/11, 31 January 2008. Note that this does not mean that the health system has to be fully run by the government. 
of all individuals whose ESC rights are not met, ${ }^{83}$ nor the political, economic, cultural, social and other characteristics of each and every country. It is thus states that have to concretize and detail the abstract content and duties flowing from the international core right to health for their particular domestic context, through discharging their general ICESCR obligation of reception and enforcement of ESC rights within national law. In that process, domestic conditions have to be taken into account, and concrete legal and other measures suitable for the implementation of the minimum core right to health in the particular domestic context can be determined. For example, guided by the abstract minimum core right to health set out above, states have to establish what the major infectious diseases affecting the local population actually are against which immunisation shall be provided; what the most prevalent epidemic and endemic diseases are against which preventive and curative health services shall be made accessible and controlling measures be taken; and what the most essential drugs are to which everyone shall have access to in a particular country. ${ }^{84}$ Moreover, states need to determine concrete domestic duty-bearers - in the context of the implementation of the minimum core right to health these can include general practitioners, hospitals, medical centres, rehabilitation centres, pharmacies, pharmaceutical companies and relevant administrative bodies - allocate the duties to them, and coordinate the discharging of these duties.

The ICESCR and the Committee's interpretation of the Covenant define a number of procedural obligations which guide states in this domestic concretisation process and thus in the implementation of the minimum core right to health in practice.

First, the Committee regularly emphasises that the "participation of the population in all health-related decision-making at the community, national

83 This is reflected in the »jurisprudence« of the ECSR, in e.g., European Roma Rights Centre (ERRC) v. Greece, complaint 15/20038, decision on the merits in December 2003, paras. 21 and 25.

84 This is reflected in the CESCR's »jurisprudence«: e.g. E/C.12/1/Add.13, 20 May 1997, where the CESCR called on Russia to address the »eightfold increase in HIV-infection in 1996 as a health question of the utmost importance« (para. 40). 
and [even $\mathrm{at}^{85}$ ] international levels ${ }^{86}{ }^{86}$ is an important aspect of the right to health [emphasis added, A.M.]. This is linked to the obligation of states to protect human rights set out in the ICESCR (and the ICCPR) in democratic

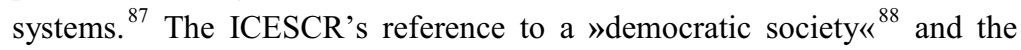
link between ESC rights and political rights highlighted in Article 6(2) ICESCR reinforce this. This means that states should provide for a mechanism that allows for "participation in political decisions relating to the right to health taken at both the community and national levels $«,{ }^{89}$ including when it comes to the concretisation of the international minimum core right to health at the domestic level, i.e. the determination of the concrete health goods and services every individual should have immediate access to within the respective states' jurisdiction. Usually, this mechanism is established in the shape of an elected parliament in line with the political participation rights of the ICCPR, ${ }^{90}$ a fact that once more highlights the strong connection between ESC rights and political rights.

Second and relatedly, the ICESCR obliges states to adopt domestic law to concretise the minimum core right and corresponding duties at the domestic level. Article 2(1) ICESCR refers to "particularly the adoption of legislative measures « to achieve the progressive realization of the right to health. ${ }^{91}$ This also highlights that the legislature is explicitly addressed by the ICESCR.

85 In reality, participation at international level remains difficult given the non-existence of relevant (democratic) international institutions.

86 E/C.12/2000/4, 11 August 2000, para. 11. The importance of participatory health-decision-making is also recognised by the European Committee of Social Rights, e.g. Marangopoulos Foundation for Human Rights (MFHR) v. Greece, complaint no. 30/2005, decision on the merits of 6 December 2006, paras. 216 and 219.

87 On obligations to realize human rights in a democratic system see Steiner (2008); Besson (2010).

88 Articles 4, 8(1)(a) and (c) ICESCR.

89 E/C.12/2000/4, 11 August 2000, para. 17.

90 In particular Article 25 ICCPR; see also Article 3 Protocol I to the ECHR.

91 The CESCR has explained this obligation in particular in its General Comment No. 9 (E/C.12/1998/24, 1 December 1998). This can happen (but does not have to) through the incorporation of the ICESCR into domestic law. 
Third, in the specification process, including the adoption of legislative measures, states need to pay particular attention to the health needs of vulnerable and marginalised members of society. ${ }^{92}$ This could imply a procedural obligation addressed to e.g. national parliaments to consult these groups about their most urgent health needs when the substantive minimum core content of the right to health is specified domestically. Even in wellestablished democratic systems so-called vulnerable and marginalised groups might not be represented sufficiently through the legislature, ${ }^{93}$ and it might therefore be necessary that they are consulted explicitly in the process of specifying the core content to ensure that their voices are heard and their primary health needs met.

Fourth, the CESCR and national courts have established that decisionmaking processes about the scope of the right to healthcare and other social services needs to be transparent and based on reliable data. ${ }^{94}$ The German Constitutional Court has, for example, determined such procedural obligations in detail addressing the legislature when it comes to the determination of the exact scope of social benefits that ensure everyone's subsistence level: the scope should be determined in a transparent and objective procedure, based on reliable data and apply a comprehensible and realistic calculation method. ${ }^{95}$ These procedural requirements are also relevant for the determination of the substance of a domestically-concretised minimum core right to health. In the context of the right to health, this might imply consultations with public health experts to get hold of >reliable datar.

Fifth, states' procedural obligations include the provision of effective remedies for alleged violations of the (minimum core) right to health. Unlike the ICCPR, ${ }^{96}$ the ICESCR does not explicitly establish a duty on state parties to provide judicial, administrative or other remedies. However, it can well be argued that such an obligation is implied also in the ICESCR:

92 E/C.12/2000/4, 11 August 2000, para. 43(a) and (f).

93 See e.g. a report from Germany concerning political influence of persons with low incomes, Elsässer et al. (2017).

94 E/C.12/2000/4, 11 August 2000, paras. 43(f), 55 and 36; this has also been recognised by the European Committee of Social Rights: Conclusions XV-2, United Kingdom, 599.

95 See the judgments of the German Constitutional Court, supra n. 47.

96 As in Article 2(3) ICCPR. 
remedies are required to ensure the effective enforcement of the domestically concretised minimum core obligations flowing from the minimum core right to health; and the democratic system in which human rights are to be realized implies the existence of an executive, legislative and judicial power, structured inter alia by the separation of powers doctrine. ${ }^{97}$ Among other, the latter suggests some judicial (or administrative) control over whether the legislature and executive comply with their obligations under the ICESCR - this can happen through enabling domestic courts and/or administrative review bodies to enforce the ICESCR directly and/or the domestic laws adopted to concretise core (and non-core) obligations flowing from Article 12 ICESCR. Such review can furthermore finetune the concretisation and contextualisation of the abstract international core right to health, as domestic courts and other review bodies can decide on a caseby-case basis whether the concretisation by the legislature/executive proves sufficient to guarantee effective access to primary healthcare services in a particular case. ${ }^{98}$ Moreover, even when sufficiently specified through domestic law and other policy measures, this specification requires constant up-dating in line with changing socio-economic circumstances, technological and medical developments and shifting major health threats that a society is facing. ${ }^{99}$ This reflects the dynamic character of human rights obliga-

97 This is most prominently developed in ECtHR jurisprudence. See e.g. Van de Hurk v. Netherlands, judgment (Chamber), appl.no. 16034/90, 19 April 1994, paras. 44-55

98 The decision by the German Constitutional Court, 1 BvL 1/09 vom 09.02.2010, reflects this. It inter alia highlights the need for taking into account the specific circumstances and unique interests of different groups (in this case children) when the amount of social cash benefits is determined allowing individuals in need to live in accordance with the national minimum subsistence level; see also Pieterse (2006), 491; Bilchitz (2007), 224-225.

99 As observed by the CESCR (E/C.12/2000/4, 11 August 2000, para. 43[f]) and recognised in the »jurisprudence« of the European Committee on Social Rights, see e.g. Conclusions I, Statement of interpretation on Article 1(1), 13; Conclusions XIII-5, Statement of Interpretation on Article 23, at 455 and Conclusions $\mathrm{XV}-2$, Belgium, 99 (referring to the right to health education as set out in Art.11(2) of the ESC); and the jurisprudence of the German Constitutional Court, as clearly formulated judgment 1 BvL 1/09 of 9 February 2010. 
tions. ${ }^{100}$ This character indeed requires constant monitoring of the situation by domestic authorities (and, subsidiarily, by regional or international courts or quasi-judicial bodies). ${ }^{101}$ This can regularly be done by domestic courts that, if they are given the power to review individual complaints, might become aware of changing circumstances that bring about new threats to individuals' abilities to enjoy their (minimum core) right to health. They may then interpret domestic law and/or the ICESCR dynamically to capture these changing circumstances, or call on the legislature and executive to adopt new or adapt existing laws and policy measures to this end.

In summary, these procedural obligations which guide states in the concretisation of the abstractly defined international minimum core right to health will ensure that minimum health needs of individuals are met in all countries around the world in a way that takes account of the local context. This ensures that even if it is (necessarily) defined in the abstract, the universal minimum core content of the right to health can make a difference for individuals who have varying health problems that shall be addressed urgently. At the same time, the abstract, internationally-defined minimum core can prevent arbitrariness in the domestic concretisation process, guiding the priorities of this concretisation process so that the national legal and other measures for the implementation of the minimum core right to health benefit everyone under the jurisdiction of a particular state. ${ }^{102}$

100 This has been clearly developed in the ECtHR's »evolutionary or dynamic interpretation« doctrine. For an overview, see Harris et al. (2014), 8-10.

101 Parallels can be drawn to the cooperation required by domestic authorities (the executive, legislature and judiciary) under the ECHR to secure the effective implementation of the ECHR in changing circumstances. For details see Müller (2016b).

102 This is based on the assumption that the internationally defined minimum core right to health as set out in section 4.1 above ensures access to health services that address most common health threats, and thus benefit a great number of people. 


\section{Utilising the Minimum Core Approach to Determine, Allocate and Coordinate DOMESTIC DUTIES AND INTERNATIONAL RESPONSIBILITIES?}

It can still be reasonably objected that the internationally-defined minimum core right to health as defined in section 4.1 and its domestic concretisation and implementation is unaffordable for low-income countries. Relatedly, there might be threats and obstacles to a state's ability to protect its population's minimum core right to health which originate from beyond the state's borders. Such threats may come from another state or states, international organisations and international law, or from private actors based in another state. The inability of a state to ensure universal access to primary healthcare of individuals under its jurisdiction because of structural adjustment policies pushed for by international organisations (e.g. the International Monetary Fund (IMF) or the EU) is one example in this context. Another is the state duty to ensure its population's access to essential medicines as required under the minimum core right to health which might be impossible because of high prices that pharmaceutical companies charge for essential drugs. These corporations may also invoke commercial and intellectual property rights when they decide which drugs to produce or to protect from generic production. ${ }^{103}$ International organisations such as the World Trade Organization (WTO), the IMF or the EU have worked to develop and embed the law protecting commercial and intellectual property rights as well as international trade law that can hinder a state to protect its population's access to essential health goods and services as required under the ICESCR. To remedy this, not only other states will usually need to be involved but also the involvement of international organisations and private (pharmaceutical) corporations may be required.

In the following, it shall be argued that the minimum core approach could help to address these challenges to some extent by concretising both duties under the ICESCR that states have as members of international or-

103 The conflicts between the right to health and international law protecting intellectual property rights have been discussed in great detail, e.g. by Steffen Guise Rosina et al. (2010); Helfer (2016); A/63/263, 11 August 2008. Despite this, these conflicts have not been solved. 
ganisations and (international) responsibilities to cooperate and assist in the realization of ESC rights, something which has been indicated by the statements of the CESCR.

First on states' duties as members of international organisations: International human rights law includes an obligation of states to protect individuals under their jurisdiction against human rights violations caused by international organisations of which they are members. This duty can be deduced from the Draft Articles on the Responsibility of International Organizations. ${ }^{104}$ In their Article 61, the Draft Articles indicate that international responsibility can be attributed to states when they intentionally circumvent their human rights duties under the ICESCR (and other human rights treaties) through membership in an international organisation and through conduct of the latter. This means that states have an obligation to ensure that their membership in an international organisation and the activities undertaken by this organisation do not prevent them from protecting the rights of individuals under their jurisdiction. ${ }^{105}$ The minimum core approach calls on states to be particularly alert when joining an international organisation whose objectives and purposes might conflict with their minimum core obligations; or when they approve activities or the adoption of legal measures by an organisation to which they are already a member, that can undermine their ability to secure minimum core rights in particular within their jurisdiction. ${ }^{106}$ This can be relevant when it comes to measures taken for the protection of intellectual property rights as well as free trade. A heightened alertness of states when it comes to their ability to protect minimum core rights is justified by the particularly urgent human interest that underlies minimum core rights, as has been argued above.

In its current shape, international law does not include an obligation on states to ensure that international organisations do not adopt measures that

104 Draft Articles on the Responsibility of International Organizations (DARIO), A/RES/66/100, 9 December 2011.

$105 \mathrm{E} / \mathrm{C} .12 / 2016 / 1$, 24 June 2016, para. 5; this is clear also from the jurisprudence of the ECtHR as summarised in the commentary to Article 61 DARIO, 93-95, at http://legal.un.org/ilc/texts/instruments/english/commentaries/9_11_2011.pdf [14.06.2017].

106 The CESCR has reminded states of this obligation frequently, e.g. E/C.12/ 2016/1, 24 June 2016, paras. 4 and 5. 
prevent other states from protecting the human rights of individuals under these other states' jurisdiction; or more generally, a duty not to create obstacles, including through the activities of private actors (e.g. multinational corporations), for other states to respect, protect and fulfil human rights of individuals under the jurisdiction of these other states. ${ }^{107}$ The reason for this is that normally ${ }^{108}$ the jurisdictional link between a state and individuals under the jurisdiction of another state is missing. ${ }^{109}$ A jurisdictional link is, however, required to pose human rights obligations on a state (or on international organisation). ${ }^{110}$

But states, international organisations, private corporations and even individuals have responsibilities for the protection of human rights in all states, and, as shall be argued in the following, in particular when it comes to the protection of minimum core rights, including the minimum core right to health. The legal basis for these responsibilities are Articles 2(1), 11(2), 15(4), 22 and 23 ICESCR, all referring to the importance of international cooperation and assistance for the realization of the rights set out in the Covenant. Unfortunately, as pointed out by political philosophers, there are »few concepts in moral and political philosophy that are more slippery than that of responsibility«. ${ }^{111}$ This is also reflected in international human rights law, where no satisfying answer has been found yet as to how the responsibility to cooperate and assist in the implementation of human rights (in particular ESC rights) which is diffusely addressed to the sinternational com-

107 See A/RES/66/100, 9 December 2011; and A/RES/56/83, 12 December 2001. See also the analysis by Besson (2015b), 482-484.

108 There are rare cases where jurisdiction is shared among two states, as recognised e.g. by the ECtHR in Catan and Others v. Moldova and Russia, judgment (Grand Chamber), appl. nos. 43370/04, 18454/06 and 8252/05, 19 October 2012, paras. 110 and 122.

109 The Maastricht Principles on Extraterritorial Obligations of States in the Area of Economic, Social and Cultural Rights, 2011, aim to close this gap, see e.g. principles 13, 21 and 23. Note, however, that the Maastricht Principles do not make a distinction between duties of states (and international organisations) of jurisdiction, and responsibilities of states, international organisations, private actors and individuals' to cooperate and assist in the realization of ESC rights.

110 Besson (2012b) and (2015b), 468-470.

111 Miller (2001), 455. 
munity $<$, can be made more concrete and assigned to one or more states (that do not have jurisdiction), international/regional organisations, private actors or individuals that make up the sinternational community in concrete cases. The statements of the Committee on these responsibilities remain very general, calling on states and »others in a position to help ${ }^{112}$ to cooperate and assist each other in the realization of ESC rights. ${ }^{113}$ The Maastricht Principles go further by establishing that "states should coordinate with each other, including in the allocation of responsibilities, in order to cooperate effectively in the universal fulfilment of economic, social and cultural rights « [emphasis added, A.M.]. ${ }^{114}$ A Commentary to the Maastricht Principles moreover suggests criteria which should guide this allocation of responsibilities to different actors, among them capacity (economical, financial, technical, technological and in form of influence in international decision-making processes ${ }^{115}$ ), causality and historical ties. ${ }^{116}$

In addition, it can be suggested that a focus on the minimum core content of the right to health (and other ESC rights) could help to give these responsibilities a clearer direction and to allocate them more effectively to different actors, including when it comes to the coordination of the implementation of (international) responsibilities with the implementation of (national) minimum core obligations flowing from the right to health that are addressed to the state of jurisdiction. This has been suggested by the CESCR in several statements, and it has been taken up by the Maastricht Principles. The Committee observed that internationally-defined minimum

112 E/C.12/2001/10, 10 May 2001, para. 16; and E/C.12/2000/4, 11 August 2000, para. 45.

113 E.g. E/C.12/GC/19, 4 February 2008, paras. 52-58; E/C.12/GC/17, 12 January 2006, paras. 36-38; E/C.12/2002/11, 20 January 2003, paras. 30-36; E/C.12/2000/4, 11 August 2000, paras. 38-42; and E/C.12/1999/5, 12 May 1999, para. 38 .

114 Maastricht Principles, 2011, principle 30.

115 This includes capacity to influence the development and entrenchment of international law that obstructs the implementation of ESC rights, like intellectual property law, trade law or law protecting foreign investments. See also E/C.12/1999/5, 12 May 1999, para. 39.

116 Maastricht Principles, 2011, principle 31; De Schutter et al. (2012), 1152-1153; Besson (2015b), 484-485. 
core content of ESC rights »give rise to national responsibilities [rather: obligations] for all States [of jurisdiction], and international responsibilities for developed States, as well as others that are in a >position to help « ${ }^{117}$ This suggests that the universal minimum core right to health as defined in section 4.1 above can guide states, international organizations and other actors with the capacity to help as to when their responsibility to offer assistance is clearly triggered: ${ }^{118}$ when the minimum core right to health of »any significant number of individuals $«{ }^{119}$ is not implemented in another country. ${ }^{120}$ Complementing this, the Committee has frequently called on states of jurisdiction who lack the capacity and resources to implement the minimum core right to health to appeal to other states, international organisations and other actors for the assistance that is needed for the implementation of minimum core obligations under the right to health. ${ }^{121}$ The particularly urgent human (survival) interests which are underlying the minimum core content of the right to health and the related fact that minimum core obligations should not be limited even by a majority decision of a democratically elected parliament make the implementation of minimum cores a legitimate focus for cooperation between domestic and foreign and/or international actors. The latter could potentially contribute to avoid the problem of possible conflict between the democratically determined health priorities in the state of jurisdiction with health priorities determined in third states which wish to discharge their international responsibilities flowing from the right to health to assist with the implementation of the right to health in another country.

117 E/C.12/2001/10, 10 May 2001, para. 16.

118 This does not mean that the responsibility to cooperate and assist is irrelevant in situations where non-core ESC rights are involved. For further elaboration, see De Schutter et al. (2012), 1156.

119 E/1991/23, 14 December 1990, para. 10; and E/C.12/2001/10, 10 May 2001, para. 17.

120 The role of the minimum core is recognised also Maastricht Principles, 2011, principle 32.

121 E.g. E/C.12/2007/1, 21 September 2007, paras. 5 and 10(f); and E/1991/23, 14 December 1990, para. 42. See also the Maastricht Principles, 2011, principle 34. 
To end on a critical note: Despite the progress that has been made towards both understanding the need to allocate responsibilities to different actors more clearly and to coordinate their implementation (including with the implementation of duties of states of jurisdiction) and the potential role that the minimum core approach could play in this context, many challenges remain. It is not clear precisely where national obligations end and international responsibilities begin for the implementation of the minimum core right to health. Nor are the criteria particularly well-defined which states, international organisations and other actors should follow when making decisions about how, when and to whom they offer assistance in respecting, protecting and fulfilling the right to health when discharging their (international) responsibilities. Last, there is no reliable institutional framework through which responsibilities can be allocated fairly and their implementation coordinated ${ }^{122}$ - something that would be needed to avoid that none of the potentially responsible actors will step in to actually discharge their responsibility when minimum core rights remain unprotected in a particular country. ${ }^{123}$ Human rights law scholarship will need to address these questions to ensure the implementation of the right to health in all countries around the world, in particular when it comes to aspects of this right that cannot be realized in one state without the assistance of another state, international organisations or private actors - e.g. when a low-income country lacks the resources and capacities to produce essential drugs; or is pushed by international organizations to introduce structural adjustment measures that interfere with the provision of primary healthcare.

\section{Concluding Remarks}

The chapter sketched out the progress which human rights law scholarship and practice has made in developing and operationalising the minimum core approach to the right to health so that this approach can achieve its aim to give the right to health a meaningful content despite the »mere« obligation of states to "progressively realize « the rights of the ICESCR. While the Committee's understanding of the approach remains unclear, it has been

122 Besson (2015b), 477 and 483-484.

123 David Miller has identified this as a »protection gap«, cf. Miller (2009), 246. 
argued that an emerging transnational consensus on the content and character of the minimum core right can be identified from the practice of domestic courts, domestic law as well as regional and international human rights courts and bodies. This consensus points into a direction of understanding the minimum core right to health as an absolute right to access essential health goods and services. More comparative research will be needed to consolidate this consensus (or refute its existence).

The discussion also shed light on the procedural obligations under the ICESCR that guide states when concretising the abstract internationallydefined content of the minimum core right to health at the domestic level, taking into account local circumstances. This concretisation process should take place within a democratic system, and material obligations flowing from the minimum core right to health have to be allocated to various domestic actors and their implementation has to be coordinated.

Last, I argued that a focus on the minimum core approach could (together with other principles and criteria) guide the specification and allocation of states', international organisations' and private entities' responsibilities to cooperate and assist in the realization of the right to health; and in the coordination of the implementation of these responsibilities of different actors, and the coordination of the implementation of responsibilities and duties of the state of jurisdiction. Such specification, allocation and coordination is urgently required to effectively realize the minimum core right to health of everyone, including those who live under a state's jurisdiction that cannot secure minimum core rights without international assistance and cooperation.

\section{REFERENCES}

Arambulo, Kitty (1999): Strengthening the Supervision of the International Covenant on Economic, Social and Cultural Rights: Theoretical and Procedural Aspects, Antwerp: Intersentia.

Besson, Samantha (2010): »The Human Right to Democracy - A Moral Defence with a Legal Nuance«, European Commission for Democracy through Law (Venice Commission), CDL-UD(2010)003, 4 May 2010, Online: http:/www.venice.coe.int/webforms/documents/default.aspx? pdffile $=$ CDL-UD $\% 282010 \% 29003$-e [14.06.2017]. 
Besson, Samantha (2011): »Human Rights and Democracy in a Global Context: Decoupling and Recoupling«, in: Ethics \& Global Politics 4, 1 (2011), 19-50.

Besson, Samantha (2012a): »The Egalitarian Dimension of Human Rights«, in: Archiv für Sozial- und Rechtsphilosophie, Beiheft 136 (2012), 1952.

Besson, Samantha (2012b): »The Extraterritoriality of the European Convention on Human Rights: Why Human Rights Depend on Jurisdiction and What Jurisdiction Amounts to«, in: Leiden Journal of International Law 25, 4 (2012), 857-884.

Besson, Samantha (2015a): »Human Rights and Constitutional Law: Patterns of Mutual Validation and Legitimation«, in: Cruft et al. (2015), 279-299.

Besson, Samantha (2015b): »Science without Borders and the Boundaries of Human Rights: Who Owes the Human Right to Science?«, in: European Journal of Human Rights 4 (2012), 462-485.

Besson, Samantha (2017): »The Influence of the Two Covenants on states Parties Across Regions - Lessons for the Role of Comparative Law and of Regions in International Human Rights Law«, in: Moeckli/Keller (2017) [forthcoming, on file with author].

Bilchitz, David (2007): Poverty and Fundamental Rights: The Justification and Enforcement of Socio-Economic Rights, Oxford: Oxford University Press.

Brand, Danie/Russell, Sage (Eds.) (2002): Exploring the Core Content of Economic and Social Rights: South African and International Perspectives, Pretoria: Protea Book House.

van Bueren, Geraldine (1999): "Alleviating Poverty through the Constitutional Court«, in: South African Journal of Human Rights 15 (1999), 52-72.

van Bueren, Geraldine (2002): »Of Floors and Ceilings: Minimum Core Obligations and Children«, in: Brand/Russell (2002), 183-200.

Campbell, Tom/Goldberg, David/McLean, Sheila (Eds.) (1986): Human Rights: From Rhetoric to Reality, New York: Basil Blackwell.

Chapman, Audrey/Russell, Sage (Eds.) (2002): Core Obligations: Building a Framework for Economic, Social and Cultural Rights, Antwerp: Intersentia. 
Clements, Luke/Simmons, Alan (2008): »European Court of Human Rights - Sympathetic Unease «, in: Langford (2008), 409-427.

COHRE (2003): »Litigating Economic, Social and Cultural Rights: Achievements, Challenges and Strategies_-Featuring 21 Case Studies«, Online: http://globalinitiative-escr.org/wp-content/uploads/2012/06/Liti gating-ESCR-Report.pdf [14.06.2017].

Coomans, Fons (2002): »In Search of the Core Content of the Right to Education«, in: Chapman/Russell (2002), 159-182.

Courtis, Christian (2008): »Argentina - Some Promising Signs«, in: Langford (2008), 163-181.

Craven, Matthew (1995): The International Covenant on Economic, Social and Cultural Rights: A Perspective on its Development, Oxford: Clarendon Press.

Cruft, Rowan/Liao, Matthew/Renzo, Massimo (Eds.) (2015): Philosophical Foundations of Human Rights, Oxford: Oxford University Press.

De Schutter, Oliver (2010): International Human Rights Law, Cambridge: Cambridge University Press.

De Schutter, Oliver/Eide, Asbjørn/Khalfan, Ashfaq/Orellana, Marcos/ Salomon, Margot/Seiderman, Ian (2012): „Commentary to the Maastricht Principles on Extraterritorial Obligations of States in the Area of Economic, Social and Cultural Rights«, in: Human Rights Quarterly 34, 4 (2012), 1084-1169.

Eide, Asbjørn/Krause, Catarina/Rosas, Allan (Eds.) (2001): Economic, Social and Cultural Rights, Dordrecht: Martinus Nijhoff.

Elsässer, Lea/Hense, Svenja, Schäfer, Armin (2017): »Wie arm ist Deutschland wirklich? Im Armutsbericht der Regierung wurde unsere Studie zum Einfluss der Reichen auf die Politik entschärft. Dies sind unsere ungefilterten Ergebnisse«, ZEIT ONLINE, 19 April 2017, Online: http://www.zeit.de/2017/17/armutsbericht-deutschland-einkommen-poli tik-wahlen [14.06.2017].

Forman, Lisa/Ooms, Gorik/Chapman, Audrey/Friedman, Eric/Waris, Attiya/Lamprea, Everaldo/Mulumba, Moses (2013): „What Could a Strengthened Right to Health Bring to the post-2015 Health Development Agenda? Interrogating the Role of the Minimum Core Concept in Advancing Essential Global Health Needs«, in: BMC International Health and Human Rights 13 (2013), 1-11. 
Frewer, Andreas/Bielefeldt, Heiner (Eds.) (2016): Das Menschenrecht auf Gesundheit. Normative Grundlagen und aktuelle Diskurse, Bielefeld: transcript.

Häfelin, Ulrich/Haller, Walter/Keller, Helen (2012): Schweizerisches Bundesstaatsrecht, Zürich: Schulthess [ $8^{\text {th }}$ edn.].

Halliday, Terence/Shaffer, Gregory (Eds.) (2016): Transnational Legal Orders, Cambridge: Cambridge University Press.

Harris, David/O'Boyle, Michael/Bates, Edward/Buckley, Carla (2014): The Law of the European Convention on Human Rights, Oxford: Oxford University Press $\left[3^{\text {rd }}\right.$ edn.].

Helfer, Laurence (2016): »Pharmaceutical Patents and the Human Right to Health«, in: Halliday/Shaffer (2016), 311-339

ILO (2011): „Social Protection Floor - For a Fair and Inclusive Globalisation«, Report of the ILO Social Protection Floor Advisory Group, 27 September 2011, Online: http://www.ilo.org/global/publications/ilo -bookstore/order-online/books/WCMS_165750/lang--en/index.htm [14.06.2017].

ILO (2012): »Social Security for All - Building Social Protection Floors and Comprehensive Social Security Systems«, 20 December 2012, Online: http://www.ilo.org/wcmsp5/groups/public/---ed_protect/--soc_sec/ documents/publication/wcms_secsoc_34188.pdf [14.06.2017].

International Commission of Jurists (2008): „Courts and the Legal Enforcement of Economic, Social and Cultural Rights. Comparative Experience of Justiciability«, Online: http://www.humanrights.ch/upload/ pdf/080819_justiziabilitt_esc.pdf [14.06.2017].

Kende, Mark (2003/2004): »The South African Constitutional Court's Construction of Socio-Economic Rights: A Response to Critics«, in: Connecticut Journal of International Law 19 (2003/2004), 617-629.

Koch, Ida (2009): Human Rights as Indivisible Rights: The Protection of Socio-Economic Demands under the European Convention on Human Rights, Leiden: Martinus Nijhoff.

Landau, David (2014): »The Promise of a Minimum Core Approach: The Colombian Model for Judicial Review of Austerity Measures«, in: Nolan (2014), 267-298.

Langford, Malcolm (Ed.) (2008): Social Rights Jurisprudence: Emerging Trends in International and Comparative Law, Cambridge: Cambridge University Press. 
Langford, Malcolm (2008): »The Justiciability of Social Rights: From Practice to Theory«, in: Langford (2008), 3-45.

Lehmann, Karin (2006): »In Defense of the Constitutional Court: Litigating Socio-Economic Rights and the Myth of the Minimum Core«, in: American University International Law Review 22, 1 (2006), 163-197.

Liebenberg, Sandra (2002): »South Africa's Evolving Jurisprudence on Socio-Economic Rights: An Effective Tool in Challenging Poverty«, in: Law, Democracy and Development 6 (2002), 159-191.

Liebenberg, Sandra (2005): »The Value of Human Dignity in Interpreting Socio-Economic Rights«, in: South African Journal of Human Rights 21 (2005), 1-31.

Liebenberg, Sandra (2006): »Needs, Rights and Transformation: Adjudicating Social Rights«, in: Stellenbosch Law Review 17 (2006), 5-36.

Meyer, Lukas (Ed.) (2009): Legitimacy, Justice and Public International Law, Cambridge: Cambridge University Press.

Mikkola, Matti (2010): Social Human Rights of Europe, Porvoo: Karelactio.

Miller, David (2001): »Distributing Responsibilities«, in: The Journal of Political Philosophy 9, 4 (2001), 435-471.

Miller, David (2009): »The Responsibility to Protect Human Rights«, in: Meyer (2009), 232-251.

Moeckli, Daniel/Keller, Helen (2017): The UN Human Rights Covenants at 50, Oxford: Oxford University Press [forthcoming].

Müller, Amrei (2009): »Limitations to and Derogations from Economic, Social and Cultural Rights«, in: Human Rights Law Review 9, 4 (2009), 557-601.

Müller, Amrei (2013): The Relationship between Economic, Social and Cultural Rights and International Humanitarian Law, Leiden: Brill.

Müller, Amrei (2016a): »Die Konkretisierung von Kernbereichen des Menschenrechts auf Gesundheit. Internationale Debatten $\mathrm{zu}>$ Minimum Core Obligations««, in: Frewer/Bielefeldt (2016), 125-168.

Müller, Amrei (2016b): »Domestic Authorities' Obligations to Co-Develop the Rights of the European Convention on Human Rights«, in: The International Journal of Human Rights 20, 8 (2016), 1058-1076.

Müller, Amrei (Ed.) (2017): Judicial Dialogue and Human Rights, Cambridge: Cambridge University Press. 
Muralidhar, S. (2008): »India - The Expectations and Challenges of Judicial Enforcement of Social Rights«, in: Langford (2008), 102-124.

Neuman, Gerald (2008): »Import, Export, and Regional Consent in the Inter-American Court of Human Rights«, in: European Journal of International Law 19, 1 (2008), 101-123.

Nolan, Aoife (Ed.) (2014): Economic and Social Rights after the Global Financial Crisis, Cambridge: Cambridge University Press.

O'Cinneide, Colm (2014): »Austerity and the Faded Dream of >Social Europe«, in: Nolan (2014), 169-201.

Örücü, Esin (1986): »The Core of Rights and Freedoms: the Limits of Limits«, in: Campbell et al. (1986), 37-59.

Pieterse, Marius (2006): »Resuscitating Socio-Economic Rights: Constitutional Entitlements to Health Care Services«, in: South African Journal of Human Rights 22 (2006), 473-502.

Pogge, Thomas (2002): World Poverty and Human Rights, Cambridge: Polity.

Porter, Bruce (2005): »The Crisis of Economic, Social and Cultural Rights and Strategies Addressing It«, in: Squires et al. (2005), 43-69.

Roberts, Anthea/Stephan, Paul B./Verdier, Pierre-Hugues/Versteeg, Mila (2015): »Comparative International Law: Framing the Field«, in: American Journal of International Law 109, 3 (2015), 467-474.

San Giorgio, Maite (2012): The Human Right to Equal Access to Health Care, Antwerp: Intersentia.

Schaks, Nils (2015): »Die Wesensgehaltsgarantie, Art. 19 II GG«, in: Juristische Schulung 407 (2015), 407-410.

Scheinin, Martin (2001): »Economic and Social Rights as Legal Rights«, in: Eide et al. (2001), 111-122.

Scott, Craig/Macklem, Patrick (1992): „Constitutional Ropes of Sand or Justiciable Guarantees?«, in: University of Pennsylvania Law Review 141, 1 (1992), 1-147.

Scott, Craig/Alston, Philip (2000): »Adjudicating Constitutional Priorities in a Transnational Context: A Comment on Soobramoney's Legacy and Grootboom's Promise«, in: South African Journal of Human Rights 16 (2000), 206-268.

Sepulveda, Magdalena (2008): „Colombia - The Constitutional Court's Role in Addressing Social Justice«, in: Langford (2008), 144-162. 
Shaver, Lea (Ed.) (2010): Access to Knowledge in Brazil: New Research on Intellectual Property, Innovation and Development, New Heaven: Bloomsbury Imprint.

Shelton, Dinah (2010): Regional Protection of Human Rights, Oxford: Oxford University Press.

Squires, John/Langford, Malcolm/Thiele, Bret (Eds.) (2005): The Road to a Remedy: Current Issues in the Litigation of Economic, Social and Cultural Rights, Sydney: UNSW Press.

Ssenyonjo, Manisuli (2009): Economic, Social and Cultural Rights in International Law, Oxford: Hart.

Steffen Guise Rosina, Monica/Wang, Daniel/de Campos, Thana Christina (2010): »Access to Medicines: Pharmaceutical Patents and the Right to Health«, in: Shaver (2010), 165-213.

Steiner, Henry J. (2008): »Two Sides of the Same Coin? Democracy and International Human Rights«, in: Israel Law Review 41, 3 (2008), 445476.

Toebes, Brigit (1999): The Right to Health as a Human Right in International Law, Antwerp: Intersentia.

Wesson, Murray (2004): „Grootboom and Beyond: Reassessing the SocioEconomic Rights Jurisprudence of the South African Constitutional Court«, in: South African Journal of Human Rights 20 (2004), 284-308. WHO (2008): »World Health Report 2008: Primary Health Care (Now More Than Ever)«, Online: http://www.who.int/whr/2008/en/ [14.06. 2017].

WHO (2013): »World Health Report 2013: Research for Universal Health Coverage«, Online: http://www.who.int/whr/2013/report/en/ [14.06. 2017].

WHO/World Bank Group (2015): »Tracking Universal Health Coverage: First Global Monitoring Report«, Online: http://www.who.int/health info/universal_health_coverage/report/2015/en/ [14.06.2017].

Young, Katharine (2008): »The Minimum Core of Economic and Social Rights: A Concept in Search of Content«, in: Yale Journal of International Law 33 (2008), 113-175. 



\title{
Conceptualising Minimum Core Obligations under the Right to Health. How Should We Define and Implement the $>$ Morality of the Depths «? ${ }^{1}$
}

\author{
LiSA Forman, LULJETA CARAOSHI, \\ Audrey R. CHAPMAN, EVERALdo LAMPREA ${ }^{2}$
}

\section{INTRODUCTION}

In his seminal book on basic rights, subsistence and affluence, Henry Shue characterized basic rights as »the morality of the depths [...] [in that they] specify the line beneath which no one is to be allowed to sink «. ${ }^{3}$ In the last two decades, the notion that economic, social and cultural rights offer similar minimum substantive guarantees has entered international human rights law in the form of minimum core obligations that delimit permissible restrictions of economic, social and cultural rights. The imperative for such demarcations is stark given that the International Covenant on Economic, Social and Cultural Rights (ICESCR) formulation of economic, social and cultural rights like the right to the highest attainable standard of physical

1 Henry Shue uses this phrase in Shue (1996), 18: »Basic rights are the morality of the depths. They specify the line beneath which no one is to be allowed to sink $\ll$.

2 This article was originally published as Forman et al. (2016). It is reprinted by permission of Taylor and Francis Ltd., see http://www.tandfonline.com.

3 Shue (1996), 18. 
and mental health (১the right to health $\measuredangle$ ) limits state duties to progressive realization within maximum available resources. To prevent progressive realization within resources from undermining both domestic and international responsibilities towards health, international human rights law institutions developed the idea that these rights hold an inviolable »core « equivalent to essential health needs. Yet few aspects of this right and indeed of economic social and cultural rights more generally have generated greater debate and unresolved questions than the core concept: Is the core fixed or moveable, non-derogable or restrictable, universal or country-specific? Is its function to guarantee specified bundles of the most essential health facilities, goods and services, or is it to require governments to act reasonably to progressively realize these minimal health entitlements? Is the concept a legitimate interpretation in terms of international law rules of treaty interpretation? And what are acceptable methods to further develop the content of these entitlements and duties? Indeed the relatively open nature of many of these questions suggests that the core concept as defined does not resolve incommensurable conflicts between fixity and movement, actions and outcomes, and needs and resources.

This paper seeks to examine several of these questions in light of the evolution of this concept in international law and human rights scholarship, focusing in particular on the development of core obligations in relation to the right to health. In this paper, and for reasons of scope alone, we restrict our attention to relevant international human rights law interpretations and to relevant global scholarship in this domain, leaving aside deep analysis of crucial cognate areas such as global economic, social and cultural rights jurisprudence and philosophical justifications of core obligations. ${ }^{4}$ Accordingly, our paper focuses first on the evolution of this concept in international human rights law. We then analyse key questions about the intended purpose, function, legitimacy and development of the core concept. We argue that greater conceptual clarity on the core concept is an essential precondition to constructing a feasible, principled and grounded conceptualiza-

4 We are co-investigators on a larger project on minimum core obligations funded through the Canadian Institutes for Health Research and the European Commission, which will devote significant attention to the jurisprudential development of this concept. 
tion of the minimum core of the right to health more likely to meet its conceptual and material ambitions.

\section{The Emergence of the Core Concept IN INTERNATIONAL HUMAN RIgHTS LAW}

A significant motivator for the genesis of the core is the dilemma created by article 2.1 of the ICESCR, which limits state duties to

staking steps, individually and through international assistance and co-operation, especially economic and technical, to the maximum of its available resources, with a view to achieving progressively the full realization of the rights recognized in the present Covenant by all appropriate means, including particularly the adoption of legislative measures.«

The duty to progressively realize ICESCR rights within financial resources was introduced into the Covenant to acknowledge that the enjoyment of economic, social and cultural rights depends upon the availability of resources. Yet even at drafting, this article was critiqued for providing a weak guarantee of Covenant rights that provided »too many loop-holes for States Parties wishing to evade their obligations « by pleading a lack of resources and permitting indefinite delays. ${ }^{5}$ The risk of evasive state action under article 2.1 is exacerbated by the vagueness of Covenant rights: For example, the generality of article 12.1's entitlement to the highest attainable standard of physical and mental health is only partially offset by the specification in article 12.2 of steps states must take to fully realize this right. ${ }^{6}$ Anticipating unjustifiably stagnant or retrogressive action, other parts of the Covenant specify that its rights can only be limited insofar as is compatible with their nature (article 4), and that acts aimed at destroying or limiting rights to a

5 A/2929, 1 July 1955, para. 23; See also Alston/Quinn (1987), analysing the drafting history of articles $2.1,4$ and 5 .

6 Article 12.2 requires states to take steps to reduce stillbirth rate and infant mortality, improve environmental and industrial hygiene, prevent, treat, and control epidemic, endemic, occupational diseases, and create conditions that assure medical services to all. 
greater extent than provided for in the Covenant are not permitted (article 5.1). Indeed the drafting history of the Covenant indicates explicit acknowledgement that article 4 in particular was deemed necessary to mediate the risk posed by article 2 since it $» d i d$ not indicate when limitations could be legitimate and it was necessary to state clearly that limitations would be permissible only in certain circumstances and under certain conditions. ${ }^{7}$

In an effort to address the challenges posed by progressive realization within resources and delimited restrictions of rights, the idea that economic, social and cultural rights have core components not subject to such limitations was introduced into human rights debates by the 1980 's. ${ }^{8}$ While articles 4 and 5 of ICESCR provided some textual justification for introducing the core concept, its origins are commonly ascribed to the convergence between scholarship on philosophy, development and human rights, and domestic constitutional laws in Germany and Turkey. ${ }^{9}$

Henry Shue's concept of basic rights to subsistence that imposed correlative duties on multiple actors played a significant generative role in the emergence of the core concept. ${ }^{10}$ Shue conceived of basic rights as »everyone's minimum reasonable demands upon the rest of humanity«, ${ }^{11}$ which would include »unpolluted air, unpolluted water, adequate food, adequate clothing, adequate shelter, and minimal preventive public health care. ${ }^{12} \mathrm{~A}$ second key influence came in a 1987 article by Bård-Anders Andreassen et al., who argued for a "practicable (ultimately even an area-specific) minimal floor of well-being as a standard for distributive analyses of each of the key economic, social and cultural rights. ${ }^{13}$ Andreassen et al. saw a minimalist approach as a necessary counterpoint to demands for unrealistic levels of redistribution via economic, social and cultural rights, and a necessary stage in the progressive realization of Covenant rights. ${ }^{14} \mathrm{~A}$ third major

7 A/2929, 1 July 1955, para. 50, quoted in Alston/Quinn (1987), 205.

8 Toebes (1999), 277.

9 See for example, Toebes (1999), 277-278; Young, 121; Bilchitz (2007), 186.

10 While the first edition was printed in 1980, this article references the second edition printed in 1996, identical but for its preface and afterword.

11 Shue (1996), 19.

12 Ibid., 23.

13 Andreassen et al. (1987/1988), 334, emphasis in the original removed.

14 Ibid., 342. 
influence came from scholarship explicitly promoting the idea that all human rights hold a >core $<,{ }^{15}$ with its most influential exploration by Esin Örücü in a 1986 chapter on human rights. ${ }^{16}$ Örücü drew from German and Turkish law which entrenched >core and >essential« rights, ${ }^{17}$ to suggest that rights should be understood to encompass a "normative scope with three distinct parts: a core, a circumjacence, and an outer edge, the core being that part of a right which is essential to its definition. ${ }^{18}$ Örücü asked whether in a world of qualified rights, the concept of the core could indicate the one area within a right's normative scope which should be protected absolutely. $^{19}$

By the late 1980's, ideas similar to those proposed by Shue, Andreassen and Örücü began to enter international discourse around economic, social and cultural rights. The 1986 Limburg Principles on the Implementation of the International Covenant on Economic, Social and Cultural Rights propose that States Parties are »obligated regardless of their level of economic development to ensure respect for minimum subsistence rights for all«, and that available resources should be $»$ mindful of the need to assure to everyone the satisfaction of subsistence requirements as well as the provision of essential services. ${ }^{20}$ A State Party would be in violation of the Covenant if $»$ it wilfully fails to meet a generally accepted international minimum standard of achievement, which is within its powers to meet. $\ll^{21}$ In 1987 , in an article in Human Rights Quarterly, Phillip Alston, the rapporteur of the newly created Committee on Economic, Social and Cultural Rights

15 The idea of a core of rights corresponding to its essential content had been proposed in earlier scholarship: see for example, Wellman (1978), 53: »What unified any right is its core. At the centre of any legal right stand one or more legal advantages that define the essential content of the right. Change the core and any remaining right would no longer be the same right.«

16 Örücü (1986), 47.

17 Ibid.

18 Ibid., 38.

19 Ibid.

20 Limburg Principles on the Implementation of the International Covenant on Economic, Social and Cultural Rights, Maastricht, 2-6 June 1986, paras. 25 and 28.

21 Ibid., para. 72. 
(CESCR or sthe Committee ), signalled the Committee's intention to adopt and develop the concept of the minimum core in its clarification of Covenant norms. Alston argued that each right must " give rise to an absolute minimum entitlement, in the absence of which a State Party is to be considered to be in violation of [its] obligations. ${ }^{22}$

In the following years, the concept and related terms began to appear in international human rights reports and resolutions, ${ }^{23}$ with a definitive entry into the Committee's jurisprudence in its 1990 General Comment No. 3 which interprets the nature of State Party obligations under article 2.1. ${ }^{24}$ Here the Committee suggests that every State Party holds »a minimum core obligation to ensure the satisfaction of, at the very least, minimum essential levels of each right. « ${ }^{25}$ In one of the most quoted provisions of this Comment, the Committee suggests that

»a State party in which any significant number of individuals is deprived of essential foodstuffs, of essential primary health care, of basic shelter and housing, or of the most basic forms of education is, prima facie, failing to discharge its obligations under the Covenant. ${ }^{26}$

A state could rebut this presumption of failure due to a lack of available resources by demonstrating »that every effort has been made to use all resources that are at its disposition in an effort to satisfy, as a matter of priority, those minimum obligations. ${ }^{27}$

Over the next seven years, the Committee investigated the suggestion in General Comment No. 3 that a state's core obligations under the right to health extend to essential primary healthcare, particularly at a day of general discussion on the right to health in 1993 which was intended to serve as the basis for a general comment on health. Speakers were urged to pay special attention to core content, with proposals for conceptualizing the core of

22 Alston (1987), 352-353.

23 See for example E/CN.4/Sub.2/1992/16, 3 July 1992; E/CN.4/RES/1994/20, 1 March 1994, para. 11.

24 E/1991/23, 14 December 1990.

25 Ibid., paras. 1 and 10.

26 Ibid., para. 10.

27 Ibid. 
the right to health including identification of its key principles, specification of its content (and equivalence with primary healthcare), and specification in some detail of minimum core obligations. ${ }^{28}$ The latter proposal by Audrey Chapman, then Director of the Science and Human Rights Programme of the American Association for the Advancement of Science and a co-author of the current paper, provided a detailed account of minimum core obligations utilizing the then novel notion of first defining violations of economic, social and cultural rights. Indeed, Chapman's >violations approach < explicated at the day of discussion and in subsequent scholarship ${ }^{29}$ provided foundational incentives for the development of the 1997 Maastricht Guidelines on Violations of Economic, Social and Cultural Rights, and for subsequent interpretations of the right to health by the CESCR. ${ }^{30}$ The Maastricht Guidelines suggest that despite the margin of discretion states enjoyed in choosing the means of implementing Covenant rights, »universal minimum standards« for economic, social and cultural rights had been developed through state practice and $»$ the application of legal norms to concrete cases and situations by international treaty monitoring bodies as well as by domestic courts. ${ }^{31}$ In contrast to General Comment No. 3 which made minimum core obligations generally limitable by resource constraints, Maastricht suggests that $»[$ s]uch minimum core obligations apply irrespective of the national availability of resources or other factors or difficulties. $\ll^{32}$

These developments laid the foundation for the authoritative interpretation of core obligations under the right to health in the seminal General Comment No. 14 on the right to health issued by the Committee in 2000, which advances several novel components of core obligations. In defining core obligations, the Committee restates General Comment No. 3's confirmation that states have core obligations to ensure minimum essential levels of rights including essential primary healthcare. It suggests that it had found compelling guidance on core obligations under article 12 by reading the

28 E/C.12/1993/SR.42, 6 December 1993, paras. 62 and 63.

29 For example, Chapman (1996) and (1998).

30 Maastricht Guidelines on Violations of Economic, Social and Cultural Rights, 22-26 January 1997, para. 8.

31 Ibid.

32 Ibid., para. 9. 
1978 Alma Ata Declaration together with contemporary instruments like the 1994 Programme of Action of the International Conference on Population and Development (ICPD). ${ }^{33}$ Accordingly the Committee proposes that a state's core obligations under the right to health would include at least: (1) ensuring non-discriminatory access to health facilities, goods and services, especially for vulnerable or marginalized people, (2) ensuring access to food, basic shelter, housing, sanitation and water, (3) providing essential drugs as defined by WHO, (4) ensuring equitable distribution of all health facilities, goods and services and (5) adopting a national public health strategy and plan of action addressing the concerns of all. ${ }^{34}$ While this list provided very little indication of the nature of health goods and services to be provided beyond essential medicines, the Committee proceeded to identify what it called »obligations of comparable priority« to ensure reproductive, maternal and child healthcare, provide immunization against major infectious diseases, take measures to prevent, treat and control epidemic and endemic diseases, provide education and access to information on the main health problems in the community, and provide appropriate training for health personnel. ${ }^{35}$ It is presumably these obligations that are drawn from the Declaration of Alma-Ata and the ICPD Programme of Action.

The Committee's approach to the limitability of core obligations is markedly different from General Comment No. 3. In General Comment No. 14, the Committee holds that a State party cannot, under any circumstances whatsoever, justify its non-compliance with the core obligations [...] which are non-derogable. $\ll^{36}$ Despite positing core obligations as non-derogable, the Committee only identifies one explicit violation of a core obligation: »The adoption of any retrogressive measures incompatible with the core obligations under the right to health. $"{ }^{37}$ This terseness may be explained by the fact that several of the violations identified under a state's positive obligation to fulfil relate to core and comparable priority obliga-

33 E/C.12/2000/4, 11 August 2000, para. 43.

34 Ibid.

35 Ibid., para. 44.

36 Ibid., para. 47.

37 Ibid., para. 48 . 
tions. $^{38}$ The implication is that a state's primary positive obligations to fulfil the right to health are equivalent for the most part to its core and comparable obligations.

\section{Debates Over the Core}

The evolution of the core concept in international human rights law reflects changing ideas about its intended purpose, function, legitimacy and development. The remainder of this paper focuses on an expanded analysis of key conceptual questions in this regard. We believe that these definitions of the core and consequent scholarly analyses provide important guidance for advancing towards a more conceptually sound approach to core obligations in relation to the right to health.

\subsection{The Purpose of the Core}

As indicated above, the primary impetus for the development of the core concept was to respond to the problem created by progressive realization within resources. The need to protect against the corrosive properties of progressive realization within resources is exacerbated by the historically limited jurisprudential development of economic, social and cultural rights given ideological opposition and their categorization as second generation/ positive rights less conducive to legal and judicial enforcement than the ostensibly first generation/negative rights categorization of civil and political rights. Indeed the introduction of the core concept forms part of a larger effort to advance the jurisprudential interpretation and enforcement of economic, social and cultural rights more generally.

38 Thus, primary violations of the obligation to fulfill would occur through state failures to take all necessary steps to realize the right to health, including failures to adopt or implement a national health policy designed to ensure the right to health for everyone; failure to monitor the realization of the right to health at the national level, for example by identifying right to health indicators and benchmarks; and failure to take measures to reduce the inequitable distribution of health facilities, goods and services. Ibid., para. 42 . 
The metaphor of the core and its usage are instructive in illustrating its intended purpose. The plain language meaning of $>$ core $<$ denotes on the one hand a central location (as in the core of an apple or the earth), which may have different properties to the periphery (as do the fibrous parts of fruit and the molten center of the earth) ${ }^{39}$ These different properties might see the core playing vital functional roles in the broader structure (as do core reactors of a nuclear plant or core computer memory). This foundational role is reflected in the secondary meaning of the core as a basic, essential or enduring part of something larger. ${ }^{40}$ These meanings of the core as both location and function within economic, social and cultural rights are evident in the core's dual role in sstructuring economic, social and cultural rights by defining essential components with different properties from the periphery. This structuring function is evident in scholarship which sees the core assisting in delineating the scope of economic, social and cultural rights, as indicated above when Örücü defines rights as comprising »a core, a circumjacence, and an outer edge. ${ }^{41}$ A similar conception is apparent in Brigit Toebes' suggestion that the scope of the right to health is comprised by all elements entrenched in international treaties that stipulate rights to health, with core content constituting the inner circle of this scope. ${ }^{42}$

This view of the core as a scoping tool suggests on the other hand, that its desired function is to assist in clarifying the range of operation rights. From this perspective, like Hart's notion that legal rules hold a core of certainty and a penumbra of doubt, ${ }^{43}$ the core assists in defining a hierarchical structure within economic, social and cultural rights, with priority radiating outwards in diminishing degrees from essentialia to incidentalia. This hierarchy is apparent in how the core concept is intended to denote those aspects of the right to health so essential that they constitute an »irreducible minimum $\aleph^{44}$ without which the right $»$ loses its value $\ll{ }^{45}$ This view

39 Merriam Webster online, >core

40 Ibid.

41 Örücü (1986), 38.

42 Toebes (1999), 243-244.

43 Hart (1958), 607: When it comes to legal rules »[t]here must be a core of settled meaning, but there will be, as well, a penumbra of debatable cases in which words are neither obviously applicable nor obviously ruled out.«

44 Örücü (1986), 45. 
of diminishing priority suggests that core aspects of rights like health provide a temporal starting point for state action. This view of the core as a foundation of action is evident in its common description as a "floor" quite literally, the lower limit of the right to health. ${ }^{46}$ This is the same language used by the Committee in its first conceptualizations of the concept: for example, its call for input to its 1993 general day of discussion on the right to health was to »the concept that there is a minimum core content of each right which constitutes a »floor« below which the conditions should not be permitted to fall in any State Party. $«{ }^{47}$ Metaphors of floors and ceilings are evocative of at least some of the intent behind the core: to on one hand, >ground $<$ and >concretize< economic, social and cultural rights, on the other, to shouse $<$ the various entitlements within rights in a feasible structure. $^{48}$

Yet the danger of understanding the core as a >floor pects of the right to health falling outside the scope of the core are deprioritized, thereby restricting the scope of the right to health rather than usefully structuring and developing it. As Chapman and Russell suggest, this is »the risk [...] that the >floor will become a >ceiling.$\ll{ }^{49}$ Moreover, that which is most essential and therefore important, seems to conflict with that which is minimum, by definition, the very least a state should do. In this light it is not surprising that the word »minimum« ultimately drops out of the Committee's discourse on the core, as it shifts away from discussions of minimum core content to an exclusive focus on core obligations. Nor is this shift away from content to obligations surprising given the Committee's in-

45 Toebes (1999), 276.

46 Merriam Webster online, >floor`.

47 E/C.12/1993/11, 22 November - 10 December 1993, para. 5. See also van Bueren (2002); Coomans (2002).

48 A similar metaphor was influential at the drafting of the UDHR, where Rene Cassin's draft conceived of the UDHR rights as a Greek temple >portico<, with various rights serving as foundation, columns and roof. It is significant in this regard, that Cassin considered the Preamble and articles 1 and 2 (equality, dignity, non-discrimination) to constitute this foundation. See Swanson Goldberg/Schultheis Moore (2012), 5.

49 Chapman/Russell (2002a), 9. 
sistence that the »raison d'être« of the Covenant is to »establish clear obligations for States Parties« to fully realize Covenant rights. ${ }^{50}$

These terminological shifts are themselves instructive, with the core described over time as "minimum subsistence rights, ${ }^{51}$ "minimum essential levels, $\varkappa^{52} »$ international minimum threshold, $\varkappa^{53} »$ core content, $\varkappa^{54} »$ minimum core obligations $\aleph^{55}$ and $»$ core obligations $«{ }^{56}$ These changing terms reflect the shift in the Committee's approach from articulating the core as an entitlement to a level, threshold or content, to describing the core as an obligation with very little explicated content. While these shifts in terminology show the evolution of the concept, they also suggest that at different points there have been efforts to develop constituent and equally important parts of the core. It is arguable that entitlements, content and duties are each essential elements of the right to health, and that without clarity on each component part, there is no meaningful way to construct this right. As Shue suggests, without spelling out the duties, one has not really spelled out the rights, and spelling out the substance of rights is essential to defining its entitlements. ${ }^{57}$ Thus, rather than reflecting confusion about the role of the core, the shifting institutional focus from entitlements and content to duties might simply reflect a deeper recognition that each component is necessary to identify the structural conditions, actions and outcomes necessary for their realization. In this light, the debate over whether to approach the core as an entitlement, content or obligation calls to mind the parable of people

$50 \mathrm{E} / 1991 / 23,14$ December 1990, para. 10: $»[\mathrm{i}] \mathrm{f}$ the Covenant were to be read in such a way as not to establish such a minimum core obligation, it would be largely deprived of its raison d'être.«

51 Limburg Principles, paras. 25 and 72; Maastricht Principles, paras. 10, 11 and 15.

52 E/1991/23, 14 December 1990, para. 10.

53 A/Conf.191/BP/7, 13 May 2001, para. 17.

54 E/C.12/1997/8, 12 December 1997, para. 7; E/C.12/1993/SR.41, 9 December 1993, para. 2; E/C.12/1999/5, 12 May 1999, paras. 6 and 8.

55 Maastricht Principles, paras. 10, 11 and 15.

56 E/C.12/2002/11, 20 January 200, para. 37.

57 Shue (1996), ix and 15. 
in the dark touching different parts of an elephant and believing that they are describing different animals. ${ }^{58}$

Yet these variations also illustrate some of the challenges in conceptualizing the core, since defining an entitlement is different from defining a level of socioeconomic provision, and in turn different from defining an obligation cognizant of progressive realization within resources. Similarly contrasting views of the core as the essence (importance), the floor (the beginning point or the foundation), and the minimum (the very least) variously posit its operation as a beginning point for action, a fixed barrier to limits, and a realm of priority. These contrasting interpretations may be responsible for some disagreements over how the core is intended to function. Yet if entitlements, content and obligations are equally important constituent parts of economic, social and cultural rights and the right to health, then the Committee's decision to describe core obligations alone cannot be a sufficient way to enable the intended operation of the core. However, if more fully elaborated entitlements and core content are required, who should define these aspects and how?

\subsection{The Function of the Core}

Scholarly debate over how the core is intended to function has mapped closely onto the shifting function ascribed to the core in international human rights law. These debates coalesce around whether the core refers to absolute or relative content (in relation to resources and national needs), or rather to state obligations in relation to such content? And if it refers to obligations, should these be of result or of conduct? ${ }^{59}$ These arguments are prompted by the apparent contradiction created by proposing a fixed set of outcomes within a right defined by progressive realization within resources. Viewed in this light, the core concept appears to set up irresolvable conflicts between entitlements and duties, actions and outcomes, and needs and resources.

58 Again, Shue presciently suggests as much: »the mere core of the right indicates little about the social institutions needed to secure it, and the core of the right does not contain its whole structure.« Shue (1996), 39.

59 The Committee introduced the distinction between obligations of conduct and result in General Comment No. 3, see: E/1991/23, 14 December 1990, para. 1. 
The Committee's changing interpretations over time have not resolved these questions. Whereas in General Comment No. 3 the Committee delineated derogable core obligations to provide core content (defined as essential foodstuffs, essential primary healthcare, basic shelter and housing, or the most basic forms of education), in General Comment No. 14 it shifted to non-derogable core obligations to assure the structural aspects of health (non-discrimination, access to food, shelter, water and drugs, equitable distributions of health facilities, goods and services, and a national public health strategy). This shift from weaker to stronger duties may attempt to respond to criticisms of the lack of financial feasibility of the core for low and middle-income countries (critiques that not coincidentally map closely onto long-standing critiques of economic, social and cultural rights). This analysis is implied by Paul Hunt's indication as Rapporteur for the Committee that it took a pragmatic decision to define obligations rather than content in General Comment No. $14 .{ }^{60}$ Yet shifting from core entitlements to obligations has not resolved debates over whether core obligations require a fixed set of outcomes or simply action reasonably capable of achieving such outcomes. Instead the debate has shifted to whether core obligations should incorporate both conduct and result-based duties, which to some extent simply relocates (without resolution) earlier discussions about the relationship between core content and obligations.

Yet the Committee has been ambiguous about the relationship between core content and obligations of conduct and result. While General Comment No. 3 introduces the distinction between obligations of conduct and result, ${ }^{61}$ the Committee never indicates explicitly where core obligations fall in this framework. For example, while the Committee defines minimum essential levels of economic, social and cultural rights, the correlative duties it outlines suggest obligations of conduct rather than result. This interpretation is implicit in the Committee's suggestion that presumptions of violation (suggested if significant numbers are deprived of essential food,

60 E/C.12/2000/SR.10, 4 May 2000, para 27. (In a previous comment on education the Committee had struggled with how to incorporate core content, eventually taking »the pragmatic approach of defining not the core content but the core obligations incumbent upon States Parties«, an approach it had decided to adopt in the general comment on health).

61 E/1991/23, 14 December 1990, para. 1. 
housing, healthcare and education) can be discharged if states can demonstrate every effort to use resources at their disposal to satisfy these obligations as a matter of priority. ${ }^{62}$ In contrast, in General Comment No. 14, the Committee appears to have shifted definitively towards non-derogable core obligations of result, which include largely structural outcomes as well as essential medicines, minimum essential food, basic shelter, housing, sanitation, and safe and potable water. ${ }^{63}$

Many scholars view the Committee's shift to non-derogable duties as unfeasible and impractical. Indeed, debates over the relationship between core content and duties of result and conduct have riven scholarship. Some like Young reject the notion of fixed core entitlements or core obligations of result. A strong critic of the minimum core concept in general, Katherine Young argues instead for an approach to economic, social and cultural rights that »establishes processes of value-based, deliberative problemsolving, rather than one which sets out the minimum bundles of commodities or entitlements. $\ll{ }^{64}$ Young argues that the practical constraints of limited judicial and CESCR competence ultimately carry the core concept too far from its normative ambitions, which should be transferred to other areas of rights like benchmarks and indicators and assessments of causality and responsibility. ${ }^{65}$ In relation to the right to health, Audrey Chapman is the strongest proponent of a primarily conduct-based interpretation of the core (albeit that she does not reject fixed core entitlements per se). She argues that rather than seeing the core as a sfloor below which health conditions must not in any circumstances fall, the core should rather describe $»$ the minimum duties all States Parties set for themselves regardless of the resources available. $"{ }^{66}$ With Russell, Chapman argues that doing so shifts focus to a more temporal consideration of what a state must do immediately on ratifying the Covenant to realize the right, ${ }^{67}$ and proposes conductoriented core obligations in the respect, protect and fulfil categories. ${ }^{68}$

62 E/1991/23, 14 December 1990, para. 10.

63 E/C.12/2000/4, 11 August 2000, para. 43.

64 Young (2012), 6.

65 Young (2008), 117-118.

66 E/C.12/1993/SR.42, 23 November 1994, para. 62.

67 Chapman/Russell (2002a), 9.

68 Chapman (2002). 
Chapman argues against an approach based primarily on obligations of result given the absence of reliable data for most countries, the absence of means to carefully measure progress, and the potential impossibility of incorporating all measures necessary to achieve particular health outcomes into a minimum applicable to all countries. ${ }^{69}$

At the other extreme, Maite San Giorgi eliminates obligations entirely and exclusively defines the core content of a right to healthcare, which encompasses primary healthcare and access to essential medicines. ${ }^{70}$ She defines these components by drawing upon treaty text in a range of fora and from the Alma Ata Declaration and ICPD program referenced in General Comment No. 14. Others argue for an approach that combines core content with core obligations of conduct and result. For example, Toebes sees the need to define core content as well as obligations, and defines core obligations to respect, protect and fulfil that are both conduct and result oriented. $^{71}$ To define the core content of the right to health, Toebes combines elements of the scope of the right to health constituted by treaty provisions relevant to health with reference to WHO policies like Health for All. ${ }^{72}$ Accordingly, Toebes characterizes what she terms >core elements of the right to health incorporating healthcare and underlying preconditions for health. ${ }^{73}$ Toebes defines core obligations under the respect, protect and fulfil paradigm, which include primarily conduct obligations and limited duties in relation to result. ${ }^{74}$ She defines a single obligation of result as a fulfil

69 Chapman (2002), 202-203.

70 San Giorgi (2012).

71 Toebes (1999).

72 Which she suggest »identify the core content of the right to health from a policy perspective, cf. Toebes (1999), 283, citing WHO Global Strategy for Health for All by the Year 2000, 1981, chapter 3, 31, para.1.

73 The former include maternal and child healthcare, including family planning; immunization against major infectious diseases; appropriate treatment of common diseases and injuries; and provision of essential drugs. The latter include an adequate supply of safe water and basic sanitation; freedom from serious environmental health freedoms, cf. Toebes (1999), 284.

74 Thus, core obligations of conduct include duties to respect equal access to basic healthcare services, refrain from acts that seriously encroach upon people's health, take legislative and other measures to assure that people have equal ac- 
duty to provide basic health services or create conditions under which individuals have adequate and sufficient access to health services. ${ }^{75}$

David Bilchitz also proposes core content and obligations (what he calls a principled minimum core), since content (what he terms spractical minimum standards $\varangle$ ) would allow for government action to be measured. ${ }^{76}$ Bilchitz argues that defining practical minimum standards would require consideration of the minimum core and other theoretical considerations, together with the resources and capacity available in a particular society. ${ }^{77}$ In the case of the right to health, these considerations would include treatment costs, resource availability, balancing preventing and curative strategies, ensuring equal opportunity for treatment, and considering the impact of such a pragmatic minimum on meeting other social needs. ${ }^{78}$ Bilchitz therefore foresees that the core of the right to healthcare would require government policy goal setting (a task not necessarily done by the courts), specification of a minimum level of services, and detailed government plans and programmes for improving healthcare with measurable indicators, targets, and deadlines. ${ }^{79}$

Bilchitz's conception follows closely from the South African Constitutional Court's rejection of the core concept on the basis that it was »impossible to give everyone access even to a >core « service immediately« and that $»[a] 11$ that is possible, and all that can expected of the state, is that it act reasonably to provide access to the [Constitution's socio-economic rights] on a progressive basis. ${ }^{80}$ Yet the South African Constitutional Court's decisions also suggest that the Court's rejection of the core is rooted in part in a sense of the institutional inadequacy of a judicial definition of core content. For example, in an extra curial statement, Justice Richard J. Goldstone ar-

cess to basic health services provided by third parties, and adopt a national health policy and devote a sufficient percentage of budget to health, cf. Toebes (1999), 337-338.

75 Ibid., 338.

76 Bilchitz (2007), 223.

77 Ibid., 224.

78 Ibid., 223.

79 Ibid., 225.

80 Minister of Health and another v. Treatment Action Campaign and others (2002) 5 S.Afr.L.R. 721 (S.Afr.Const.Ct) (TAC decision), para. 35. 
gues that the South African Constitutional Court decisions should be considered as a challenge to provide more information/data on the concept of the minimum core and not to abandon any future reliance on it. ${ }^{81} \mathrm{He}$ argues that there is need for adoption of $>$ Brandeis Briefs $\measuredangle$, which could provide the court with factual data and information in addition to the legal aspect, in order to enable the court to effectively implement the minimum core standard. ${ }^{82}$ This judicial approach stands in stark contradiction to that adopted in many Latin American countries, such as in Colombia where the idea of »minimo vital - a set of minimum conditions for a dignified life - has been the basis for key right to health decisions. ${ }^{83}$ These contrasting judicial approaches to core obligations provide important illustrations of the practical implications and outcomes of an applied perspective, and are important for the continued conceptualization of core obligations. As indicated above, for questions of scope alone, in this paper we do not more deeply engage this fundamental area of legal practice.

In contrast to Bilchitz, John Tobin argues for a far narrower set of obligations of conduct and result. Tobin is deeply critical of the Committee's definition of the core, which he views as unjustified and impractical, and argues for a >modest and practical« vision of the core of right to health. ${ }^{84}$ Tobin suggests a far more minimal list of minimum core obligations of result than in General Comment No. 14 given resource constraints and the fact that local conditions will determine definitive lists applicable in particular countries ${ }^{85} \mathrm{He}$ also argues against importing obligations on shelter and housing into minimum core obligations under the right to health, given the interdependence of human rights and the fact the realization of obligations under the right to health must be accompanied by efforts to secure the minimum core obligations of other relevant rights. ${ }^{86}$ Instead Tobin argues for the development of a "presumptive list of result obligations ${ }^{87}$ focused on the provision of selective and integrated primary healthcare and the provi-

81 Gauri/Brinks (2010), xii.

82 Ibid.

83 Arango (2003).

84 Tobin (2012), 243.

85 Ibid., 247.

86 Tobin (2012), 247.

87 Ibid. 
sion of food and water necessary to survive. ${ }^{88}$ Tobin foresees a core obligation to provide essential elements of primary healthcare developed through participatory processes to produce a widely accepted model that all states should be capable of adopting with appropriate assistance. ${ }^{89}$

A related debate over the fixed or relative nature of the core extends to whether there should be a common universal definition of the core or whether such definitions should be country-specific. Andreassen and his colleagues foresaw country-specific thresholds measured by various indicators as necessary to create a minimum threshold for realization of rights. ${ }^{90}$ Similarly, Asbjørn Eide viewed Andreassen's minimum threshold approach as requiring governments to establish national systems to identify local needs and opportunities for economic and social rights, as well as identifying the needs of groups with the greatest difficulties in enjoying such rights. ${ }^{91}$ Eide did not foresee that this approach would generate universal models: »different governments may find different approaches most suitable to deal with the vulnerability thus identified. No blueprint, no general model will be applicable in all settings. $"{ }^{92}$ Indeed, Eide saw such variability as an intrinsic implication of >progressive realization « and simmediate obligations`, which meant that states with higher resources have a higher level of core content or immediate duties than those with limited resources. ${ }^{93}$

In contrast, Toebes saw Andreassen's idea of formulating country based minimum thresholds as »almost an impossible task « given the resources needed to establish such benchmarks and the unlikelihood of states setting their own benchmarks and thereby voluntarily hold themselves accountable. ${ }^{94}$ Instead Toebes saw value in an approach which defined general universal core contents, distinguishing thresholds for countries at different levels of development. ${ }^{95}$ Similarly, Danie Brand argues that understanding the minimum core as a general standard is suitable for the international en-

88 Tobin (2012), 247.

89 Ibid., 251.

90 Bård-Anders (1987/1988), 341, emphasis in the original removed.

91 Eide (1989), 46.

92 Ibid.

93 Eide (1995).

94 Toebes (1999), 279.

95 Ibid., 279-280. 
forcement of economic, social and cultural rights, but it is not that useful for the domestic context where we must be »far more specific, particular, concrete, context-sensitive and flexible in our thinking about basic standards, core entitlements and minimum obligations. ${ }^{96}$ Others saw the possibility of both international and domestic cores: for example, Craven argued that while the universal nature of Covenant rights suggests that a common core should be developed to apply internationally, given the Committee's practice of requiring states to establish benchmarks of poverty, »in the short term at least, state-specific minima are the only viable options. ${ }^{97}$ Craven believed however that there was evidence that the Committee planned to establish international standards. ${ }^{98}$

As the foregoing indicates, neither international interpretation nor scholarly debate has resolved key questions about the function of the core, the relationship (if any) between core content and obligations, and the relationship between the core and progressive realization and resources. If content is an important component of the core, what methods should be used to define it, and by whom? And to what extent can obligations of conduct and/or result guide appropriate action in the absence of defined content?

\subsection{Methods of Developing the Core of the Right to Health}

The final area of contention we will explore concerns the legitimacy of the concept from an international law perspective, and by implication, what might constitute appropriate methods for its further development. Efforts to forestall critiques on the grounds of legitimacy appear in every international interpretation, which suggests that the concept is justified for a range of reasons, all of which are implicitly grounded within accepted sources of international law and methods of treaty interpretation. Thus, when scholars suggest that the core is justified by treaty text, jurisprudence and scholarship, they are implicitly referencing the accepted sources of international law defined in the Statute of the International Court of Justice to include

96 Brand (2002).

97 Craven (1995), 142.

98 He cites Sparsis, E/C.12/1990/SR.146, at para. 43, as providing this evidence, cf. ibid., 142. 
treaties, custom and judicial decisions and teachings as subsidiary means of determining legal rules. ${ }^{99}$ When scholars cite drafter's intention, treaty purpose and state practice, they are relying on the Vienna Convention on the Law of Treaties (VCLT) which requires interpreting treaties in good faith according to the ordinary meaning of treaty terms in light of the treaty's object and purpose, and their context (ascertained from treaty text, agreements between parties, subsequent state agreement and practice and relevant rules of applicable international law). ${ }^{100}$ The broader intent of the VCLT rules is to give meaning to treaties that accords with that agreed to during the drafting of a treaty and in subsequent practice. ${ }^{101}$

Reliance on treaty text, Committee jurisprudence, rights scholarship, drafter's intention, treaty purpose and state practice pervades elaborations of the core in international human rights documents. For example, in his 1987 article signalling the Committee's intention to introduce the core concept, Alston argues that acknowledgement that there might be reasonable differences of opinion on the extent of state responsibility for the material welfare of its citizens, reflected drafters' intention that the Committee should identify "some minimum core content of each right that cannot be diminished under the pretext of permitted >reasonable differences $<. \ll{ }^{102} \mathrm{Al}$ ston also suggests that the existence of a core subject to limited derogations was a »logical implication of the use of the terminology of rights, « since there »would be no justification for elevating a >claim» to the status of a right $[. .$.$] if its normative content could be so indeterminate as to allow for$ the possibility that the rightsholders possess no particular entitlement to anything. « ${ }^{103}$ Similarly, Alston indicates that core entitlements would be identified through interpretation by States Parties, by the Committee through systematic examination of state reports, and through detailed studies by the Committee and groups acting on its behest of the normative implications of

99 Statute of the International Court of Justice (entry into force 24 October 1945) (3 Bevans 1179; 59 Stat. 1031; T.S. 993; 39 AJIL Supp. 215 (1945), article 38(1).

100 Vienna Convention on the Law of Treaties (1980), 1155 U.N.T.S. 331, 8 I.L.M. 679, entered into force 27 January 1980, Articles 31.1-3.

101 Forman (2011), 163.

102 Alston (1987), 352, citing A/C.3/SR.367 (1951), para. 3.

103 Ibid., 352-353. 
Covenant rights, ${ }^{104}$ methods consistent with accepted international law practice. Alston, nonetheless, defends a bolder approach when he suggests that the Committee has the authority to unilaterally develop the core through the preparation of »draft issue outlines speculating as to the possible core content of each right $\ll .{ }^{105}$

These former approaches foreshadow those adopted in General Comment 3 when the Committee justified the introduction of the core concept on the basis of Committee and state practice as well as treaty purpose. Thus the Committee indicates that it introduced the core concept on »the basis of the extensive experience gained by the Committee, as well as by the body that preceded it, over a period of more than a decade of examining States Parties' reports. ${ }^{106}$ Treaty purpose is argued to support this interpretation: the Committee suggests that »[i]f the Covenant were to be read in such a way as not to establish such a minimum core obligation, it would be largely deprived of its raison d'être. « ${ }^{107}$ This raison d'être, or overall objective is explicated elsewhere in the Comment, as being to »establish clear obligations for States Parties in respect of the full realization of the rights question. $\ll^{108}$

Similar justifications appear in the Maastricht Guidelines, which argue that »universal minimum standards « for economic, social and cultural rights had been developed through state practice under the Committee's reporting process and domestic court decisions. ${ }^{109}$ They argue that the earlier Limburg principles and the Committee's developing jurisprudence confirm »resource scarcity does not relieve states of certain minimum obligations in respect of the implementation of economic, social and cultural rights. « $^{110}$ Reliance on state practice appears again in General Comment No. 14, when the Committee suggests that the entire Comment is »based on the Committee's experience in examining States Parties' reports over many years. « ${ }^{111}$

104 Alston (1987), 353-354.

105 Ibid., 354.

106 E/1991/23, 14 December 1990, para. 10.

107 Ibid.

108 Ibid., para. 9.

109 Maastricht Guidelines, para. 8.

110 Ibid., para. 10.

111 E/C.12/2000/4, 11 August 2000, para. 4. 
The argument that contemporary global health declarations and programs like the 1978 Alma Ata Declaration and the 1994 Programme of Action of the International Conference on Population and Development (ICPD) guide elaboration of core content, similarly locate this interpretation within state practice. $^{112}$

This kind of justification was explicitly required since the core concept is only implicitly suggested in the Covenant's text in articles 2.1, 4 and 5 . Yet these justifications have not convinced scholars in the field of its legitimacy within international law. David Fidler argues that the framework of progressive realization does not allow for a minimum core concept and that the concept cannot have any impact on treaty and customary law. ${ }^{113}$ While John Tobin does not reject the concept in totality, he critiques the Committee's suggestion that cumulative state reports enable it to develop minimum core obligations, arguing that state practice cannot provide consensus on the Committee's list of core obligations since states don't refer to minimum core obligations in the CESCR reports in any uniform way, and only a handful of judicial systems apply minimum core obligations. ${ }^{114}$ Nonetheless, Tobin see treaty interpretation rules as providing a

"strong argument that the concept of a minimum core obligation is essential to guide states in their efforts to realize economic and social rights and give effect to the object and purpose of treaties such as the ICESCR and the CRC. ${ }^{115}$

In this light, Tobin views the minimum core concept as a modest attempt to develop a necessary interpretive tool to guide states to fulfil treaty obligations in good faith. ${ }^{116}$ Yet while Tobin argues that one can make a principled defence of minimum core obligations, he also acknowledges that there is no consensus on how to determine the content of minimum core obligations. $^{117}$

112 E/C.12/2000/4, 11 August 2000, para. 43.

113 Fidler (2001), 348.

114 Tobin (2012), 243.

115 Ibid., 242.

116 Ibid.

117 Ibid., 243. 
In this regard, scholars have not moved far afield from the Committee's approach in suggesting that new core content and obligations can be developed from state practice, judicial decisions, academic scholarship and treaty text. Thus, Toebes sees the development of rights through judicial application, assisted in cases of limited applications such as the right to health by academic reflections. ${ }^{118}$ Donna Sullivan argues that some minimum core obligations can be derived from the practice of regional and international human rights bodies, goals endorsed by government in the UN Conferences, legislation and jurisprudence at the national level. ${ }^{119}$ San Giorgi defines core content of the right to healthcare by looking at the interpretive documents including the Committee's concluding observations, European Committee of Social Rights conclusions, ILO conventions and recommendations, the Council of Europe European Code of Social Security, and the Declaration of Alma Ata and ICPD Program of Action. ${ }^{120}$

Yet Young cautions against an overreliance on what she terms a consensus approach in ascertaining the settled and therefore legitimate meaning of the core of economic, social and cultural rights. ${ }^{121}$ Young sees a purely consensus based approach to defining core economic, social and cultural rights as threatening to set a lowest common denominator biased »towards the status quo, as well as to deliberately vague, uncontroversial, and unimaginative expressions. ${ }^{122}$

While Young's critique of consensus as a basis for interpreting core obligations highlights the limitations of this approach, we argue that consensus, nonetheless, provides an important starting point for advancing the conceptualization of core obligations through other legal, political and social means. Questions about the legitimacy of the core concept are particularly cogent given the South Africa Constitutional Court's rejection of its domestic application, and the Committee's own indication that it will adopt an approach to adjudicating Optional Protocol complaints in line with the

118 Tobin (2012), 288.

119 Sullivan (1995).

120 San Giorgi (2012), 21-26.

121 Young (2008), 141-144.

122 Ibid., 145-148. 
South African Constitutional Court's reasonableness approach. ${ }^{123}$ The Committee's inclination towards a reasonableness approach to adjudicating economic, social and cultural rights raises questions about the role that core obligations will play in this framework. Moreover, if core content is to be developed as an adjunct and necessary component of a fuller core concept, then the processes of development must accord with international legal theory and practice if they are to have legitimacy and relevance.

\section{Conclusion}

In this paper we have argued that much debate over the core derives from contrasting notions of how it should function. We argue further that to build a more workable concept requires greater clarity about its intended role in concretizing, clarifying, enforcing and realizing the right to health. We believe that this clarity is an essential precondition for constructing a feasible, principled and grounded conceptualization of the minimum core of the right to health. We conclude that the concept is essential and justified both by ICESCR text in article 4 and 5 and by recognized rules of treaty interpretation. However we believe that further development of the core concept requires going considerably beyond the status quo to develop each constituent component of entitlements, content and duties. If these components of the core are appropriately developed by the Committee and judicial authorities, then additional core content could be developed by social and political actors from a variety of health and human rights related domains. An augmented core concept of this sort could remedy some of the deficits of its current formulation and feasibly advance towards achieving some of the concept's normative ambitions.

$123 \mathrm{~A} / \mathrm{RES} / 63 / 117,10$ December 2008, article 8.4: »When examining communications under the present Protocol, the Committee shall consider the reasonableness of the steps taken by the State Party in accordance with part II of the Covenant.« 


\section{REFERENCES}

Alston, Philip/Quinn, Gerad (1987): »The nature and scope of states parties' obligations under the International Covenant on Economic, Social and Cultural Rights«, in: Human Rights Quarterly 9 (287), 156-229.

Alston, Philip (1987): »Out of the abyss: The challenges confronting the new U.N. Committee on Economic, Social and Cultural Rights«, in: Human Rights Quarterly 9 (1987), 332-381.

Andreassen, Bård-Anders/Skålnes, Tor/Smith, Alan G./Stokke, Hugo (1987/1988): »Assessing Human Rights Performance in Developing Countries: The Case for a Minimal Threshold Approach to the Economic and Social Rights«, in: Human Rights in Developing Countries (1987/1988), 333-355.

Arango, Rodolfo (2003): »Basic Social Rights, Constitutional Justice, and Democracy«, in: Ratio Juris 16, 2 (2003), 141-154.

Bilchitz, David (2007): Poverty and fundamental rights: The justification and enforcement of socio-economic rights, Oxford: Oxford University Press.

Brand, Danie (2002): »The minimum core content of the right to food in context: A response to Rolf Kunnemann«, in: Brand/Russell (2002), 99-110.

Brand, Danie/Russell, Sage (Eds.) (2002): Exploring the core content of socio-economic rights: South African and international perspectives, Pretoria: Protea Book House.

van Bueren, Geraldine (2002): »Of Floors and Ceilings: Minimum Core Obligations and Children«, in: Brand/Russell (2002), 183-200.

Campbell, Tom/Goldberg, David/Mclean, Sheila/Mullen, Tom (Eds.) (1986): Human Rights: From Rhetoric to Reality, New York: Blackwell.

Chapman, Audrey R. (1996): »A >violations approach International Covenant on Economic, Social and Cultural Rights«, in: Human Rights Quarterly 18 (1996), 23-66.

Chapman, Audrey R. (1998): »Conceptualizing the right to health: A violations approach«, in: Tennessee Law Review 65 (1998), 389-418.

Chapman, Audrey R. (2002): "Core Obligations Related to the Right to Health«, in: Chapman/Russell (2002a), 185-215. 
Chapman, Audrey R./Russell, Sage (2002a): »Introduction«, in: Chapman/Russell (2002), 1-20.

Chapman, Audrey R./Russell, Sage (Eds.) (2002b): Core Obligations: Building a Framework for Economic, Social and Cultural Rights, Antwerp: Intersentia.

Coomans, Fons (2002): »In search of the core content of the right to education«, in: Chapman/Russell (2002), 217-246.

Craven, Matthew (1995): The International Covenant on Economic, Social and Cultural Rights: A Perspective on its Development, Oxford: Oxford University Press.

Eide, Asbjørn (1989): »Realization of social and economic rights and the minimum threshold approach«, in: Human Rights Law Journal 10, 1/2 (1989), 35-51.

Eide, Asbjørn (1995): »Economic, social and cultural rights as human rights«, in: Krause et al. (1995), 21-40.

Fidler, David (2001): »Geographical Morality revisited: International Law, international relations and the controversy of the Placebo Controlled HIV clinical trials in developing countries«, in: Harvard International Law Journal 42, 2 (2001), 299-355.

Forman, Lisa (2011): »An Elementary Consideration of Humanity? Linking Trade-Related Intellectual Property Rights to the Human Right to Health in International Law«, in: Journal of World Intellectual Property 14, 2 (2011), 155-175.

Forman, Lisa/Caraoshi, Luljeta/Chapma, Audrey/Lamprea, Everaldo (2016): »Conceptualizing the >morality of the depths $\triangleleft$ : How should we define and implement core obligations under the right to health?«, in: International Journal of Human Rights 20, 4 (2016), 531-548.

Gauri, Varun/Brinks, Daniel M. (Eds.) (2010): Courting Social Justice Judicial Enforcement of Social and Economic Rights in Developing World, Cambridge: Cambridge University Press.

Gauri, Varun/Brinks, Daniel M. (2010): »Foreword«, in: Gauri/Brinks (2002), vii-xiii.

Hart, H. L. A. (1958): »Positivism and the Separation of Law and Morals«, in: Harvard Law Review 71, 4 (1958), 593-629.

Kemenka, Eugene/Erh-Soon Tay, Alice (Eds.) (1978): Human rights, London: E. Arnold. 
Krause, Catarina/Eide, Asbjørn/Rosas, Allan (Eds.) (1995): Economic, Social and Cultural Rights: A textbook, Dordrecht: M. Nijhoff Publishers).

Örücü, Esin (1986): »The Core of Rights and Freedoms: the Limits of Limits«, in: Campbell et al. (1986), 37-59.

San Giorgi, Maite (2012): The human rights to equal access to healthcare, Cambridge: Intersentia Publishing Ltd.

Shue, Henry (1996): Basic rights: Subsistence, affluence and US foreign policy, Princeton New Jersey: Princeton University Press [ $2^{\text {nd }}$ edition].

Sullivan, Donna J. (1995): »The nature and scope of human rights obligations concerning women's right to Health«, in: Health and Human Rights 1, 4 (1995), 368-398.

Swanson Goldberg, Elizabeth/Schultheis Moore, Alexandra (Eds.) (2012): Theoretical Perspectives on Human Rights and Literature, New York: Routledge.

Tobin, John (2012): The right to health in international law, Oxford: Oxford University Press.

Toebes, Brigit (1999): The Right to Health as a Human Right in International Law, Antwerp: Intersentia.

Wellman, Carl (1978): »A new conception of human rights«, in: Kemenka/Erh-Soon Tay (1978), 48-58.

Young, Katharine G. (2008): »The Minimum Core of Economic and Social Rights: A Concept in Search of Content«, in: The Yale Journal of International Law 33 (2008), 113-175.

Young, Katharine G. (2012): Constituting Economic and Social Rights, Oxford, Oxford University Press. 


\section{The Right to Health and the Global Rise of Non-Communicable Diseases}

BRIGIT TOEBES

\section{INTRODUCTION}

Due to global changes in lifestyle, the world is facing a dramatic change in disease incidence and patterns. Chronic or snon-communicable $<$ diseases (NCDs), including diabetes, cancer, cardiovascular and respiratory diseases are currently responsible for two thirds of the world's yearly deaths, more than $40 \%$ of which were premature deaths under the age of 70 years. ${ }^{1}$ Almost three quarters of all NCD deaths occur in low- and middle-income countries, which could lose $\$ 500$ billion per year over the period 2011-2025 due to NCD morbidity and mortality. ${ }^{2}$ NCDs are, therefore, not only a health challenge but also a most important development challenge, both in terms of the human suffering they cause and the harm they inflict on the socio-economic position of countries. ${ }^{3}$ In 2015 all UN Member States agreed in the Sustainable Development Goals (SDGs) to »[b]y 2030, reduce by one third premature mortality from non-communicable diseases through prevention and treatment $[\ldots] \ll^{4}$

1 WHO (2015).

2 WHO (2014), ix and xi; Magnussen/Patterson (2014), 1; referring to the report by the World Economic Forum/Harvard School of Public Health (2011).

3 WHO (2014), ix and xi.

4 UN Sustainable Development Goals, available https://sustainabledevelopment. un.org/?menu=1300 [13.03.2016]. See also WHO (2013). 
While NCDs have now gradually emerged onto the global health and development agenda, ${ }^{5}$ there is still very little shared understanding of how NCDs can best be prevented and reduced through international and domestic law, including human rights law. ${ }^{6}$ Human rights play an increasingly important role in other global health areas, including in the field of HIV/AIDS, ${ }^{7}$ however their contribution to NCD prevention and control is still ill-understood and limited in practice. ${ }^{8}$ More specifically, little attention has been paid to how the concepts as developed under the right to health framework can be applied in the context of the NCD pandemic.

To address this gap, this contribution analyses whether the tools developed under the right to health framework offer any support and guidance in curbing the NCD pandemic. Important notions that are discussed in the context of the right to health include the so-called >AAAQ< (availability, accessibility, acceptability and quality), the concept of progressive realization, and the social determinants of health. Before addressing these matters, this contribution will briefly outline the current NCD pandemic and the international response to this new development in global health.

\section{The Nature of the NCD Pandemic and the Public Health Response}

NCDs were responsible for 38 million (68\%) of the world's 56 million deaths in 2012 , more than $40 \%$ of which were premature deaths under the age of 70 years. As mentioned, almost three quarters of all NCD deaths occur in low- and middle-income countries. ${ }^{9}$ According to the World Health Organization (WHO), NCDs are particularly devastating in poor and vulnerable populations. ${ }^{10}$ We can speak of a vicious circle where NCDs wors-

\footnotetext{
5 Gruskin et al. (2014), 773.

6 Ibid.

7 Magnusson/Patterson (2014), 3.

8 Ibid.

9 WHO (2014), ix and xi.

10 Ibid., 1.
} 
en poverty, while poverty contributes to rising rates of NCDs, thus posing a threat to public health and economic and social development. ${ }^{11}$

Four types of NCDs make the largest contribution to morbidity and mortality: cardiovascular diseases, cancer, chronic respiratory diseases and diabetes. ${ }^{12}$ They can be linked to four shared so-called >behavioural risk factors \& that enhance the incidence of these diseases: tobacco use, unhealthy diet, physical inactivity and harmful use of alcohol. ${ }^{13}$

The international public health community, including the WHO, have slowly but increasingly engaged with this matter over the past two decennia. In 1998 the World Health Assembly ${ }^{14}$ adopted a resolution calling on WHO member states to develop a global strategy for the prevention and control of NCDs. ${ }^{15}$ This led to the adoption of the Global Strategy for the Prevention and Control of Noncommunicable Diseases in 2000 and subsequent action plans for the periods of 2008 to 2013 and 2013 to $2020 .^{16}$ To give an idea of what the Strategy aims to achieve, the latter contains the following nine voluntary targets: ${ }^{17}$

\section{Box 1: WHO's Action Plan 2013-2020}

A $25 \%$ reduction in the overall mortality from cardiovascular diseases, cancer, diabetes, or chronic respiratory diseases

At least $10 \%$ relative reduction in the harmful use of alcohol, as appropriate, within the national context

A $10 \%$ relative reduction in prevalence of insufficient physical activity

A $30 \%$ relative reduction in mean population intake of salt/sodium

A $30 \%$ relative reduction in prevalence of current tobacco use

A $25 \%$ relative reduction in the prevalence of raised blood pressure or contain the prevalence of raised blood pressure, according to national circumstances

11 A/66/L.1, 16 September 2011, para. 4.

12 Sixty-Sixth World Health Assembly, WHA 66,10, 27 May 2013, para. 6.

13 Ibid.

14 Decision-making body of the WHO.

15 World Health Assembly, WHA 53, 17, 11-16 May 1998.

16 WHA 53.14, March 2000; WHO (2008a) and (2013).

17 WHO (2013). 


\begin{tabular}{|l|}
\hline Halt the rise in diabetes and obesity \\
\hline $\begin{array}{l}\text { At least } 50 \% \text { of eligible people receive drug therapy and counselling } \\
\text { (including glycaemic control) to prevent heart attacks and strokes }\end{array}$ \\
\hline An $80 \%$ availability of the affordable basic technologies and essential \\
medicines, including generics, required to treat major non-communicable \\
diseases in both public and private facilities.
\end{tabular}

In the interim, the UN General Assembly adopted a resolution (2011) which encourages UN member states to implement cost-effective population-wide interventions to address the NCD risk factors, including through regulatory and legislative actions. ${ }^{18}$ Four years later, it adopted the Sustainable Development Goals (SDGs) at its $70^{\text {th }}$ Session to be held from 25 to 27 September 2015. As mentioned above, in these SDGs all UN Member States have pledged to reduce premature mortality from NCDs through prevention and treatment by one-third in $2030 .{ }^{19}$

\section{The Right to Health AND NCDs}

The above illustrates that there is an increasing political commitment to stem the global increase in NCDs. The question arises, how do human rights and the right to health in particular respond to this development? Given that human rights law is aimed at protecting the human dignity and social well-being of individuals - how can it serve as a suitable framework for advancing NCD prevention and reduction as the current most pressing threat to global health? And what is the role of the right to health more specifically, as a human right that aims to protect the health of individuals worldwide?

Many rights are implicated in NCDs, including a range of economic and social rights such as the rights to health, food, education and development, as well as civil and political such as rights to privacy, freedom of expression and ultimately the right to life. As Baytor and Cabrera explain, human rights have been used to both to attack and to advocate for NCD reduction,

18 A/66/L.1, 16 September 2011.

19 UN Sustainable Development Goals, available: https://sustainabledevelopment. un.org/?menu=1300 [13.03.2016]. 
in particular when it comes to the regulation of tobacco, alcohol and healthy foods as so-called >behavioural risk factors $<.{ }^{20}$ Opponents of such regulation have argued that regulation of these products is paternalistic and interferes with personal autonomy. ${ }^{21}$ Along these lines, the tobacco industry has claimed a >right to smoke $<.{ }^{22}$ Proponents of addressing NCDs through regulation, on the other hand, have argued that the incidence of NCDs impacts on human rights, in particular the rights to health and food. ${ }^{23}$ The analysis below will focus mostly on how human rights standards offer protection against the NCD pandemic, and will thus be more in line with the arguments of the proponents.

While the right to health is set forth in a range of international and regional human rights treaties, most emphasis will be placed in this contribution on the right to health in Article 12 of the International Covenant on Economic, Social and Cultural Rights (ICESCR, 1966) as the most authoritative international expression of the right to health. In this context, elaborate attention will be paid to General Comment No. 14 on the right to the highest attainable standard of health, ${ }^{24}$ which provides a comprehensive explanation of Article 12 ICESCR. By way of background information, it may be important to explain that general comments are authoritative yet non-binding documents adopted by the human rights treaty-monitoring bodies providing an explanation of a wide range of subjects, including on the nature of the substantive rights.

It should be noted that General Comment No. 14 was adopted in 2000 by the Committee on Economic, Social and Cultural Rights and drafted at a time that there was not yet much awareness about the global NCD pandemic. While the term non-communicable or chronic diseases does not appear in this General Comment, the text more generally refers to >formerly unknown diseases such as HIV/AIDS and cancer, and recognizes that these create new obstacles for the realization of the right to health which need to be taken into account. ${ }^{25}$ More recent documents reflect the contemporary

20 Baytor/Cabrera (2015), 69.

21 Ibid., 78.

22 Ibid.

23 Inter alia, Human Rights Council (2011).

24 E/C.12/2000/4, 11 August 2000.

25 Ibid., para. 10. 
developments and insights in the field and are, therefore, more specific in regulating NCDs. General Comment No. 15 on the right to health of the child in Article 24 of the Convention on the Rights of the Child (CRC), adopted thirteen years later by the Committee on the Rights of the Child (CRC Committee), is more explicit on NCDs and also refers to, for example, obesity and fast food. ${ }^{26}$

Returning to General Comment No. 14, while it does not elaborate on NCDs, it does offer a suitable set of tools for addressing NCDs. Importantly, the document explains that the right to health is a broad human right extending not only to access to healthcare services but also to the underlying determinants of health, including access to safe and potable water and adequate sanitation, healthy occupational and environmental conditions, and access to health-related education and information. ${ }^{27}$ As such, the right to health has two dimensions: a right to healthcare services and a right to the above-mentioned broad set of underlying conditions or determinants. ${ }^{28}$ Given its broad scope it has many cross-connections with the other existing human rights standards (indirectly) aimed at protecting health, including the right to education, housing, and (health-related) information. ${ }^{29}$ This broad approach towards protecting health is an important starting point for the analysis in relation to NCDs, as it underlines that laws and policies addressing NCDs should focus not only on regulating access to healthcare, but also on securing the underlying determinants to health (Box 2):

\section{Box 2: The right to health: two dimensions}

\begin{tabular}{|c|c|}
\hline $\begin{array}{l}\text { Access to healthcare: laws and } \\
\text { policies regulating access to } \\
\text { healthcare and medicines for } \\
\text { NCDs }\end{array}$ & $\begin{array}{l}\text { Underlying determinants to } \\
\text { health: creating the conditions } \\
\text { under which people are less } \\
\text { vulnerable to NCDs }\end{array}$ \\
\hline
\end{tabular}

This overview shows that a balance needs to be drawn between the delivery of healthcare services to persons with an NCD and attention to preventive

$26 \mathrm{CRC} / \mathrm{C} / \mathrm{GC} / 15,17$ April 2013, inter alia, paras. 5 and 47.

27 E/C.12/2000/4, 11 August 2000, paras. 8 and 11.

28 Ibid., para. 4.

29 Ibid., para. 3. 
policies for the wider population and for future generations. ${ }^{30}$ Below, these two dimensions in the right to health are taken as a starting point for a further discussion of the implications of right to health in relation to NCD prevention and control (sections 4.1 and 4.2 respectively).

\section{NCDS AND THE Two Dimensions IN THE RIGHT TO HEALTH}

\subsection{Securing Fair Access to Healthcare: The \AAAQ, and >Progressive Realization،}

The so-called >AAAQ < as recognized under General Comment No. 14 sets an authoritative standard for ensuring equitable access to healthcare services in relation to NCDs. ${ }^{31}$ It requires that health-related services are available, accessible, acceptable and of good quality for everyone. ${ }^{32}$ Accessibility has four overlapping dimensions, i.e. non-discrimination, physical accessibility, economic accessibility (affordability) and information accessibility (Box 3). ${ }^{33}$ These or comparable principles are also mentioned in the Committee on Economic, Social and Cultural Rights General Comments on the rights to water, food, and education. ${ }^{34}$ The broad acknowledgment of these principles is also evidenced by state practice. To quote from the explanatory memorandum of the Dutch Health Insurance Act (Zvw):

»The Constitution of the Netherlands and international treaties require that the Dutch government establishes a health care system that provides the Dutch population with access to necessary and good quality medical services. $\ll^{35}$

Along similar lines, the Australian and Danish National Human Rights Institutions have applied the AAAQ in their policies, ${ }^{36}$ while the Colombian

30 Magnusson/Patterson (2014), 3.

31 E/C.12/2000/4, 11 August 2000, para. 12.

32 Ibid.

33 Ibid.

34 Hesselman (2017).

35 The Dutch House of Representatives, Tweede Kamer der Staten-Generaal 20032004, Explanatory memorandum Health Insurance Act., No. 29 763, 2. 
Constitutional Court has applied the AAAQ in a case concerning the right to water. $^{37}$

Box 3: The $A A A Q$

\begin{tabular}{|c|c|}
\hline Principle & Health facilities, goods and services must \\
\hline Availability & $\begin{array}{l}{[\ldots] \text { be available in sufficient quantity }} \\
\text { within the State party }[\ldots] \text {. }\end{array}$ \\
\hline Accessibility & {$[\ldots]$ be accessible to everyone $[\ldots]$. } \\
\hline Non-discrimination & $\begin{array}{l}{[\ldots] \text { be accessible to all, especially the most }} \\
\text { vulnerable sections of the population }[\ldots] \text {. }\end{array}$ \\
\hline Physical accessibility & $\begin{array}{l}{[\ldots] \text { be within safe physical reach for all }} \\
\text { sections of the population }[\ldots] \text {. }\end{array}$ \\
\hline Economic accessibility & {$[\ldots]$ be affordable to all $[\ldots]$} \\
\hline Information accessibility & $\begin{array}{l}{[\ldots] \text { include the right to seek, receive and }} \\
\text { impart information }[\ldots] .\end{array}$ \\
\hline Acceptability & $\begin{array}{l}{[\ldots] \text { be respectful of medical ethics }[\ldots] \text { and }} \\
\text { of the culture of individuals }[\ldots] \text {. }\end{array}$ \\
\hline Quality & $\begin{array}{l}{[\ldots] \text { be scientifically and medically }} \\
\text { appropriate and of good quality }[. . .] \text {. }\end{array}$ \\
\hline
\end{tabular}

Source: E/C.12/2000/4, 11 August 2000, para. 12

In the context of this contribution, the question arises: what are the consequences of the AAAQ for NCD treatment and care? In terms of availability, adequate treatment for NCDs requires that NCD services and drugs are available in a sufficient quantity to service the entire population within a State. ${ }^{38}$ It should be noted that securing >availability< in this context is not an easy challenge, as treatment for cancer and other NCDs is often complex and costly, often going far beyond offering primary care. The global rise in NCDs exerts a heavy strain on domestic health budgets, as a result of which

36 Australian Human Rights Commission (2012); Danish Institute for Human Rights (2014).

37 Colombian Constitutional Court, T-916 of 2011, Judge Rapporteur: Jorge Ignacio Pretelt Chaljub, 7 December 2011, para. 6.3.2, in: Murillo Chávarro (2016).

38 E/C.12/2000/4, 11 August 2000, para. 12. 
countries struggle to ensure that health-related services are sufficiently available. ${ }^{39}$ So how does the principle of savailability< apply in this context?

San Giorgi, in her study on the human right to access to healthcare, provides a comprehensive analysis of the AAAQ in relation to access to healthcare. ${ }^{40}$ According to San Giorgi, criteria adopted by the CESCR for the assessment of the availability of healthcare comprise, for example, the amount of resources allocated to healthcare, and the length of waiting time for admission to healthcare services. ${ }^{41}$ This author explains that although these criteria are applied as indicators to evaluate the available healthcare in a specific State, such assessments remain dependent on various factors, amongst which the developmental level of a State and the demand for healthcare within that State. ${ }^{42}$ As such, States parties to the ICESCR can realize the right to health >progressively< and sto the maximum of their available resources $<{ }^{43}$

The term >progressive realization< potentially leaves States with a wide margin to decide when and how to ensure the availability of health-related services. ${ }^{44}$ Based on human rights law there are, nonetheless, certain commitments that have to be guaranteed immediately (Box 4): ${ }^{45}$

\section{Box 4: Immediate obligations under human rights law}

- States should use the maximum of their available resources; ${ }^{46}$

- States should move as expeditiously and effectively as possible towards the realization of the rights; ${ }^{47}$

- $\quad$ States should take deliberate, concrete and targeted steps towards the full realization of the right to health; ${ }^{48}$ and

39 For the African perspective see also Aantjes et al. (2014).

40 San Giorgi (2012). See also Toebes/San Giorgi (2014).

41 San Giorgi (2012), 52.

42 E/C.12/2000/4, 11 August 2000, para. 12.

43 See Article 2(1) ICESCR.

44 See Saul et al. (2014), 133-172.

45 E/C.12/2000/4, 11 August 2000, para. 31 (see also para. 30); E/1991/23, 14 December 1990, paras. 1 and 2 .

46 Article 2(1) ICESCR.

47 E/1991/23, 14 December 1990, para. 9. 
- States should guarantee that the right to health is exercised without discrimination of any kind. ${ }^{49}$

While it goes beyond the scope of this contribution to discuss all these elements elaborately, some attention is paid here to the key notion of >maximum of available resources $<$. The CESCR does not provide for concrete yardsticks or benchmarks on how this obligation is to be met, yet we may assess this target in light of international statistics on domestic health expenditures. $^{50}$

In fact, WHO statistics indicate that some countries have a relatively low health expenditure as a proportion of total government expenditure (less than $10 \%$, as compared to a global average of $14 \%$ ). ${ }^{51}$ Along similar lines, the European Committee on Social Rights (Council of Europe) concluded that where States spent less than $5 \%$ of their gross domestic product (GDP) on healthcare, the situation in that specific State was not in conformity with the right to protection of health in Article 11, para. 1 of the European Social Charter. ${ }^{52}$ However, health expenditure does not tell the whole story. The WHO estimates that $20-40 \%$ of all health spending is currently wasted through inefficiency. ${ }^{53}$ It observes that:

$»[\ldots]$ national wealth is not a prerequisite for moving closer to universal coverage. Countries with similar levels of health expenditure achieve strikingly different health outcomes from their investments. Policy decisions help explain much of this difference $[\ldots] .{ }^{54}$

Hence, while States have considerable leeway to realize the right to health sto the maximum of their available resources $`$, insufficient health expendi-

48 E/C.12/2000/4. 11 August 2000, para. 30.

49 Ibid.

50 E/C12/2007/1, 10 May 2007.

51 Gostin (2012), 2088, referring to WHO (2011).

52 San Giorgi (2012), 53, inter alia referring to the Conclusions of the European Committee of Social Rights with regard to: XVII-2Turkey: 2,43\% of GDP in 2003 and XVII-2 Poland, 3.96 in 2002.

53 WHO (2010).

54 Ibid. 
ture, health sector inefficiency and corruption can be signs that the State is not meeting its obligations under the right to health.

Another important human rights term is the notion of >retrogressive steps $<$. When entering a financial crisis or situation of emergency, States may consider the taking of >retrogressive measures $`$, i.e. diminishing the level of essential services provided. If such measures are taken, the State has the duty to prove that they have been taken »after the most careful consideration of all alternatives and that they are duly justified [...] in the context of the full use of the State party's maximum available resources. ${ }^{55}$ Should the state use >resource constraints\& as an explanation for retrogressive steps, according to the CESCR they should be considered in light of:

\section{Box 5: States' retrogressive measures under human rights law}

\begin{tabular}{|ll|}
\hline - & The country's level of development; \\
\hline - & The severity of the alleged breach; \\
\hline - & The country's economic situation; \\
\hline - & The existing of other serious claims on the state's budget \\
- & (e.g. natural disasters); \\
\hline - & Whether the country had identified low-cost options; and \\
\hline - & Whether the state had sought cooperation and assistance. \\
\hline
\end{tabular}

As mentioned, accessibility implies non-discrimination, financial accessibility (affordability), and physical accessibility. ${ }^{57}$ Firstly and as mentioned, non-discrimination is a key obligation of immediate effect when it comes to providing access to NCD services. San Giorgi describes how the criterion of non-discrimination is considered of great importance by various human rights committees, institutions and organisations. In addition to the CESCR, the Parliamentary Assembly of the Council of Europe argued in its recommendation The reform of health care systems in Europe: reconciling equity, quality and efficiency that:

$»[\ldots][T]$ he main criterion for judging the success of health system reforms should be effective access to health care for all without discrimination, which is a basic hu-

55 E/C.12/2000/4, 11 August 2000, para. 32.

56 E/C12/2007/1, 10 May 2007, para. 10.

57 San Giorgi (2012), 54. 
man right. This also has the consequence of improving the general standard of health and welfare of the entire population. ${ }^{58}$

This implies, according to the Parliamentary Assembly, that the pursuit of cost containment and maximizing efficiency should not go at the expense of equality in access to healthcare. ${ }^{59}$

As explained by San Giorgi, there should be no discrimination on the grounds of any of the prohibited grounds, and healthcare organizations should be responsive to the needs of the recipients. ${ }^{60}$ There should be no discrimination in access to healthcare which has the intention or effect of nullifying or impairing the equal enjoyment or exercise of the right to healthcare. ${ }^{61}$ Unequal enjoyment of the right to health is at stake when an apparently equal treatment in obtaining access to healthcare results in unequal access to healthcare. This can, for example, be the case when the personal characteristics of a patient or group of patients, such as healthcare needs and financial possibilities, are not sufficiently taken into account, i.e. they are treated the same as others. ${ }^{62}$ When it comes to NCD treatment, the principle of non-discrimination plays a key role in making fair decisions in the allocation of scarce resources. From a different perspective, there is also a need to address discrimination and stigma around obesity, diabetes, and alcoholism. ${ }^{63}$

In the context of NCD treatment, thorny questions arise when it comes to reimbursing expensive new medicines, some targeting only small patient populations. While the principle of non-discrimination implies that everyone's needs should be taken into account, difficult choices arise when an expensive medicine potentially eats up a considerable portion of the overall health budget. As argued by Perehudoff et al., the human rights approach

58 Council of Europe (2003), para. 4.

59 Ibid., paras. 2 and 5.

60 San Giorgi (2012), 55.

61 San Giorgi (2012), 55, referring to Concluding Observations of the CESCR with regard to India, E/C.12/IND/CO/5, para. 52; E/CN.4/2003/58, 13 February 2003, para. 61 .

62 San Giorgi (2012), 16.

63 Magnusson/Patterson (2014), 7. 
does not automatically create an immediate right for treatment at any cost. ${ }^{64}$ In light of the principle of progressive realization that was discussed above, the order and timing of the fulfilment of the right to services can only be gradual. Thus, progressive realization justifies ranking treatments for reimbursement, with more cost-effective treatment being included first. This ranking system ensures that available resources are used as effectively as possible. $^{65}$

Financial accessibility, thirdly, requires that healthcare, including drugs, are affordable for everyone. ${ }^{66}$ The costs of healthcare should, therefore, not place an excessive financial burden on individuals as access to healthcare should be based on need and not on ability to pay. ${ }^{67}$ If necessary, steps must be taken to reduce the financial burden on patients. ${ }^{68} \mathrm{NCD}$ treatment often requires a costly combination of drugs, as a result of which large segments of the population in low and middle income countries are pushed into poverty. ${ }^{69}$

Fourthly, physical accessibility implies that healthcare has to be within safe reach and physically accessible for everyone. ${ }^{70} \mathrm{NCD}$ treatment often requires complex interventions, thus the need to offer specialist care. This may lead to a concentration of hospitals, which may affect the physical accessibility of NCD treatment and care. Although not an explicit element of the AAAQ, timely accessibility is also an important component of the right to health. General Comment No. 14 stresses in para. 17 that the right to health facilities, goods and services includes timely access to basic preventive, curative or rehabilitative health services. ${ }^{71}$

64 Perehudoff et al. (2016).

65 Ibid.

66 E/C.12/2000/4, 11 August 2000, para. 12(b); E/C.12/2008/2, 24 March 2009, paras. 56(b) and 57(f).

67 Council of Europe, Digest of case law of the European Committee of Social Rights, September 2008, 83.

68 San Giorgi (2012), 57.

69 Magnusson/Patterson (2014), 5.

70 E/C.12/2000/4, 11 August 2000, para. 12(b); E/C.12/2008/2, para. 56(a). See also Toebes/San Giorgi (2014), 409.

71 Toebes/San Giorgi (2014), 11. 
According to General Comment No. 14 acceptable healthcare signifies that it must be »culturally appropriate, i.e. respectful of the culture of individuals, minorities, peoples and communities, sensitive to gender and lifecycle requirements. ${ }^{72}$ This means that the cultural tradition of persons may have to be respected. When it comes to NCD treatment and control, what could be discussed in this context is whether alternative treatments and medicines should be reimbursed.

Lastly, quality requires that health services are scientifically and medically appropriate and of good quality. ${ }^{73}$ As San Giorgi explains, this requires scientifically approved and unexpired drugs and up-to-date hospital equipment and an adequate training of healthcare personnel, including as regards health and human rights. ${ }^{74}$ Other elements that are of importance in order to obtain an impression of the level of quality of the healthcare provided and of the healthcare system, is life expectancy, infant mortality rates, the number of healthcare professionals with secondary or higher education, waiting lists, and waiting times. ${ }^{75}$

\subsection{Underlying or 'Social Determinants - and Regulating Lifestyle}

As pointed out above, from a human rights perspective there is a need to ensure equitable and inclusive access to health services. But it is also important to address the socio-economic conditions which enhance NCD incidence. In the well-known > Whitehall study<, conducted in the UK in the 1960s, civil service clerks were four times more likely to die young than civil servants with higher positions but with the same access to healthcare services. ${ }^{76}$ It is widely acknowledged that the causes of ill health and health inequalities go far beyond the possibility to access healthcare services, which affirms the need to address the sunderlying determinants of health in

72 E/C.12/2000/4, 11 August 2000, para. 12(c).

73 Ibid., para. 12(d).

74 San Giorgi (2012), 57; E/C.12/2000/4, 11 August 2000, para. 12(d); E/C.12/2008/2, 24 March 2009, para. 56(c) and 56(d).

75 San Giorgi (2012), 60, referring to Council of Europe/Committee of Ministers (1999), para. 3.

76 As quoted in, inter alia, Marmot (2004), 38-39; Gostin (2014), 24. 
the context of the right to health. Public health experts use the broader term ssocial determinants of health`, which go as far as to include our general living environment and the structures of society at large as decisive conditions to our health. ${ }^{77}$

This raises the difficult question of how the social determinants of health can be addressed from the perspective of human rights and international law more generally. After all, the social determinants are very broad, which may lead to a very complex human rights analysis. Part of the solution may lie in connecting the different human rights together. Knowing that the ways we are raised, educated and work are decisive to our health implies looking into how the right to health is connected to other healthrelated rights, including the rights to education, housing and work, which reflect the need to provide good quality education and to guarantee healthy working conditions. This approach is very much in keeping with the notion of the sindivisibility, interdependence and interrelatedness rights, as was affirmed in the Vienna Declaration and Programme of Action, adopted in $1993 .^{78}$

So what does all this mean for NCD prevention and control? In this context, it is key that attention be paid more specifically to lifestyle, given that the most prominent NCDs have been linked by WHO to four risk factors, i.e. tobacco use, harmful use of alcohol, unhealthy diets, and lack of physical activity. ${ }^{79}$ While the right to health provides a general framework for addressing such issues, more specific regulation could be provided through specific treaties under international law. However, so far tobacco is the only risk factor that is addressed through a legally binding international treaty. The Framework Convention on Tobacco Control (FCTC, adopted by the WHO in 2005), was the first global health treaty adopted by the WHO and is now adopted by 180 countries. The Preamble of the FCTC mentions the right to health, thus building a bridge between this treaty and human rights law. The FCTC is an authoritative treaty in the field of tobacco control which has a strong impact on domestic tobacco control regulation. But

77 WHO (2008b).

78 Vienna Declaration and Programme of Action, A/Conf.157/23, 12 July 1993, para. 5. See also Marmot et al. (2012).

79 WHO (2015). 
it also sets an important standard and example for potential new standard setting instruments regulating food, alcohol and other beverages. ${ }^{80}$

Clearly, there is a need to develop more domestic and international instruments regulating lifestyle. Yet regulating lifestyle choices raises the difficult question if, and if so how, international and domestic authorities should attempt to influence the behavioural and consumption patterns of individuals. ${ }^{81}$ Due to an emphasis on autonomy and spersonal responsebility< in many high-income countries there is a certain resistance to the implementation of such preventive measures. ${ }^{82}$

Influencing consumer behaviour can be done, for example, through the regulation of consumer information, the taxation of unhealthy products, but more broadly also through the creation of healthy living environments, which may include tobacco free school yards and the banning of soda machines from schools. So far, Governments have attempted to regulate certain aspects of tobacco, food and beverages, such as the advertisement, number of sale points, packaging, size and salt, sugar and (trans) fat content. $^{83}$

\section{NON-StATE Actors, NCDs AND THE RIGHT TO HEALTH}

Health insurance companies, hospitals, pharmaceutical companies, the pharmaceutical industry as well as the tobacco, food and beverage industries all exert a tremendous influence and power over our health and wellbeing. This is why there has been an increasing call on governments to submit these actors to tighter rules. To bring this back to human rights law: under the right to health, States are under a >duty to protect $<$ the health and well-being of individuals against the human rights violations of non-state actors. General Comment No. 14 provides many important examples of when the State violates the right to health when failing to regulate private actors:

80 Consumers International/World Obesity Forum (2014).

81 Sunstein (2014).

82 Magnusson/Patterson (2014).

83 Taylor (2015). 
$»[\ldots]$ failure to regulate the activities of individuals, groups or corporations so as to prevent them from violating the right to health of others; the failure to protect consumers and workers from practices detrimental to health, e.g. by employers and manufacturers of medicines or food; the failure to discourage production, marketing and consumption of tobacco, narcotics and other harmful substances; the failure to protect women against violence or to prosecute perpetrators; the failure to discourage the continued observance of harmful traditional medical or cultural practices; and the failure to enact or enforce laws to prevent the pollution of water, air and soil by extractive and manufacturing industries. ${ }^{84}$

Subsequently, the question arises whether private actors also carry moral or even legal responsibilities under human rights law. Whilst recognizing the primary obligation to protect of States, the human rights framework recognizes that the protection and promotion of health involves a shared responsibility, requiring a multi-stakeholder approach. General Comment No. 14 recognizes that:

"[...] all members of society - individuals, including health professionals, families, local communities, intergovernmental and non-governmental organizations, civil society organizations, as well as the private business sector - have responsibilities regarding the realization of the right to health [...]. ${ }^{85}$ [emphasis added, B.T.]

Hence, many different actors have responsibilities under the right to health - setting aside the question of whether such responsibilities are legal or moral in character. Potentially thus, the food and beverage producers themselves, although strictly speaking not legally bound by the human rights treaties, have indirect responsibilities under human rights law to ensure the quality and healthiness of their products. ${ }^{86}$

84 E/C.12/2000/4, 11 August 2000, para. 51.

85 Ibid., para. 42.

86 See, for example, Corporations in the Global Food System and Human Rights (2014). 


\section{Conclusions}

The broad understanding of the right to health is important when it comes to NCD prevention and control. It mandates that attention should be directed not only at providing equitable and inclusive access to healthcare and medicines, but also at securing a range of determinants to health. Investments in treatment should be matched by laws and policies targeting the whole population, aimed at empowering individuals to lead healthier lives. $^{87}$

While the right to health framework is not very specific in regulating NCDs, it offers a set of principles or guideposts that may guide the field, that have been discussed in this contribution. Given the striking nature of the NCD pandemic, it is worth paying more attention to this framework. Potentially, it offers a robust set of norms and standards that define the legal obligations of governments, while adding accountability mechanisms to traditional public health strategies. ${ }^{88}$

\section{References}

Aantjes, Carolien J./Quinlan, Tim K. C./Bunders, Joske F. G. (2014): »Practicalities and challenges in re-orienting the health system in Zambia for treating chronic conditions«, in: BMC Health Services Research 14, 295 (2014), 1-14.

Australian Human Rights Commission (2012): »Respect and Choice, A Human Rights Approach for Ageing and Health«, Online: https://www.humanrights.gov.au/sites/default/files/document/publicatio n/human_rights_framework_for_ageing_and_health.pdf [13.05.2016].

Baytor, Tanya E./Cabrera, Oscar A. (2015): »International Human Rights Law«, in: Voon et al. (2015), 65-85.

Consumers International/World Obesity Forum (2014): »Recommendations towards a Global Convention to protect and promote healthy diets«, May 2014, Online: www.worldobesity.org [13.05.2016].

87 Magnussen/Patterson (2014), 3.

88 Gruskin (2014), 773. 
Corporations in the Global Food System and Human Rights (2014): »Conference Statement of the Oslo Conference 11-12 September 2014«, Online: https://www.jus.uio.no/smr/english/research/projects/fohrc/ab solutefinal-report-from-september-conference_22may2015_korrwbe _26mai-(2).pdf [13.05.2016].

Council of Europe (2003): »Recommendation 1626 of the Parliamentary Assembly of the Council of Europe on >The Reform of Health Care Systems in Europe: Reconciling Equity, Quality and Efficiency«", Online: http://assembly.coe.int/nw/xml/XRef/Xref-XML2HTML-en.asp ?fileid=17152\&lang=en [30.05.2016].

Council of Europe (2008): »Digest of case law of the European Committee of Social Rights«, September 2008, Online: https://rm.coe.int/CoERM PublicCommonSearchServices/DisplayDCTMContent?documentId=09 0000168049159f [30.05.2016].

Council of Europe/Committee of Ministers (1999): »Recommendation No. R (99)21 of the committee of ministers to member states on criteria for the management of waiting lists and waiting times in health care«, 30 September 1999, Online: http:/www.aip-bg.org/lichnidanni/ pdf/r_99_21.pdf [30.05.2016].

Danish Institute for Human Rights (2014): »The AAAQ Manual and the Right to Water - contextualizing indicators, $2014 \lll$, Online: http://www. humanrights.dk/publications/aaaq-manual-right-water-contextualisingindicators [13.05.2016].

Gostin, Lawrence (2014): Global Health Law, Cambridge: Harvard University Press.

Gruskin, Sofia/Ferguson, Laura/Tarantola, Daniel/Beaglehole, Robert (2014): »Non-communicable Diseases and Human Rights, a Promising Synergy«, in: American Journal of Public Health 104, 5 (2014), 773775, Online: http://www.ncbi.nlm.nih.gov/pmc/articles/PMC3987606/ [18.05.2016].

Hesselman, Marlies/de Wolf, Antenor Hallo/Toebes, Brigit (2017): Socio-Economic Human Rights for Essential Public Service Provision, London/New York: Routledge.

Hogerzeil, Hans V. (2006): »Essential medicines and human rights: what can they learn from each other?«, in: Bulletin of the World Health Organization 84 (2006), 371-375. 
Magnusson, Roger/Patterson, David (2014): »The role of law and governance reform in the global response to non-communicable diseases«, in: Globalization and Health 10, 44 (2014), 1-18.

Marmot, Michael (2004): The Status Syndrome: How Social Standing Affects Our Health and Longevity, New York: Henry Holt and Company.

Marmot, Michael/Allen, Jessica/Bell, Ruth/Bloomer, Ellen/Goldblatt, Peter (2012): »WHO European review of social determinants of health and the health divide«, in: The Lancet 380, 9846 (2012), 1011-1029.

Murillo Chávarro, Jimena (2016): »Effective Court Remedies for the Protection of Human Rights in Essential Public Services Provision in Colombia«, in: Hesselman et al. (2016), 256-274.

Perehudoff, Katrina/Toebes, Brigit/Hogerzeil, Hans (2016): »A Human rights-based approach to the reimbursement of expensive medicines«, in: Bulletin of the World Health Organization 94, December (2016), 935-936.

San Giorgi, Maite (2012): The Human Right to Equal Access to Health Care, Antwerp: Intersentia.

Saul, Ben/Kinley, David/Mowbray, Jacqueline (Eds.) (2014): The International Covenant on Economic, Social and Cultural Rights, Oxford: Oxford University Press.

Sunstein, Cass R. (2014): Why Nudge - The Politics of Libertarian Paternalism, New Haven/London: Yale University Press.

Taylor, Allyn A./Parento, Emilio W./Schmidt, Laura A. (2014): »The Increasing Weight of Regulation: Countries Combat the Global Obesity Pandemic«, in: Indiana Law Journal 1, 90 (2016), Online: http://scholar ship.law.georgetown.edu/cgi/viewcontent.cgi? article $=2338 \&$ context $=$ fa cpub [18.05.2016].

Toebes, Brigit/San Giorgi, Maite (2014) »Dutch realities: evaluating the Dutch health care reform from a human rights perspective«, in: Toebes et al. (2014), 403-436.

Toebes, Brigit/Ferguson, Rhonda/Markovic, Milan M./Nnamuchi, Obiajulu (2014): The right to health: a multi-country study of law, policy and practice, The Hague: TMC Asser Press/Springer.

Voon, Tania/Mitchell, Andrew/Liberman, Jonathan (Eds.) (2015): Regulating Tobacco, Alcohol and Unhealthy Foods: The Legal Issues, Oxford: Routledge. 
WHO (2008a): »2008-2013 Action Plan for the Global Strategy for the Prevention and Control of Noncommunicable Diseases«, A61/8, 18 April 2008, Online: http://www.who.int/nmh/publications/9789241 597418/en/ [24.05.2016]

WHO (2008b): „Commission on the Social Determinants of Health $(\mathrm{CSDH})$, Closing the gap in a generation: health equity through action on the social determinants of health«, Final report of the Commission on Social Determinants of Health, Online: http://www.who.int/social_ determinants/thecommission/finalreport/en/index.html [13.05.2016].

WHO (2010): »World Health Report 2010 >Health Systems Financing, the path to universal coverage (executive summary)«, Online: WHO [13.05.2016].

WHO (2011): »World Health Statistics 2011«, Online: http://www.who. int/whosis/whostat/2011/en/ [13.05.2016].

WHO (2013): »Global Action Plan for the Prevention and Control of Noncommunicable diseases«, Online: http://apps.who.int/iris/bitstream/ 10665/94384/1/9789241506236_eng.pdf?ua=1 [13.03.2016].

WHO (2014): »Global status report on noncommunicable diseases 2014«, Online: http://www.who.int/nmh/publications/ncd-status-report-2014/ en/ [13.03.2016].

WHO (2015): »NCD Factsheet«, updated January 2015, Online: http://www.who.int/mediacentre/factsheets/fs355/en/ [13.05.2016].

World Economic Forum/Harvard School of Public Health (2011): »The Global Economic Burden of Noncommunicable Diseases«, Geneva: World Economic Forum, Online: http://www3.weforum.org/docs/ WEF_Harvard_HE_GlobalEconomicBurdenNonCommunicableDisease s_2011.pdf [30.01.2017]. 



\section{The Human Right to Health and Primary Health Care (PHC) Policies}

WALTER BRUCHHAUSEN

\section{INTRODUCTION}

Due to its position between legal systems, politics, socio-economic conditions and the health sector, the human right to health has to accommodate, among others, institutions and persons commissioned and dedicated to healthcare. This necessary »structural coupling « of different functional systems (in the sense of Luhmann's social theory) ${ }^{1}$ may cause friction in the competition for supremacy as well as giving rise to synergies and thus cooperation in pursuing common goals. Even agencies and experts in the health sector do not speak with a single voice, since bodies such as the WHO on the one hand and the World Medical Association (WMA) on the other, or professional groups such as public health officials and medical doctors, are especially and deeply divided on several issues pertaining to the right to health. Low-cost care vs. professionalism, prevention vs. cure and public vs. private organization of services are some of the most important lines of conflict between the various interests. These multiple conflicts became especially evident in the debates around the WHO policy of Primary Health Care (PHC) adopted in 1978 at the international conference of the WHO und UNICEF at Alma-Ata, now Almaty, in Kazakhstan. The aim of this new strategy was to improve the health of all human beings

1 Meyer et al. (2015), 349-351. 
worldwide by concentrating on essential areas, favouring prevention and those curative interventions where importance and effectiveness were well known. Thus its elements, listed in the order of their supposed impact, were health education, water and sanitation, nutrition, vaccination, mother and child health services, control of the most common diseases and basic treatment of common conditions.

Although intended as a new approach for the whole world, PHC became a policy especially for Low Income Countries (LICs) and less privileged regions and groups in Middle Income Countries (MICs). PHC did not change the health policies of industrialized countries in either the West or the East. Powerful groups in market economies in the West felt their approach of consumer-friendly healthcare provision to be superior where resources were sufficient, and official socialism in the East claimed to have already implemented the program for a long time. Therefore the most important institutional context for PHC turned out to be development cooperation and health planning in the countries receiving »development aid«. Among those countries where PHC became the official health policy for the whole (biomedical) ${ }^{2}$ healthcare system were even some of the failing or already failed states of Africa. Thus the standards of many Upper MidIncome Countries (UMICs), like the BRICS states (Brazil, Russia, India, China, and South Africa), where civil society organizations and sometimes even individuals go to court to claim the right to health, do not concern the situation PHC was most vigorously applied to. This uneven pattern of health policies in the Global South requires that any examination of PHC needs to integrate not only a strong public health and partly medical perspective into the debate on the right to health, but also that of LICs, especially the formerly so-called Least Developed Countries (LDCs).

Such an introduction of the perspective of healthcare policies into the discourse on the human right to health means reversing the common approach of activism, i.e. the legal or moral way of looking at the questions: Not only does the human right to health inform health policy, but this also applies the other way round, i.e. health policy informs human rights poli-

2 Although the author has also extensively worked on so called >Traditional Medicine this contribution focusses for various reasons the science-based type of medicine developed in 19th century Europe and globalized since then, simplifying called 〉biomedicine‘; cf. Bruchhausen (2011). 
cies. Such a shift can serve three important aspects: It may explain a certain common uneasiness among health experts and within health policy concerning the human right to health; it can help to overcome this unsatisfactory divide; and it demonstrates the previous as well as the current role played by human rights language within and regarding healthcare in LICs. All these issues primarily concern empirical questions of practicability and usefulness in pursuing common aims rather than normative or theoretical debates. The theoretical discussion on the »conceptional soundness« of human rights, »in particular the so-called economic and social rights, or welfare rights« or »second generation rights «, is therefore rarely touched upon in this contribution. ${ }^{3}$ But theoretical implications cannot be avoided completely, e.g. when looking at the relationship between social and individual aspects of health. Such a distinction between an individualizing and a socially integrating understanding of claims is also a frequent issue in other areas of human rights. In the present paper, however, there will be no discussion of a fundamental clash between the individual and the social dimension, as human rights are - following Amartya Sen - understood here as »pronouncements in social ethics ${ }^{4}{ }^{4}$

\section{Human Rights and PHC - an Issue at All?}

Just looking into the official documents seems to render the topic of tensions between the right to health and PHC a »non-issue«. Neither of the authoritative texts - the Declaration of Alma-Ata in 1978 and the previous resolution on »Health for All by the Year 2000 « of the World Health Assembly (WHA) in $1977^{5}$, which together form the foundation of PHC as an official policy of the WHO - lacks clarity of expression in this regard: The first article of the declaration »strongly« reaffirms that health, in the definition of the WHO constitution's preamble, »is a fundamental human right«, in the introducing participle clauses the second declared motivation behind the WHA resolution states it to be »a basic human right«.

3 Sen (2004), 316.

4 Ibid., 355.

5 Res. WHA30.43, 19 May 1977. 
Thus from this official point of view the case is clear: PHC is based on the human right to health, and PHC strives to fulfil what this right requires. Yet there were already certain occurrences during the conference of Alma-Ata that may cast doubt on the perception of a completely easy relationship between the two:

1. The accompanying WHO program was called »health for all«, no longer health for everyone, as the Preamble of the WHO constitution of 1946 would have wished and the Norwegian co-founder of WHO Karl Evang had formulated in his retrospective dating from $1973 .{ }^{6}$ The reasons do not seem to be merely linguistic.

2. As medical historian Michael Knipper has established, Director-General Halfdan Mahler had the term »human right« in the manuscript for his speech in Alma-Ata but left it out in the spoken version. ${ }^{7}$ Therefore it is missing in the protocol. We can only speculate whether this omission stemmed from the strategic consideration of avoiding resistance or from other reasons.

3. Backstage, conflicts between an individualistic and a collectivistic understanding of rights and duties persisted between the US and Soviet delegations in particular. These conflicts left traces in the declaration, e.g. when the only other use of the word »right« in the whole declaration said in Article IV: »The people have the right and duty to participate individually and collectively in the planning and implementation of their health care." Combining right and duty in this manner indicates a certain uneasiness with an exclusive reference to a right.

4. The human right to health itself was not an explicit point of discussion at the conference. It seems to have entered the first article undebated, just from the preamble of the WHO's already accepted constitution. The conclusion regarding PHC put forward by Alison Lakin in a British dissertation in 2001 is that »the approach was developed without any consideration of human rights. $\aleph^{8}$ And two lawyers, US-American Benjamin Mason Meier and the former WHO legal advisor, now UK-based African scholar William Onzivu, saw in 2013 a »failed effort to employ

\footnotetext{
6 Evang (1973).

7 Personal communication on unpublished research.

8 Lakin (2010), 10.
} 
rights-based language for primary health care «. ${ }^{9}$ There is no reference to PHC in the short version of the WHO genealogy of the human right to health. ${ }^{10}$

5. The first article of the Alma-Ata Declaration, quoted in part above, continues - similar to the resolution of 1977: "and that the attainment of the highest possible level of health is a most important world-wide social goal.« By the very wording, the »attainment of the highest possible level of health « is no longer a human right itself, unlike as stated in the International Covenant on Economic, Social and Cultural Rights of $1966,{ }^{11}$ but $» a$ most important world-wide social goal«. This is a very telling shift or difference, and the possible underlying tensions and their solution will be the central question of this paper.

What the paper does not want to discuss in detail are two further areas that might also be expected, i.e. the role of human rights other than the right to health, especially civil and political rights, in the field of health. The question as to how such rights may be limited by public health considerations is already specifically dealt with in the Siracusa principles 25 and 26 of $1985 .^{12}$ And the opposite question regarding how civil and political human rights guide and limit the action of healthcare providers touches on much of the enormous field of professional, biomedical and clinical ethics and cannot therefore be tackled here. The paper will confine itself to the right to

9 Meier/Onzivu (2013).

10 WHO (2015); it is only briefly mentioned in the 51 pages of the complete fact sheet.

11 ICESCR, Article 12.

12 E/CN.4/1985/4, 28 September 1984: (besides the areas »law«, »democracy«, »public order«, »public morals« etc.) »iv. public health

25. Public health may be invoked as a reason for limiting certain rights in order to allow a state to take measures dealing with a serious threat to the health of the population or individual members of the population. These measures must be specifically aimed at preventing disease or injury or providing care for the sick and injured.

26. Due regard shall be had to the international health regulations of the World Health Organization.« 
health itself, without ignoring its necessary place in the net or fabric of all human rights, or to put it another way: the indivisibility of rights.

\section{The Ambiguity and Decline of the HuMAN RIght TO HEALTH IN WHO}

An ambiguous position towards the right to health is not only characteristic of Alma-Ata, but is part of the whole history of the WHO up to about the year 2000. Even in the constitution of the WHO of 1946, there was already tension between an individual and a collective understanding: Showing an ambivalence between »human right « and »social goal« similar to that evident in the later WHA resolution of 1977 and the Declaration of Alma-Ata, the preamble of the WHO constitution spoke of a right of »every human being " whereas its Article 1 referred to an »attainment by all peoples" as the objective. Since many - wrongly, as current majority opinion says - regarded the articles of the constitution as the only binding part and the preamble with its principles as a mere declaration of good will, there was not much resistance against the later focus on peoples rather than on individual people.

The ensuing development of WHO activities clearly favoured the health of populations over that of each individual. Eradication campaigns against malaria, yaws or polio dominated when compared to individual care. The growing Cold War and a new Director-General supported this change. Between the options of policy-setting and operational activities, the WHO moved - incentivised by additional funds for such work by the UN Extended Program on Technical Assistance (EPTA) and by earmarked funding from individual member countries as well as on request of receiving member countries - to the latter, i.e. to field operations in the control of single diseases. ${ }^{13}$ In 1963, even a legal advisor to the WHO expressed it as follows:

13 van Zile Hyde (1953). 
»a programme based on the notion of priorities has given way to one based on the needs of the countries themselves, expressed through their requests for advice and assistance. ${ }^{14}$

The WHO was transformed from what had been a partly political agency into a mostly technical one. It therefore withdrew its co-operation from the 1966 International Covenant on Economic, Social and Cultural Rights and - as seen - paid only lip-service to the right to health in its declaration on PHC in 1978. Meier has demonstrated this in much detail with new historical evidence and argues therefore that the WHO became apolitical. ${ }^{15}$ According to Meier, it was the HIV/AIDS activism of Jonathan Mann that reintroduced a major political and human rights perspective into WHO work.

\section{POLITICAL VS. TECHNICAL OR INDIVIDUAL- VS. Population-CEnTERed Policies?}

Meier's two major hypotheses, first, that the WHO was turned from a political into a technical agency in the 1950s and why this was so, and second, that the practice of PHC is notorious for not incorporating a human rights approach, are certainly correct. ${ }^{16}$ His claim, however, that the former is the main cause or even the only explanation for the latter has to be doubted profoundly. Several of the debates on the tensions between an individual

14 Gutteridge (1963).

15 Meier (2010).

16 Meier's attempt to contrast the normative and the factual is not convincing. In his argument that - without practical success - the WHO intended a return to a human rights base, Meier (2010) saw in the »Health for All« strategy of the WHA und WHO (that both rather avoided the language of rights) a »rightsbased policy«. For this argument, he uses a series of re-interpretations of paragraphs that is not backed by the document of Alma-Ata itself. The right to health is mentioned a single time only, in the first paragraph, but Meier calls the eight elements of PHC listed in para. VII »rights-based government obligations « (ibid., 178), turns the definition of PHC into a »collective right « to health care (ibid., 177) and maintains - referring to MacDonald - that Alma-Ata put »public health under the aegis of the right to health « (ibid., 178). 
right and very limited resources provide a better explanation than this alleged causality. The optimism around 1950 that science would soon enable the world to grant all human beings maximum health had disappeared by the early 1970s. The apparent victory over infectious diseases prompted health experts to look at other problems. The already mentioned physician and health politician Dr. Karl Evang wrote in the WHO Journal in 1973 that the greatest limitations in health are no longer the lack of scientific knowledge:

»Now we have reached the point where the limiting factor is not knowledge but resources. Even the richest countries cannot offer optimum health services to individuals and communities in prevention, cure and rehabilitation in the combined field of somatic, mental and social disease. We are faced with the unpleasant, for psychological as well as political reasons perhaps insurmountable, task of stating priorities which would automatically exclude certain types of patients from an optimum type of service. $\ll^{17}$

This tension between individual claims and limited resources extends well into the recent debates on the relationship between the human right to health and public health ethics. ${ }^{18}$ These debates have often taken the form of a basic conflict between a purely individualistic (mis)understanding and a social or collective perspective on health - the well-known conflict that has to be overcome in other areas of human rights as well. Considering this conflict, the simplistic attribution of roles alleged by Meier and others that the later WHO was more technical and the view of the individual human right to health was more political can even be partially reversed: An individualistic view of health tends to technical solutions of biomedicine such as treatment and secondary prevention whereas a collective understanding of health favours political decisions on social measures such as the improvement of housing, nutrition, water supply, sanitation and education.

Evang saw the new challenges in »man-made pathogenic agents«, and the resulting long list includes cardio-vascular diseases, road traffic accidents, »dependence-producing drugs«, environmental pollution and urbanization with »muscular immobilization and various forms of social maladap-

17 Evang (1973), 6.

18 Nixon/Foreman (2008); Steinmetz-Wood (2014). 
tation«, »population explosion« and even infectious diseases by the reference to »venereal disease «. ${ }^{19}$ The present UN concern for »non-communicable diseases« on a global scale was already previewed in the early 1970s, but did not receive much attention at that time.

The common fundamental conflicts between individual rights and social interests are more than obvious in the case of health:

- Individual rights demand e.g. freedom from coercion (such as quarantine, isolation or compulsory vaccination), even very expensive medical care and protection if urgently needed, and protection or care even for »unproductive« individuals (the unborn/children, disabled, retired, caredependent).

- Crude social interest, however, would want collective protection against infectious individuals, cost-efficient healthcare for as many as possible and the survival of economically productive individuals only. Compared to this, public health with an egalitarian understanding is already more normatively charged than pure common interest as it also has obligations towards the health of the unproductive members of society. In a utilitarian understanding, however, it would value the health interests of the vast majority more highly than those of individuals or minorities.

Precisely these debates were the background when PHC was developed in the early 1970s: development workers and public health experts, especially in the Christian Medical Commission (CMC) of the World Council of Churches (WCC) in Geneva, ${ }^{20}$ protested against the dominant position of the hospital and the medical profession, which favoured expensive care for individuals rather than more cost-efficient and socially just preventive medicine and »medicine des masses" (mass medicine). Although many doctors and nurses feared that the new focus on prevention and low-cost treatment would disadvantage patients in need of hospital care (and were proven to be right), most Northern and Southern governments and NGOs followed the new paradigm of PHC in their development policies. Forcing the governments of some »developing countries« to give up their preference for hospitals in the cities in favour of preventive and rural healthcare was highly po-

19 Evang (1973), 6.

20 Taylor (1969). 
litical. This political decision, however, was rather justified by social justice or national interest and not by the human right to health.

This ambiguity had continued in the WHO, e.g. when the 1977 resolution of the WHA reaffirmed the declaration of the WHO constitution that »health is a basic human right and a worldwide social goal «. ${ }^{21}$ Today, the WHO still seems to be cautious: As late as 2013 it treated in a discussion paper the human right to health and health equity as separate goals. ${ }^{22}$ This hints at their necessarily complementary character rather than subsuming one under the other.

Thus the debates on the relationship between the rights approach and public health, between individualistic and collectivist views, stem from the profound fears and mistrust developed among proponents of public health and PHC. Many of the provisions in the authoritative General Comment (GC) No. 14 of the UN Committee on Economic, Social and Cultural Rights (CESCR) of 2000, i.e. after the end of the East-West-conflict, reflect these fears. The principle of "progressive realization « and the attempt to limit it by »minimum core« obligations are all expressions of these tensions. $^{23}$

\section{How the human Right to Health INFRINGES PHC IN THE AlLOCATION OF SCARCE RESOURCES}

I will now discuss three necessary restrictions to unquestioned advocacy of the right to health from a PHC perspective, starting each time from personal experiences or involvements and concerning different levels of decisionmaking. Two of the examples started years before GC No. 14, one even after. The background to this perspective is formed by philosophical and theological healthcare ethics, medical work and responsibility for a health district in Rwanda in the 1990s, field research in medical anthropology in East Africa in the 2000s as well as teaching and research on global health since 2009. A medical and empirical perspective of this kind is certainly different

21 Res. WHA30.43, 19 May 1977.

22 WHO (2013), 2.

23 Forman et al. (2013). 
from that of human rights work in legal or political action. It has the intention of informing the latter since the empirical dimension needs to be respected in normative approaches more than has been the case to date.

\subsection{The Privileged Urban Elite vs. the Rural Poor: The Responsibility of National Governments}

The following example illustrates how a right to healthcare accessible only to a privileged few might even infringe on the health of many others. I remember a young patient in our hospital in Rwanda in 1995 who had a heart condition that required life-saving open heart surgery. This could not be done in the country, and I inquired into chances for surgery abroad. I was told by the Rwandese hospital staff that there was a passage in the law guaranteeing the right to all necessary medical care even abroad - but that only politicians and higher civil servants had so far got this opportunity for expensive treatment in Nairobi or South Africa paid by the Ministry of Health. Thus the right to maximum care, in this case at the price of several ten thousand dollars, clearly drew on resources that were urgently needed for quite basic healthcare for the rural population, where people died every day because some cents for transport, medicines or vaccines were lacking.

This is a major reason why public health experts and PHC protagonists before GC No. 14 refrained from always unambiguously emphasizing the right to medical care or health. They wanted it to be applied for the benefit of as many disadvantaged people as possible, not as a further possible privilege for those already better off. And as my story shows, this risk was and remains very real. GC No. 14 therefore needed to emphasize non-discrimination. $^{24}$

This risk is especially great in highly centralized states with low civil society control of the government and with weak legal systems. Thus, contrary to the former Soviet claim at and after the conference of Alma-Ata that only a tightly state controlled system could guarantee the right to health, ${ }^{25}$ it seems to be clear that decentralization and the strengthening of civil society are preconditions for the implementation of rather than the misuse of an (individual) right to health. The declaration of Alma-Ata had

24 E/C.12/2000/4, 11 August 2000, paras. 12, 18 and 19.

25 Venediktov (1998). 
acknowledged this in its principles of community participation. And GC No. 14 therefore also made this requirement explicit when it mentioned $»$ in particular, participation in political decisions relating to the right to health taken at both the community and national levels $\ll .{ }^{26}$ Legislation and jurisdiction alone are not sufficient to safeguard the right to health against misuses. The importance of monitoring is paramount. Several civil and political rights must be implemented as well, otherwise justifying a particular treatment by referring to the right to health could diminish health equity instead of promoting it.

\subsection{The Bread Earners vs. the »Unproductive«: Options for International Donors}

The second, somehow similar conflict of interests that I personally observed arose in the late 1990s in the context of the availability of antiretroviral therapy (ART) against HIV/AIDS. Initially in sub-Saharan Africa, the men who were affected above average by AIDS were those who had money, who could afford more women than others: the rich, those in public service like teachers, and thus the more articulate and powerful. Their mass dying, their loss was rightly regarded as a threat to the socioeconomic development achieved up to that point, and this prompted economically motivated international concern. Later, the even higher burden for women and the poor became obvious. Withholding possible ART for AIDS patients was then seen as a violating the human right to health. ${ }^{27}$ Therefore there was a widespread fear among PHC adherents that a massive diversion of funds from established and urgently needed programs such as mother and child health or vaccination services in favour of fighting and treating AIDS would deprive the most vulnerable of already achieved standards of healthcare.

The only solution to this threat was that all the resources for AIDS programmes had to come from additional, new sources, and should not be taken from existing PHC programmes. This did not seem likely to many, as the consistent message of the neoliberal approaches since the 1980s with their enormous cuts in health budget by the Structural Adjustment Pro-

26 E/C.12/2000/4, 11 August 2000, para. 17.

27 Stemple (2008). 
grams (SAPs) had been that more funding for health was out of the question. ${ }^{28}$ Two unexpected developments prevented the AIDS programmes from squeezing out other health programs: the production and use of ART medicines without license (especially through the courage of South Africa as a major user and India as a producer) and the enormous external funding for these drugs. We do not know what would have happened without the astonishing, unprecedented extra donations by governments and »philanthropocapitalists« like Bill Gates, which were certainly facilitated by the new economic approach to health in the World Bank and WHO reports.

The condition that resources for countering such new »violations « of the right to health must be additional to existing PHC funding should be the consequence of this example. This corresponds with the concept of the minimum core obligations which demands some basic health services in any case and with General Comment No. 3 of 1990 (GC No. 3) which already stated that »even in times of severe resource constraints [...] the vulnerable members of society can and indeed must be protected by the adoption of relatively low-cost targeted programmes. ${ }^{29}$

\subsection{Lifestyle vs. Living Conditions: NCDs vs. Communicable Diseases in Current UN Programmes}

The third example showing necessary precautions against the unwanted effects of an isolated implementation of the right to health concerns the recent shift of international attention to non-communicable diseases (NCDs), i.e. cardiovascular and respiratory diseases, diabetes and cancer. This new initiative is located at UN level as well as at the WHO and is contained in the Sustainable Development Goals (SDGs) as 3.4: »By 2030 reduce by onethird premature mortality from non-communicable diseases (NCDs) through prevention and treatment $[\ldots] \ll$. The hitherto common combination of prevention and best therapy in WHO programmes, e.g. for malaria (bednets and the medication co-artem), HIV/AIDS (safe sex and ART) and worms (sanitation and pharmaceutical de-worming), would be disastrous

28 Turshen (1999).

$29 \mathrm{E} / 1991 / 23$, 14 December 1990, para. 12, referred to also in E/C.12/2000/4, 11 August 2000, para. 18. 
for the resources of most healthcare systems in the case of NCDs. The assessment of the increasing problem is certainly correct. The rise of these diseases, which are often or mostly life-style related - caused by too much sugar, fat, salt or harmful substances like tobacco and alcohol, low intake of fibres or vitamins and lack of physical exercise - and a decrease in several infectious diseases caused by poor living conditions has been almost universally observed, notably more in MICs than in LICs. Yet again, if the right to health and its therapeutic requirements were applied to NCDs without any conditionality, a further threat to health equity could arise. I vividly remember the question posed by an expert in international health when the NCDs concept was presented: "Does it mean that Siemens [the German manufacturer of radiography equipment] can now approach the BMZ [German Ministry for Economic Cooperation and Development] demanding that equipment for heart catheterization has to be supplied all over the world? « The question, of course, was polemical, and the NCDs programme was clearly aimed at prevention, as increasing treatment of NCDs was precisely seen as overburdening most healthcare systems. But the fear and the danger are obvious: Treating all common life-saving therapies alike as would be required by an undifferentiated human right to medical care would be the end of PHC and the striving for more health equity. Considerations of comparative costs and equity cannot be excluded. The prioritization of cheap or cost-effective measures is an indispensable constituent of PHC. This is reflected in the warning in GC No. 14:

»investments should not disproportionately favour expensive curative health services which are often accessible only to a small, privileged fraction of the population, rather than primary and preventive health care benefiting a far larger part of the population. $\ll^{30}$

Nevertheless, it has to be admitted that some cost-effective preventive and curative measures, especially those requiring access to biomedical services, might still benefit the better-off more than the already marginalized and thus further increase health inequity. ${ }^{31}$

30 E/C.12/2000/4, 11 August 2000, para. 19.

31 Schmidt/Barnhill (2015). 


\section{The ReConciliation of PHC AND the Human Right to Health}

It is obvious that PHC today can take account of human rights approaches more than ever before. But it is also true that there were historically contingent as well as argumentatively plausible reasons for cautioning against an insufficiently reflected and undifferentiated incorporation of the right to health into policies and laws before GC No. 14 in 2000. Even after this watershed in the history of the right to health, the scarcity of resources remains the major constraint. The social and economic realities cannot be excluded in normative discourses. The question remains one of distributive justice or equity, not primarily of law. For many decades it has been discussed under this heading of justice within the context of ethics - including biomedical and public health ethics - as a question of allocation which cannot simply be solved by referring to equal rights. Unlike civil and political rights, where fulfilling the rights of one group does not for the most part violate and often even promotes the same rights of others, completely fulfilling the right to healthcare for one group of patients may principally diminish the enjoyment of this very right for others quite substantially. The statement of the WHO constitution's preamble in 1946 that the "achievement of any State in the promotion and protection of health is of value to all may be true for the preventive aspects but it is certainly not so for medical care where the level of treatment in the richest countries depends on economic means and on staff lacking in others. The »brain drain« of health workers into stronger national economies has caused a human resources crisis that the WHO has described as one of the major global health problems. ${ }^{32}$ And some types of highly sophisticated treatment demand financial means that are increasingly far from imaginable in terms of global availability: Certain cancer therapies cost more per year than many people in the world earn during their whole lives - and in countries like the USA half of the population will be diagnosed with cancer during their lives. ${ }^{33}$ Clearly some health achievements are not of value to all states.

GC No. 14 is proof that a reconciliation of individual and collective interest in healthcare can be attempted. The greatest part of its content is ob-

32 WHO (2006), 8-12.

33 Lochlann Jain (2013), I. 
viously a result of PHC experiences and thus of Alma-Ata. For someone familiar with PHC since the late 1980s, the five core obligations and the AAAQ (Availability, Accessibility, Acceptability and Quality) approach are just an extension of what Alma Ata already aimed at under the framework of health policy. Instead of complaining that PHC did not take up the right to health, one could also argue the other way round - that before GC No. 14 the rights approach was not sufficiently mature for PHC and that it needed these two decades as a learning process.

The human rights discourse is not the only one relevant to health for all. Quite similar discussions on negotiating individual and social interest were and are found in many other disciplines. It is a question of more and new interdisciplinary cooperation. In a similar way, the diverse processes of mainstreaming in health attempt to reconcile access for the hitherto disadvantaged with majority perspectives. Think tanks with advisory functions in drawing up the SDGs of 2015 demanded fewer top-down and fewer hierarchical approaches, favouring $»$ Multi-stakeholder decision-making processes $\ll^{34}$ instead. The future will show whether this can be realized for health or whether we will have a struggle for power between the WHO fighting for governing global health and the UN claiming supremacy for rights issues. The last years have demonstrated that human rights are a powerful contribution to health for all if interpreted and applied in the spirit of PHC. But if used in the highly individualistic and legalistic way feared in the USA (where e.g. the enormous sums for compensation for malpractice threaten obstetric coverage), they could actually embody the enemy PHC was set out to fight at its very beginning.

\section{Human Rights Language AND ITS IMPACT IN OR ON PHC IN »LEAST DEVELOPED COUNTRIES»}

The human right to health is mentioned more often in programmes from the Global North, e.g. of development co-operation, than in the countries that have the most pressing health problems. It appears as self-commitment on the part of donor countries or aid organizations and as a moral or political

34 Independent Research Forum (2013), 2. 
appeal rather than in legislation. In such Northern programmes, human rights language is clearly invoked against specific and generally undesirable developments:

- The Humanitarian Charter of 1998 and the ongoing Sphere Project, a joint initiative of the major players in humanitarian assistance, referred to human rights in the case of humanitarian emergency aid (including PHC) - mostly without emphasizing a special human right to health - in order to avoid unprofessional philanthropy as well as undue foreign political interest. ${ }^{35}$ The quality and quantity of humanitarian aid has to be based on the rights of the individuals, not on the preferences or even arbitrary decisions of the donors or providers, which might be influenced by the favouring of certain groups, countries or measures to others. The main references for the right to health are Jonathan Mann's reader of $1999,{ }^{36}$ GC No. 14 of 2000 and a WHO »Questions and Answers « of $2002,{ }^{37}$ but the scope of the Charter und the Sphere Project is purposely confined to emergency situations. The double character of rights between social appeal and law is clearly reflected in the second edition of the Sphere handbook: »The Charter is based on both ethical and legal foundations and refers to $>$ moral and legal rights $<.{ }^{38}$

- The German Government and its Federal Ministry for Economic Cooperation and Development have in various documents explicitly based their development policy in health on the human right to health, e.g. in a publication on health and human rights of $2009,{ }^{39}$ in the sector paper for development policies on health a month later ${ }^{40}$ and in the global health policy paper of $2013 .^{41}$ The aim here is to support the long-standing major focus on strengthening health systems against purely economic

35 Sphere Project (2011); in the text, the right to health is explicitly mentioned on pages 83 and 291 only, in the bibliography pages 348 and 351.

36 Mann et al. (1999).

37 WHO (2002).

38 Sphere Project (2012), 3.

39 Bundesministerium für wirtschaftliche Zusammenarbeit und Entwicklung (2009a).

40 Ibid., (2009b) 4, 7-8 and 20-23.

41 Bundesregierung (2013), 2 and 19. 
arguments and against the dominance of vertical health programmes. The reference to the right to health has become an important argument in German development politics, with the purpose of avoiding inappropriate approaches of the past, i.e. the focus on foreign political interest so dominant in the 1950s and 1960s, on social utility in the 1970s, on austerity in the 1980s, on economic gain in the 1990s and on the feasibility of campaigns in the 2000s.

- In the advocacy by NGOs for health equity, promoted in Germany by medico international and the Aktionsbündnis gegen AIDS in particular, the human right to health has a very prominent place in the titles of actions and publications. ${ }^{42}$ It is, however, above all a strong moral appeal to politics and individual conscience that is addressed in these uses of the word »right «, not a legally binding framework. Legal action by civil society organizations in partner countries is supported against both governments and companies, but has not usually been attempted to date by German NGOs in German courts for populations abroad.

The major field where the right to health is invoked for people living in countries of the Global North is that of the legal restrictions in healthcare for refugees and asylum-seekers. Withholding necessary treatment for those with a limited period of residence is interpreted as »human rights violation ${ }^{43}$

In comparison, the right to health is not or is just rarely mentioned in the health policies and debates in LDCs/LICs in Africa and by Africans. This at least is the impression gained from publications and from my own experience at a series of conferences on healthcare in Eastern, Southern, Central and West African capitals, including a session with the high court of Mali. African states and governments would be the first address to which claims to the right to health would be directed. It therefore seems that these institutions are not interested in raising this issue themselves. If civil society and its media are rather weak, a major debate on the right to health will be unlikely. In the more democratic of the BRICS states, by contrast, civil society organizations such as the Treatment Action Campaign in South Af-

42 Medico (2013); Aktionsbündnis gegen AIDS (2016).

43 Ärzte der Welt (2015); Mylius (2016). 
rica are able to force the government into a public debate and some initiatives.

There are several international initiatives that promise to considerably improve the attainment of health in LICs, such as Universal Health Coverage (UHC), which is also part of the SDGs. These initiatives are certainly strengthened by being able to refer to and apply the right to health. However, doubts remain as to whether the legal framework of human rights will be the most important contribution to better health or health for all over the next few years, at least in those places where improvement is most needed and would be the greatest. Even the current concept of the human right to health, i.e. that of GC No. 14, cannot replace relevant policies, but can only inform some important aspects of these that derive from a common learning experience over the last decades.

\section{References}

Aktionsbündnis gegen AIDS (2016): »Leben ist ein Menschenrecht!«, Online: http://www.aids-kampagne.de [20.06.2016].

Ärzte der Welt/Doctors of the World/Médecins du Monde (2015): »Stellungnahme zur Gesundheitsversorgung von Flüchtlingen«, Online: http://www.aerztederwelt.org/fileadmin/pdf/Publikationen/Position_Ges undheit_Fluechtlinge_ADW.pdf [20.06.2016].

Bruchhausen, Walter (2011): »)Biomedizin schaftlichen Beiträgen. Eine Begriffskarriere zwischen Analyse und Polemik«, in: NTM. Zeitschrift für Geschichte der Wissenschaften, Technik und Medizin 18 (2011), 497-522.

Bundesministerium für wirtschaftliche Zusammenarbeit und Entwicklung (2009a): Gesundheit und Menschenrechte, BMZ Spezial 161, Bonn: BMZ.

Bundesministerium für wirtschaftliche Zusammenarbeit und Entwicklung (2009b): Sektorkonzept Gesundheit in der deutschen Entwicklungspolitik, BMZ Konzepte 183, Bonn: BMZ.

Bundesregierung (2013): Globale Gesundheitspolitik gestalten - gemeinsam handeln - Verantwortung wahrnehmen. Konzept der Bundesregierung, Bonn: BMG. 
Collyer, Fran (Ed.) (2015): The Palgrave Handbook of Social Theory in Health, Illness and Medicine, Basingstoke: Palgrave Macmillan.

Evang, Karl (1973): »Human rights: health for everyone«, in: World Health 3 (1973), 3-11.

Forman, Lisa/Ooms, Gorik/Waris, Attiya/Mulumba, Moses/Lamprea, Everaldo/Chapman, Audrey (2013): »What could a strengthened right to health bring to global health policy?: Interrogating the role of the minimum core concept with regard to the post-2015 health development agenda«, in: BMC International Health and Human Rights 13 (2013), 48.

Gutteridge, Frank (1963): »The World Health Organization: its scope and achievements«, in: Temple Law Quarterly 37 (1963), 1-14.

Harrington, John/Stuttaford, Maria (Eds.) (2010): Global health and human rights: legal and philosophical perspectives, Oxford: Routledge.

Independent Research Forum (2013): »Post-2015: framing a new approach to sustainable development«, IRF2015 Policy Paper, Online: https://www.irforum.org/sites/default/files/publications/IRF\%20briefing \%20paper_FINAL.pdf [20.06.2016].

Lakin, Alison Elisabeth (2010): The World Health Organization and the right to health, $\mathrm{PhD}$ dissertation, King's College, London.

Lochlann Jain, Sarah S. (2013): Malignant. How Cancer Becomes Us, Berkeley: University Cambridge Press.

Mann, Jonathan M./Gruskin, Sofia/Grodin, Michael A./Annas, George J. (Eds.) (1999): Health and Human Rights. A Reader, New York: Routledge.

Medico (2013): »Gesundheit ist ein Menschenrecht! Globalisierung des Solidarprinzips nötig«, Online: https://www.medico.de/gesundheit-ist-einmenschenrecht-14133/\# [20.06.2016].

Meier, Benjamin Mason (2010): »The World Health Organization, human rights, and the failure to achieve health for all«, in: Harrington/Stuttaford (2010), 163-189.

Meier, Benjamin Mason/Onzivu, William (2013): »The evolution of human rights in World Health Organization policy and the future of human rights through global health governance«, in: Public health 30 (2013), $1-9$. 
Meyer, Samantha/Gibson, Barry/Ward, Paul (2015): »Niklas Luhmann: Social Systems Theory and the Translation of Public Health Research«, in: Collyer (2015), 340-354.

Mylius, Maren (2016): Die medizinische Versorgung von Menschen ohne Papiere. Studien zur Praxis in Gesundheitsämtern und Krankenhäusern, Bielefeld: transcript.

Nixon, Stephanie/Forman, Lisa (2008): »Exploring synergies between human rights and public health ethics: A whole greater than the sum of its parts«, in: BMC International Health and Human Rights 8, 2 (2008). doi:10.1186/1472-698X-8-2.

Schmidt, Harald/Barnhill, Anne (2015): »Equity and Noncommunicable Disease Reduction under the Sustainable Development Goals«, in: PLoS Medicine 12, 9 (2015), e1001872.

Sen, Amartya (2004): »Elements of a Theory of Human Rights«, in: Philosophy \& Public Affairs 42 (2004), 315-356.

Sphere Project (2011): »The Sphere Handbook: Humanitarian Charter and Minimum Standards in Humanitarian Response«, Online: http://www.spherehandbook.org [20.06.2016].

Sphere Project (2012): »2011 edition of the Sphere Handbook: What is new?«, Online: http://www.sphereproject.org/silo/files/what-is-new-inthe-sphere-handbook-2011-edition-v2.pdf [20.06.2016].

Steinmetz-Wood, Madelaine (2014): »A Synergistic Approach to Human Rights and Public Health Ethics: Effective or a Source of Conflict?«, in: BioéthiqueOnline 3, 20 (2014).

Stemple, Lara (2008): »Health and human rights in today's fight against HIV/AIDS«, in: AIDS 22, Supplement 2 (2008), S113-S121.

Taylor, Carl E. (1969): »A Christian Medical Commission's Role in Health Planning«, in: International Review of Mission 58 (1969), 181-194.

Turshen, Meredeth (1999): Privatizing Health Services in Africa, New Brunswick/N.J.: Rutgers University Press.

Venediktov, Dimitry (1998): »Alma-Ata and after«, in: World Health Forum 19 (1998), 79-86.

Van Zile Hyde, Henry (1953): »The nature of the World Health Organization«, in: Public Health Report 68, 6 (1953), 601-605. 
WHO (2002): "25 Questions \& Answers on Health \& Human Rights«, Health \& Human Rights Publication Issue No. 1, Geneva: WHO, Online: http://whqlibdoc.who.int/hq/2002/9241545690.pdf [20.06.2016].

WHO (2006): »The World Health Report 2006 - working together for health«, Geneva: WHO, Online: http://www.who.int/whr/2006/en/ [24.10.2016].

WHO (2013): »Positioning Health in the Post-2015 Development Agenda«, WHO Discussion Paper, Geneva: WHO, Online: http://www.world wewant2015.org/bitcache/7c4f4f265f3d2dfdfed54c06afee93903986552 2?vid=302852\&disposition=attachment\&op=download [24.10.2016].

WHO (2015): »Health and Human Rights«, Fact Sheet No. 323, Online: http://www.who.int/mediacentre/factsheets/fs323/en/ [24.10.2016]. 


\section{EMPIRICAL VULNERABILITIES AND CONFLICTS}





\section{Using EquiFrame and EquIPP to Support and Evaluate the Implementation of the Sustainable Development Goals}

Tessy Huss, Malcolm MaCLaCHLaN

\section{Health Inequalities, Social Exclusion AND POLICY}

The impact of globalization, economic, and financial crises has led to a deepening and expansion of inequalities across many dimensions of human well-being, within and between societies. ${ }^{1}$ Individuals and groups experiencing multiple deprivations (i.e. low-income, poor nutrition, bad housing etc.) are disproportionately more exposed to economic shocks, more affected by cuts in services and benefits, and often vulnerable to ill-health and disease. $^{2}$ Identity-based forms of disadvantage pervade most societies and manifest as arbitrary social hierarchies. ${ }^{3}$ No society is truly egalitarian; different levels of status and power are assigned to different identity categories. ${ }^{4}$ In terms of population health, these dynamics manifest as the social gradient in health. ${ }^{5}$ The global burden of disease and injury predominantly

1 Lombe/Sherraden (2008); MacLachlan/O'Connell (2000); OECD (2013b).

2 Mannan et al. (2011); Mathieson et al. (2008).

3 Kabeer (2005); Pratto et al. (2013).

4 MacLachlan (2014); Pratto et al. (2013).

5 Marmot et al. (2008). 
befalls the poor, the vulnerable and the most excluded. ${ }^{6}$ As a result, these individuals and groups are even further restricted to participate in society. Poor health jeopardizes their ability to generate income, reinforcing or contributing to their financial fragility. ${ }^{7}$ The Commission on the Social Determinants of Health $(\mathrm{CSDH})^{8}$ attributes the unequal distribution of disease and injury amongst vulnerable groups to the Social Determinants of Health (SDH). ${ }^{9}$ Explained through an SDH lens, health is as much a manifestation as it is a determinant of social exclusion. ${ }^{10}$ Social exclusion is the product of unequal power relationships in society; between an individual's or a group's relationships and social entities such as institutions, organizations, spaces (social or physical) or individuals. ${ }^{11}$ These relational dynamics intersect with deprivation to affect a wide array of social determinants of health. ${ }^{12}$

Complex and multidimensional phenomena such as social exclusion must be addressed through a holistic and joined-up response, and must involve a variety of actors. ${ }^{13}$ Such interventions should seek to empower vulnerable groups in the process by improving the terms of their engagement with society at large. ${ }^{14}$ Multi-sectoral and multi-agency approaches are being advocated to meet Goal Number 3 of the Sustainable Development Goals (SDGs) which urges governments to ensure »healthy lives and promote well-being for all at all ages « by $2030 .{ }^{15}$ The complex relationship between health and socioeconomic development necessitates coherent intersectoral action, capable of addressing multiple health determinants simultaneously. ${ }^{16}$

6 Marmot et al. (2008); Mathieson et al. (2008).

7 Ibid.

8 CSDH (2008).

9 Labonté/Schrecker (2007).

10 Mathieson et al. (2008).

11 Popay et al. (2008); Kronauer (1998) as cited in Mathieson et al. (2008), 12.

12 Mathieson et al. (2008).

13 Guy et al. (2010); World Bank (2013).

14 Fraser (1998); Silver (2015); World Bank (2013), 3.

$15 \mathrm{~A} / \mathrm{Res} / 70 / 1$, adopted by the UN General Assembly in September 2015.

16 CSDH (2008); Leppo et al. (2013), 43; McQueen et al. (2012). 
The »Health in All Policies« (HiAP) philosophy recognizes, for example, that virtually every sector (i.e. finance, education, housing, employment, transport, and health) affects population health. ${ }^{17}$ It also recognizes that reducing health inequalities and social exclusion demands a change in agency, particularly in the political realm. Vulnerable groups and their representatives must not just be included, but also empowered in policy formulation and decision-making processes that affect their lives. ${ }^{18}$ If inclusive, such processes may challenge prevailing power structures that undermine the political participation of those most vulnerable in society. ${ }^{19}$ Political participation is crucial to realizing a comprehensive set of socio-economic rights premised upon a fair distribution of resources. ${ }^{20}$ In order to achieve social inclusion and health equity, policy makers and institutional actors must also demonstrate a commitment to human rights and equity. ${ }^{21}$

Public policies are important instruments in the creation of socially inclusive societies. $^{22}$ They set out courses of action and determine the wider framework within which inclusion or exclusion occurs. ${ }^{23}$ To this end, policies must confer entitlements, protect the human rights of vulnerable groups, whilst aligning actions and objectives with the global vision of sustainable development. Commitments to human rights and social inclusion are unlikely to be enacted unless they are explicitly outlined in policy documents. ${ }^{24}$ Similarly, policies are more likely to achieve equitable and inclusive outcomes if an equitable and inclusive policy process supports them. ${ }^{25}$ The operationalization of global approaches, ambitious goals and their guiding principles, do however pose difficulties for policy makers. We review two methodologies, EquiFrame and EquIPP, which have been specifically designed to render public policies and processes more equitable and inclusive, and we discuss these in the context of health inequalities.

17 CSDH (2008).

18 Dani/de Haan (2008); Lavalle et al. (2005); UNDESA (2009).

19 Huss/MacLachlan (2016).

20 CSDH (2008), 18.

21 Braveman/Gruskin (2003); Mannan et al. (2011).

22 Ahmimed et al. (2014).

23 Anderson (2015), 3; Cocozzelli (2014).

24 Ahmimed et al. (2014).

25 Huss/MacLachlan (2016); OECD (2015). 
EquiFrame and EquIPP are systematic methodologies to analyse the content of, as well as the wider process of development, implementation and evaluation of public policies. We highlight their potential for policy dialogue and review their application to date. We argue that these tools are useful for policy makers and civil society organizations to guide and monitor progress in achieving social inclusion.

\section{Getting the Content Right: Inclusion of Vulnerable Groups and CoRe Human RightS CONCEPTS IN POLICY DOCUMENTS}

The Committee on Economic, Social and Cultural Rights imposes a duty on each state to take the required steps to certify that each person has access to health facilities, goods, and services through the adoption of a national strategy to ensure the enjoyment of the right to health for all citizens. ${ }^{26}$ The content of national health strategies or policies sets out what the policy hopes to achieve, whom it is supposed to benefit, as well as any future actions by the government to achieve the objectives outlined. The content of such documents therefore functions as a point of reference. To minimize the gap between intention and the delivery of a policy, the language of documents and the normative values upon which they are premised must be supportive of social inclusion. ${ }^{27}$ Mannan et al. developed a policy assessment and formulation tool, EquiFrame, which provides a standardized formulation and measurement instrument to develop and analyse public policies within a human rights framework. ${ }^{28}$ EquiFrame outlines 21 core concepts of human rights (Table 1) and twelve vulnerable groups (Table 3), identified in a series of consultation workshops in four African countries Malawi, Namibia, Sudan and South Africa. The core concepts were derived from United Nations declarations, literature and research evidence relating to human rights and well-being. ${ }^{29}$ Core concepts of human rights are concepts that relate »to principles underlying the provision of universal, equi-

26 E/C.12/2000/4, 11 August 2000.

27 Amin et al. (2011).

28 Mannan et al. (2011). See also MacLachlan et al. (2012); O’Dowd et al. (2013).

29 Ahmimed et al. (2014). 
table and accessible health services «. ${ }^{30}$ These concepts are evidence-based in terms of being empirically linked to inclusion/exclusion and health status in the research literature and they align with fundamental human rights declarations and concepts. They do not, however, claim to be exhaustive and may vary in their relevance across different contexts.

EquiFrame employs "a structured content analysis of policies« to measure the commitment to social inclusion and human rights. ${ }^{31}$ As such, it identifies which human rights are accorded to which vulnerable groups. ${ }^{32}$ It is premised upon the assumption that the content of a policy must reference the specific vulnerable groups it seeks to protect and the human rights it seeks to safeguard, for the policy to contribute to equity and inclusion in any meaningful way. ${ }^{33}$ The inclusion of vulnerable groups and core concepts of human rights in policy documents, or policy on »the books«, allows us to discern the level of commitment to equity in the context of service provision, particularly for those facing the most difficulties in accessing services. ${ }^{34}$

Table 1: EquiFrame core concepts and key language

\begin{tabular}{|l|l|l|}
\hline No. & \multicolumn{1}{|c|}{ Core concept } & \multicolumn{1}{c|}{ Key language } \\
\hline 1. & Non-discrimination & $\begin{array}{l}\text { Vulnerable groups are not discriminated } \\
\text { against on the basis of their } \\
\text { distinguishing characteristics (i.e. living } \\
\text { away from services; persons with } \\
\text { disabilities; ethnic minority or aged). }\end{array}$ \\
\hline 2. & $\begin{array}{l}\text { Individualized ser- } \\
\text { vices }\end{array}$ & $\begin{array}{l}\text { Vulnerable groups receive appropriate, } \\
\text { effective and understandable services. }\end{array}$ \\
\hline 3. & Entitlement & $\begin{array}{l}\text { People with limited resources are entitled } \\
\text { to some services free of charge or } \\
\text { persons with disabilities may be entitled } \\
\text { to respite grants. }\end{array}$ \\
\hline
\end{tabular}

30 Mannan et al. (2011), 13.

31 Ahmimed et al. (2014), 13.

32 Ibid.

33 Huss/MacLachlan (2016).

34 Mannan et al. (2011). 


\begin{tabular}{|c|c|c|}
\hline 4. & $\begin{array}{l}\text { Capability-based } \\
\text { services }\end{array}$ & $\begin{array}{l}\text { For instance, peer-to-peer support among } \\
\text { women-headed households or shared } \\
\text { cultural values among ethnic minorities. }\end{array}$ \\
\hline 5. & Participation & $\begin{array}{l}\text { Vulnerable groups can exercise choices } \\
\text { and influence decisions affecting their } \\
\text { life. Such consultation may include } \\
\text { planning, development, implementation } \\
\text { and evaluation. }\end{array}$ \\
\hline 6. & $\begin{array}{l}\text { Coordination of } \\
\text { services }\end{array}$ & $\begin{array}{l}\text { Vulnerable groups know how services } \\
\text { should interact where inter-agency, } \\
\text { intra-agency and intersectoral } \\
\text { collaboration is required. }\end{array}$ \\
\hline 7. & $\begin{array}{l}\text { Protection from } \\
\text { harm }\end{array}$ & $\begin{array}{l}\text { Vulnerable groups are protected from } \\
\text { harm during their interaction with health } \\
\text { and related systems. }\end{array}$ \\
\hline 8. & Liberty & $\begin{array}{l}\text { Vulnerable groups are protected from } \\
\text { unwarranted physical or other } \\
\text { confinement while in the custody of the } \\
\text { service system/provider. }\end{array}$ \\
\hline 9. & Autonomy & $\begin{array}{l}\text { Vulnerable groups can express } \\
\text { »independence« or »self-determination«. } \\
\text { For instance, persons with an intellectual } \\
\text { disability will have recourse to an } \\
\text { independent third party regarding issues } \\
\text { of consent and choice. }\end{array}$ \\
\hline 10 . & Privacy & $\begin{array}{l}\text { Information regarding vulnerable groups } \\
\text { need not be shared among others. }\end{array}$ \\
\hline 11. & Integration & $\begin{array}{l}\text { Vulnerable groups are not barred from } \\
\text { participation in services that are provided } \\
\text { for the general population. }\end{array}$ \\
\hline 12. & Contribution & $\begin{array}{l}\text { Vulnerable groups make a meaningful } \\
\text { contribution to society. }\end{array}$ \\
\hline 13. & Family resource & $\begin{array}{l}\text { The policy recognizes the value of } \\
\text { family members of vulnerable groups as } \\
\text { a resource for addressing health needs. }\end{array}$ \\
\hline 14. & Family support & $\begin{array}{l}\text { Persons with chronic illness may have } \\
\text { mental health effects on other family }\end{array}$ \\
\hline
\end{tabular}




\begin{tabular}{|c|c|c|}
\hline & & $\begin{array}{l}\text { members, such that these family } \\
\text { members themselves require support. }\end{array}$ \\
\hline 15. & $\begin{array}{l}\text { Cultural } \\
\text { responsiveness }\end{array}$ & $\begin{array}{l}\text { i) Vulnerable groups are consulted on the } \\
\text { acceptability of the service provided; ii) } \\
\text { Health facilities, goods and services must } \\
\text { be respectful of ethical principles and } \\
\text { culturally appropriate, i.e. respectful of } \\
\text { the culture of vulnerable groups }\end{array}$ \\
\hline 16. & Accountability & $\begin{array}{l}\text { Vulnerable groups have access to } \\
\text { internal and independent professional } \\
\text { evaluation or procedural safeguard. }\end{array}$ \\
\hline 17. & Prevention & \\
\hline 18. & Capacity building & \\
\hline 19. & Access & $\begin{array}{l}\text { Vulnerable groups have accessible health } \\
\text { facilities (i.e., transportation; physical } \\
\text { structure of the facilities; affordability } \\
\text { and understandable information in an } \\
\text { appropriate format). }\end{array}$ \\
\hline 20. & Quality & $\begin{array}{l}\text { Vulnerable groups are assured of the } \\
\text { quality of the clinically appropriate } \\
\text { services. }\end{array}$ \\
\hline 21. & Efficiency & \\
\hline
\end{tabular}

Source: Mannan et al. (2011)

In order to evaluate public policies within a human rights framework, Mannan et al. ${ }^{35}$ developed a scoring system measuring vulnerable group coverage, core concept coverage and core concept quality. Depending on the number of vulnerable groups and core concepts of human rights mentioned in a policy document, percentages are calculated to reflect the level of concept coverage. Core concepts referenced within policy documents are rated on scale from 1 to 4 . The score indicates the quality of commitment to individual core concepts. A score of four indicates that the policy specifies an intention to monitor a core concept. An overall summary ranking is then calculated which qualifies a policy as low, moderate or high in terms of its

35 Mannan et al. (2011). 
intention to promote human rights and social inclusion. A policy qualifies as high if it achieves $\geq 50 \%$ on all of the three scores outlined above. ${ }^{36}$

A variety of policy documents and revision processes have been undertaken using EquiFrame. A full review of these is beyond the scope of this chapter, and so we simply indicate its range of uses here. Ivanova et al. ${ }^{37}$ conducted an EquiFrame analysis on the Sexual and Reproductive Health policies of Ukraine, Scotland, Moldova, and Spain. EquiFrame has also been used to assess regional policies on health priorities in Africa; ${ }^{38}$ a variety of international health documents; ${ }^{39}$ international donor policies; European Policies on Disability and Development Cooperation; ${ }^{40}$ India's Disability Policy ${ }^{41}$ and three South African policies on Black economic empowerment, employment and cooperation. ${ }^{42}$ It has also been applied to the United Nations Convention on the Rights of Persons with Disabilities (CRPD). ${ }^{43}$ EquiFrame has been or is currently being applied to develop new, or revise existing policies in South Africa (disability and rehabilitation policies), Malawi (National Health Policy and National Health Research Policy) and Sudan (to guide the future development of all health policies). In Laos Democratic Republic, Handicap International has used EquiFrame to support the process of developing a Policy/Strategy/Action Plan process on disability. EquiFrame has also been employed outside the strict policy evaluation context; to identify the use of disability inclusive good practice behaviours across 24 countries worldwide. ${ }^{44}$

To promote Health for All, there is a need to focus on equitable, rather than equal healthcare. Policies should strive to promote well-being for all; yet, they must also be sensitive to differential needs. In order to ensure equitable healthcare, special provisions need to be written into public policies to ensure that those most marginalized - politically, socially, culturally or

36 Mannan et al. (2011).

37 Ivanova et al. (2015).

38 Eide et al. (2013).

39 Schneider et al. (2013).

40 Andersen/Mannan (2012).

41 O'Dowd et al. (2013).

42 O’Donnell (2008).

43 Mannan et al. (2012).

44 Emms (2014). 
economically - are not left out. This is arguably even more important in low-income contexts, where vulnerability may be more pervasive, and resources even more limited. ${ }^{45}$ An inclusive policy content, however, does not guarantee that policies accurately reflect the needs and demands of vulnerable groups or that designated policy benefits accrue to such groups. ${ }^{46}$ It is not sufficient to reference vulnerable groups and core concepts of human rights in policy documents; rather considerations of equity and inclusion must shape the entire policy process - from formulation, through to implementation, monitoring and evaluation. ${ }^{47}$

\section{EquALITY aS AN OUTCOME Requires EQUITY IN THE PROCESS}

EquIPP (Equity and Inclusion in Policy Processes) seeks to complement EquiFrame by proposing a series of key actions (KAs) to support the development, implementation and evaluation of inclusive policies. Whereas EquiFrame is concerned with the quality of policy content, EquIPP is concerned with the wider processes of policy development and implementation. This relationship is outlined in Figure 1. EquIPP is a framework for an inclusive policy process to support public policies promoting equity and inclusion. An inclusive policy process creates experiences of inclusion for vulnerable groups who often remain marginalized in policy processes; it does this by according them a more central role in policy development, implementation and evaluation. ${ }^{48}$ EquIPP is an inventory of $17 \mathrm{KAs}$ and forms a blueprint for an equitable and inclusive policy process (Table 2). The higher the commitment to equity and inclusion is, the greater the degree to which policy makers and stakeholders will afford thorough consideration to these KAs; and be able to point to the evidence of having done so. These actions, if executed in a comprehensive manner have the potential to further the needs and interests of excluded groups and actively involve them in shaping decisions that affect their lives. Like EquiFrame, EquIPP

\footnotetext{
45 Mannan et al. (2011).

46 MacLachlan et al. (2016).

47 MacLachlan et al. (2015).

48 Huss/MacLachlan (2016).
} 
measures the extent to which social inclusion is enacted equitably, and it provides a score and a mapping of the strengths and weaknesses of the process of inclusion in policy development and implementation. EquIPP was developed in partnership with several United Nations agencies; and in particular the Knowledge Management Programme of the United Nations Partnerships on the Rights of Persons with Disabilities (KnowUNPRPD). ${ }^{49}$ It was developed through a literature review of stakeholder approaches to equity and social inclusion and several iterations of stakeholder consultations with representatives of more than twenty countries. Draft versions of the framework were also presented at conferences, meetings and workshops across a number of countries representing a range of high-, middle and lowincome contexts, as well as cultural and religious differences (for instance, it has been presented in Ireland, Malaysia, Panama, Thailand and TimorLeste).

Figure 1: The relationship between and functions of EquiFrame and EquIPP

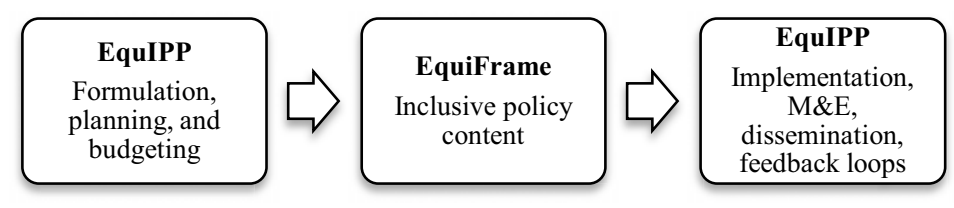

Conceptually, EquIPP draws on Walt and Gilson's ${ }^{50}$ policy triangle, which attributes equal importance to the content of policies, the actors involved in such processes, and the wider processes surrounding policies, as well as the context within which these elements are embedded. EquIPP promotes a participatory, equitable and inclusive policy process in which the needs and interests of vulnerable and excluded populations are prioritized and which supports the formulation of an inclusive policy content as well as its translation into practice. ${ }^{51}$ Bureaucrats and civil servants are often too far re-

49 UNDP (2016).

50 Walt/Gilson (1994).

51 Huss/MacLachlan (2016); MacLachlan et al. (2015). 
moved from actual experiences of marginalization and exclusion and should therefore not be the exclusive designers of policies. ${ }^{52}$

Public policies should be designed and implemented in a collaborative and not in a top-down manner. ${ }^{53}$ The value of the EquIPP framework is that it seeks to render the entire policy process equitable, inclusive and measureable. While development, implementation, and evaluation are standard components of a policy cycle, budgeting and dissemination intersect with the aforementioned components in important ways but are often not embraced in policy analysis. Budget analyses can draw attention to issues of resource generation and redistribution in matters of health and social policy. ${ }^{54}$ Similarly, an emphasis on dissemination shifts the focus to how government communicates information to its citizen, particularly vulnerable groups. Equitable access to information is of course crucial in the creation of equal opportunities within policy processes. ${ }^{55}$

\section{Table 2: EquIPP key actions and definitions}

\begin{tabular}{|l|l|}
\hline Key action & Definition \\
\hline $\begin{array}{l}\text { Ket up inclusive and } \\
\text { participatory } \\
\text { mechanisms }\end{array}$ & $\begin{array}{l}\text { This key action involves detailing a public } \\
\text { engagement strategy for the purpose of } \\
\text { policy development/revision. }\end{array}$ \\
\hline $\begin{array}{l}\text { Key action 2: } \\
\text { of participation }\end{array}$ & $\begin{array}{l}\text { This key action involves maximizing the } \\
\text { quality of participation and ensuring that all } \\
\text { relevant stakeholders participate directly or } \\
\text { are adequately represented in policy } \\
\text { deliberations. }\end{array}$ \\
\hline $\begin{array}{l}\text { Key action 3: } \\
\text { strengthen cross- }\end{array}$ & $\begin{array}{l}\text { This key action involves strengthening } \\
\text { communication and the flow of information } \\
\text { across government departments and the } \\
\text { integration of plans and policies. }\end{array}$ \\
\hline
\end{tabular}

$52 \operatorname{OECD}(2013 \mathrm{a})$.

53 Carey et al. (2015); Rittel/Weber (1973); Roberts (2000).

54 Bonner et al. (2005); Holmes (1998); OECD (1996).

55 OECD (2013a), 7. 


\begin{tabular}{|c|c|}
\hline $\begin{array}{l}\text { Key action 4: } \\
\text { Strengthen } \\
\text { intergovernmental } \\
\text { cooperation } \\
\end{array}$ & $\begin{array}{l}\text { This key action involves the harmonization } \\
\text { of national and local level initiatives } \\
\text { through the creation of an overarching } \\
\text { policy framework. }\end{array}$ \\
\hline $\begin{array}{l}\text { Key action 5: } \\
\text { Plan according to need }\end{array}$ & $\begin{array}{l}\text { This key action involves the adoption of } \\
\text { participatory planning techniques to tailor } \\
\text { policy provisions to local complexity of } \\
\text { needs. }\end{array}$ \\
\hline $\begin{array}{l}\text { Key action 6: } \\
\text { Specify actions by } \\
\text { which social needs will } \\
\text { be addressed }\end{array}$ & $\begin{array}{l}\text { This key action involves the identification } \\
\text { of explicit projects, programmes, and } \\
\text { interventions to address social needs and } \\
\text { level the playing field and promote social } \\
\text { inclusion. }\end{array}$ \\
\hline $\begin{array}{l}\text { Key action 7: } \\
\text { Build equity } \\
\text { considerations into } \\
\text { budgets }\end{array}$ & $\begin{array}{l}\text { This key action involves the prioritization } \\
\text { and funding of programmes, projects and } \\
\text { interventions specifically designed to } \\
\text { benefit vulnerable groups in government } \\
\text { budgets. }\end{array}$ \\
\hline $\begin{array}{l}\text { Key action 8: } \\
\text { Minimise gaps between } \\
\text { real and planned } \\
\text { budgets }\end{array}$ & $\begin{array}{l}\text { This key action involves creating a } \\
\text { favourable and participatory oversight } \\
\text { environment to monitor anticipated and } \\
\text { actual expenditure. }\end{array}$ \\
\hline $\begin{array}{l}\text { Key action 9: } \\
\text { Devise a responsive and } \\
\text { flexible implementation } \\
\text { plan }\end{array}$ & $\begin{array}{l}\text { This key action involves developing a } \\
\text { detailed and overarching implementation } \\
\text { plan in a participatory manner, and which } \\
\text { should involve key stakeholders, including } \\
\text { relevant government sectors, local } \\
\text { governments, service users and service } \\
\text { providers. }\end{array}$ \\
\hline $\begin{array}{l}\text { Key action 10: } \\
\text { Adopt the most } \\
\text { inclusive selection } \\
\text { methodology }\end{array}$ & $\begin{array}{l}\text { This key action involves taking necessary } \\
\text { steps to ensure that beneficiaries are } \\
\text { identified in the most inclusive manner to } \\
\text { yield a maximum of policy coverage. }\end{array}$ \\
\hline $\begin{array}{l}\text { Key action 11: } \\
\text { Select the most } \\
\text { appropriate } \\
\text { implementation partners }\end{array}$ & $\begin{array}{l}\text { This key action involves mobilizing the } \\
\text { non-governmental, civil society and private } \\
\text { sector for the operationalization of social } \\
\text { inclusion policies. }\end{array}$ \\
\hline
\end{tabular}




\begin{tabular}{|l|l|}
\hline $\begin{array}{l}\text { Key action 12: } \\
\text { Encourage cooperation } \\
\text { between agencies and } \\
\text { service providers }\end{array}$ & $\begin{array}{l}\text { This key action involves strengthening the } \\
\text { links between implementers on the ground } \\
\text { to deliver a more tailored and holistic } \\
\text { response to social inclusion. }\end{array}$ \\
\hline $\begin{array}{l}\text { Key action 13: } \\
\text { Collect qualitative and } \\
\text { quantitative data }\end{array}$ & $\begin{array}{l}\text { This key action involves setting up mixed } \\
\text { and multi-methods monitoring and } \\
\text { evaluation frameworks in a participatory } \\
\text { manner. }\end{array}$ \\
\hline $\begin{array}{l}\text { Key action 14: } \\
\text { Integrate, aggregate, } \\
\text { disaggregate and share } \\
\text { data }\end{array}$ & $\begin{array}{l}\text { This key action involves integrating, } \\
\text { aggregating, disaggregating and sharing } \\
\text { data to monitor and evaluate policies across } \\
\text { multiple domains and over time. }\end{array}$ \\
\hline $\begin{array}{l}\text { Key action 15: } \\
\text { indicator dimensions }\end{array}$ & $\begin{array}{l}\text { This key action involves the participatory } \\
\text { design of an indicator framework to } \\
\text { measure appropriate social outcomes. }\end{array}$ \\
\hline $\begin{array}{l}\text { Key action 16: } \\
\text { Share information with } \\
\text { policy beneficiaries }\end{array}$ & $\begin{array}{l}\text { This key action involves taking steps to } \\
\text { ensuring equitable access to all information } \\
\text { relating to policy benefits. }\end{array}$ \\
\hline $\begin{array}{l}\text { Key action 17: } \\
\text { Share information with } \\
\text { the policy community }\end{array}$ & $\begin{array}{l}\text { This key action involves taking steps to } \\
\text { ensuring equitable access to all information } \\
\text { relating to the policy more broadly. }\end{array}$ \\
\hline
\end{tabular}

Source: Huss/MacLachlan (2016)

A policy process qualifies as inclusive and equitable if evidence can be gathered from documents or stakeholder testimonials to demonstrate engagement with the key actions outlined in EquIPP. An assessment matrix, comprising a 7-point scale was developed to assess the level of prospective or retrospective engagement with the 17 key actions. Higher-level ratings are awarded for Process and Outcome criteria and can only be achieved if stakeholders indicate satisfaction with the process and outcomes of engagement. Scores for individual key actions are plotted on a spider diagram to visualize the inclusiveness of policy processes.

To date EquIPP has been used in conjunction with EquiFrame across a number of diverse contexts. EquIPP is currently being used in a two-year project to promote social inclusion in South-East Asia as part of UNESCO's Management of Social Transformation (MOST) programme. More specifically, EquIPP has been used in an assessment of the National 
Disability Policy in Timor-Leste. ${ }^{56}$ The findings from the evaluation were presented at a National Dialogue in Dili, Timor-Leste and will be presented to the Council of Ministers to inform the revision of the document. EquiFrame and EquIPP are also being used to guide assessments and subsequent policy revisions in Cambodia (National Disability Policy) and in Malaysia (Science and Technology Funding Policy). Both instruments have been used to assess the National HIV/AIDS strategy in Malawi. ${ }^{57}$ Both instruments have also formed an important part of training and capacity building for policy development, revision and analysis for staff from the United Nations Educational, Scientific and Cultural Organization (UNESCO), World Health Organization (WHO), International Labour Organization (ILO), United Nations Development Programme (UNDP) and United Nations Children's Fund (UNICEF) as part of the United Nations Partnership to Promote the Rights of Persons with Disabilities (UNPRPD). ${ }^{58}$

\section{Special Considerations in Using EQUIFRAME AND EQUIPP}

This overview of various applications of both EquiFrame and EquIPP demonstrates the usefulness of these tools in a range of countries with greatly different cultures, contexts and political systems. This is largely as a result of the flexibility and adaptability of both methodologies; users of these tools are encouraged to adapt the methodologies to suit their contextual needs. Insights and findings from the application of both tools will feed into future revisions of the instruments. Users may find certain core concepts, vulnerable groups or KAs more salient than others. We recognise that EquiFrame's twelve vulnerable groups, or 21 core concepts, are not exhaustive and may also be influenced by the nature of different policy areas. We encourage therefore, the identification of additional vulnerable groups and core concepts as they pertain to specific contexts.

56 Timor-Leste National Commission for UNESCO (2016).

57 Chinyama et al. (2016).

58 UNDP (2016). 
In relation to vulnerable groups in particular, we believe that processes of identification must be evidence-based to ensure that the groups in question are in actual fact particularly disadvantaged with regard to the relevant policy area. ${ }^{59}$ As noted earlier, while each of the vulnerable groups and core concepts outlined is supported by a significant evidence base and international resolution or conventions, ${ }^{60}$ the identification of vulnerable groups was also constrained by the political context of the countries involved. For instance, while we would have liked to recognise the need to promote inclusion of LGBTI persons, in some of the countries involved in the development of EquiFrame, such activities were legally prohibited, and indeed punishable by death. Clearly inclusion works within political contexts that mediate what is legally permissible in society. However, we are painfully aware that promoting inclusion for some marginalized groups, while ignoring it for others, is morally problematic, even given the constraints of what is practically possible in different jurisdictions.

We would encourage others to adopt, add to or subtract from our core concepts or vulnerable group categories; but crucially, to do so on the basis of an explicit and evidence-based rationale. Ivanova et al., in their analysis of Sexual and Reproductive Health policies from the Ukraine, Scotland, Moldova and Spain, argued for the inclusion of four additional vulnerable groups: Lesbian, Gay, Bisexual, Transgender (LGBT), people living with HIV, sex workers and victims of sexual abuse, gender violence and human trafficking. ${ }^{61}$ At a workshop on social inclusion in Malaysia participants representing government, academia and civil society identified the additional vulnerable groups of street children, prisoners and indigenous communities. $^{62}$

As already noted, the inclusion of some groups can be contentious in countries, where the legal environment discriminates against or criminalizes their very existence. ${ }^{63}$ However, even within such constricting contexts the rights of those marginalized by national laws, may still be considered in national policy. An example can be found in the recently completed analy-

59 MacLachlan et al. (2015).

60 Mannan et al. (2012).

61 Ivanova et al. (2015).

62 National Working Group (2016).

63 MacLachlan et al. (2015). 
sis of the National HIV/AIDS Policy of Malawi using EquiFrame and EquIPP. The policy is a notable example of an inclusive policy for men who have sex with men (MSM). In Malawi, the law criminalizes same-sex practices, yet as a vulnerable group, MSM are included as a priority group in the country's public health response in recognition of the significant barriers faced by them in accessing health care. ${ }^{64}$ Often disconnected from the pragmatics of need, policy makers can benefit greatly from involving groups or representatives of groups who are marginalized, and therefore best positioned to enrich policies with lived experiences of exclusionary processes. This argument chimes with the Jakarta Declaration on Health Promotion, which states that "people have to be at the centre of health promotion action and decision-making processes $\ll{ }^{65}$

While there may be situations where certain core concepts are less relevant in some policy documents, we would expect the empirical evidence for this to be presented by way of justification for their omission. The final 21 core concepts in EquiFrame were deemed to represent a broad range of salient concerns central in achieving equitable, accessible and universal healthcare. ${ }^{66}$ We have applied these concepts well beyond health and welfare and found most of them to be salient in others areas too. The core concepts of human rights were not positioned in terms of relative importance but are presented as a generally coherent 'gestaltr. We note that any omission of a core concept within a policy assessment therefore automatically assigns differential importance to individual concepts.

Table 3: Vulnerable groups outlined in EquiFrame

\begin{tabular}{|l|l|l|}
\hline 1 & Limited Resources & $\begin{array}{l}\text { Referring to poor people or people } \\
\text { living in poverty }\end{array}$ \\
\hline 2 & $\begin{array}{l}\text { Increased Relative Risk } \\
\text { For Morbidity }\end{array}$ & $\begin{array}{l}\text { Referring to people with one of the } \\
\text { top 10 illnesses, identified by WHO, } \\
\text { as occurring within the relevant } \\
\text { country }\end{array}$ \\
\hline
\end{tabular}

64 Chinyama et al. (2016).

65 Keygnaert (2016); WHO (2009).

66 Mannan et al. (2011), 13. 


\begin{tabular}{|c|c|c|}
\hline 3 & Mother Child Mortality & $\begin{array}{l}\text { Referring to factors affecting } \\
\text { maternal and child health ( } 0-5 \text { years })\end{array}$ \\
\hline 4 & $\begin{array}{l}\text { Women Headed } \\
\text { Household }\end{array}$ & $\begin{array}{l}\text { Referring to households headed } \\
\text { by a woman }\end{array}$ \\
\hline 5 & $\begin{array}{l}\text { Children } \\
\text { (with special needs) }\end{array}$ & $\begin{array}{l}\text { Referring to children marginalized } \\
\text { by special contexts, such as orphans } \\
\text { or street children }\end{array}$ \\
\hline 6 & Aged & Referring to older age \\
\hline 7 & Youth & $\begin{array}{l}\text { Referring to younger age without } \\
\text { identifying gender }\end{array}$ \\
\hline 8 & Ethnic Minorities & $\begin{array}{l}\text { Referring to non-majority groups in } \\
\text { terms of culture, race or ethnic iden- } \\
\text { tity }\end{array}$ \\
\hline 9 & Displaced Populations & $\begin{array}{l}\text { Referring to people who, because of } \\
\text { civil unrest or unsustainable liveli- } \\
\text { hoods, have been displaced from } \\
\text { their previous residence }\end{array}$ \\
\hline 10 & $\begin{array}{l}\text { Living Away } \\
\text { from Services }\end{array}$ & $\begin{array}{l}\text { Referring to people living far from } \\
\text { health services, either in time or } \\
\text { distance }\end{array}$ \\
\hline 11 & $\begin{array}{l}\text { Suffering from } \\
\text { Chronic Illness }\end{array}$ & $\begin{array}{l}\text { Referring to people who have an } \\
\text { illness which requires continuing } \\
\text { need for care }\end{array}$ \\
\hline 12 & Disabled & $\begin{array}{l}\text { Referring to persons with } \\
\text { disabilities, including physical, } \\
\text { sensory, intellectual or mental health } \\
\text { conditions, and including synonyms } \\
\text { of disability }\end{array}$ \\
\hline
\end{tabular}

Source: Mannan et al. (2011)

Grounded in the United Nations declarations and resolutions, we are fully cognizant that the values and philosophy of inclusion, fairness and human rights espoused by these methodologies are a reflection of the dominance of some socio-political thinking and philosophical paradigms over others. Nonetheless, we contend that our approach is justifiable in light of the existence of ill-suited models of social cooperation and unjust societies. Fol- 
lowing Braveman and Gruskin, ${ }^{67}$ we insist that reductions in health disparities can only be achieved if governments explicitly commit to equity and human rights by according equal opportunities for health for the most vulnerable and excluded groups in society. ${ }^{68}$ Government has a legal obligation and society must accept its moral duty to alleviate health disparities. By combining the two, EquiFrame and EquIPP can support States in moving beyond the rhetoric and towards the operationalization of the principles of equity and inclusion.

\section{USING EQUIFRAME AND EQUIPP TO Guide, Monitor and Evaluate the IMPLEMENTATION OF THE SUSTAINABLE DeVelopment GoAls (SDGs)}

The Post 2015 Sustainable Development Agenda constitutes a unique opportunity for countries and the wider global community to realise the right to health for all. As Hawkes and Buse ${ }^{69}$ point out, the Sustainable Development Goals (SDGs) represent an attempt by the global community to move beyond a narrow conceptualisation of health in a biomedical sense and to promote a more holistic approach to health and well-being. SDG No. 3 encourages governments to implement Universal Health Coverage (UHC), including financial risk protection, to ensure access to health services, medicines and vaccines for all (target 3.8). While the provision of UHC has been equated to the practical expression of the right to health, ${ }^{70}$ SDG No. 3 also promotes action to curb current and future threats of communicable and non-communicable diseases (targets 3.1-3.6). ${ }^{71}$ These health related targets must be situated within the broader development agenda, which promotes action on the underlying social, economic, cultural, political and structural determinants of ill-health and social exclusion. ${ }^{72}$

67 Braveman/Gruskin (2003).

68 Ahmimed et al. (2014).

69 Hawkes/Buse (2016).

70 Ooms et al. (2014); Tangcharoensathien et al. (2015).

71 WHO (2016).

72 Buse/Hawkes (2015); Hawkes/Buse (2016), 337. 
Health inequity is often referred to as a »wicked problem«, presenting complexities difficult to resolve using siloed policy responses. Kickbush and Gleicher argue that

»successfully solving or at least managing wicked policy problems requires reassessing some traditional ways of working and solving problems, challenging governance structures, skill bases and organizational capacity. ${ }^{73}$

To this end, working arrangements and relationships amongst different policy actors, across government sectors and levels must be re-oriented towards more collaboration and better coordination. ${ }^{74}$ According to Hawkes and Buse, achieving the SDGs require new forms of inter-sectoral coordination as well as new partnership frameworks with an increased emphasis on accountability. Similarly, policy processes must be inclusive, with mechanisms for monitoring and review. ${ }^{75}$ Policies promoting health and well-being must be guided by principles of equity and respect for human rights. ${ }^{76}$ The methodologies reviewed in this chapter lend themselves particularly well to guide, monitor and evaluate the implementation of the right to health.

In order to promote healthy lives and well-being for all, at all ages, whilst reducing existing health disparities, it is vital to address and rectify fundamental inequalities among different groups in society. The Office of the United Nations High Commissioner for Human Rights and the WHO specified that the application of the right to health for specific groups demands that countries

»disaggregate their health laws and policies and tailor them to those most in need of assistance rather than passively allowing seemingly neutral laws and policies to benefit mainly the majority groups. ${ }^{77}$

73 Kickbusch/Gleicher (2012), 93.

74 Huss/MacLachlan (2016).

75 Hawkes/Buse (2016).

76 Ibid.; Kickbush/Gleicher (2012); MacLachlan (2014).

77 WHO (2008), 24; see also MacLachlan (2016b); Mji et al. (2009). 
Explicitly mentioning vulnerable groups, as they exist in a particular context and in relation to a specific issue area, strengthens their claims to entitlements and nominally commits governments to act on their obligation to secure access to services, goods and facilities for them. Similarly, an emphasis on core concepts of human rights within a policy document commits governments to implement policies in line with such principles. By promoting overt references to core concepts of human rights, EquiFrame can guide policy makers in strengthening the human rights language in their policies.

While the content of such documents constitutes a crucial point of reference, the manner in which they are developed, implemented, evaluated and disseminated presents ubiquitous opportunities to create experiences of inclusion. ${ }^{78}$ The Organization for Economic Cooperation and Development (OECD) contends that »the nature of the policymaking process matters [...] for the quality of policies, and thus their outputs « ${ }^{79}$ Ideally, inclusive policies are the outcome of a participatory development process. Key actions 1 and 2 in EquIPP focus on the creation of inclusive engagement strategies, which would allow vulnerable groups and their representatives to partake in the decision-making processes at the highest level possible. EquIPP also encourages the continuous involvement of vulnerable groups and/or their representatives throughout the policy life cycle, from the design phase through to implementation and evaluation, ensuring that policies address priority needs of such groups (key action 5). It does so in recognition of the fact that participation has the potential to improve the design and deliverance of better public services. ${ }^{80}$ Moreover, continued inclusion creates new partnerships and collaborations between issue areas and in which, governments, providers and »consumers « of services co-produce the process and content of decision-making. ${ }^{81}$

Inter-sectoral approaches have been deemed most appropriate to address socially determined phenomena such as health inequities and social exclusion. The remit for population health goes beyond responsibility of the health sector; efforts to address particular instances of exclusion thus neces-

78 Huss/MacLachlan (2016).

$79 \operatorname{OECD}(2013 \mathrm{a}), 5$.

80 UNDESA et al. (2013); Speer (2012).

81 Quick/Feldman (2011). 
sitate the coordinated intervention of a variety of stakeholders. ${ }^{82}$ Key actions 3 and 4 in EquIPP detail how the strengthening of cross-sectoral and inter-governmental cooperation and coordination promotes equity and social inclusion at an organizational and institutional level. If located within a whole-of-government approach, they can foster critical linkages across previously disconnected silos and levels of operation. Additional avenues for equity and inclusion exist at various junctures of the policy process. Monitoring and evaluation frameworks, for example, should employ a combination of quantitative and qualitative appraisals. Evaluations involving vulnerable groups (as service users or beneficiaries more broadly) display transformative potential, for they seek out the knowledge and experiences of vulnerable groups, which can influence the future course of policies and programmes. ${ }^{83}$ Braveman and Gruskin contend that qualitative information collected from vulnerable groups and their representatives is important for it allows the documentation of $»$ unmet need, perceptions of service quality, and obstacles to receiving recommended services in any sector influencing health «. ${ }^{84}$ Quantitative data collected should be amenable to disaggregation for different vulnerable groups, to establish differential impact to feed back into the policy cycle and inform the adaptation of policy designs. ${ }^{85}$ Moreover, equity and human rights principles require that quantitative data be disaggregated for vulnerable groups and by variables such as age, sex, ethnicity, disability, migratory status, income and geographic location. ${ }^{86}$ Key actions 13, 14 and 15 emphasize the importance of routine data collection of quantitative and qualitative information to monitor progress towards social inclusion. EquIPP also addresses information poverty (key actions 16 and 17), which has been recognized as a significant barrier to healthcare access and as a manifestation of social exclusion. ${ }^{87}$ The failure to translate policies into local languages, for example, constitutes a prime example of exclusion. Limited access to policy relevant information prevents individu-

82 Hawkes/Buse (2016); Kickbusch/Gleicher (2012).

83 Mertens (2012); Samson et al. (2015).

84 Braveman/Gruskin (2003), 542.

85 Open Society Foundation (2010).

86 Piron/Curran (2005); UNFPA (2016).

87 Britz (2004); Ensor/Cooper (2004); Kennan et al. (2011), 193. 
als and groups from fully participating in society. ${ }^{88}$ To ensure equitable access to all information relating to benefits a policy has to offer (i.e. entitlements, goods and services, specific provisions), governments must improve how it communicates with citizen. ${ }^{89}$ Inclusive dissemination strategies engage in extensive distribution of information in a culturally appropriate manner. ${ }^{90}$

EquiFrame and EquIPP both permit quantitative assessments of the extent to which policy makers are engaging with principles of equity, inclusion and human rights. In EquIPP, for example, evaluators are encouraged to seek out evidence from vulnerable groups or their representatives on their satisfaction with the process and the outcome of inclusion. If vulnerable groups or their representatives state ssatisfaction` with the process and outcomes of engagement, this is likely to be indicative of a genuine government commitment towards equity and inclusion.

\section{Conclusion: What Get's Measured, GET'S DONE!}

We argue that in order to address exclusion most effectively, the content of policies as well as the overall policy process must be inclusive. Governments are uniquely positioned to reverse processes of exclusion. Policy makers are interested in quantitative evidence-based evaluations of their work, as it permits them to demonstrate a clear commitment to promoting social inclusion and human rights in their policies. The advent of the SDGs, with their much stronger commitment to social inclusion, means that financial and technical support for the development plans produced by low- and middle-income countries will require governments to clearly demonstrate a strong commitment to promoting social inclusion and equity. The extent of inclusion in such processes has proven difficult to encourage and to evaluate, at least for some marginalized groups. ${ }^{91}$ EquiFrame and EquIPP both offer flexible methodologies that allow for quantitative comparison and

88 Kennan et al. (2011).

89 Britz (2004); WHO (2008).

90 Kennan et al. (2011); WHO (2008).

91 MacLachlan et al. (2014). 
demonstration of the extent to which policy content and policy processes are inclusive. These instruments seek to encourage and to evaluate; and we encourage others to build on our own work and that of others by using these >free to use and free to access instruments in new ways and new places to promote social inclusion and human rights in health, welfare and other polices.

\section{References}

Ahmimed, Charaf/MacLachlan, Malcolm/Mannan, Hasheem (Eds.) (2014): Policies \& Processes for Social Inclusion: Volume I: Possibilities from South East Asia, Jakarta: UNESCO.

Amin, Mutamad/MacLachlan, Malcolm/Mannan, Hasheem/El Tayeb, Shala/El Khatim, Amani/Swartz, Leslie/Munthali Alister, van Rooy, Gert/ McVeigh, Joanne/Eide, Arne/Schneider, Marguerite (2011): »EquiFrame: A framework for analysis of the inclusion of human rights and vulnerable groups in health policies«, in: Health \& Human Rights 13, 2 (2011), 1-20.

Anderson, James E. (2015): Public policymaking. 8th edition, Boston: Cengage Learning.

Andersen, Ask/Mannan, Hasheem (2012): »Assessing the Quality of European Policies on Disability and Development Cooperation: A Discussion of Core Concepts of Human Rights and Coherence«, in: Behinderung und internationale Entwicklung. Disability and International Development 23, 1 (2012), 16-23.

Bonner, Ann Marie/Holland, Jeremy/Norton, Andy/Sigrist, Ken (2005): Monitoring Social Policy Outcomes in Jamaica: Democratic Evaluation and Institutional Change, Arusha Conference, New Frontiers of Social Policy.

Braveman, Paula/Gruskin, Sofia (2003): »Poverty, equity, human rights and health «, in: Bulletin of the World Health organization 81, 7 (2003), 539-545.

Britz, Johannes J. (2004): »To know or not to know: a moral reflection on information poverty«, in: Journal of Information Science 30, 3 (2004), 192-204. 
Buse, Kent/Hawkes, Sarah (2015): »Health in the sustainable development goals: ready for a paradigm shift?«, in: Globalization and Health 11, 1 (2015), 1.

Carey, Gemma/McLaughlin, Pauline/Crammond, Bradley (2015): »Implementing Joined-Up Government: Lessons from the Australian Social Inclusion Agenda«, in: Australian Journal of Public Administration 74, 2 (2015), 176-186.

Chinyama, Mathews Junior/MacLachlan, Malcolm/McVeigh, Joanne/ Huss, Tessy/Gawamadzi, Sylvester (2016): »Analysing the extent of social inclusion and equity consideration in Malawi's National HIV and AIDS policy review process« (Manuscript under review).

Cocozzelli, Fred (2014): Revisiting Post-conflict social policy, Draft paper prepared for the UNRISD Conference New Directions in Social Policy: Alternatives from and for the Global South 7-8 April 2014, Geneva, Switzerland, United Nations Research Institute for Social Development. CSDH (Commission on Social Determinants of Health) (2008): Closing the gap in a generation: health equity through action on the social determinants of health, Final report of the commission on social determinants of health, Geneva: WHO.

Dani, Anis A./de Haan, Arjan (Eds.) (2008): Inclusive States: Social Policy and Structural Inequalities. New Frontiers in Social Policy, Washington DC: World Bank.

Eide, Arne/Amin, Mutamad/MacLachlan, Malcolm/Mannan, Hasheem/ Schneider, Marguerite (2013): »Human rights, social inclusion and health equity in international donors' policies«, in: Disability, $C B R$ and Inclusive Development 23, 4 (2013), 24-40.

Emms, Cheryl (2014): Analysis of disability inclusive development good practice, Nossal Institute for Global Health, Melbourne: University of Melbourne.

Ensor, Tim/Cooper, Stephanie (2004): Overcoming Barriers to Health Service Access and Influencing the Demand Side through Purchasing, Health, Nutrition and Population (HNP) Discussion Paper, Washington, DC: World Bank.

Fraser, Nancy (1998): Social justice in the age of identity politics: Redistribution, recognition, participation, Berlin: Wissenschaftszentrum Berlin für Sozialforschung.

Guy, Will/Liebich, André/Marushiakova, Elena (2010): Improving the tools 
for social inclusion and non-discrimination of Roma in the EU. Summary and selected projects, Luxembourg: Publications Office of the European Union.

Hawkes, Sarah/Buse, Kent (2016): »Searching for the Right to Health in the Sustainable Development Agenda: Comment on >Rights Language in the Sustainable Development Agenda: Has Right to Health Discourse and Norms Shaped Health Goals?«, in: International Journal of Health Policy and Management 5, 5 (2016), 337.

Holmes, Malcolm (1998): Public expenditure management handbook, Washington DC: World Bank.

Huss, Tessy/MacLachlan, Malcolm (2016): Equity and Inclusion in Policy Processes (EquIPP): A Framework to support Equity \& Inclusion in the Process of Policy Development, Implementation and Evaluation, Dublin: Global Health Press.

Iriarte, Edurne García/McConky, Roy/Gilligan, Robbie (Eds.) (2015): Disability \& Human Rights in a Global Age, London: Palgrave.

Ivanova, Olena/Dræbel, Tania/Tellier, Siri (2015): »Are sexual and reproductive health policies designed for all? Vulnerable groups in policy documents of four European countries and their involvement in policy development«, in: International Journal of Health Policy and Management 4, 10 (2015), 663-671.

Kabeer, Naila (2005): Social exclusion: concepts, findings and implications for the MDGs, Paper commissioned as background for the Social Exclusion Policy Paper, London: Department for International Development (DFID).

Kennan, Mary Anne/Lloyd, Annemaree/Qayyum, Asim/Thompson, Kim (2011): »Settling in: The Relationship between information and social inclusion«, in: Australian Academic \& Research Libraries 42, 3 (2011), 191-210.

Keygnaert, Ines (2016): »In Search of the Third Eye, When the Two Others Are Shamefacedly Shut? Comment on >Are Sexual and Reproductive Health Policies Designed for All? Vulnerable Groups in Policy Documents of Four European Countries and Their Involvement in Policy Development«", in: International Journal of Health Policy and Management 5, 5 (2016), 325-327. 
Kickbusch, Ilona/Gleicher, David (2012): Governance for Health in the 21st century, Copenhagen: World Health Organisation, Regional office for Europe.

Labonté, Ronald/Schrecker, Ted (2007): „Globalization and social determinants of health: Introduction and methodological background (part 1 of 3)«, in: Globalization and Health 3, 5 (2007), doi:10.1186/17448603-3-5.

Lavalle, Adrián Gurza/Acharya, Arnab/Houtzager, Peter P. (2005): »Beyond comparative anecdotalism: lessons on civil society and participation from São Paulo, Brazil«, in: World Development 33, 6 (2005), 951-964.

Leppo, Kim/Ollila, Eeva/Pena, Sebastian/Wismar, Mathias/Cook, Sarah (2013): Health in all policies. Seizing opportunities, implementing policies, Helsinki, Finland: Ministry of Social Affairs and Health.

Lombe, Margaret/Sherraden, Michael (2008): »Inclusion in the policy process: An agenda for participation of the marginalised «, in: Journal of Policy Practice 7, 2/3 (2008), 199-213.

MacLachlan, Malcolm (2014): »Macropsychology, Policy \& Global Health«, in: American Psychologist 69 (2014), 851-863.

MacLachlan, Malcolm/O'Connell, Michael (Eds.) (2000): Cultivating Pluralism: Cultural, Psychological and Social Perspectives on a Changing Ireland, Dublin: Oak Tree Press.

MacLachlan, Malcolm/Amin, Mutamad/ Mannan, Hasheem/El Tayeb, Shala/Bedri, Nafisa/Swartz, Leslie/Munthali, Alister/Van Rooy, Gert/ McVeigh, Joanne (2012): »Inclusion and human rights in African health policies: Using EquiFrame for comparative and benchmarking analysis of 51 policies from Malawi, Sudan, South Africa and Namibia«, in: PLoS One 7, 5 (2012), doi:10.1371/journal.pone.0035864.

MacLachlan, Malcolm/Mji, Gubela/Chataika, Tsisti/Wazakili, Magret/ Dube, Andrew K./Mulumba, Moses/Massah, Boniface O./Wakene, Dagnachew/Kallon, Frank/Maughan, Marcella (2014): »Facilitating Disability Inclusion in Poverty Reduction Processes: Group Consensus Perspectives from Disability Stakeholders in Uganda, Malawi, Ethiopia, and Sierra Leone«, in: Disability \& the Global South 1, 1 (2014), 107127.

MacLachlan, Malcolm/Mannan, Hasheem/McVeigh, Joanne (2015): »Disability and Inclusive Health«, in: Iriarte et al. (2015), 150-172. 
MacLachlan, Malcolm/Mannan, Hasheem/Huss, Tessy/Munthali, Alister/ Amin, Mutamad (2016): »Policies and processes for social inclusion: using EquiFrame and EquIPP for policy dialogue: Comment on >Are sexual and reproductive health policies designed for all? Vulnerable groups in policy documents of four European countries and their involvement in policy development «, in: International Journal of Health Policy and Management 5, 3 (2016), 193-196.

Mannan, Hasheem/Amin, Mutamad/MacLachlan, Malcolm/the EquitAble Consortium (2011): The EquiFrame Manual: A Tool for Evaluating and Promoting the Inclusion of Vulnerable Groups and Core Concepts of Human Rights in Health Policy Documents, Dublin: Global Health Press.

Mannan Hasheem/MacLachlan, Malcolm/McVeigh, Joanne/the EquitAble Consortium (2012): »Core concepts of human rights and inclusion of vulnerable groups in the United Nations Convention on the rights of persons with disabilities«, in: ALTER - European Journal of Disability Research/ Revue Européenne de Recherche sur le Handicap 6, 3 (2012), 159-177.

Marmot, Michael/Friel, Sharon/Bell, Ruth/Houweling, Tanja A./Taylor, Sebastian/Commission on Social Determinants of Health (2008): »Closing the gap in a generation: health equity through action on the social determinants of health «, in: The Lancet 372, 9650 (2008), 1661-1669.

Mathieson, Jane/Popay, Jennie/Enoch, Etheline/Escorel, Sarah/Hernandez, Mario/Johnston, Heidi/Rispel, Laetitia (2008): Social Exclusion Meaning, measurement and experience and links to health inequalities. A Review of Literature, WHO Social Exclusion Knowledge Network Background Paper 1, Geneva: WHO.

McQueen, David V./Wismar, Matthias/Lin, Vivian/Jones, Catherine. M./ Davies, Maggie (Eds.) (2012): »Intersectoral Governance for Health in All Policies: Structures, actions and experiences«, World Health Organization on behalf of the European Observatory on Health Systems and Policies, Online: http://www.euro.who.int/_data/assets/pdf_file/0005/ 171707/Intersectoral-governance-for-health-in-all-policies.pdf [26.10.2016].

Mertens, Donna. M. (2012): »Transformative Mixed Methods Addressing Inequities«, in: American Behavioral Scientist 56, 6 (2012), 802-813. 
Mji, Gubela/MacLachlan, Malcolm/Melling-Williams, Natalie/Gcaza, Siphokazi (2009): »Realising the rights of disabled people in Africa: an introduction to the special issue«, in: Disability and Rehabilitation 31, 1 (2009), 1-6.

National Working Group (2016): Harnessing Talent towards an Inclusive Malaysia: An Assessment of the National Policy on Science and Technology and Innovation (NPSTI) in Enhancing Social Inclusion in Research and Innovation, UNESCO Jakarta.

OECD (1996): »Budgeting and Policy Making«, SIGMA Papers No. 8, Paris: OECD Publishing, Online: http://www.oecd-ilibrary.org/doc server/download $/ 5 \mathrm{kml6g} 6 \mathrm{wccq} 0$-en.pdf? expires $=1489403002 \& \mathrm{id}=\mathrm{id} \&$ accname=guest\&checksum=B9A1A7B2ADCB7673C298D8D540A5 79C9 [26.10.2016].

OECD (2013a): »Investing in Trust: Leveraging Institutions for Inclusive Policy Making«, Background Paper, Online: http://www.oecd.org/gov /ethics/Investing-in-trust.pdf. [02.09.2016].

OECD (2013b): »Policy coherence for inclusive and sustainable development«, OECD and Post-2015 reflections, Element 8, Paper 1, Online: https://www.oecd.org/dac/POST-2015\%20PCD.pdf [26.10.2016].

OECD (2015): »Inclusive government for a more inclusive society«, in: Government at a Glance 2015, Paris: OECD Publishing, 25-49.

Open Society Foundation (2010): »No data no progress: Data Collection in Countries Participating in the Decade of Roma Inclusion 2005-2015«, Online: https://www.opensocietyfoundations.org/reports/no-data-no-pro gress-country-findings [26.10.2016].

O'Donnell, Rossa (2008): An examination of the economic empowerment of people with disabilities in South Africa, Dublin: Centre for Global Health, Trinity College Dublin, University of Dublin.

O’Dowd, Jessica/Mannan, Hasheem/McVeigh, Joanne (2013): »India's Disability Policy-Analysis of Core Concepts of Human Rights«, in: Disability, CBR \& Inclusive Development 24, 4 (2013), 69-90.

OHCHR (2008): Fact Sheet No. 31. The Right to Health, June 2008, No. 31, Geneva: OHCHR.

Ooms, Gorik/Latif, Laila A./Waris, Attiya/Brolan, Claire E./Hammonds, Rachel/Friedman, Eric A./Mulumba, Moses/Forman, Lisa (2014): »Is universal health coverage the practical expression of the right to health 
care?«, in: International Health and Human Rights 14, 3 (2014). doi: 10.1186/1472-698X-14-3.

Piron, Laure-Hélène/Curran, Zaza (2005): Public policy responses to exclusion: evidence from Brazil, South Africa and India, London: Overseas Development Institute.

Popay, Jennie/Escorel, Sarah/Hernández, Mario/Johnston, Heidi/ Mathieson, Jane/Rispel, Laetitia (2008): »Understanding and tackling social exclusion«, Final Report to the WHO Commission on Social Determinants of Health From the Social Exclusion Knowledge Network, Online: http://www.who.int/social_determinants/knowledge_networks/ final_reports/sekn_final\%20report_042008.pdf [26.10.2016].

Pratto, Felicia/Stewart, Andrew L./Zeineddine, Fouad. B. (2013): »When inequality fails: Power, group dominance, and societal change «, in: Journal of Social and Political Psychology 1, 1 (2013), 132-160.

Quick, Kathryn S./Feldman, Martha S. (2011): »Distinguishing Participation and Inclusion«, in: Journal of Planning Education and Research 31, 3 (2011), 272-290.

Rittel, Horst W./Webber, Melvin M. (1973): »Dilemmas in a general theory of planning«, in: Policy Sciences 4, 2 (1973), 155-169.

Roberts, Nancy (2000): »Wicked problems and network approaches to resolution«, in: International public management review 1, 1 (2000), 119.

Samson, Michael/van Katwyk, Sasha/Fröling, Maarten/Ndoro, Rumbidzai/ Meintjes, Cara/Buts, Lien/Renaud, Bryant (2015): Methods of Measuring the Impacts of Social Policy in Political, Economic and Social Dimensions, Working Paper 2015-4, Geneva: United Nations Research Institute for Social Development.

Schneider, Margie/Eide, Arne Henning/Amin, Mutamad/MacLachlan, Malcom/Mannan, Hasheem (2013): »Inclusion of vulnerable groups in health policies: Regional policies on health priorities in Africa«, in: African Journal of Disability 2, 1 (2013), 1-9.

Silver, Hilary (2015): »The Contexts of Social Inclusion«, Department of Economic and Social Affairs (DESA)«, Working Paper No. 144, ST/ESA/2015/DWP/144, Online: http://www.un.org/esa/desa/papers/ 2015/wp144_2015.pdf [26.10.2016]. 
Speer, Johanna (2012): »Participatory Governance Reform: A Good Strategy for Increasing Government Responsiveness and Improving Public Services?«, in: World Development 40, 12 (2012), 2379-2398.

Tangcharoensathien, Viroj/Mills, Anne/Palu, Toomas (2015): »Accelerating health equity: the key role of universal health coverage in the Sustainable Development Goals«, in: BMC Medicine 13, 1 (2015), 1.

Timor Leste National Commission for UNESCO (2016): »Promoting Social Inclusion in Timor-Leste«, Report submitted to the Minister of Social Solidarity, pending presentation to the Council of Ministers, Online: http://timor-leste.gov.tl/wp-content/uploads/2011/07/Timor-Le ste-Strategic-Plan-2011-20301.pdf [26.10.2016].

UNDESA (2009): »Report of the Expert Group Meeting on Practical Strategies to Promote Social Integration: Lessons Learned from Existing Policies and Practices«, Organised by the Division for Social Policy and Development (DPSP). Department of Economic and Social Affairs, in collaboration with the Government of Ghana, Online: http://www.un. org/esa/socdev/egms/docs/2009/Ghana/ghanareport.pdf [26.10.2016].

UNDESA/DPADM/ESCWA (2013): »Citizen Engagement and the Post2015 Development Agenda: Report of the Expert Group Meeting «, ST/ ESA/PAS/SER.E/191， E/ESCWA/ECRI/2013/WG.1/Report, Online: http://workspace.unpan.org/sites/Internet/Documents/EGM\%20ReportBeirut-3-4Dec-2012_FINAL_cleared\%20on\%2008-07-2013.pdf [26.10.2016].

UNFPA (2016): »Programmes and Innovations to Strengthen the Demographic Evidence Base for ICPD and the 2030 Agenda for Sustainable Development«, Online: http://www.un.org/en/development/desa/popula tion/commission/pdf/49/CPD49_UNFPA_Snow_22March2016.pdf [26.10.2016].

UNDP (2016): »Connections: Building partnerships for disability rights«, Online: mptf.undp.org/document/download/16578 [26.10.2016].

Walt, Gill/Gilson, Lucy (1994): »Reforming the health sector in developing countries: the central role of policy analysis«, in: Health policy and planning 9, 4 (1994), 353-370.

WHO (2008): »Human rights, health and poverty reduction strategies«, Health and Human Rights Publications Series, Issue No. 5, Online: http://www.ohchr.org/Documents/Publications/HHR_PovertyReduction sStrategies_WHO_EN.pdf [26.10.2016]. 
WHO (2009): »Milestones in Health Promotion. Statements from Global Conferences«, Geneva: WHO, Online: http://www.who.int/health promotion/Milestones_Health_Promotion_05022010.pdf [26.10.2016].

WHO (2016): „Sustainable Development Goal 3: Health«, Online: http://www.who.int/topics/sustainable-development-goals/targets/en/ [01.09.2016].

World Bank (2013): Inclusion Matters: The Foundations for Shared Prosperity. New Frontiers in Social Policy (advance edition), Washington DC: World Bank. 



\title{
Conscientious Objection in the Medical Sector
}

Towards a Holistic Human Rights Approach

\author{
HEINER BIELEFELDT ${ }^{1}$
}

\section{A Highly Contested Theme}

On 7 October 2010, the Parliamentary Assembly of the Council of Europe (PACE) adopted resolution 1763 on »the right to conscientious objection in lawful medical care«. The resolution inter alia demands that

$»[\mathrm{n}] \mathrm{o}$ person, hospital or institution shall be coerced, held liable or discriminated against in any manner because of a refusal to perform, accommodate, assist or submit to an abortion, the performance of human miscarriage or euthanasia or any act which could cause the death of a human fetus or embryo, for any reason. ${ }^{2}$

While 56 PACE members voted in favour of the resolution, 51 rejected the text and four abstained from the vote. When adding the abstentions to the

1 An earlier version of this article was published in Frewer et al. (2016b). The present version has been updated and further complemented.

2 PACE resolution 1763 (2010), para. 1. It is worth noting that the resolution goes beyond the issue of conscientious objection by also including hospitals and other institutions. However, freedom of conscience - as well as the right to conscientious objection as its necessary implication - applies to individuals only. 
no-votes, the resolution received the smallest majority imaginable, i.e. by one vote. This narrow outcome testifies to the highly controversial nature of the subject, which had been a matter of fierce and emotional controversies in the weeks preceding the vote. A few months after the adoption, the Swedish Parliament explicitly distanced itself from the PACE resolution and called upon Swedish PACE members to try to change the text. ${ }^{3}$ This unprecedented move likewise illustrates the degree of contestation that the theme can trigger. It polarizes legislators and judiciaries, and it has even led to splits within the human rights community.

Conscientious objection in the medical sector is a thorny issue, because it may cause tensions or even direct collisions between two fundamental human rights: freedom of conscience, which is part of freedom of religion or belief, ${ }^{4}$ and the right to the highest attainable standard to health, ${ }^{5}$ which includes the availability and accessibility to reproductive health services. Both rights are enshrined in international conventions; and they both have received broad endorsement by states as well as civil society organisations and other stakeholders. Qua their nature as human rights they are furthermore considered »inalienable«. This precludes simplistic solutions, such as the idea that one of the two rights could just »trump« the other. ${ }^{6}$ Just as it would be irresponsible to endorse an unqualified right to conscientious objection without considering the possible consequences for the right to health, it would likewise be problematic simply to dismiss conscientious objection in healthcare by giving a general priority to the right to health. Setting up a clear and simple normative hierarchy, as envisaged by some commentators, would be at variance with the invisibility, interrelatedness and interdependency of all human rights, as corroborated by the $1993 \mathrm{Vi}$ -

3 See Astra Network (2011). Sweden does not accommodate any conscientious objection by health professionals when requested to perform abortions.

4 For references see below, under section 2.

5 The right to health has inter alia been enshrined in Article 12 of the International Covenant on Economic, Social and Cultural Rights. See Krennerich (2016), 5792.

6 This seems to be the predominant understanding in Sweden. The Swedish midwife Ellinor Grimmark, who refuses to participate in abortions, cannot work in her country and has lodged a complaint against Sweden with the Committee overseeing the implementation of the European Social Charter. 
enna World Conference. ${ }^{7}$ Hence, any viable coping strategy for conflict situations must do justice to both human rights at issue - or at least try to do so to the maximum degree possible in a given context.

In this article, ${ }^{8}$ I try to shed some light on the complex and prima facie uneasy relationship between the two rights at stake: the right to freedom of conscience and the right to health. I start by exploring the normative significance of respecting the conscience within the system of human rights protection. As we will see, due respect for the inner nucleus of a person's moral identity confronts us with the ultimate foundations as well as the insuperable limits of any legal order. Assuming that in many cases it will be impossible to reach fully-fledged »solutions « that would easily satisfy the interests of all involved parties, it will be all the more necessary to develop criteria on how to cope with remaining conflicts occurring in healthcare in a fair, consistent and manageable way. My conclusion is that for all the difficulties that doubtless arise in this area, respecting the right to conscientious objection in the medical sector is ultimately also in the interest of the right to health, which - qua its nature as a human right - presupposes responsible agency, in particular also on the side of doctors and nurses.

\section{The Conscience in the Context of HUMAN RIGHTS}

Freedom of conscience constitutes a strangely underexplored component within a comprehensive human right that is usually summarized under the heading of »freedom of religion or belief« - or even more succinctly: »religious freedom«. The full title »freedom of thought, conscience, religion or belief « is rarely cited. This comprehensive right has been enshrined in Article 18 of the Universal Declaration of Human Rights (UDHR), Article 18 of the International Covenant on Civil and Political Rights (ICCPR), Article 9 of the European Convention of Human Rights (ECHR) and other hu-

7 See Vienna Declaration and Programme of Action, A/CONF.157/24 (Part I), chap. III, sect. I, para. 5: »All human rights are universal, indivisible and interrelated and interdependent.«

8 This article is based in parts on chapter 1.3.11 of the book by Bielefeldt et al. (2016), 258-305. 
man rights instruments. Its purpose is to protect the existential selfunderstanding of human beings with regard to their profound convictions and the ways in which they lead their lives, individually and together with others, in conformity with those convictions. ${ }^{9}$ In this context, the conscience represents a person's moral identity, often, albeit not always, originating from a particular religion or belief. While other aspects of freedom of religion or belief also cover institutional aspects of community life, freedom of conscience is a right held by individuals, strictly speaking. ${ }^{10}$ Its exercise remain limited to human beings and does not include institutions or organizations, whose representatives when wishing to uphold a certain moral policy have to resort to other normative titles.

A famous metaphor describing the moral authority exercised by the conscience is the person's »inner court" - in Latin: the »forum internum«. Mahatma Gandhi, who often referred to his conscientious convictions when opposing British colonial rule in South Africa and later in India, underlined the specific rank of the conscience by declaring: »There is a higher court than the courts of justice and that is the court of conscience. It supersedes all other courts. $\ll^{11}$ When dealing with this theme, Gandhi inter alia liked to cite Socrates. He apparently saw his own political fight in analogy to the Socratic search for justice. Gandhi even translated Socrates' famous "Apology« into his native language Gujarati. In that Apology, Socrates defended himself before a criminal court in Athens. When addressing his jury he invoked an inner moral voice from which he had found guidance from childhood onwards. Using religious language, Socrates circumscribed that peculiar inner voice as a »divine« command or »the daimónion«. Interestingly, the commands issued by the daimónion, he said, were usually nega-

9 The preamble of the 1981 UN Declaration on the Elimination of All Forms of Intolerance and of Discrimination Based on Religion or Belief stresses: »religion or belief, for anyone who professes either, is one of the fundamental elements of his conception of life $\ll$.

10 The PACE resolution cited at the beginning mixed freedom of conscience with the autonomy of religious or belief-related institutions. Although both derive from freedom of thought, conscience, religion or belief, these two aspects must be kept distinct.

11 Mahatma Gandhi, Young India, 15 December 1921, quoted from the compilation by Mishra/Gupta (2008), 23. 
tive commands in the sense of moral vetoes. ${ }^{12}$ By insisting on the superior authority of his inner voice, Socrates ultimately went as far as to accept the death penalty, thus bearing witness to the apodictic force of his conscience.

Another famous notion illustrating the peculiar authority attributed to the person's conscience is the »categorical imperative«. According to Kant, »the moral law within me« arouses an admiration akin to the majesty of »the starry heavens above« me. ${ }^{13}$ Similar concepts, metaphors, images and proverbs exist in most different religious, cultural and philosophical traditions. They reflect the basic insight that normative obligations among human beings ultimately derive from profound moral convictions whose inner personal nucleus commands respect.

Before turning to a brief analysis of the human right to freedom of thought, conscience, religion or belief, as it has been enshrined international human rights law, it is worth noting that this specific right is not the only place within human rights documents where the term conscience occurs. The preamble of the 1948 UDHR invokes »barbarous acts which have outraged the conscience of mankind « thereby coining a metaphor (»conscience of mankind «) which is historically located in the world community's necessary response to crimes of unprecedented dimensions (»crimes against humanity «). ${ }^{14}$ In a non-metaphorical meaning, the term conscience furthermore occurs in Article 1 of the UDHR. The first sentence of that article may be the most-frequently cited sentence of any human rights document: »All human beings are born free and equal in dignity and rights.« By contrast, the rest of the same article receives much less attention. It reads: »They [i.e. human beings] are endowed with reasons and conscience and should act towards one another in a spirit of brotherhood." The term »brotherhood" sounds somewhat anachronistic, which may give a partial explanation why the whole sentence is not very popular nowadays. On top of that, everyone's »endowment with reason and conscience« is certainly not self-explanatory and thus may warrant a short interpretation.

12 See Plato, The Apology of Socrates: »This sign I have had ever since I was a child he sign is a voice which comes to me and always forbids me to do something which I am going to do [...]«, quoted from Plato (2002), 36.

13 Kant (1996), 269.

14 See Morsink (2009). 
What does it mean that all human beings are »endowed with reason and conscience $\ll$ ? What is the epistemological quality of that participular proposition? Obviously, the assumed »endowment« does not describe any particular empirical talents, skills or gifts. Article 1 makes an all-inclusive, universalistic claim by covering no less than »all human beings«. Hence, the sentence cannot refer to particular empirical qualities that different individuals may possess in different measures. However, if the proposition cannot be read as a description - certainly not as an empirical description - would it make more sense to understand it as a prescriptive proposition, e.g. as a moral appeal? Actually, such an interpretation may lead to even bigger problems, since any moral appeal (e.g. the subsequent request that human beings »should act in a spirit of brotherhood «) already presupposes that the addressees of that appeal possess reason and conscience. Moral appeals would be impossible without the underlying assumption that the addressed individuals are receptive to moral considerations and demands. It is this very receptiveness that the formula »endowed with reason and conscience« tries to capture.

I would suggest that the formula »endowed with reason and conscience makes more sense as an »ascriptive» (rather than »descriptive« or "prescriptive«) proposition, i.e. a quality we have to ascribe to all human beings. The assumption that human beings are endowed with reason and conscience has the status of a necessary presupposition without which normative interaction in human society would simply be inconceivable. Whatever example of normative interaction we may have in mind, the potential of human beings to act responsibly is always presupposed. Binding promises, contracts, normative standards or institutions from the local to the global level would not even be conceivable without the assumption that human beings have the potential of responsible agency for which they and indeed all of them - deserve an elementary respect. ${ }^{15}$ Even if a person actually does not live up to that expectation, the presupposition as such remains meaningful. In some cases this may manifest itself as a (moral or legal) reproach. Blaming a certain individual for not acting responsibly corroborates counterfactually the necessity to stick to the assumption that human beings deserve respectful treatment as persons endowed with reason and conscience. Indeed, this presupposition has an axiomatic status for any

15 See Bielefeldt (2011), 31-41. 
normative interaction. As the wording of Article 1 of the UDHR furthermore testifies, this basic respect is closely associated with respect for human dignity, i.e. the foundational normative insight underpinning human rights in general. ${ }^{16}$

\section{Freedom of Conscience as a Specific Human Rights Claim}

The following interpretation of freedom of conscience mainly refers to Article 18 of the ICCPR, which is the most important relevant norm in international human rights protection. However, the wording used in Article 9 of the ECHR is very similar. The general insights derived from the following observations thus also apply to the European system of human rights protection.

\subsection{Absolute Protection of the Person's Inner Moral Nucleus}

As one of the few absolute formulations of the ICCPR, Article 18 paragraph 2 rejects any coercive interference with the inner nucleus of a person's existential conviction: "No one shall be subject to coercion which would impair his freedom to have or to adopt a religion or belief of his choice «. ${ }^{17}$ Although the term »conscience« does not occur in this sentence, it is implicitly included as the moral corollary of a person's religion or belief. The strict rejection of any coercive interference positively means to re-

16 By presupposing a potential of responsible agency, recognition of human dignity does not depend on a person's any actual positive performance. It precedes any concrete normative actions, efforts, accomplishments, laws or institutions to which it relates as their implicit sine qua non. In other words, human dignity is not a meritocratic concept.

17 See also CCPR/C/21/Rev.1/Add.4, 30 July 1993, para. 3: The Covenant »does not permit any limitations whatsoever on the freedom of thought and conscience or on the freedom to have or adopt a religion or belief of one's choice. These freedoms are protected unconditionally $[. ..] \ll$ 
spect an internal sphere of personal freedom in questions of thought, conscience, religion or belief, which therefore enjoy unconditional legal protection. ${ }^{18}$ Article 18 paragraph 2 of the ICCPR belongs to those few international human rights norms, which do not allow for any »balancing« with conflicting norms or interests, not even in situations of emergency. The prohibition of coercive interferences can neither be limited, nor balanced against other consideration, nor be derogated, whatever situation of conflict may occur. The UN Human Rights Committee, tasked with monitoring the implementation of the ICCPR, corroborates this apodictic understanding in its General Comment No. 22 by emphasizing that Article 18 paragraph 2

»does not permit any limitations whatsoever on the freedom of thought and conscience or on the freedom to have or adopt a religion or belief of one's choice. These freedoms are protected unconditionally. [...]. $\ll^{9}$

It is worth noting that the Human Rights Committee expressis verbis lists freedom of conscience as part of the unconditional prohibition of coercion.

18 It should be noted in passing that the term »choice« can lead to misunderstandings. In the context of Article 18 para. 1 and 2 of the ICCPR »choice« is used only as a legal term. The existential experience of a person in questions of conscientious position may be they have in fact »no choice«. For instance, conscientious objectors to military service may claim that they obey the »dictates of their conscience«, which seems to be the opposite of »choice« in the everyday understanding of the word. In order to avoid confusion around the term choice it is important not to mistake the legal concept of freedom of choice as representing the existential experiences in the area of conscience. In other words, legal terminology and legal languages have its specific functions and concomitant limitations which one should bear in mind.

19 CCPR/C/21/Rev.1/Add.4, 30 July 1993, para. 3. Incidentally, the same holds true for Article 19 para. 1 of the ICCPR which concerns the forum internum of freedom of opinion and expression. Here again, the Human Rights Committee points out in a more recent General Comment that $»[t]$ his is a right to which the Covenant permits no exception or restriction « (CCPR/C/GC/34, 12 September 2011, para. 9). Both norms jointly protect human beings in their freedom to develop their own independent thinking, to form their own personal opinions and to build their own identity-shaping religious or non-religious convictions. 
Other examples of apodictic human rights norms not permitting any limitations on whatever grounds are the prohibition of slavery and the prohibition of torture. ${ }^{20}$ The rejection of coercion in the person's forum internum has a similarly elevated normative status, because coercive interferences with the inner nucleus of an identity-shaping existential conviction would directly collide with the due respect for human dignity. Being forced to conceal one's profound moral or religious conviction or to feign a conviction that is not authentic ultimately means no less than to betray oneself, which can undermine the preconditions for developing a stable sense of self-respect. This justifies the analogy of the unconditional prohibition formulated in Article 18 paragraph 2 of the ICCPR to the equally unconditional bans on slavery and torture. ${ }^{21}$

Against a possible misunderstanding, I would like to emphasize that respecting conscience as the inner core of a person's moral identity does not mean to turn it into a fortress immune to any societal influences. Conscientious positions held by a person usually reflect socialization processes within the family, community norms and practices, existing religious or nonreligious values in the society and other moral factors to which that person has been exposed. In short, conscientious positions presuppose human interaction and communication; they can never develop in isolation. Although in this sense always influenced and informed by fellow-humans and the broader social environment, however, there remains a decisive element of active identification or "adoption « of a position by the individual person. A genuine moral conviction is more than the merely passive reception of normative ideas that happen to exist in a society. In responding to normative positions of others, existing community practices, values and belief systems etc., which he or she encounters, the human being actively develops conscientious convictions.

Such moral development can never finish as long as the person lives. Driven by new insights, ideas and experiences, individuals can also change their conscientious positions. Fundamental changes in this regard are never easy and typically proceed in complicated and sometimes painful learning processes. The formulation of Article 18 paragraph 2 of the ICCPR reflects and explicitly protects that possibility. Thus, the freedom to »have or

20 See Article 7 and 8 of the ICCPR.

21 For a detailed discussion see Bielefeldt et al. (2016), 77-82. 
adopt « a religion or belief of one's choice also includes respect for an individual's freedom to change a conscientious position and adopt a new position. $^{22}$

\subsection{The Right to Act in Accordance with One's Conscientious Position}

Representing the inner moral »court«, the conscience is inherently linked to a person's moral identity - and frequently also to their religious or beliefrelated identity. In this sense, the conscience is a highly personal and even »intimate $\ll$ dimension of human existence. At the same time, the conscience drives the person to take actions in the external world, in accordance with his or her moral convictions. A conscientious position can hardly be serious without practical consequences taken by the individual, often together with fellow-humans who share the same moral intuition.

Thus, freedom of conscience would be pointless without the right to take actions in conformity with one's conscientious positions. However, since the results of conscientious actions may directly affect the rights and freedoms of others and/or important interests of public order, the right to act upon one's conscience is not without possible limitations. It falls within Article 18 paragraph 3 of the ICCPR, which deals with external »manifestations « of a religious, philosophical or conscientious conviction in »worship, observance, practice and teaching $«$. The term "practice« must be broadly interpreted so as to also include conscientious actions originating from a person's identity-shaping profound moral convictions.

Whereas Article 18 paragraph 2 of the ICCPR provides an unconditional protection of the forum internum and precludes any coercive interferences in this sphere for whatever reasons, external manifestations in the understanding of Article 18 paragraph 3 of the ICCPR can be limited under certain conditions. For limitations to be justifiable, however, they have to meet all the criteria set out in that paragraph. Accordingly, limitations must be legally prescribed and they must be obviously needed to pursue a legitimate aim - the protection of »public safety, order, health, or morals or the fundamental rights and freedoms of others«. In addition, restrictions must remain with the realm of proportionality, which inter alia means they must

22 For details see Bielefeldt et al. (2016), 55-69. 
be limited to a minimum degree of interference needed to pursue one of the said legitimate purposes. In General Comment No. 22, the Human Rights Committee insists

»that paragraph 3 of article 18 is to be strictly interpreted: restrictions are not allowed on grounds not specified there [...]. Limitations may be applied only for those purposes for which they were prescribed and must be directly related and proportionate to the specific need on which they are predicated. Restrictions may not be imposed for discriminatory purposes or applied in a discriminatory manner. ${ }^{23}$

These strict conditions for setting limitations are intended to protect freedom of thought, conscience, religion or belief also in the external sphere. While this protection - unlike in the forum internum - cannot be absolute, it is still quite strong.

Although »internal« conscientious convictions and their »external« manifestations in conscientious actions enjoy different degrees of legal protection, ${ }^{24}$ these two dimensions are typically closely intertwined. A conscientious conviction must be more than just wishful thinking with no consequences in the real world; it can only demonstrate its seriousness by manifesting itself in real actions. Vice versa, a moral action receives its moral quality by originating from a genuine conviction, which has taken shape in the forum internum. The internal and external dimensions protected under Article 18 of the ICCPR should therefore be viewed in their interrelatedness, since neither of these dimensions could even hypothetically exist in isolation. Hence, the unconditional protection accorded to the person's forum internum strengthens his or her conscientious agency in general, including in the area of practical actions deriving from a conscientious position in the person's social environment. These external actions themselves, however, are not beyond possible limitations, but can be limited in accordance with the criteria set out in Article 18 paragraph 3 of the ICCPR.

Conscientious actions also include $»$ negative $\ll$ actions in terms of refusals or objections. As already evidenced by the testimony of Socrates, the commands of the conscience are often particularly clear and strong when assuming a veto function. Dictates of the conscience frequently take shape

23 CCPR/C/21/Rev.1/Add.4, 30 July 1993, para. 8.

24 See also Bielefeldt et al. (2016), 82-85. 
as a categorical »no«. It thus may be more than a coincidence that issues of conscience have typically been treated under the heading of »conscientious objections«. Recent years have seen an increasingly broad endorsement of conscientious objection, which - at least when concerning compulsory military service - now has been accorded the status of an international human right. Hallmark decisions within that development are the views expressed by the UN Human Rights Committee on a number of South Korean cases of objection to performing compulsory military service in $2011^{25}$ and the European Court's 2011 judgment on Bayatyan versus Armenia, which equally dealt with military service. ${ }^{26}$

There have been discussions, including within the UN Human Rights Committee, as to whether conscientious objection falls within the forum internum or the forum externum of freedom of thought, conscience, religion or belief. ${ }^{27}$ Given the different degrees of legal protection accorded to the forum internum and the forum externum, this is not a merely academic question. In my view, conscientious objections constitute a subcategory of external actions broadly speaking, thus falling within external manifestations of freedom of conscience as enshrined in Article 18 paragraph 3 of the ICCPR. This means that acts of conscientious objections are not without possible limitations. Locating conscientious objection within the forum externum, does not amount to denying the seriousness of conscientious claims, which of course will be ultimately rooted in the forum internum where else should they originate? But the point is that an act of objection is a »manifestation « that may have - and often is intended to have - an impact on the person's social environment. In other words, it is an action with consequences for others as well. That is why the rights and freedoms of others, too, warrant systematic attention. The right to health, including the availability and accessibility of reproductive health, is a prominent example.

25 See CCPR/C/101/D/1642-1741/2007, 24 March 2011.

26 See Bayatyan v. Armenia, Application No. 23459/03, 7 July 2011.

27 For details see Bielefeldt et al. (2016), 264-275 and 289-290. 


\section{General Criteria for Conscience-based EXEMPTIONS FROM LAWFUL OBLIGATIONS}

The issue of conscientious objection confronts us not only with the very foundations of any legal order (and even of any normative interaction whatsoever); it likewise pushes us to the insuperable limits of what a legal order can provide. Laws governing societal coexistence in a pluralistic society usually are not - and cannot be - fully in line with every individual's conscientious convictions. Why is that so? The reason simply is that conscientious positions may point in different and often irreconcilably conflicting directions, while the legal order claims binding force upon all members of a society. ${ }^{28}$ Taking the conscience seriously requires becoming aware of a broad range of sometimes irreconcilable moral positions held by people who often live closely together. Strict pacifists live alongside people who strongly believe that the military plays an indispensable role in upholding peace and defending human rights. Vegetarians objecting to the slaughter of animals sometimes cannot avoid sharing their kitchen with meat-eaters. While some people abhor stem-cell research as an act of human hubris, others appreciate such research as an important step towards enhancing human life expectancy. Issues like abortion or euthanasia have triggered moral wars in some societies, and they are typically controversial among professionals working in healthcare, too.

Given the wide range of irreconcilable moral positions in modern society, the legal order will never be identical with every individual's moral convictions. ${ }^{29}$ Whoever expects that all existing legal obligations harmoniously correspond with their own conscientious convictions would be either naïve or arrogant - or even both. Obviously, obedience towards legitimately enacted laws cannot generally hinge on every individual's full moral approval of those laws; otherwise laws would from the outset lose their binding force in a morally pluralistic society. Thus, conflicts between one's deeply held moral convictions on the one hand and lawful obligations on the other are to be expected. Indeed, such conflicts are just normal in a morally pluralistic society.

28 See also Maclure/Taylor (2011), 100-105.

29 In his Metaphysics of Morals, Kant therefore conceptually differentiates between morality and law. 
Conscientious objection cannot provide the general recipe for coping with discrepancies between existing laws and one's own moral conviction. A democratic society offers numerous possibilities to tackle such discrepancies. For instance, people are free to voice their opposition in public discourse, they can appeal to their fellow citizens and hold public demonstrations, and they can try to put their moral convictions on political agendas that might even become binding for their political representatives. Issues of profound moral concern can thus enter public discourse, where the boundaries between majorities and minorities remain fluid. Moral dissenters from mainstream politics always have a chance to make their conscientious convictions heard in public, with a view to changing public opinion and eventually creating new laws.

Conscientious objection is not part of the general arsenal of voicing moral dissent. It must remain an exception reserved for specific dilemma situations when a person would otherwise feel torn between feelings of moral self-betrayal and the requirement to honour lawful obligations. I would like to propose a combination of five criteria for qualifying conscientious objections that may warrant exemptions from lawful obligations:

- the gravity of the moral concern,

- the situation of a conscientious veto,

- the connectedness to an identity-shaping principled conviction,

- immediacy of involvement in the requested action and

- the willingness to perform an alternative service. ${ }^{30}$

\subsection{Gravity of the Moral Concern}

The urgency of a conscientious objection naturally depends on the gravity of the moral issue that has caused the conflict. Although it may be difficult and ultimately impossible to reach a consensus in a morally pluralistic soci-

30 In order to avoid misunderstandings, I would like to reiterate that such qualifications can merely concern the forum externum dimension of freedom of conscience, i.e. actions deriving from a conscientious position which itself - as belonging to the forum internum dimension of Article 18 of the ICCPR - remains beyond any legitimate restrictions, limitations or qualifications for whatever grounds. 
ety on how to measure "gravity« in this regard, it remains important to understand that the objected action would run counter to profound moral concerns of the objecting person. In other words, the moral pathos of conscientious objections should not be wasted for minor issues. In fact, in most (albeit not all) of the cases in which the right to conscientious objection has been claimed human life seems to be at stake. Even those who finally do not share the conscientious position based on which an objection is made should thus be able to at least understand the moral seriousness of the issue.

\subsection{Situation of a Conscientious Veto}

Conscientious objection goes beyond moral criticism in that it presupposes the experience of an existential moral conflict. Many people may have critical reservations against certain laws, often based on moral grounds. As pointed out, this is a normal situation, even more so in a pluralistic society in which everyone can actively voice their criticism and publicly campaign for legislative changes. Conscientious objection differs from mere criticism voiced on moral grounds. It represents the situation of a direct conflict, in which the individual's conscience strictly vetoes any personal involvement, as it were. As the only way to avoid an existential moral dilemma, which would otherwise occur, conscientious objection concerns situations of such a direct conscientious veto and it should be limited to such situations.

\subsection{Connectedness to an Identity-shaping Principled Conviction}

Conscientious objection presupposes profound convictions, which differ from ad-hoc opinions that a person may have on this or that moral question. This does not mean that conscientious positions are unchangeable. As emphasized earlier, conscientious convictions always develop; they can even change fundamentally. What counts is the identity-shaping quality of religious and/or moral convictions, which the concerned individual cannot waive without thereby betraying himself or herself. The right to conscientious objection is a way to avoid such situations of threatened betrayal of one's identity-shaping principles, i.e. the nucleus of the moral self. 


\subsection{Immediate Involvement in the Requested Action}

Many people are somehow involved in practices that run counter to their conscientious convictions of a religious and/or moral nature. Usually, such involvement is an indirect one. For instance, citizens must pay taxes although the tax money supports projects they may disapprove on moral grounds. The classical paradigm is the pacifist who pays taxes thereby cofinancing the military that he morally rejects. People may also oppose stemcell research and nonetheless contribute to the public budget, thereby indirectly supporting such research. This kind of indirect involvement is unavoidable in a morally pluralistic society. ${ }^{31}$ Conscientious objection therefore presupposes a certain degree of »immediacy « of the requested involvement.

\subsection{Willingness to Perform an Alternative Service}

Conscientious objection is not a "privilege « some individuals request for themselves. Rather, it reflects an existential predicament in which a person seems to be caught between conflicting normative requirements. The guiding idea must be to do justice to both the imperative of one's conscience and the requirement to uphold the lawful order in general - or at least to try to do so to the maximum degree possible. Insistence on the supremacy of the conscience in a particular case should therefore go together with a willingness to honour the lawful public order by performing an alternative service to society whenever this seems possible. The meanwhile classical paradigm is the alternative civilian service replacing mandatory military service.

The proposed five criteria should be seen and applied in combination. Although their application to concrete cases may still be difficult and lead to controversial assessments, the criteria may help to determine those conscientious objections that warrant exemptions from lawful obligations. In order to apply them in practice, claims of conscientious objection require a

31 The appropriate way to resolve the resulting moral conflicts is by campaigning publicly for a change of the respective policies and law. By contrast, refusal to pay taxes would qualify as »civil disobedience«, which includes the willingness to accept the prescribed penalties for such acts. See Thoreau (2003). 
willingness on all sides to communicate in a spirit of mutual respect. On the one hand, those who claim an exemption based on their conscientious position face legitimate expectations to explain such a demand to the broader society. They may point to the gravity of their concerns and the existential dilemma they would otherwise face, since these concerns may follow from an identity-shaping profound moral conviction. The idea cannot be that objectors have to be successful in "persuading" others that their position is right or plausible, but they should be willing credibly to declare that their concerns are of a serious, existential nature. On the other hand, the state has a responsibility to try the utmost to avoid situations of an existential moral dilemma, which would tear some people apart, as it were. ${ }^{32}$ This inter alia requires the availability of alternative options whenever and wherever possible. Such options must not be connected with undue burdens, and above all, they should not be based on any disrespectful interrogations. Bearing in mind the criterion of immediacy of involvement, alternative options are particularly important in situations in which people may be forced to get directly involved in practices that would run counter to their deeply held conscientious positions.

Hence, conscientious objection is a morally demanding concept based on the due respect for everyone's human dignity. Above all, it requires sensitivity within society for the moral convictions of fellow-humans whose concerns may substantially differ from one's own moral positions. In other words, it means to take diversity in moral questions seriously and seek for ways to do justice to all parties concerned, to the maximum degree possible. Particular attention must be given to the moral concerns of religious or other minorities who may be particularly vulnerable to manifestations of disrespect or ridicule. Here, the state has a responsibility to promote a climate in which moral pluralism - alongside other forms of pluralism - can unfold without fear and without discrimination.

32 Admittedly, there may be situation in which a tragic conflict cannot be solved. However, this possible experience cannot justify policies of indifference to requests of conscientious objection. 


\section{The Voluntary Nature of Employment in HeALTHCARE}

International, regional and national jurisdiction on conscientious objection has by and large developed in the context of compulsory military service. It is mainly with regard to the refusal to take arms that the right to objection has taken shape. Many objections within the medical sectors likewise relate to situations where human life is at stake, e.g. issues like abortion or euthanasia. Nonetheless, there is one obvious difference that warrants further analysis: no one is drafted to the medical sector. People working in healthcare usually do so based on their own decision. Doctors or nurses voluntarily undertake obligations stemming from an employment contract that they have signed up to as result of their personal choice. Analogously, this is also applies to pharmacists or other positions in the medical sector.

Obviously, individuals cannot take employment in an institution whose core functions they reject on conscientious grounds. A conscientious objector to military service cannot keep his or her employment as a paid soldier. ${ }^{33}$ Likewise, a person rejecting stem-cell research on conscientious ground, will not be able work in an institute specialized on exactly that sort of research. It would be utterly absurd for a nurse refusing to being involved in abortions to seek employment in an abortion clinic. In such situations, the only viable solution would be for the concerned person to look for another professional activity. However, in most cases the situation is more complex. Hospitals usually offer a broad variety of services. A doctor or nurse may be able and willing to fulfil the expected professional duties in general with enthusiasm, while at the same time objecting to direct personal involvement concerning a few specific functions. To insist that the person nonetheless carry out the objected functions or, alternatively, leave the employment, may amount to an illegitimate limitation of their freedom of conscience, depending on the specific situation. This is likely the case if there is enough staff available and willing to guarantee the full functioning of the institution, so that pragmatic options to prevent a conflict would be possible and manageable.

33 This does not mean that soldiers are excluded from the right to conscientious objection. For details see Bielefeldt et al. (2016), 277-278. 
It is worth emphasizing in this regard that by signing an employment contract, employees do not waive their freedom of thought, conscience, religion or belief. This freedom has the status of an »inalienable« human right, after all, and thus cannot be simply superseded by an employment contract. Moreover, Article 4 of the UN Declaration on the Elimination of All Forms of Intolerance and of Discrimination Based on Religion or Belief (of November 1981) clarifies that freedom of thought, conscience, religion or belief applies to »all fields of civil, economic, political, social and cultural life « - and hence also to professional employment in whatever sector. If limitations and stipulations are deemed necessary, they must thus meet the criteria listed in Article 18 paragraph 3 of the ICCPR, as elaborated above. Although mainly addressing the state, they analogously also apply to limitations or stipulations imposed by an employment contract, which itself fall within the general regulations imposed by labour laws. Limitations of freedom of conscience, as stipulated in employment contracts, must be specific rather than general; they must relate to legitimate purpose and should be proportionate to the pursuance of such a purpose; and they should not discriminate people based on their religion or belief. Whenever there is a reasonable way to avoid conscientious conflicts in the running of an institutions, those in charge have a responsibility to find practical solutions - or at least to try the utmost to do so. The state bears the overarching responsibility to ensure that freedom of thought, conscience, religion or belief receives respect - not only in state institutions but also in the larger society. ${ }^{34}$

\section{Additional Stipulations for OBJECTIONS IN HEALTHCARE}

As previously emphasized, the right to conscientious objection can be limited inter alia in the interest of securing the rights and freedom of others, provided the criteria for justifying limitations are fully satisfied. Obviously, people working in healthcare directly impact on a number of human rights, including the right to life, the right to health, the right to physical, psychological and mental integrity, the right not to suffer unnecessary pain, the

34 See interim report of the Special Rapporteur on freedom of religion or belief to the General Assembly 2014, A/69/261, para. 26-41. 
right to reproductive self-determination, the right not to be discriminated against on the basis of sex/gender etc. Given this broad range of human rights issues that may be at stake, there are good reasons to complement the above general criteria for claiming conscience-based exemptions from lawful obligations by adding some further stipulations. Beside the criteria already mentioned for conscientious objection in general (gravity of the concern, situation of a direct conscientious veto, connectedness to an identityshaping principled conviction, immediacy of requested involvement, willingness to offer some alternative) the following additional stipulations seem reasonable and indeed necessary.

\subsection{Primacy of Professional Duties in Risk Situations}

No health professional can invoke conscientious objection in situations when they are needed to save another person from serious risks of life or physical integrity. Of course, whenever possible, such functions should be performed by a colleague who has no conscientious objection to tackling the task ahead. But maybe this will not be possible in all circumstances. Although legislators or those administering the respective institutions should to do the utmost to prevent moral dilemma situations and avoid existential conflicts of that nature, there can be no ultimate guarantee of success in all cases. Tragic predicaments remain a possibility. In such situations, the right to health of patients must prevail.

\subsection{No Imposition on One's Moral Convictions on Others, in Particular Patients}

Accommodating conscientious objection can provide a way out of a situation of an existential dilemma. However, conscientious objection can never become an excuse for medical professionals to impose their views on others, in particular patients, by exploiting their vulnerable situation. In its judgment on P. and S. versus Poland, the European Court of Human Rights dealt with the case of a teenage girl who had been raped and was effectively denied an abortion by the personnel of a hospital. The Court found that the behaviour of the health professionals in that case, whatever their motivation, led to a violation of the patient's human rights, including the prohibi- 
tion of cruel and inhumane treatment. ${ }^{35}$ Generally speaking, conscientious objectors should inform patients from early on clearly about the objections and about possible consequences arising from that situation so that patients have time to find alternative solutions.

\subsection{In-advance Information of Employers or Other Relevant Institutions}

As part of their positive cooperation duties, conscientious objectors must furthermore notify in advance their employers or health institutions about possible conflicts. This may help to provide alternatives, before complicated situations arise. The various parties involved - objectors, healthcare institution, oversight bodies and ultimately the state - have a shared responsibility to seek for adequate ways of preventing dilemma situations. This presupposes an active communication not least by objectors in order to facilitate timely activities.

\subsection{Cooperation in Finding Alternatives}

Conscientious objectors must actively support patients in finding alternative solutions, including by referring them to colleagues willing to perform the requested treatment. Refusal to refer to colleagues would amount to active obstruction, which cannot be acceptable. In its General Recommendation on women and health (1999), the Committee on the Elimination of Discrimination Against Women (CEDAW) pointed out that whenever health service providers refuse to perform certain functions based on conscientious objection, "measures should be introduced to ensure that women are referred to alternative health providers «" ${ }^{36}$ Conscientious objectors working in healthcare institutions can be legitimately requested to generally cooperate within such a referral system.

35 See P. and S. versus Poland, Application No. 57375/08, 30 October 2012. Grégor Puppinck (2017) correctly points out that having an abortion is not in itself a human right (see ibid., 62).

36 CEDAW, General Recommendation No. 24 (1999) on Article 12, para. 11. 


\section{Conclusion: the Need to Uphold a Holistic Human Rights ApProach}

Conscientious objection is a right with a number of qualifications. Although originating from the person's forum internum, conscientious objection nonetheless falls within the forum externum dimension of freedom of thought, conscience, religion or belief, since is amounts to an external "manifestation « of a conscientious position that may impact on other people's rights as well. This is particularly obvious in the medical sector where a number of other rights - right to life, right to physical integrity, right to health, including access to reproductive health services etc. - may be at stake. Hence, the general criteria for exempting objectors from lawful obligations on conscientious grounds must be complemented by a number of specific stipulations that aim to secure the rights of other people, in particular patients.

In light of numerous complications that may arise, some commentators have proposed generally to dismiss claims of conscientious objection in healthcare. For example, Julian Savulescu opines: »If people are not prepared to offer legally permitted, efficient and beneficial care to a patient because it conflicts with their values, they should not be doctors. ${ }^{37}$ However, not only would such a simple take-it-or-leave-it-position be at odds with the right to freedom of conscience; it would also undermine a holistic understanding of human rights in general, as proclaimed in the formula coined by the Vienna World Conference that all human rights are "universal, indivisible and interrelated and interdependent $\ll$.

What worries me more is that even some $\mathrm{UN}$ human rights bodies have at times employed a wording that does not seem to acknowledge the human rights dimension of conscientious objection. When referring to conscientious objection concerning reproductive health care, the Committee on the Elimination of All Forms of Discrimination Against Women (CEDAW) seems to consciously avoid the term »right«. For example, in its concluding observations on Hungary, the CEDAW Committee recommends to the state party:

37 Julian Savulescu, quoted in Winclair (2010), 33. 
»Establish and adequate regulatory framework and a mechanism for monitoring the practice of conscientious objection by health professionals and ensure that conscientious objection is accompanied by information to women about existing alternatives and that it remains a personal decision rather than an institutionalized practice. $\ll^{38}$ [emphasis added, H.B.]

A similar tendency exists in the Committee on Economic, Social and Cultural Rights. In its concluding observations on Poland, the Committee

»calls upon the State party to take all effective measures to ensure that women enjoy their right to sexual and reproductive health, including by [...] implementing a mechanism of timely and systematic referral in the event of conscientious objection. $\ll^{39}$ [emphasis added, H.B.]

In its recently adopted General Comment on the right to sexual and reproductive health, the same Committee points out:

»Where health care providers are allowed to invoke conscientious objection, States must appropriately regulate this practice to ensure that it does not inhibit anyone's access to sexual and reproductive health care, including by requiring referrals to an accessible provider capable of and willing to provide the services being sought, and the performance of services or emergency situations. ${ }^{40}$ [emphasis added, H.B.]

The various formulations just cited merely acknowledge conscientious objection as a reality - i.e. as a »practice«, an »event« to be taken into account or something »allowed « by the state - without clearly appreciating its status as a human right. While the Human Rights Committee, tasked with the monitoring of the ICCPR, does acknowledge the human rights dimension of conscientious objection, it so far has limited its jurisdiction on cases concerning objection to military service.

Anand Grover, former Special Rapporteur on the right to the highest attainable standard of health (2008-2014), went a step farther by acknowl-

$38 \mathrm{CEDAW} / \mathrm{C} / \mathrm{HUN} / \mathrm{CO} / 7-8,26$ March 2013, para. 31(d).

$39 \mathrm{E} / \mathrm{C} .12 / \mathrm{POL} / \mathrm{CO} / 5,2$ December 2009, para. 28.

40 E/C.12/GC/22, 2 May 2016, para. 43. 
edging »legitimate concerns« on both sides. For example, in his mission report on Poland, he pointed out

»that there is a need for decisive action in this regard: such action should reconcile the legitimate concerns of health providers exercising their right to conscientious objection with the legitimate and pressing interests of patients «. ${ }^{41}$ [emphasis added, H.B.]

Unlike the CEDAW Committee and the Committee on Economic, Social and Cultural Rights, the former Rapporteur on the right to health remarkably used the language of »right« when referring to conscientious objection. Some years ago, the former E.U. Network of Independent Experts on Fundamental Rights likewise used the term »right« when requesting member states to issue clear and comprehensive legislative regulations in order to reconcile the various human rights at issue in healthcare. The Experts postulated:

»Such a regulation should thus accommodate the right to religious conscientious objection, which is derived from the freedom of religion, while ensuring that the exercise of this right will not lead to others either being deprived of access to certain services in principle available to all in the State concerned, or being treated in a discriminatory fashion. ${ }^{42}$

According to the Experts of the Network, what remains to be done is the tiresome business of searching for adequate solutions in view of all the human rights at issue. With specific regard to reproductive health Christina Zampa and Ximena Andión-Ibanez, too, see a lot of work ahead in Europe: »The law and practice in European countries is peppered with differences, indicating a great need to develop comprehensive standards in this area. ${ }^{43}$ The two authors refer to Norway as a positive example demonstrating that

41 A/HRC/14/20/Add.3, 20 May 2010, para. 55.

42 E.U. Network of Independent Experts on Fundamental Rights (2005), 20.

43 Zampa/Andión-Ibanez (2012), 232. 
viable solutions, including systematic oversight with a view to guaranteeing transparent and efficient referral, can successfully be elaborated. ${ }^{44}$

Admittedly, conscientious objection in the medical sector is a thorny issue and can lead to numerous complications, especially in morally pluralistic societies. Simplistic slogans cannot do justice to the various human rights at stake in this area. Whereas I have so far argued from the specific angle of freedom of thought, conscience, religion or belief, I would like to conclude by claiming that respect for the right to conscientious objection may also strengthen the human rights nature of the right to health. Like other human rights, the right to health facilitates and shapes human interaction. While obviously strengthening the position of patients, the right to health also presupposes responsible agency on the side of doctors and nurses. This responsibility, however, is never only a professional one; it is at the same time a moral one, deriving from moral concerns, positions and ultimately convictions. Healthcare is not a service we would like to delegate to robots without moral convictions. Thus, the right to health would cease to make sense without recognizing that all those interacting in healthcare are human beings who deserve respect for their moral convictions - even at the price of complications that may arise from such respect.

\section{REFERENCES}

Astra Network (2011): »CEE Bulletin on Sexual and Reproductive Rights, No 06 (97) 2011«, Online: http://www.astra.org.pl/pdf/bulletin/biuletyn 97.pdf [11.07.2016].

Bielefeldt, Heiner (2011): Auslaufmodell Menschenwürde? Warum sie in Frage steht und warum wie sie verteidigen müssen, Freiburg: Herder.

Bielefeldt, Heiner (2016): »Conscientious Objection in Healthcare«, in: Frewer et al. (2016b), 319-342.

44 See Zampa/Andión-Ibanez (2012), 247: »Norway is one of the few countries in Europe with a comprehensive regulatory and oversight framework on conscientious objection to abortion that includes ensuring the availability of providers willing and able to perform abortions.« 
Bielefeldt, Heiner/Ghanea, Nazila/Wiener, Michael (2016): Freedom of Religion or Belief. An International Law Commentary, Oxford: Oxford University Press.

E.U. Network of Independent Experts on Fundamental Rights (2005): »The Right to Conscientious Objection and the Conclusion by EU Member States of Concordats with the Holy See«, Ref. CRF-CDR Opinion No. 4-2005L, 14 December 2005.

Frewer, Andreas/Bielefeldt, Heiner (Eds.) (2016a): Das Menschenrecht auf Gesundheit. Normative Grundlagen und aktuelle Diskurse, Bielefeld: transcript.

Frewer, Andreas/Bergemann, Lutz/Jäger, Christian (Eds.) (2016b): Interessen und Gewissen. Moralische Zielkonflikte in der Medizin, Würzburg: Könighausen \& Neumann, 2016.

Kant, Immanuel (1996): Critique of Practical Reason, Cambridge: Cambridge University Press.

Krennerich, Michael (2016): »Das Menschenrecht auf Gesundheit. Grundzüge eines komplexen Rechts«, in: Frewer/Bielefeldt (2016), 57-92.

Maclure, Jocelyn/ Taylor, Charles (2011): Secularism and Freedom of Conscience, Cambridge/Mass.: Harvard University Press.

Morsink, Johannes (2009): Inherent Human Rights: Philosophical Roots of the Universal Declaration, Pennsylvania: University of Pennsylvania Press.

Mishra, Anil Dutta/Gupta, Ravi (2008): Inspiring Thoughts of Mahatma Gandhi. Gandhi in Daily Life, Delhi: Concept.

Plato (2002): Five Dialogues: Eutyprho, Apology, Crito, Meno, Phaedo, revised by Cooper, John M., Indianapolis: Hackett.

Puppinck, Grégor (2017): »Conscientious Objection and Human Rights: A Systematic Analysis«, in: Brill Research Perspectives in Law and Religion 1, 1 (2017), 1-75.

Thorau, Henry David (2003): Civil Disobedience, Rockford: Presa Press.

Winclair, Mark R. (2010): Conscientious Objection in Heath Care, Cambridge: Cambridge University Press.

Zampa, Christina/Andión-Ibanez, Ximena (2012): »Conscientious Objection to Sexual and Reproductive Health Services. International Human Rights Standards and European Law and Practice«, in: European Journal of Health Law 19 (2012), 231-256. 


\title{
The Implications of the Right to Health for Border Management
}

\author{
Emergency Assistance and Medical Screenings \\ in the Context of Forced Migration
}

Veronika Flegar, MARIE-Nö̈Lle Veys

\section{INTRODUCTION}

Currently, about 300 land borders and numerous sea borders divide states worldwide from one another. ${ }^{1}$ These borders are not necessarily permanent as a changing domestic, regional or global political climate can lead to borders which are softer (e.g. the internal borders of the EU) or harder (e.g. the border between Mexico and the United States). In all circumstances, however, these borders are governed by national legislation aiming to construct »the limits of nationality, citizenship and identity « as well as by international human rights law which aims to curtail the power of this inherently exclusionary character of borders. ${ }^{2}$

In this context, border management has gained increased attention throughout the last years, not lastly because of the war in Syria and the high number of people seeking asylum in Europe. ${ }^{3}$ People want to cross borders,

1 Paasi (2010), 13.

2 Ibid., 13-16.

3 For the purpose of this study, border management is understood broadly, including not only the physical border context but also border procedures which might 
even if there is no legal way to do so. This is not only taking place in the context of war or violent conflict. Rather, individuals might also be trafficked, flee persecution or try to escape environmental hazards, poverty or other life-threatening conditions. It is these irregular and mass migratory movements and their management at the border which the present study is concerned with. ${ }^{4}$ For the purpose of this study, these movements are referred to as forced migration. ${ }^{5}$

Previous authors have argued that border management traditionally focused almost exclusively on security concerns. ${ }^{6}$ However, calls for humanitarian border management are increasing, especially in light of the number of persons who fall within the scope of the abovementioned forced migration context. ${ }^{7}$ Humanitarian border management aims to »ensure that humanitarian principles and accepted international legal standards are increasingly applied by the security sector at times of migration crisis. ${ }^{8}$ This chapter argues that the right to health can and must play a prominent role in this respect. Whether and how the right to health can contribute to clarify-

already take place within the borders of a state (such as in transit zones, registration centres or immigration detention).

4 Hence, the present study does not deal with nationals of a particular state who are crossing the border to return to their own country and whether the state has similar obligations in that respect. The current study is dealing only with the rights and obligations with regard to non-citizens.

5 The boundaries and exact definition of forced migration is still issue to academic debate. See e.g. Fiddian-Qasmiyeh et al. (2014), 5-6.

6 Paasi (2010), 13; Pottler (2014).

7 Border management is understood in line with the International Organization for Migration (IOM) guidelines on health and humanitarian border management to include four different pillars. The present study will focus particularly on the third pillar (the enhanced capacity of health systems and border management services), especially with regard to the points >Health Screening and Referral System $<$ and >Health Management and Public Health Response ‘. cf. IOM (2016), 5.

8 Pottler (2014). Although not further explained in the quote cited, humanitarian principles in the context of this paper are understood as human rights principles, i.e. the rights and obligations derived from international human rights law treaties. 
ing the individual rights of and state obligations towards forced migrants in order to contribute to humanitarian border management is investigated through outlining the scope of two different aspects of the right to health: first, the rights and obligations with regard to medical care and emergency assistance and second, the rights and obligations with regard to medical screenings. Based on this analysis, the chapter discusses the added value of the right to health: does it indeed have to be viewed as an »empty promise« in the context of border management or does it provide valuable guidance, for instance, as a moral concept, as an advocacy framework and evaluation tool and/or as a legal principle? ${ }^{9}$

In answering this question, Dembour's distinction between four different schools of thought in the field of human rights serves as a valuable guideline. She identifies a natural school, a deliberative school, a protest school and a discourse school of human rights. ${ }^{10}$ When simplifying Dembour's distinction into concrete purposes of human rights, it seems like the natural school sees human rights primarily as moral concept, the deliberative school sees them primarily as legal principles, the protest school sees them essentially as advocacy tools and the discourse school dismisses human rights altogether. ${ }^{11}$ As is outlined in more detail in the discussion section of this chapter, the present study most closely identifies with the protest school in finding the added value of the right to health primarily in the field of advocacy.

In light of this framework and based on an analysis of the right to health at the border, the present study thus aims to highlight two contentious points in which the right to health of the International Covenant on Economic, Social and Cultural Rights (ICESCR) plays a prominent and clarifying role. In so doing, the study hopes to show the limitations and potential of the right to health for clarifying individual rights and state obligations at the border. The aim of this chapter is not to build a comprehensive legal framework on health and border management but to point into two relevant directions which can serve as possible starting points for future inquiries.

The chapter is structured as follows: It starts by clarifying the selection, interpretation and relevance of the applicable legal framework. The chapter

9 Flegar et al. (2016), 17.

10 Dembour (2010), 11.

11 Compare Dembour (2010); Flegar et al. (2016). 
then provides an analysis of the individual rights and state obligations with regard to medical care and emergency assistance before, subsequently, scrutinizing the individual rights and state obligations for medical screenings at the border. Lastly, the chapter discusses the findings in light of whether the right to health should be seen as an empty promise or not.

\section{Selection, InTERPRETAtion AND ReleVANCE OF THE APPLICABLE LEGAL FRAMEWORK}

The chapter is based on desk research conducted in the period of March until June 2016. It provides a textual analysis of legal sources recognized under Article 38 of the Statute of the International Court of Justice. As such, the documents outlined below are international human rights law treaties as well as supplementary, non-binding but authoritative, General Comments and General Recommendations issued by the treaty bodies monitoring the implementation of these international human rights law treaties. ${ }^{12}$ The primary focus remains the right to health enshrined in Article 12 of the International Covenant on Economic, Social and Cultural Rights (ICESCR) as the most authoritative and widely applicable source. This selection is not necessarily complete but aims to highlight some articles and interpretations which might be of particular relevance in the border context. The traditional doctrinal analysis of these documents is supplemented by a more normative discussion at the end of this chapter.

12 The study does not include the Convention Relating to the Status of Refugees as this treaty is primarily relevant for already recognized refugees. In the context of border management, however, the type of persons which fall within the scope of border management measures is much broader and includes many persons who are not protected under that convention. The study therefore focuses on the human rights treaties which are applicable to all persons, regardless of their migration status. 


\subsection{Territorial Scope}

Currently, there exists no clear legal framework that explicitly governs health rights in the border context. Nevertheless, international treaties such as the International Covenant on Economic, Social and Cultural Rights (ICESCR) and the Convention on the Rights of the Child (CRC) can be considered to also explicitly apply at the border through holding that the rights entailed in the treaty apply within the state party's jurisdiction. ${ }^{13}$ In line with the object and purpose of these treaties, it can be concluded that the border domain falls within the jurisdiction of a state. As such, the rights and obligations of these treaties apply.

Other treaties, such as the International Convention on the Elimination of Racial Discrimination (ICERD), the Convention on the Elimination of Discrimination Against Women (CEDAW) and the Convention on the Rights of Persons with Disabilities (CRPD) do not contain a specific territorial limitation. However, Articles 3, 6 and 14 of the ICERD explicitly refer to the scope of their application as within the jurisdiction of a state party and Article 4(5) CRPD holds that it shall extend to all parts of federal states without any limitations or exceptions«. Moreover, General Recommendation No. 28 on the CEDAW core obligations highlights the fact that the convention applies to "women within the jurisdiction of the state party (including non-citizen, migrant, refugee, asylum-seeking, and stateless women) $\aleph^{14}$ and CEDAW General Recommendation No. 32 explicitly asserts that the responsibilities of states towards »women during displacement« does not only comprise »women within their territory« but also »under their effective control or jurisdiction, even if not situated within their territory. ${ }^{15}$

Only the International Convention on the Rights of All Migrant Workers and Their Families (ICMWF) is explicit on the border context in stating in Article 1(2) that the convention applies

13 Compare e.g. E/C.12/2000/4, 11 August 2000, paras. 12 and 51; Article 2(1) CRC.

14 CEDAW/C/GC/28, 16 December 2010, para. 26.

15 CEDAW/C/GC/32, 14 November 2014, para. 7. See also CEDAW/C/2009/ WP.1/R, 15 December 2008, para. 3 which refers to responsibilities during the full $»$ migration cycle $\ll$. 
»during the entire migration process of migrant workers and members of their families, which comprises preparation for migration, departure, transit and the entire period of stay and remunerated activity in the State of employment as well as return to the State of origin or the State of habitual residence.«

However, it must be noted that, while all other treaties are widely accepted and ratified by a large number of states, this convention has only been ratified by migrant sending rather than by migrant receiving states and by only a small number of 50 state parties. ${ }^{16}$

\subsection{Personal Scope}

International human rights law must be considered to apply without discrimination and the personal scope in most treaties is clear in that respect. ${ }^{17}$ Yet, as regards the personal scope of the international human rights law treaties discussed below, it should be noted that not all treaties explicitly refer to non-citizens or to persons in the context of forced migration.

The personal scope of the International Convention on the Rights of All Migrant Workers and Their Families (ICMWF) needs particular clarification: Article 3 holds that the convention does not apply to refugees or stateless persons. However, this cannot be interpreted to mean that they are entitled to a lesser standard than the rest of persons covered by the convention as it is simply a different regime under which their rights are protected. Moreover, while the term »migrant workers « suggests that the convention does not apply to all border crossers, the treaty's scope is, nevertheless, broad and, as Ryan and Mantouvalou assert, the fact that it covers everyone "who is to be engaged, is engaged or has been engaged in a remunerated activity« as well as »both employees and the self-employed « and »immediate family members« suggests that this convention closely resembles a treaty which is concerned with the rights of all migrants. ${ }^{18}$

16 UN Treaty Collection (2016).

17 Compare Article 2 ICESCR, Article 2 CRC, Articles 1 and 2 CEDAW, Article 1 CERD and Article 1 CRPD.

18 Ryan/Mantouvalou (2014), 186. 


\subsection{Other Considerations}

Like most human rights, the right to health can be limited in certain circumstances and, being an economic, social and cultural right, is subject to progressive realization: Article 2(1) of the International Covenant on Economic, Social and Cultural Rights (ICESCR) allows states to realize "progressively« the rights and obligations entailed in the convention and »to take steps $[\ldots]$ to the maximum of its available resources«. It is this progressive realization which makes economic, social and cultural rights controversial and which allows states a large margin of appreciation when not complying with the convention. In addition, General Comment No. 14 of the ICESCR's treaty body, the Committee on Economic Social and Cultural Rights, allows for limitations of the right to health if these measures are »strictly necessary for the promotion of the general welfare in a democratic society «. ${ }^{19}$ While most other international human rights law treaties discussed below are less explicit on these issues, the convention is commonly considered the most authoritative standard and therefore also influences the interpretation of these other treaties. These two mentioned provisions which severely limit the applicability of the right to health thus indeed raise the question of whether the right to health is merely an empty promise. The following therefore analyses two aspects of the right to health at the border, first the requirements regarding medical care and emergency assistance and, subsequently, the requirements regarding medical screenings.

\section{Medical Care and Emergency Assistance AT THE BORDER}

States usually grant emergency medical care as the very least requirement to everyone. ${ }^{20}$ However, the term which is used and the scope of what exactly falls within any such definition vary between countries and are still debated. Moreover, the extent to which this treatment also requires any emergency assistance other than medical care is still controversial.

19 E/C.12/2000/4, 11 August 2000, para. 28; Flegar (2015), 92.

20 Compare Spencer/Hughes (2015). 
Previous research has outlined the rights and obligations under the right to health with regard to providing medical assistance to undocumented migrants. ${ }^{21}$ Based on these studies it becomes evident that a number of international treaties and subsidiary documents require the provision of at least some sort of medical care to all persons and in all circumstances. It seems that at least some of these rights and obligations should also apply at the border. However, the exact extent and content of these rights and obligations under the right to health, particularly with regard to what medical care and emergency assistance should be provided at the very least, is less clearly defined.

The following therefore asks: To what extent is the provision of medical care and emergency assistance at the border a State obligation under the right to health? Does the right to health clarify the exact content of what should be provided? This section outlines the relevant provisions and tries to identify a minimum level of medical care and emergency assistance which States should provide at the border in order to abide by their human rights obligations. It starts with the most relevant and ends with the least relevant international human rights law treaty in this context.

\subsection{International Covenant on Economic, Social and Cultural Rights}

The provision of medical care and emergency assistance is most prominently required in Article 12 of the International Covenant on Economic, Social and Cultural Rights (ICESCR) and the relevant General Comment which outlines the concrete rights and obligations under the right to health.

Article 12 holds $/$ the right of everyone to the enjoyment of the highest attainable standard of physical and mental health «. Based on this general provision, the article is instructive for further outlining the rights and obligations on the provision of medical care in the border context: States must create $»$ conditions which would assure to all medical service and medical attention in the event of sickness «. ${ }^{22}$ However, the extent to which this also refers to the border context and the exact scope of this medical service and attention can only be clarified by looking at the relevant General Comment.

21 Compare Biswas et al. (2012); Flegar (2015).

22 Article 12(2)(d) ICESCR. 
»States are under the obligation to respect the right to health by, inter alia, refraining from denying or limiting equal access for all persons, including prisoners or detainees, minorities, asylum-seekers and illegal immigrants, to preventive, curative and palliative health services. « $^{23}$

This provision suggests that everyone at the border should be granted full access to medical care and that health services should not be limited to only providing emergency treatment. However, it is unlikely that states would recognize such a broad obligation at the border in the near future as these rights are not even granted to persons who have already crossed the border and are clearly on the state territory. ${ }^{24}$ It is therefore valuable to consider what states would have to provide as a very minimum standard. The so-labelled core obligations under the right to health can be insightful in that regard.

The core obligations of the right to health which must be ensured »at the very least « comprise the duty to provide »essential primary healthcare ${ }^{25}{ }^{25}$ This seems to suggest that states thus have an obligation to provide more than just emergency medical care and rather have to provide essential primary healthcare at the border. Primary healthcare is defined in a footnote as »typically« concerning »common and relatively minor illnesses and is provided by health professionals and/or generally trained doctors working within the community at relatively low cost $\ll .{ }^{26}$ However, the fact that this definition is only mentioned in a footnote and the fact that it involves the term »typically« suggests that not too much weight should be placed on this definition and that other definitions are also possible and potentially within the scope and meaning. No clear definition of essential primary care is included in the main text. In addition to the obligation of states to provide essential primary healthcare, the core obligations also require states to provide emergency assistance, which comprises the $\gg$ right of access to health facilities, goods and services « as well as a right to food, shelter and essential drugs. ${ }^{27}$ While more clarity on the exact content of these

23 E/C.12/2000/4, 11 August 2000, para. 34.

24 Compare Flegar et al. (2016).

25 E/C.12/2000/4, 11 August 2000, para. 43.

26 Ibid., footnote 9.

27 Ibid., para. 43. 
provisions would have been desirable, it must nevertheless be noted that these are far-reaching and innovative core obligations that should not go unnoticed in the border context.

Moving beyond the core obligations, General Comment further clarifies the state obligations with regard to the provision of emergency assistance as having sto cooperate in providing disaster relief and humanitarian assistance in times of emergency, including assistance to refugees and internally displaced persons«. This suggests that states have to cooperate on both sides of the border in order to ensure the right to health of border crossers is not violated. Moreover, it holds that »each State should contribute to this task to the maximum of its capacities «. In addition, states should give priority to persons in vulnerable situations in the provision of $»$ safe and potable water, food and medical supplies, and financial aid «. Although the phrase "to the maximum of its capacities " is always open to interpretation, the responsibility of states to provide emergency assistance at the border is clearly established and especially outspoken with regard to the prioritization of persons in vulnerable situations. ${ }^{28}$

Summing up, the General Comment is very clear on the state obligations under the right to health at the border. States should provide at the very least essential primary healthcare rather than only emergency medical care and, as regards emergency assistance, states must provide food, shelter and essential drugs. When considering the right to health beyond the core obligations, states should provide access to preventive, curative and palliative health services and, in the provision of emergency assistance, persons in vulnerable situations should be prioritized. While the content of emergency assistance seems to be rather clear the relevant General Comment as comprising the provision of healthcare, food, shelter and essential drugs, the exact content of essential primary healthcare is left undefined in the main text of the convention.

\subsection{Convention on the Rights of the Child}

For children, the rights and obligations with regard to health at the border are similar but more extensive than Article 12 of the International Covenant on Economic, Social and Cultural Rights (ICESCR). The Convention on

28 E/C.12/2000/4, 11 August 2000, para. 40. 
the Rights of the Child (CRC) itself is already a lot more specific on the exact content of the right to health of children. Similar to Article 12 ICESCR, Article 24 CRC holds »the right of the child to the enjoyment of the highest attainable standard of health«. Moreover, according to the same article, states »shall pursue full implementation « (which suggests progressive realization) in the fields of infant and child mortality, primary healthcare, disease and malnutrition, health education and preventive healthcare. Additionally, Article $22 \mathrm{CRC}$ is particularly relevant for the border context as it contains specific provisions on asylum-seeking and refugee children. Accordingly, states

»shall take appropriate measures to ensure that a child who is seeking refugee status or who is considered a refugee in accordance with applicable international or domestic law and procedures shall, whether unaccompanied or accompanied by his or her parents or by any other person, receive appropriate protection and humanitarian assistance in the enjoyment of applicable rights«

of international human rights law. Hence, as part of this emergency assistance, states are obliged to help with family tracing for unaccompanied minors and to afford them the same assistance as national children without family.

The relevant General Comment further clarifies the right to health in the border context in stating that, as a core obligation, states must ensure »universal coverage of quality primary health services, including prevention, health promotion, care and treatment services, and essential drugs «, provide "an adequate response to the underlying determinants of children's health « and adopt a »human rights-based approach to fulfilling children's right to health ${ }^{29}{ }^{29}$ As a core minimum, this goes much further than the essential primary healthcare criterion of the core obligations under the ICESCR. Hence, for children, states have even broader obligations that stretch much further than only providing emergency medical care at the border.

Regarding emergency assistance, the General Comment is clear in holding that states must also cooperate internationally to ensure the global implementation of the right to health. Hence, also at the border, states on both sides must collaborate in providing the necessary medical care and emer-

$29 \mathrm{CRC} / \mathrm{C} / \mathrm{GC} / 15,17$ April 2013, para. 73. 
gency assistance. ${ }^{30}$ The General Comment of the Committee on the Rights of the Child is very similar to General Comment No. 14 of the Committee of Economic, Social and Cultural Rights in clarifying that states must »cooperate in providing disaster relief and humanitarian assistance in times of emergency « and must pay particular attention to persons in vulnerable situations when distributing medical aid and supplies, food, water and shelter. ${ }^{31}$ These provisions are of a similar scope and content as the emergency assistance provisions under the ICESCR.

Overall, the CRC contains much broader provisions regarding the medical care that should be provided to children at all times and therefore also at the border. This contains not only a responsibility for the provision of essential primary healthcare but also, among other aspects, an obligation to address the underlying determinants of health. Regarding the provision of emergency assistance, however, the convention does not go beyond the rights and obligations entailed in the ICESCR.

\subsection{Convention on the Elimination of Discrimination Against Women}

The Convention on the Elimination of Discrimination Against Women (CEDAW) does not refer to anything border- or migration-related in its treaty. Nevertheless, the right to health is defined in Article 12 and a General Recommendation further clarifies a few aspects that are relevant for the border context. As such, it becomes clear that states have an obligation to pay special attention to the health needs of migrant and refugee women. ${ }^{32}$ Moreover, states

»should ensure that adequate protection and health services, including trauma treatment and counselling, are provided for women in especially difficult circumstances, such as those trapped in situations of armed conflict and women refugees. $\ll^{33}$

30 CRC/C/GC/15, 17 April 2013, para. 86.

31 Ibid., para. 88.

32 A/54/38/Rev. 1, chap. 1, 1999, para. 6.

33 Ibid., para. 16. 
No specific mention is made of emergency assistance except for the need to provide »emergency obstetric services «. ${ }^{34}$ However, this refers to an individual emergency situation rather than to an external situation of humanitarian distress. Generally, states »should ensure that the special nutritional needs of all women within their jurisdiction are met«, which suggests that more than only medical care must be provided at the border. ${ }^{35}$

The General Recommendation does not define any core obligations. ${ }^{36}$ Nevertheless, it can be concluded that it reinforces the right to health of women at the border. This General Recommendation should be read as supplementing the right to health under Article 12 of the International Covenant on Economic, Social and Cultural Rights (ICESCR) and as simply specifying some aspects that are of particular relevance to women. Although clearer definitions on the content are lacking, the document thus suggests that women in transit have a right to health beyond only essential primary healthcare which, instead, also includes psychological support and adequate nutrition.

Summing up, this convention thus moves beyond the ICESCR in emphasizing the obligation to provide psychological support and adequate nutrition to women in transit. However, in clarifying any more specific state obligations at the border with regard to medical care and emergency assistance, the convention is not very insightful.

\subsection{International Convention on the Rights of All Migrant Workers and Their Families}

Article 28 of the International Convention on the Rights of All Migrant Workers and Their Families (ICMWF) is particularly relevant when defining the right to health at the border as it refers to migrants in particular. However, unlike the Convention on the Rights of the Child (CRC) and the Convention on the Elimination of Discrimination Against Women (CEDAW), it limits the essential primary healthcare standard of the Inter-

34 A/54/38/Rev. 1, chap. 1, 1999, para. 27.

35 Ibid., para. 7.

36 Rather, General Recommendation No. 24 talks about key elements. However, these cannot be compared to core obligations as basically anything in this General Recommendation is part of the key elements. 
national Covenant on Economic, Social and Cultural Rights (ICESCR) to something even more narrowly defined:

»Migrant workers and members of their families shall have the right to receive any medical care that is urgently required for the preservation of their life or the avoidance of irreparable harm to their health on the basis of equality of treatment with nationals of the State concerned. Such emergency medical care shall not be refused to them by reason of any irregularity with regard to stay or employment. « ${ }^{37}$

This is the first and only clear definition of emergency medical care which everyone is entitled to. According to this article, border crossers explicitly have this right to emergency medical care where it is »urgently required for the preservation of their life or the avoidance of irreparable harm«. Although this is the clearest standard so far, one can still ask what the exact definition and content of this phrase is as regards, for instance, the meaning of urgency or irreparable harm.

The Committee on Migrant Workers' General Comment No. 2 is also clear on the fact that access to health services should under no circumstances be used as an instrument of immigration control. ${ }^{38}$ It clarifies that, in circumstances of extreme poverty and vulnerability, emergency assistance should be provided to irregular migrant workers and their families but any further definition or reference to emergency assistance in the context of immigration control, i.e. at the border, is lacking. ${ }^{39}$ However, this General Comment emphasizes that the provision of any medical care does not have to be free of charge but exemption rules should apply to migrants in the same way as they would apply for nationals and excessive fees or requesting proof of payment before the service is delivered should be prohibited. It is surprising that the convention as the treaty for migrant rights provides a more limited definition of the healthcare that should be provided to everyone than other international human rights law had already established. In this respect, it should be noted that this General Comment clarifies that Article 28 is not to be understood narrowly but that, read in combination with other international human rights law instruments, broader obligations

37 Article 28 ICMWF.

$38 \mathrm{CMW} / \mathrm{C} / \mathrm{GC} / 2,23$ August 2013, para. 74.

39 Ibid., para. 71. 
are created. ${ }^{40}$ It then repeats the abovementioned state obligations under the ICESCR and CRC. Similar to the CEDAW, the convention or its General Comment do not define any core obligations.

Overall, the ICMWF is insightful in providing a clear definition of urgent medical care. However, any further clarification as regards medical care or emergency assistance at the border is lacking. It must be emphasized that the convention must not be read to limit any state obligations already entailed in other treaties but it is worrying that the convention at first glance provides a different and therefore rather confusing standard. This confusion is further enhanced by the distinction of non-citizens into different groups which are suggested to have different rights. ${ }^{41}$ This clearly contradicts the universality argument commonly implied in all other international human rights law treaties.

\subsection{Convention on the Elimination of Racial Discrimination}

The Convention on the Elimination of Racial Discrimination (CERD) does not mention anything border- or migration-related in the treaty itself but the relevant General Recommendation highlights the obligation of states to srespect the right of non-citizens to an adequate standard of physical and mental health by, inter alia, refraining from denying or limiting their access to preventive, curative and palliative health services $«$. ${ }^{42}$ As this entails a general reference to all non-citizens, it must be assumed that residence status plays no role here and that this obligation therefore also applies at the border.

Furthermore, although no reference is made to emergency assistance, states should »remove obstacles that prevent the enjoyment of economic, social and cultural rights by non-citizens « in the fields such as housing, education and employment. ${ }^{43}$ However, »removing obstacles« does not seem

$40 \mathrm{CMW} / \mathrm{C} / \mathrm{GC} / 2,23$ August 2013, para. 72.

41 As outlined above, the ICMWF excludes refugees, distinguishes between undocumented and documented migrants and further limits the scope due to primarily talking about migrant workers.

42 A/59/18, 2004, 23 February - 12 March 2004, para. 36.

43 Ibid., para. 29. 
to require the active provision of these rights to non-citizens, which leaves this provision as a rather weak and insufficiently defined right. No further core obligations are defined and no reference is made to medical care or emergency assistance in a more profound manner.

It can thus be concluded that the convention neither clarifies nor contradicts the ICESCR provisions regarding rights and obligations in the field of medical care and emergency assistance at the border in any meaningful way.

\subsection{Convention on the Rights of Persons with Disabilities}

The Convention on the Rights of Persons with Disabilities (CRPD) does not mention migrants, asylum seekers, refugees or any other non-citizens in its treaty or General Comments. Nevertheless, Article 11 refers to the obligations of states for persons in humanitarian emergencies which seems to imply a certain responsibility at least towards asylum seekers and refugees. Moreover, as the scope of the convention extends to all persons with disabilities, Article 25 is relevant in clarifying the scope of the right to health for citizens as well as non-citizens with disabilities as having to be at least of the same level as for all other persons - regardless of whether that person is at the border or within the territory of a state. However, no specific mention is made of a minimum standard of medical care or emergency assistance that should be provided.

\subsection{Concluding Remarks}

The above analysis revealed that none of the international human rights law treaties relevant for the right to health explicitly allow for any differential treatment at the border as compared to within a state. Additionally, it is clear that one does not have to be on the territory of a state for any particular amount of time before the obligations under international human rights law apply.

Moreover, the International Covenant on Economic, Social and Cultural Rights (ICESCR) seems to still offer the clearest standard on what minimum level of medical care and emergency assistance should be provided at the border. Accordingly, medical care should be understood as essential primary healthcare and emergency assistance as medical care, food, shelter 
and access to essential drugs. It is clear that the obligation to provide emergency assistance extends beyond the own border so even on the territory between two states both states would be responsible for providing emergency assistance. However, the exact content of the medical care and emergency assistance which should be provided remains unclear. The International Convention on the Rights of All Migrant Workers and Their Families (ICMWF) suggests a definition for urgent medical care, which is any care that is »urgently required for the preservation of their life or the avoidance of irreparable harm«. Yet, it must be emphasized that this approach seems more limited than the provision of essential primary healthcare and cannot be considered to overrule the ICESCR's approach. More extensive rights seem to apply for persons in vulnerable situations - a finding which is also supported by the provisions in the Convention on the Rights of the Child (CRC) and the Convention on the Elimination of Discrimination Against Women (CEDAW).

Despite the diverging standards it is clear that, while progressive realization and derogation might be applicable with regard to more specific treatment at the international level, nothing allows states to not grant any medical care or emergency assistance at the border. It is an established international standard that, as a core minimum, all persons must have access to essential primary healthcare. However, as its content is not further defined, this is left to the discretion of individual states which might harm the enjoyment of the right to health. Clear rules and legal certainty are essential for effective human rights implementation, monitoring and protection. No matter whether rights are seen as legal standards, advocacy tools or moral claims, clarity on the content of the rights and obligations at the border as regards medical care and emergency assistance is favourable to all three purposes of human rights. In order to ensure that the right to health is not an empty promise, it is therefore crucial to clearly define the applicable standard and to give coherent content and meaning to the concepts which are propagated.

Overall, the above section showed how the right to health does help to clarify the rights and obligations in terms of medical care and emergency assistance at the border. At the same time, it revealed that clear definitions and a coherent approach across the different treaties at the international and regional level could contribute to limit any existing allegations about the empty promise of the right to health. 


\section{Medical Screenings at the Border}

Medical screenings include tests, examinations, or other procedures which can be applied rapidly in order to identify persons likely to have a disease. A screening test is not intended to be diagnostic. ${ }^{44}$ Border screenings, together with isolation and quarantine measures, are implemented to delay or prevent the entry of infected persons to a country or a geographic area or to prevent the global spread of a disease from a source country. ${ }^{45}$ In addition to border screenings, medical screenings can be imposed pre-departure (e.g. for a work or residence permit) and upon stay in the host country (e.g. for a change of visa status). Post-arrival screenings are also undertaken for refugees, humanitarian entrants and undocumented migrants. ${ }^{46}$ The diseases screened for are mainly communicable diseases with a public relevance, such as tuberculosis, but also HIV/AIDS. ${ }^{47}$

Border screenings are a complex matter: not only do infectious diseases affect the public health, but the right to health of migrants is equally at stake when they have to undergo a screening for these diseases. The following section therefore focuses on the individual rights and state obligations under the right to health with regard to medical screenings at the border: To what extent are medical screenings upon entering a country a state obligation under the right to health? Does the right to health clarify the conditions for applying them? Based on international human rights law treaties and subsidiary documents, this section tries to delineate the state obligations under the right to health with regard to migration-related medical screenings. This is done on the basis of the traditional understanding of medical screening of migrants as measures aimed at protecting the host population. The main focus is thus on infectious disease control upon arrival at the border rather than on any other types of screening, such as, for instance, psy-

44 Porta (2014), 275.

45 Selvey et al. (2015), 197.

46 WHO et al. (2013), 33; Wickramage/Mosca (2014), 9955.

47 For example, some EU countries screen migrants before, at or after entry for tuberculosis: van der Werf/Zellweger (2016), 2. According to UNAIDS some 35 countries, territories and areas impose some form of restriction on the entry, stay and residence of people with HIV based on their HIV status: UNAIDS (2015). 
chological screenings. When deemed relevant for humanitarian border management, other health assessments are included in the overview as some international human rights law treaties adopt a broader understanding of medical screenings. However, the denial to enter a country for the protection of public health goes beyond the scope of this analysis.

\subsection{International Covenant on Economic, Social and Cultural Rights}

No explicit reference is made to medical screenings under the right to health in the International Covenant on Economic, Social and Cultural Rights (ICESCR). However, Article 12(2)(c) obliges states, in order to achieve the full realization of the right to health, to take steps $»$ for the prevention, treatment and control of epidemic, endemic, occupational and other diseases $«$.

The relevant General Comment provides further clarification as to how the »control of diseases « has to be understood, namely as »States' individual and joint efforts« which include, but are not limited to,

»making available relevant technologies, using and improving epidemiological surveillance and data collection on a disaggregated basis, implementing or enhancing of immunization programmes and other strategies of infectious disease control. ${ }^{48}$

It can be assumed that medical screenings are included in the term »other strategies of infectious disease control«. In this regard, it should be noted that the General Comment focuses on »infectious« disease control, whereas the wording in the convention is broader and also includes control measures for non-communicable diseases. ${ }^{49}$

While not all obligations under the right to health are of immediate effect or enforceable, the Committee on Economic, Social and Cultural Rights refers to the obligation »to take measures to prevent, treat and control epidemic and endemic diseases « as an obligation of »comparable prior-

48 E/C.12/2000/4, 11 August 2000, para. 16.

49 An infectious disease is "a disease due to an infectious agent. While some infectious diseases are contagious, others are noncontagious. All infections and infestations are communicable [Syn: transmissible] diseases.« Porta (2014), 148. 
ity to the core obligations. ${ }^{50}$ Furthermore, it calls not only for individual, but also for »joint efforts «, which is further explained as collective responsibility of the international community to address the spread of transmissible diseases. ${ }^{51}$ This extends State obligations to the control of infectious diseases beyond their borders.

In addition to providing at least this minimum of necessary measures at the border, states also have to respect the right to free and informed consent of border crossers when imposing medical screenings. ${ }^{52}$ As such, the General Comment states that $\gg$ the right to control one's health and body, $[\ldots]$ the right to be free from interference, such as the right to be free from [...] non-consensual medical treatment « and the right to privacy and information are integral components of the right to health. ${ }^{53}$ Yet, this does not automatically mean that states cannot screen someone who is crossing a border and refuses to give his free and informed consent to a medical screening for an infectious disease: Article 4 of the convention only allows for limitations "for the purpose of general welfare«. Accordingly, restrictions for public health reasons must be legitimate, in the interest of »legitimate aims « and strictly necessary for the general welfare. ${ }^{54}$ In addition, Article 5(1) requires that the limitation is "proportional«, this means that the least restrictive alternative must be adopted and they should be of limited duration and subject to review. ${ }^{55}$ General Comment No. 14 further clarifies that coercive treatment for the prevention and control of communicable diseases is allowed »on an exceptional basis «. ${ }^{56}$ Nevertheless, this is no general permission as such exceptional coercive treatment should be »subject to specific and restrictive conditions, respecting best practices and applicable international standards $\ll{ }^{57}$

In this context, it is also worth pointing out that, even where other screenings might be allowed without consent, General Comment No. 22 is

50 E/C.12/2000/4, 11 August 2000, para. 44.

51 Ibid., paras. 16 and 40.

52 Henrard (2008), 169.

53 E/C.12/2000/4, 11 August 2000, paras. 3 and 8.

54 Ibid., para. 28.

55 Ibid., para. 29.

56 Ibid., para. 34.

57 Ibid. 
clear on prohibiting any »mandatory HIV/AIDS, virginity or pregnancy testing $«{ }^{58}$ Moreover, it is a core obligation to ensure privacy, confidentiality and free, informed consent for sexual and reproductive needs « and to »repeal or eliminate laws, policies and practices that criminalize, obstruct or undermine individual's or particular group's access to sexual and reproductive health $\ll{ }^{59}$ Thereby the Committee on Economic, Social and Cultural Rights excludes in its latest General Comment all mandatory screening related to sexual and reproductive health.

To sum up, the ICESCR contributes significantly to the clarification of the obligation of states to control the spread of infectious diseases at the border. States should take at least a minimum of measures at their borders in order to control the spread of epidemic and endemic diseases. Screenings require a free and informed consent under the right to health. Nevertheless, medical screenings for other infectious diseases might be allowed for the protection of public health and in accordance with the conditions set forth in Article 4 and 5(1) of the convention. Yet, all sexual health-related mandatory screening is prohibited.

\subsection{Convention on the Rights of the Child}

The right to health as enshrined in the Convention on the Rights of the Child (CRC) contains no explicit reference to either medical screenings or to the control of diseases. However, under Article 24(2)(c) states have the obligation to take measures to combat diseases within the framework of primary healthcare. ${ }^{60}$ According to paragraph VII(3) of the Alma-Ata Declaration, such primary healthcare includes at least, inter alia, »the control of locally endemic diseases«. General Comment No. 15 lists ensuring "universal coverage of primary health services" among the core obligations, which suggests that, when read in combination with the Alma-Ata

58 E/C.12/GC/22, 14 March 2016, para. 57.

59 Ibid., para. 49(d).

60 The Committee on the Rights of the Child refers to the Alma-Ata Declaration where the approach to primary healthcare was defined to also include the control of infectious diseases. CRC/C/GC/15, 17 April 2013, para. 4. 
Declaration, the control of locally endemic diseases falls within the minimum a state should ensure at its border. ${ }^{61}$

Similar to General Comment No. 14 of the Committee on Economic, Social and Cultural Rights, General Comment No. 15 clarifies that children's right to health includes the right $"$ to control one's health and body « ${ }^{62}$ Children's right to consent to certain medical treatments and interventions might nevertheless be conditional on the permission or assistance of a parent, caregiver or guardian, depending on the child's age and maturity. ${ }^{63}$ However, with regard to HIV testing, states should consider to allow children to consent without the permission of a parent or caregiver. ${ }^{64}$ State parties must thereby protect the confidentiality of HIV test results and information on the HIV status of children may not be disclosed without the child's consent to third parties, including parents. ${ }^{65}$ In addition, states should ensure that girls can make autonomous and informed decisions on their reproductive health. ${ }^{66}$ Moreover, General Comment No. 3 is very clear in stating that mandatory HIV/AIDS testing of children is prohibited under all circumstances and that states should ensure protection against it. ${ }^{67}$

In addition to the screening for infectious diseases, General Comment No. 6 requires states to conduct additional screenings in the border context: it calls upon states, with the best interests of the child as a guiding principle, to prioritize the identification of unaccompanied and separated children "upon arrival at ports of entry or as soon as their presence in the country becomes known to the authorities $«{ }^{68}$ Subsequently, states are required to assess and record during the »necessary initial assessment process «, »particular vulnerabilities, including health, physical, psychosocial [...] needs, including those deriving from domestic violence, trafficking or trauma«. The aim of this kind of assessment is to meet the specific needs of the

$61 \mathrm{CRC} / \mathrm{C} / \mathrm{GC} / 15,17$ April 2013, para. 73.

62 Ibid., para. 24.

63 Ibid., para. 21.

64 Ibid., para. 31.

$65 \mathrm{CRC} / \mathrm{GC} / 2003 / 3,17$ March 2003, para. 24.

$66 \mathrm{CRC} / \mathrm{C} / \mathrm{GC} / 15,17$ April 2013, para. 56.

$67 \mathrm{CRC} / \mathrm{GC} / 2003 / 3,17$ March 2003, para. 23.

$68 \mathrm{CRC} / \mathrm{GC} / 2005 / 6,1$ September 2005, para. 31. 
child. ${ }^{69}$ Furthermore, in order to ensure their access to health services which must be the same as for children who are nationals - states should "assess and address the particular plight and vulnerabilities of such children ${ }^{70}{ }^{70}$ States should pay particular attention to the psychological condition of unaccompanied and separated children and to specific genderrelated needs of girls. ${ }^{71}$ Hence, the convention focuses not only on infectious disease control, but obligates states also to make health(-related) assessments in the interest of the child crossing the border.

In conclusion, interesting new insights can be drawn from the analysis of this convention. In contrast to the International Covenant on Economic, Social and Cultural Rights (ICESCR), the CRC does not explicitly mention the obligation to control diseases under the right to health. Rather, it incorporates it in primary healthcare and shifts the emphasis from control to care. Thus, voluntary and confidential testing is stressed as a means to prevent diseases and to ensure children's access to health services. ${ }^{72}$ Both the CRC and the ICESCR require a free and informed consent to medical screenings and explicitly prohibit mandatory HIV/AIDS testing. However, whereas the ICESCR leaves room in Article 4 and 5(1) for mandatory screenings - with the exception of screenings related to sexual health - the CRC does not. Finally, and particularly relevant, the CRC imposes a duty upon states to prioritize early identification of unaccompanied and separated children in order to guarantee their access to health services.

\subsection{Convention on the Elimination of Discrimination Against Women}

The right to health in Article 12 of the Convention on the Elimination of Discrimination Against Women (CEDAW) does not specify any obligation for the control of infectious diseases. However, the relevant General Recommendation states that $"$ State parties should report on what they have done to address the magnitude of women's ill-health, in particular when it

$69 \mathrm{CRC} / \mathrm{GC} / 2005 / 6,1$ September 2005, para. 31.

70 Ibid., para. 47.

71 Ibid., paras. 46-47.

72 See specifically about HIV/AIDS testing: CRC/GC/2003/3, 17 March 2003, para. 22. 
arises from preventable conditions, such as tuberculosis and HIV/AIDS « ${ }^{73}$ Notwithstanding that this General Recommendation is not explicit on the reach of this obligation, paragraph 6 highlights that special attention should be paid to inter alia the health needs and rights of migrant women and refugee women. ${ }^{74}$

In addition, this General Recommendation prohibits coercive measures such as mandatory testing for sexually transmitted diseases. ${ }^{75}$ States are required to ensure women's »right to autonomy, privacy, confidentiality, informed consent and choice« in all health services. ${ }^{76}$ However, it is unclear if border screenings would fall within the definition of a health service.

General Recommendation No. 26 defines state obligations on predeparture health screenings of women migrant workers: where predeparture HIV/AIDS testing and pre-departure health examinations are required by the country of destination, they must be respectful of the human rights of women migrants. Here, special attention should be paid to voluntariness and to problems of stigmatization. ${ }^{77}$ In referring to the obligation to respect women's human rights and voluntariness, this General Recommendation provides a solution for the possibly conflicting interests of public health and the individual. Thus, even in cases of mandatory screenings, free and informed consent is required.

Moreover, General Recommendation No. 32 urges states to establish adequate screening mechanisms for the early identification of women asylum seekers »with specific protection and assistance needs, including women with disabilities, unaccompanied girls, victims of trauma, victims of trafficking and/or forced prostitution, victims of sexual violence and victims of torture and/or ill-treatment $\ll{ }^{78}$ However, the convention does not specifically link this requirement to the right to health.

In conclusion, the convention provides significant clarification on migration-related screenings. Particularly remarkable is the fact that it also requires free and informed consent for obligatory pre-departure medical

73 A/54/38/Rev. 1, chap. 1, 1999, para. 17.

74 Ibid., para. 6.

75 Ibid., para. 22.

76 Ibid., para. 31(e).

77 CEDAW/C/2009/WP.1/R, 15 December 2008, para. 24(d).

78 Ibid., para. 46. 
screenings. The International Covenant on Economic, Social and Cultural Rights is far less specific on this subject and even allows for forced medical interventions, with the exclusion of screenings related to sexual and reproductive health. Similar to the Convention on the Rights of the Child (CRC), the CEDAW links medical screenings with the obligation to ensure access to care. Moreover, it also explicates that obligatory screenings have to be free of charge. Finally, the CEDAW, like the CRC, calls for early identification of vulnerability at the border.

\subsection{The International Convention on the Rights of All Migrant Workers and Their Families}

The International Convention on the Rights of All Migrant Workers and their Families (ICMWF) provides no prima facie guidance on infectious disease control. As outlined above, Article 28 of the convention limits migrant workers and their families' right to health to medical care which is urgently required.

Although the Committee on Migrant Workers has not (yet) issued a General Comment on the right to health, General Comment No.1 is instructive on states' limitations regarding medical screenings at the border. Thus, medical testing of female migrant domestic workers, including tests for pregnancy or HIV, is only allowed with their free and informed consent. Additionally, state parties should $»$ repeal discriminatory laws, regulations and practices related to HIV $\ll .{ }^{79}$ Thus, the loss of work visas based on HIV status is prohibited. ${ }^{80}$

In summary, contrary to the International Covenant on Economic, Social and Cultural Rights, but like the Convention on the Elimination of Discrimination Against Women (CEDAW), the convention is not informative on the public health aspects of disease control. But, like the Convention on the Rights of the Child (CRC) and the CEDAW, it explicitly demands free and informed consent for migration-related medical screenings. However, unlike the CEDAW, it gives no further clarification on the conditions and costs of screenings when required before or upon arrival or stay in a coun-

$79 \mathrm{CMW} / \mathrm{C} / \mathrm{GC} / 1,3$ February 2011, para. 61.

80 Ibid. 
try. In contrast to the CRC and the CEDAW, no reference is made to any obligation to identify particular vulnerabilities of migrants.

\subsection{Convention about the Rights of Persons with Disabilities}

The Convention about the Rights of Persons with Disabilities (CRPD) does not add anything specific with regard to the border-related control of diseases. However, Article 25(b) requires another kind of assessment. Accordingly, states are obliged to provide disability-related health services, including early identification. Its wording resembles the calls by General Comment No. 6 of the Committee of the Rights of the Child and General Recommendation No. 24 of the Committee on the Elimination of Discrimination Against Women to identify vulnerable women and children at the border in order to ensure their access to health services. By comparison, the obligation under Article 25(b) might imply that states should also actively screen for persons with disabilities at their borders in case they would be in need of access to health services.

Furthermore, it is worth noting that Article 25(d) prescribes states to $»[r]$ equire health professionals to provide care of the same quality to persons with disabilities as to others, including on the basis of free and informed consent $\ll$. This is the first treaty which contains an explicit reference to the right to free and informed consent. The Committee on the Rights of Persons with Disabilities's General Comment No. 1 outlines the extent of this obligation as applying to all health and medical professsionals. ${ }^{81}$ Moreover, this General Comment recognizes the right to free and informed consent »everywhere« and »on an equal basis with others «. ${ }^{82}$ However, considering the wording of Article 25(d) of the convention, the question remains whether medical screenings at the border would fall within the definition of »care" or whether any compulsory screening would not be considered to constitute a provision of care within the meaning of this article.

To summarize, the convention highlights two aspects of the right to health relevant for border medical screenings. First, like General Comment No. 6 of the Committee on the Rights of the Child and General Recommen-

$81 \mathrm{CRPD} / \mathrm{C} / \mathrm{GC} / 1,19$ May 2014, para. 41.

82 Ibid., paras. 5, 8 and 41. 
dation No. 32 of the Committee on the Elimination of Discrimination Against Women, it calls for the early identification of persons with specific needs, i.e. disability. Second, it is the first treaty to explicitly guarantee the right to free and informed consent. However, it remains questionable whether the scope of this provision would also extend to border screenings. In this regard, General Recommendation No. 26 of the Committee on the Elimination of Discrimination Against Women and the Committee on Migrant Workers' General Comment No. 2 provide stronger guidelines as they require free and informed consent even for obligatory migration-related medical screenings.

\subsection{International Convention on the Elimination of Racial Discrimination}

Article 5(e)(iv) of the International Convention on the Elimination of Racial Discrimination (ICERD) stipulates that States should guarantee the right of everyone to »public health«. General Recommendation No. 20 explains that Article 5(e)(iv) does not create »new« rights, as their existence and recognition is presumed by listing them. ${ }^{83}$ Upon first reflection, this seems disappointing, as no clarification of the content of »the right to public health « is provided. Nevertheless, it is not an empty concept, as it refers to all the other treaties incorporating it.

In addition, General Recommendation No. 30 stipulates under which conditions different treatment based on citizenship or immigration status constitutes discrimination. ${ }^{84}$ Accordingly, medical screenings of (certain groups of) migrants crossing the border, is a discrimination if it is not in accordance with a »legitimate aim« and not »proportional to the achievement of this aim«. These criteria are similar to the criteria that allow for limitations of rights under Article 4 and 5(1) of the International Covenant on Economic, Social and Cultural Rights.

Altogether, the ICERD does not shed light on the content of »the right to public health« as such. It only provides general criteria to discern discriminating measures.

83 A/51/18, annex VIII, sect. A, 1996, 26 February - 15 March 1996, para. 1.

84 A/59/18, 2004, 23 February - 12 March 2004, para. 4. 


\subsection{Concluding Remarks}

Overall, international human rights law provides fragmentary clarifications about medical border screenings for infectious diseases. Nevertheless, some important conclusions can be drawn from the above analysis.

The clearest reference to medical screenings is found in Article 12(2)(2) of the International Covenant on Economic, Social and Cultural Rights (ICESCR) that enshrines the obligation »to control diseases«. Surprisingly, this obligation is much broader than its literal meaning, including availability of technological measures, data collection and surveillance, immunization and other strategies. This description is trend-setting for an overall approach in international human rights law that consider screenings as an obligation that does not come solely. Thus, the link between medical screenings and ensuring access to care is made under the ICESCR, the Convention on the Rights of the Child (CRC) and the Convention on the Elimination of Discrimination Against Women (CEDAW). Only the CEDAW and the International Convention on the Rights of All Migrant Workers and their Families (ICMWF) specifically state that migration-related health assessments should be free of costs. Moving away from screenings related to (infectious) diseases, the CRC, CEDAW and the Convention about the Rights of Persons with Disabilities (CRPD) require the identification of certain categories of vulnerable people at the border in order to assess their health needs and ensure their access at the border.

Altogether, the treaties highlight different aspects of the conditions that should accompany medical border screenings. However, only the Committee on Economic Social and Cultural Rights (CESCR) has given a - rather blurred - explanation regarding the enforceability of the obligation »to control endemic and epidemic diseases « by calling it an obligation of »comparable priority« to a core obligation. In order to ensure that the right to health in relation to border screenings does not become an empty promise, it would therefore be useful to be crystal-clear about the exact extent (core obligation or not) and the exact content of the obligation to control diseases (in relation to the obligation to ensure access to care).

A second important conclusion is that the right to free and informed consent is implied as a general obligation in all treaties under the right to health. It is, nevertheless, only expressly stated in the newest treaty, the CRPD. The extent to which states can derogate from the right to free and 
informed consent is therefore difficult to determine. This might also point to the fact that some international human rights law standards are getting outdated and, in light of the CRPD and the General Comments and General Recommendations of other treaty bodies, a new and authoritative interpretation of the limitation clause in CESCR General Comment No. 14 regarding forced medical interventions could prove to be useful. ${ }^{85}$ Ideally, this interpretation would take into account the criteria already set forth in other treaty bodies.

More generally, it is also worth to consider in more depth in the future to what extent and how human rights should relate to so-called public health evidence and to the recommendations or even enforceable regulations from specialized agencies such as WHO. ${ }^{86}$

\section{Discussion}

Based on the above analysis of the rights and obligations in international human rights law with regard to medical care and emergency assistance as well as medical screenings at the border, the following pinpoints four aspects of particular relevance when discussing whether the right to health is an empty promise. These aspects are: clarity and consistency, the margin of appreciation, vulnerability and human rights as advocacy tools.

\subsection{Clarity and Consistency}

States are generally reluctant to accept international human rights law obligations, particularly in the field of economic, social and cultural rights, and enforcement mechanisms for human rights are generally weak. For the right to health to constitute more than an empty promise, it is therefore necessary to establish clear guidelines. Preferably, the guidelines should be consistent across different treaties in order to build one single comprehensive framework and avoid confusion about the applicable standard. The example of

85 See also Minkowitz (2007), 407.

86 See e.g. Article 32 of the International Health Regulations (2005) which balances the right to informed consent against public health interests. 
the rights and obligations under the right to health has shown that such a clear standard does not yet exist in the border context.

There is a clear obligation to provide some sort of medical care and emergency assistance to everyone, regardless of their legal status. However, the exact content of these two terms differs depending on the treaty that is considered. It currently seems to be left to the discretion of the medical practitioner - or even to a border agent - to judge what treatment or assistance is necessary. If international human rights law treaty bodies were to adopt a coherent definition of the content of medical care and emergency assistance, this certainly could contribute to the right to health not becoming an empty promise.

With regard to medical border screenings, it is clear that States are allowed - and even required - to conduct medical screenings at the border. However, it is unclear to what extend States can screen a person who has not given her/his informed consent. Moreover, some international human rights law treaty bodies relate medical screening to access to healthcare but this is not yet highlighted consistently across the different international human rights law treaties. Connecting medical screenings more prominently to the access to healthcare would be pivotal to ensure the effective realization of the right to health.

\subsection{The Margin of Appreciation}

Whether the provisions of the right to health are an empty promise also depends on the margin of appreciation granted to member states to diverge from the treaty obligations and to interpret the treaty in their own terms. The right to health remains a right which is not absolute and, in accordance with the Committee on Economic Social and Cultural Rights' General Comment No. 14, can thus be limited in the general public interest. This means that limitations to the rights to medical care and emergency assistance are not completely ruled out under all circumstances. However, any such measures must be »in accordance with the law", for a legitimate aim and $»$ strictly necessary for the promotion of the general welfare". ${ }^{87}$ Also in the context of medical screenings, coercive medical treatment is allowed in »exceptional cases « for »the prevention and control of communicable dis-

87 E/C.12/2000/4, 11 August 2000, para. 28. 
eases «. ${ }^{88}$ Such measures must be »proportional«, »of limited duration« and »subject to review «. ${ }^{89}$ The right to health thus offers a rather clear guide on the conditions which have to be met by states in order to allow for any limitation of the right to health. Nevertheless, states can thus potentially limit the scope and possible impact of the right to health in the context of humanitarian border management.

\subsection{Vulnerability}

In light of insufficient clarity and the margin of appreciation granted to states in the field of health, the question remains whether there are any additional safeguards which could help to ensure the right to health is not an empty promise. This is even more so the case in contexts such as at the border where states are particularly reluctant to grant extensive rights because of state sovereignty concerns. Particular consideration for persons in vulnerable situations seems to provide a helpful additional safeguard in that respect.

Many of the treaties discussed above recognize that states have a special responsibility for persons who might be in a situation of vulnerability and that, due to that vulnerability, these persons should be treated on a preferential basis. Moreover, most of the specialized treaties such as the Convention on the Rights of the Child or the Convention on the Elimination of Discrimination Against Women even exist because of this very understanding of the need of particular attention to these vulnerable groups. Generally, the scope of the right to health thus seems to be more easily acceptable for states with regard to particular vulnerable groups, such as women or children. However, such a group-based approach has often been criticized as »paternalistic«, »stigmatizing« and static. ${ }^{90}$ Moreover, although treaties which deal with particular vulnerable groups might sometimes go beyond the standard of the International Covenant on Economic Social and Cultural Rights, the question for future research remains whether this also leads to a higher level of protection in practice.

88 E/C.12/2000/4, 11 August 2000, para. 34.

89 Ibid., para. 29.

90 Brown (2011), 316; Peroni/Timmer (2013), 1057; Flegar (2016). 
The extent to which the conditions at the border or during a migratory journey may put persons in a vulnerable position is not (yet) explicitly recognized in most treaties.

While concern for particular vulnerable groups can thus certainly be considered to constitute a first step towards the realization of the right to health of those persons who are most needy of protection, the lack of a more nuanced understanding of vulnerability currently increases the arguments in favour of the right to health as an empty promise in the border context.

\subsection{Human Rights as Advocacy Tools}

The above analysis showed the difficulties in defining any clear standard. Wherever the state sovereignty to control its territory is (perceived as) threatened, it is less likely that extensive rights are granted. Despite the above critique and limitations of the right to health, the present analysis tried to show some of the potential the right to health still has.

Returning to Dembour's four schools of human rights, the present analysis suggests that human rights can generally be perceived as a legal tool, advocacy framework or moral claim. Although the four types Dembour identifies are ideal types and the present study cannot solely be ascribed to one of the four schools, the study considers the right to health within the protest school paradigm. The above analysis revealed that the right to health is more than just a moral principle (as the natural school would suggest). However, it is not yet an enforceable legal claim (as the deliberative school would suggest). Framing the right to health within the protest school thus best underlines the current effectiveness of the right to health in viewing it as a constantly fought for principle which is valuable because of its expression of far-reaching claims and aspirations. ${ }^{91}$ Following this approach would lead to the conclusion that the right to health is more than just an empty promise. It is a guideline which clarifies states' human rights obligations in the field of health. Even if these are in many cases not (yet) enforceable, this guideline provides useful principles to strive for in policy and practice.

91 Compare Dembour (2010). 
In lack of sufficiently clear legal guidelines or enforcement mechanisms, the right to health can thus be understood as deriving particular value from being an advocacy tool that can support the fight for human rights not only in the context of humanitarian border management but also in more general terms. While the legal enforceability of human rights is often problematic and especially the progressive realization of economic, social and cultural rights feeds criticism on the right to health, certain aspects are clearly defined and can provide strong arguments when, for instance, monitoring compliance with or promoting the right to health.

This is not to say that there are no possibilities to further improve the role of the right to health in order to counter any criticism of it being an empty promise: the issues of clarity, proportionality and vulnerability as well as other limitations which were not addressed in this chapter might still have to be considered in more depth for the right to health to become a stronger legal rule. Overall, however, the right to health should be acknowledged for providing valuable arguments and concrete suggestions that can contribute to improving the health of every individual human being.

\section{Conclusion}

The present chapter tried to highlight the scope and content of the rights and obligations under the right to health at the border. It focused, first, on medical care and emergency assistance before clarifying the issue of medical screenings. In so doing, it tried to answer the question of whether the right to health does indeed have to be viewed as an empty promise in the context of border management or whether it provides valuable guidance. Three problematic issues were highlighted which should be addressed if the right to health is to be strengthened: clarity and consistency, the margin of appreciation and vulnerability. Placing the right to health into the context of a broader debate on the added value of human rights, the present study follows Dembour's protest school and would argue that the right to health is certainly not an empty promise if understood as advocacy tool. The present study revealed that, even if the right to health is not yet a reality, it is certainly valuable and an essential factor for clarifying individual rights and state obligations at the border - if not (yet) as purely legal criteria, then at least as claims and aspirations worth fighting for. 


\section{References}

Biswas, Dan/Toebes, Brigit/Hjern, Anders/Ascher, Henry/Norredam, Marie (2012): »Access to Health Care for Undocumented Migrants from a Human Rights Perspective: A Comparative Study of Denmark, Sweden, and the Netherlands«, in: Health and Human Rights 14, 2 (2012), 4960.

Brown, Kate (2011): »)Vulnerability<: Handle with Care«, in: Ethics and Social Welfare 5, 3 (2011), 313-321.

Dembour, Marie-Bénédicte (2010): „What Are Human Rights? Four Schools of Thought«, in: Human Rights Quarterly 32 (2010), 1-20.

Fiddian-Qasmiyeh, Elena/Loescher, Gil/Long, Katy/Sigona, Nando (Eds.) (2014): The Oxford Handbook of Refugees and Forced Migration Studies, Oxford: Oxford University Press.

Fiddian-Qasmiyeh, Elena/Loescher, Gil/Long, Katy/Sigona, Nando (2014): »Introduction: Refugee and Forced Migration Studies in Transition«, in: Fiddian-Qasmiyeh et al. (2014), 1-20.

Flegar, Veronika (2015): »The Principle of Non-discrimination: An Empty Promise for the Preventive Health Care of Asylum Seekers and Undocumented Migrants?«, in: Groningen Journal of International Law 3, 2 (2015), 80-95.

Flegar, Veronika (2016): »Towards Individualized Vulnerability in Migration Policies«, Online: https://ghlgblog.wordpress.com/2016/04/01/to wards-individualized-vulnerability-in-migration-policies/ [07.06.2016].

Flegar, Veronika/Dallí, María/Toebes, Brigit (2016): »Access to Preventive Health Care for Undocumented Migrants: A Comparative Study of Germany, the Netherlands and Spain from a Human Rights Perspective«, in: Laws 5 (2016), 9.

Henrard, Kristin (2008): Mensenrechten vanuit internationaal en nationaal perspectief, Den Haag: Boom Uitgevers.

IOM (2016): »Health, Border and Mobility Management«, Online: https://www.iom.int/sites/default/files/our_work/DMM/IBM/updated/H ealth_and_Humanitarian_Border_Management.pdf [07.06.2016].

Minkowitz, Tina (2007): »The United Nations Convention of the Rights of Persons with Disabilities and the Right to be free from nonconsensual psychiatric interventions«, in: Syracuse Journal of International Law and Commerce 34, 2 (2007) 405-428. 
Paasi, Anssi (2010): »A Border Theory: An Unattainable Dream or a Realistic Aim for Border Scholars?«, in: Wastl-Walter (2010), 11-31.

Peroni, Lourdes/Timmer, Alexandra (2013): „Vulnerable Groups: The Promise of an Emerging Concept in European Human Rights Convention Law«, in: International Journal of Constitutional Law 11, 4 (2013), 1056-1085.

Porta, Miquel (2014): A dictionary of epidemiology, Oxford: Oxford University Press.

Pottler, Maximilian (2014): »Humanitarian Border Management«, in: Forced Migration Review 45 (2014), 46-47.

Rubio-Marin, Ruth (Ed.) (2014): Human Rights and Immigration, Oxford: Oxford University Press.

Ryan, Bernard/Mantouvalou, Virginia (2014): »The Labour and Social Rights of Migrants in International Law«, in: Rubio-Marin (2014), 177211.

Selvey, Linda A./Antão, Catarina/Hall, Robert (2015): »Entry Screening for Infectious Diseases in Humans«, in: Emerging Infectious Diseases 21, 2 (2015), 197-201.

Spencer, Sarah/Hughes, Vanessa (2015): »Outside and In: Legal Entitlements to Health Care and Education for Migrants with Irregular Status in Europe«, COMPAS, University of Oxford, Online: https:/www.com pas.ox.ac.uk/2015/outside-and-in/ [07.06.2016].

UNAIDS (2015): »Infographic. Welcome (not): before and after«, Online: http://www.unaids.org/fr/node/44190 [16.05.2016].

UN Treaty Collection (2016): »UN Treaty Collection: Chapter IV Human Rights: ICMWF«, Online: https://treaties.un.org/Pages/ViewDetails .aspx?src=IND\&mtdsg_no=IV-13\&chapter=4\&lang=en [07.06.2016].

Wastl-Walter, Doris (Ed.) (2010): Ashgate Research Companion to Border Studies, Aldershot: Ashgate

van der Werf, Marieke J./Zellweger, Jean-Pierre (2016): »Impact of Migration on Tuberculosis Epidemiology and Control in the EU/EEA«, Online: http://www.eurosurveillance.org/images/dynamic/EE/V21N12/ art21421.pdf [06.05.2016].

WHO (2016): »Migration and Health: Key Issues«, Online: http://www. euro.who.int/en/health-topics/health-determinants/migration-and-health/ migrant-health-in-the-european-region/migration-and-health-key-issues [05.06.2016]. 
WHO/OHCHR/IOM (2013): »International Migration, Health and Human Rights«, Online: https://publications.iom.int/books/international-mig ration-health-and-human-rights [07.06.2016].

Wickramage, Kolitha/Mosca, Davide (2014): »Can Migration Health Assessments Become a Mechanism for Global Public Health Good? «, in: International Journal of Environmental Research and Public Health 11, 10 (2014), 9955-9957. 


\section{Prevention of Torture and Cruel or Inhuman and Degrading Treatment in Healthcare}

ADRIAAN VAN ES

\section{INTRODUCTION}

Torture and healthcare are - at first sight - contradictory realities. In healthcare sick, wounded and vulnerable people are given attention, treatment and safety, while in torture human beings are intentionally submitted to cruelties and methods to destroy their integrity.

However, over and over in time, healthcare professionals have been complicit in grave human rights violations voluntarily or under pressure, for instance by lending their expertise to torture methods. This was and is a gruesome reality, especially since health professionals are in positions, where they are often the first, or even only one to notice and witness torture or maltreatment, being in the position to document these human rights violations authoritatively.

Increasingly medical expertise has been developed and made available for the investigation of human rights violations. Internationally accepted authoritative protocols have been developed for the investigation and documentation of extra-judiciary killings (Minnesota Protocol) ${ }^{1}$ and the investigation and documentation of torture (Istanbul Protocol) ${ }^{2}$. Medical expert

1 »Minnesota Protocol«, ST/CSDHA/12, 1991.

2 »Istanbul Protocol«, HR/P/PT/8/Rev.1, 9 August 1999. Frewer et al. (2009). 
opinion in human rights court rulings have increasingly proven to be instrumental in establishing the body of evidence.

Recent research, documentation and developments in international human rights law have shown that torture and/or cruel and inhuman treatment in (within the context of) healthcare occur on a daily basis and at a disquieting level. The human rights debate, stimulated by research, jurisprudence and reports of Special Rapporteurs have made it clear that application of the definition of torture and/or cruel or inhuman and degrading treatment on healthcare is appropriate and expedient. And this is a huge challenge to health professionals: How can they make sure to be part of the solution rather than to be part of the problem?

This paper discusses the 2011 campaign »Stop Torture in Health Care«, focusing on the denial of access to adequate pain treatment, forced and coerced sterilization of women and the detention of drug-users in lieu of adequate treatment. A number of examples is described where medical knowledge is abused, leading to large-scale ill-treatment or torture, and an example is given how medical knowledge can be decisive in human rights court cases to prove torture and/or ill-treatment. The paper then discusses the 2013 report of the Special Rapporteur on torture and other cruel, inhuman and degrading treatment or punishment »Torture in healthcare settings« and the reactions this report aroused (mainly from organizations of health professionals). The problem of "torture language « in healthcare is discussed and the »dual loyalty concept « is presented. The paper ends with a challenging question: In what extent (and how) does the problem of torture in healthcare setting apply in healthcare settings at home (outside institutions), where volunteers and family members are involved?

\section{Campaign »Stop Torture in Health Care»}

In 2011 a coalition of organizations, including the International Federation of Health and Human Rights Organizations (IFHHRO) ${ }^{3}$ launched the campaign »Stop Torture in Health Care«. Although aware of the fact that torture and/or cruel or inhuman and degrading treatment may occur in all sectors of healthcare, the campaign highlighted three areas: (1) inaccessibility

3 See Homepage: www.ifhhro.org. 
of adequate pain treatment, (2) forced/coerced sterilization of women and (3) detention of drug users in lieu of adequate treatment.

\subsection{The Right to Access to Adequate Pain Treatment}

The International Association for the Study of Pain started to frame the problem of unrelieved pain as an ethical and legal problem in $2004,{ }^{4}$ and formulated its »Montreal Declaration $\aleph^{5}$ in 2010 :

$»[\ldots]$ recognizing the intrinsic dignity of all persons and that withholding of pain treatment is profoundly wrong, leading to unnecessary suffering which is harmful; we declare that the following human rights must be recognized throughout the world:

Article 1. The right of all people to have access to pain management without discrimination.

Article 2. The right of people in pain to acknowledgment of their pain and to be informed about how it can be assessed and managed.

Article 3. The right of all people with pain to have access to appropriate assessment and treatment of the pain by adequately trained health care professionals."

The problem of inaccessibility of adequate pain treatment was extensively researched and mapped by Human Rights Watch. Their global research showed that in the vast majority of countries worldwide, access to adequate pain treatment is totally inadequate. In its report »Please do not make us suffer anymore«, Human Rights Watch describes the »pain treatment gap«, with the following background figures:

$»[\ldots]$ approximately 80 percent of the world population has either no or insufficient access to treatment for moderate to severe pain and tens of millions of people around the world [...]. Approximately 89 percent of the total world consumption of morphine occurs in countries in North America and Europe. Low and middle income countries consume only 6 percent of the morphine used worldwide - while having about half of all cancer patients and 95 percent of new HIV infections. Thirty-two

4 Brennan et al. (2007).

5 IASP (2010). 
countries in Africa have almost no morphine distribution at all, and only fourteen have oral morphine. ${ }^{6}$

The Human Rights Watch report shows that in 2009 the number of patients in need of opioid treatment was in many countries extremely low, in many cases below 1\%. The figures are based on an estimate by Foley et al. that $80 \%$ of terminal cancer patients and $50 \%$ of terminal AIDS patients will require an average of 90 days of pain treatment with $60 \mathrm{mg}$ to $75 \mathrm{mg}$ of morphine per day These figures, applied on country estimates obtained from website of the International Narcotic Control Board and projections for annual cancer and AIDS deaths based on cancer and AIDS mortality figures reported by the $\mathrm{WHO}$, provide horrific figures of the extreme »pain treatment gap « in many countries. ${ }^{7}$

Table 1: Morphine estimates, mortality and pain treatment need

\begin{tabular}{|c|c|c|c|c|c|c|c|}
\hline Country & $\begin{array}{c}\text { Cancer } \\
\text { Deaths } \\
2002 \\
\text { Estimate }\end{array}$ & $\begin{array}{c}\text { AIDS } \\
\text { Deaths } \\
2005 \\
\text { Estimate }\end{array}$ & $\begin{array}{c}\text { \# of } \\
\text { Individuals } \\
\text { expected to } \\
\text { need Pain } \\
\text { Treatment } \\
\text { in } 2009\end{array}$ & $\begin{array}{c}\text { Estimate } \\
\text { total } \\
\text { morphine } \\
\text { need in } \\
2009(\mathrm{kgs})\end{array}$ & $\begin{array}{c}\text { Estimate of } \\
\text { morphine } \\
\text { need } \\
\text { provided } \\
\text { by country } \\
\text { to INCB } \\
\text { for } 2009 \\
(\mathrm{kgs})\end{array}$ & $\begin{array}{l}\text { \# of } \\
\text { Individuals } \\
\text { estimate is } \\
\text { sufficient } \\
\text { for }\end{array}$ & $\begin{array}{l}\% \text { of those } \\
\text { needing } \\
\text { treatment } \\
\text { who would } \\
\text { be covered } \\
\text { by estimate }\end{array}$ \\
\hline Benin & 13,490 & 9,986 & 15,786 & 96 & 0.5 & 83 & 0.50 \\
\hline Senegal & 17,625 & 5,432 & 16,816 & 102 & 0.6 & 99 & 0.60 \\
\hline Rwanda & 14,196 & 21,956 & 22,335 & 136 & 0.8 & 132 & 0.60 \\
\hline Gambia & 2,395 & 1,430 & 2,631 & 16 & 0.18 & 31 & 1.20 \\
\hline Bhutan & 727 & $\begin{array}{l}>10 \text { per } \\
100,000\end{array}$ & 582 & 3.5 & 0.08 & 14 & 2.30 \\
\hline
\end{tabular}

6 Human Rights Watch (2009).

7 Lohman et al. (2010). 


\begin{tabular}{|c|c|c|c|c|c|c|c|}
\hline $\begin{array}{l}\text { Burkina } \\
\text { Faso }\end{array}$ & 23,262 & 13,067 & 25,143 & 153 & 0.05 & 8 & 0.03 \\
\hline Eritrea & 6,240 & 5,959 & 7,972 & 48 & 0.075 & 12 & 0.15 \\
\hline Gabon & 2,071 & 4,457 & 3,886 & 24 & 0.088 & 14 & 0.40 \\
\hline $\begin{array}{l}\text { Swazi } \\
\text { Land }\end{array}$ & 1,837 & 17,577 & 10,258 & 62 & 0.5 & 82 & 0.80 \\
\hline Egypt & 62,299 & $\begin{array}{l}>10 \text { per } \\
100,000\end{array}$ & 49,840 & 303 & 10 & 1,646 & 3 \\
\hline $\begin{array}{l}\text { Philip- } \\
\text { pines }\end{array}$ & 78,500 & $\begin{array}{l}>10 \text { per } \\
100,000\end{array}$ & 62,800 & 382 & 31 & 5,103 & 8 \\
\hline Kenya & 50,809 & 149,502 & 115,398 & 701 & 30 & 4,938 & 4 \\
\hline $\begin{array}{l}\text { Russian } \\
\text { Federa- } \\
\text { tion }\end{array}$ & 21,7696 & N/A & 174,157 & 1,058 & 200 & 32,922 & 15 \\
\hline Mexico & 92,701 & 6,321 & 77,321 & 470 & 180 & 29,630 & 38 \\
\hline
\end{tabular}

Source: Lohman et al. (2010)

\subsection{Non-accessibility of Adequate Pain Treatment: Violation of the Right to the Highest Attainable Standard of Health (»the Right to Health«)}

The human right to health is recognized in numerous international instruments, including the Universal Declaration of Human Rights, Article 25:

"Everyone has the right to a standard of living adequate for the health of himself and of his family, including food, clothing, housing and medical care and necessary social services $[\ldots] \ll$.

The relevant General Comment No. 14 of the Committee on Economic, Social and Cultural Rights elaborates extensively on Article 12 of the International Covenant on Economic, Social and Cultural Rights (ICESCR), 
which provides the most comprehensive article on the right to health in international human rights law:

»States parties recognize sthe right of everyone to the enjoyment of the highest attainable standard of physical and mental health ««, and »enumerates [...] a number of >steps to be taken by the States parties ... to achieve the full realization of this right $<. \ll^{8}$

Besides the General Comment, the right to health is also based on Article 24 of the Convention on the Rights of the Child (CRC); Article 12 of the Convention on the Elimination of All Forms of Discrimination against Women (CEDAW); Article 5 of the International Covenant on the Elimination of Racial Discrimination (ICERD); Article 25 of the Convention on the Rights of Persons with Disabilities (CRPD); and Article 28 of the International Convention on the Protection of the Rights of All Migrant Workers and Members of Their Families (ICRMW). In addition to the international standards, the right to health is recognized in various regional human rights treaties.

The right to health includes freedoms (e.g. from torture and cruel or inhuman and degrading treatment) and entitlements and ascertains in the $\gg$ triple A« (availability, affordability, accessibility) and »Q« (quality): the availability of functioning public health and healthcare facilities, goods and services, as well as programmes, the accessibility (non-discrimination, physical accessibility, economic accessibility or affordability, and information accessibility), and accessibility (cultural and gender), as well as quality.

The State (the accountable party) has specific legal obligations (trias: the obligations to respect, to protect and to fulfil), and the obligation to immediately implement the core obligations and ensure the progressive realization of the right to health.

Among the core obligations is the provision of essential drugs, as defined under the WHO Action Programme on Essential Drugs. ${ }^{9}$ This »essential medicines list« includes opioids and other pain medication. Non-accessi-

8 E/C.12/2000/4, 11 August 2000, para. 2.

9 WHO (1998). 
bility of opioids is therefore a violation of a core obligation under the right to the highest attainable standard of health.

\subsection{Denial of Access to Pain Treatment: Violation of the Right to be Free from Torture and/or Cruel or Inhuman and Degrading Treatment}

In January 2009, the then Special Rapporteur on torture and other cruel, inhuman and degrading treatment or punishment Manfred Nowak, wrote in his report to the Human Rights Council that: »the de facto denial of access to pain relief, if it causes severe pain and suffering, constitutes cruel, inhuman or degrading treatment or punishment. ${ }^{10}$ This first time application of the torture framework on healthcare settings by the Special Rapporteur was a major step forward in international law. The present Special Rapporteur on torture and cruel, inhuman and degrading treatment Juan Mendez reiterated this position is his report to the General Assembly of the UN of February 2013:

»failure to ensure access to controlled medicines for the relief of pain and suffering threatens fundamental rights to health and to protection against cruel, inhuman and degrading treatment. $^{11}$

Denial of access to adequate pain treatment and failure to ensure access to controlled medicines for the relief of pain are thus a two-sided or two-level violation of international law (the International Covenant on Civil and Political Rights and the International Covenant on Economic, Social and Cultural Rights. The jus cogens character of the right to be free from torture and/or cruel or inhuman and degrading treatment gives the struggle for the right to access to adequate pain treatment urgency and high profile.

A major cause of the inaccessibility of adequate pain treatment is the dominant »war on drugs « component in the control of illicit drugs and substances. The International Narcotic Control Board (INCB) controls the amount of »illicit substance « that individual countries are allowed to use for the procurement of opioids. The same agency is also the world body

$10 \mathrm{~A} / \mathrm{HRC} / 10 / 44,14$ January 2009, para. 72.

11 A/HRC/22/53, 1 February 2013, para. 56. 
controlling »illicit substances « that are used for the illegal trade in drugs (the »war on drugs «). This dual responsibility, namely to wage the »war on drugs « and at the same time to make sure that opioids are available in sufficient quantity for every person in need of pain control, has proven to be a very difficult, if not impossible combination. The Special Rapporteur on the right to health has repeatedly criticized this mechanism for the provision and control of opioids. ${ }^{12}$

During the campaign »Stop Torture in Healthcare« a conference was held in the Netherlands, co-hosted by the International Federation of Health and Human Rights Organizations, the International Association for the Study of Pain and facilitated by the Open Society Foundation, where international pain and palliative organizations, human rights organizations and organizations of health professionals discussed on the right to access to adequate pain treatment and prepared a draft resolution for the World Medical Association (WMA). The resolution was adopted by the WMA on 11 October 2011 during its 62th session in Montevideo, Uruguay. The WMA is the world body of physicians, and represents almost all doctors in the world. The resolution recognizes the right to

$»[\ldots]$ access to pain treatment for all people without discrimination «, emphasizes that $»[\ldots]$ physicians and other health care professionals have an ethical duty to offer proper clinical assessments to patients with pain and to offer appropriate treatment« and recommends that $»[\ldots]$ instruction on pain management, including clinical training lectures and practical cases, should be included in mandatory curricula and continuing education for physicians and other health professionals « and that $»[\ldots]$ government should provide the necessary resources for the development and implementation of a national pain treatment plan, including a responsive monitoring mechanism and process for receiving complaints when pain is inadequately treated. ${ }^{13}$

\subsection{Forced/Coerced Sterilization of Women}

Not only in history, but still today women are undergoing forced or coerced sterilization. Some are forcibly sterilised, not knowing the procedure, not having been given the opportunity to consent. Others were coerced into

12 Grover (2012).

13 WMA (2011). 
sterilisation by financial or other incentives, denial of medical services, or by being misinformed or otherwise compelled to undergo the procedure. The case of A.S. v. Hungary is a clear illustration of this issue:

»Upon going into labor, Ms. A.S., a member of the Roma community, needed an emergency Caesarian section. Immediately before the surgery, a doctor asked Ms. A.S. to sign consent forms on which the doctor had hand-written a statement that Ms. A.S. consented to a sterilization procedure. Ms. A.S. did not understand the statement or that she had been sterilized until after the operation took place. Her claim of civil rights violations and negligent sterilization was rejected at the local level. In her communication to the CEDAW Committee, it found that the Ms. A.S. exhausted her domestic remedies because under Hungarian law she was unable to appeal this decision to the Constitutional Court given the nature and facts of her case. Hungary was found to have violated Ms. A.S.'s rights to (1) fully informed consent to medical procedures; (2) right to information on family planning; (3) right to appropriate services in connection with pregnancy and the post-natal period; and (4) right to determine the number and spacing of her children, under Articles 10(h), 12 and 16(1)(e) of the Convention on the Elimination of Discrimination Against Women. ${ }^{14}$

This significant ruling of 2006 on behalf of a victim of forced sterilization before an international body (the Committee on Elimination of all forms of Discrimination Against Women, CEDAW) hold the State responsible for »failing to provide a woman with necessary information and obtain full consent for reproductive health procedures «. The ruling was a milestone and a strong stimulus in the struggle against this form of torture or cruel or inhuman and degrading treatment in healthcare.

In its Position Statement on Forced and/or Coerced Sterilization of 2011, the International Federation of Health and Human Rights Organizations describes the background of the problem:

»A sterilisation procedure performed safely, complying with medical and ethical standards after the full informed choice of the patient is an acceptable option of contraception for people who wish to have no more children.

14 CEDAW/C/36/D/2004, Communication No. 4/2004, 12 February 2004. 
However in recent years, cases of coerced and forced sterilization have been reported in countries across the globe. [...] In Africa, recent cases of forced sterilization were documented by the International Community of Women Living with HIV/AIDS. The organisation found that since 2008 women living with HIV/AIDS had undergone forced or coerced sterilization by tubal ligation. Practices of forced and coerced sterilization performed on women living with HIV/AIDS have also been recently documented in Chile, Dominican Republic, Mexico, South-Africa and Venezuela.

In Europe cases of forced and coerced sterilization have been documented against women of ethnic minorities. In 2005, the Czech Ombudsman issued a report in which he reviewed more than 80 allegations of forced and coerced sterilization of women, most of whom are members of the Roma minority. ${ }^{15}$

In October 2012, the World Medical Association adopted a similar position statement in its Statement on forced and coerced sterilization in Bangkok. ${ }^{16}$ The International Organization of Gynaecologists and Obstetrics also adopted ethical guidelines in accordance with human rights provisions. ${ }^{17}$

\subsection{Detention of Drug Users in Lieu of Adequate Treatment}

»A new report from UNAIDS, ${ }^{18}$ the United Nations program on HIV/AIDS, estimates that in 2014 - the last year for which the agency has data - about 450,000 people were being held in centers in China and other countries in Southeast Asia. These centers are supposed to provide treatment for people who use drugs, although their >treatment< consists primarily of arduous physical exercises and military-like drills. Former detainees also describe sadistic violence - being shocked with electric batons, whipped with twisted electrical wire, beaten, and being chained while standing in the sun. ${ }^{19}$

Stigmatization and criminalization of drug-users has led in many countries to inhuman treatment of drug-users. Instead of providing state-of-the-arts

15 IFHHRO (2011), 2.

16 WMA (2012).

17 FIGO (2012).

18 UNAIDS (2016).

19 Pearshouse (2016). 
treatment, they are committed to detention facilities where they are forced to slavery-like working conditions, and where adequate medical treatment is withheld or absent.

Such practices are deeply in contradiction with medical ethics and international guidelines. In the International Federation of Health and Human Rights Organization's position statement:

»The medical community has recognized that streatment of addiction, like treatment for any disease or condition, should be undertaken in the best interests of the patient and according to established principles of medical ethics.< Drug therapy should be administered according to professional guidelines and supervised by specially trained physicians. Community-based services such as substitution therapy are recognized as effective, evidence-based rehabilitation and treatment strategies. Such services also decrease the risk of HIV transmission.

The human rights of individuals who use or are addicted to controlled substances should always be respected, including the right to the highest attainable standard of health and freedom from discrimination, arbitrary detention, torture and cruel, inhuman or degrading treatment. They have a right to equitable access to medical treatment and allied rehabilitation services in accordance with generally approved medical principles. ${ }^{20}$

\subsection{Abuse of Medical Expertise}

Medical skills and knowledge has been (and is being) abused on a large scale (see also the chapter on Dual Loyalty). Participation in torture is perhaps the most pervasive and disturbing practice. The UN Principles of Medical Ethics relevant to the Role of Health Personnel, particularly Physicians, in the Protection of Prisoners and Detainees against Torture and Other Cruel, Inhuman or Degrading Treatment or Punishment are very explicit in the prohibition of such participation, even under pressure. This is mentioned in principle 6: »There may be no derogation from the foregoing principles on any ground whatsoever, including public emergency. $\ll^{21}$

Doctor's complicity in torture and ill-treatment has been described many times, for example in the USA, where Iacopino et al. found that

20 IFHHRO (2011), 2.

21 A/RES/37/194, 18 December 1982. 
»medical personnel neglected and/or concealed medical evidence of intentional harm «. ${ }^{22}$ Physicians for Human Rights investigated and documented complicity of psychologists in interrogation techniques amounting to torture. $^{23}$

This article does not allow to mention all examples of medical complicity in torture and/or ill-treatment. However, I will mention two examples of initiatives from »medical side « that help to expose abuses of »medical expertise « which are completely unfounded and amount to torture: virginity testing and rectal examination to »prove homosexual intercourse $\ll$.

The International Forensic Expert Group published a statement on virginity testing:

»The practice of forcibly conducting virginity testing to determine whether a woman is still a virgin is a clear human rights violation that is likely to leave the victim with significant physical and psychological scars, and constitutes ill-treatment and possibly torture says the Independent Forensic Expert Group (IFEG). $\ll^{24}$

Despite the illegality of the practice in many states and the clear violation of international human rights standards, women around the world are still forced to undergo virginity examinations. Recent cases in Indonesia, Egypt and Afghanistan confirm the continuing use of this practice.

»The expert opinion concludes that >forcibly conducted virginity examinations have no clinical or scientific value and constitute cruel, inhuman and degrading treatment, and may amount to torture depending on the individual circumstances $\measuredangle$. >Virginity examinations are medically unreliable and inherently discriminatory<, states the IFEG. [...] According to the experts, due to its invasive and sexual nature, forcibly conducted virginity testing is likely to cause severe and lasting psychological symptoms and disabilities that remain over time. $\ll^{25}$

22 Iacopino/Xenakis (2011).

23 See http://physiciansforhumanrights.org/issues/torture/us-torture/ [27.03.2017].

24 IRCT (2012).

25 Ibid. 
The same International Forensic Expert Group published an expert statement on forced rectal examination with suspects of homosexuality in countries where homosexuality is criminalized. The statement

»strongly condemns the practice of anal examinations in cases of alleged homosexual activity. The statement categorically asserts that forcibly conducted anal examinations are medically and scientifically worthless in establishing whether consensual anal intercourse has occurred and that the practice constitutes cruel, inhuman and degrading treatment and possibly torture $[\ldots]$ anal examinations to $>$ detect homosexuality have no scientific value, are unethical, and constitute cruel, inhuman and degrading treatment and possibly torture. Sexual identity and orientation is not a disease or a crime and health professionals have no business diagnosing it or aiding State officials in policing and punishing people on the basis of their sexuality. ${ }^{26}$

\subsection{Forensic Evidence in Exposing III-treatment}

The opposite of the above mentioned examples is the use of medical knowledge in court cases where human rights violations have to be established. Perhaps the best known examples are those where the Istanbul Protocol has been used. This UN Manual on the Effective Investigation and Documentation of Torture and Other Cruel, Inhuman or Degrading Treatment or Punishment ${ }^{27}$ was written by medical and legal experts in 1999 and has been an authoritative instrument in numerous court cases.

Medical expert opinions can make a substantive and decisive difference in human rights court cases. An illustrative example of a court case where a State has been held accountable for gross medical negligence is the case of Valentin Câmpeanu v. Romania.

»On 17th July, 2014, the European Court of Human Rights (ECHR) held the Romanian government accountable for violating the human rights of Valentin Câmpeanu, a youth with severe mental disabilities and HIV positive, who died in 2004. Abandoned at birth, he lived in public institutions all his life. When he turned eighteen, he was shifted to a social care home for adults, and afterwards, to a mental hospital. Here, left in isolation, and in the cold, without necessary health care and treatment,

$26 \operatorname{IRCT}(2016)$.

27 United Nations (2004). 
and deprived also of food and proper clothing, he died within seven days. [...] This case is a groundbreaking disability rights case concerning both access to justice for individuals with disabilities and also, their ill-treatment in long-term stay institutions. The decision shines a light on the plight of people with disabilities who face institutional abuse and are particularly vulnerable since due to their disability they are often unable to complain or seek judicial remedies to ameliorate their situation.

The decision will impact legal systems across Europe as the ECHR has held that NGOs can represent people with disabilities who died due to violations of their rights, when there was no one else to seek justice on their behalf. $\ll^{28}$

The European Court of Human Rights ruling ${ }^{29}$ extensively quoted the expert opinion end relied on the medical expert's conclusion of gross medical negligence. ${ }^{30}$

\section{THE 2013 REPORT OF the SPECIAL RAPPORTEUR ON TORTURE AND CRUEL, INHUMAN AND Degrading Treatment and Punishment}

This report to the General Assembly in January 2013 by the Special Rapporteur on Torture and cruel, inhuman and degrading treatment and punishment $^{31}$ Juan Mendez is generally viewed as a most comprehensive and authoritative »milestone" report on torture and cruel or inhuman and degrading treatment in healthcare setting. The report applies the torture framework systematically on healthcare settings and provides clear and far-reaching recommendations. It has also raised questions and reservations, notably from the health sector and organizations of health professionals, and has raised fierce debate on some crucial elements in the report such as the absolute ban on seclusion and restraint. Mendez has

28 ECHR: »Case of Centre for Legal Resources on Behalf of Valentin Câmpeanu v. Romania«(GC), Judgement 17 July 2014, No. 47848/08.

29 Ibid.

30 IRCT (2014).

31 A/HRC/22/53, 1 February 2013. 
»[...] examined the key elements of the definition of torture and ill-treatment and its applicability to the abuses in health-care settings « and found that $»[\ldots]$ the application of the criteria of severe pain or suffering, intent, and involvement of a public official or other person acting in an official capacity, by consent or acquiescence to abuses in health-care settings, is relatively straightforward and that the criterion of the specific purpose warrants some analysis. $\ll^{32}$

\subsection{Concerns and Criticism from the Medical Community}

Some of the recommendations in Mendez' report that raised fundamental discussions are under the paragraphs 85(e) and 89(b):

»Safeguard free and informed consent on an equal basis for all individuals without any exception, through legal framework and judicial and administrative mechanisms, including through policies and practices to protect against abuses. Any legal provisions to the contrary, such as provisions allowing confinement or compulsory treatment in mental health settings, including through guardianship and other substituted decision-making, must be revised [...] [and] [p]aragraph 89 (b)[:] Impose an absolute ban on all forced and non-consensual medical interventions against persons with disabilities, including the non-consensual administration of psychosurgery, electroshock and mind-altering drugs such as neuroleptics, the use of restraint and solitary confinement, for both long- and short-term application. The obligation to end forced psychiatric interventions based solely on grounds of disability is of immediate application and scarce financial resources cannot justify postponement of its implementation $[\ldots] . \ll^{33}$

Criticism from the medical community focused on the absolute ban on seclusion and surrogate consent without any exception. In his response of May 2013 to the report of Mendez, the secretary-general of the World Medical Association, Dr. Otmar Kloiber, referring to Recommendation No. 85(e):

»[...] provisions allowing confinement or compulsory treatment in mental health settings, including through guardianship and other substituted decision-making, must

32 Centre for Human Rights \& Humantarian Law (2014), XVI.

33 Ibid., 145. 
be revised. ${ }^{34}$ Furthermore, he emphasizes: $»$ The patient's judgment should be respected in areas where he/she is legally capable of making decisions, unless they present a risk of serious harm to themselves or others. [...] If the patient lacks the capacity to make a decision as to his/her medical care, surrogate consent should be sought from an authorized representative in accordance with applicable law. « ${ }^{35}$

In exceptional circumstances, surrogate consent can constitute a medical necessity for the safety of the patient and/or the society. And on the absolute ban on the use of restraint and solitary confinement Kloiber writes:

»[H]ere again, in exceptional circumstances [...] restraining the movement of the patients can constitute a medical necessity. Medical ethics principles require the following conditions: >(a) a severe mental disorder that prevents the individual from making his/her own treatment decisions; and/or (b) the likelihood that the patient may harm him/her self or others «. He continues: »[...] the recommendations of the report advocate that measures restricting movements of >persons with psychosocial disabilities should be prohibited. According to us, this affirmation is invalid and risky, in suggesting that the medical necessity never justifies coercive measures. It reflects clear unawareness of the degree of illness of some patients, and an alarming negligence likely to endanger the patient him/herself and others. It also misinterprets the function of doctors as backbone of the health care system and indirectly undermines the expected privileged relationship between physicians and patients based on trust, professionalism and confidentiality. [...] More generally, we are concerned that your report generates prejudice and distress on psychiatric services, while supporting the current trend to consider mental disorders, not anymore as real diseases to be treated by psychiatrists, but rather as social deviation or just psychological suffering to be treated by psychologists and other mental health professionals. [...] Health professionals work often under very precarious situations. Blaming them for these abuses is unfair and inappropriate. ${ }^{36}$

In response to the report of the Special Rapporteur, the World Psychiatric Association and the American Psychiatric Association also expressed concern that

34 WMA (2013), 1.

35 Ibid., 2.

36 Ibid., 2-3. 
"the adoption of these perspectives and recommendations may be detrimental to the interests of individuals with serious mental disorders, and likely to cause serious harm to the very groups it intends to protect. $\ll^{37}$

Mendez responded to these concerns in January 2014:

»[...] I did not mean to propose an absolute ban on non-consensual interventions (including institutionalization and restraints) under any and all circumstances. I meant to restrict my condemnation to non-consensual treatment based exclusively on discrimination against persons with disabilities. In other words, the fact that a person is diagnosed as having a psychosocial disability should not by itself be enough to justify non-consensual treatment. Unfortunately, in many countries that is standard practice, often validated by domestic courts and even by international tribunals (in some decisions that my report criticizes). As you point out, elsewhere in my report (paragraphs 68 and 69) I do mention that involuntary detention and treatment is legitimate if its purpose is to prevent the patient harming him or herself or causing serious harm to others, and then for the limited time and scope necessary to prevent such harm. I firmly believe, however, that legislation should be revised to place the burden on the State to justify each decision to apply non-consensual treatment under such narrow grounds.

I do not doubt that my proposal coincides - in large part, at least - with the highest professional standards of your profession as reflected in the policy statements relevant to this topic that you have attached. My concern is with the many parts of the world where those professional standards are not applied. $\aleph^{38}$

The milestone 2013 thematic report of the Special Rapporteur and the subsequent concerns of and communications with (organizations of) health professionals illustrate the existing and potentially continuing gap between evolving international law (focussed on healthcare) and perceptions and convictions of health professionals. In my opinion, it is of utmost importance to bridge this gap, because of the necessity to have health professionals »on board « in the struggle against torture and cruel or inhuman and degrading treatment in healthcare. Health professionals should be part of

37 Levin (2014).

38 Méndez (2014), para. 32. 
and be perceived as part of the solution rather than (only) be seen as part of the problem.

\subsection{The Problem of »Torture Language»}

In a substantive and principal contribution »Torture in Health Care Settings: Urgent Issues and Challenging Questions« in the »Reflections on the Special Rapporteur on Torture's 2013 Thematic Report« Yuval Ginbar and James Welsh argue that

»the torture/other ill-treatment legal framework must be applied carefully and precisely, taking into account that the human rights of persons, other than those being treated, may be involved. This requires maintaining openness to the possibility that other legal frameworks for the protection of human rights may at times be better equipped to address certain issues within healthcare settings. It also requires considering the far-reaching legal consequences of a finding of any ill-treatment, particularly torture, in cases where law and professional regulations are being followed. Whereas international law obviously prohibits torture and ill-treatment absolutely and in all circumstances, we are concerned that framing positions on certain measures which are not inherently torturous in absolute terms would not serve the rights of persons with disabilities; nor would linking such sweeping positions to the prohibition on torture and other ill-treatment encourage observance of that prohibition, which is indeed absolute. $\ll^{39}$

The problem of »torture language« is also acknowledged by Tamar Ezer, Jonathan Cohen and Ryan Quinn in their contribution »The Problem of Torture in Healthcare«, discussing the application of the »torture framework« on healthcare settings: Before applying the norms against torture and cruel or inhuman and degrading treatment systematically to the field of healthcare, it is necessary to review them and consider the similarities and differences between (1) torture; (2) cruel and inhuman treatment; and (3) degrading treatment. This is particularly important because the stigma that results from applying the label of »torture« to acts involving medical professionals can be counterproductive if applied carelessly. Moreover, it is important to recognize that applying a human rights approach focuses atten-

39 Centre for Human Rights \& Humantarian Law (2014), 264. 
tion on state responsibility and systemic violations and not on penalizing individual healthcare providers. A useful concept when considering the application of anti-torture norms to the healthcare context is that of dual loyalty, defined as

»simultaneous obligations, express or implied, to a patient and a third party, often the state. Where the interests of the patient and the state are aligned, dual loyalty imposes little risk. Where they conflict, however, this creates potential for abuse, including torture. $\aleph^{40}$

\section{The Dual Loyalty Concept}

The International Dual Loyalty Working Group, convened by Physicians for Human Rights and the University of Cape Town in 2002, has identified common situations where dual loyalty conflicts arise and has provided recommendations for preventing them.

This working group on dual loyalty was formed after the hearings of the health sector by the Truth and Reconciliation Committee in South Africa, where the dual loyalty problem had become extremely evident. ${ }^{41}$

»This project grew out of a disturbing trend: Governments and other third parties often demand that health professionals put allegiance to their patients aside, in deference to the demands of these powerful actors [...]. The report of South Africa's Truth and Reconciliation Commission (TRC) documenting the complicity of health professionals in the apartheid regime, provides a particularly compelling illustration of the problem. [...] The report urged the adoption of effective standards of conduct in situations of potential dual loyalty, as well as institutional arrangements and educational programs to ameliorate the problem. $\aleph^{42}$

40 Centre for Human Rights \& Humantarian Law (2014), 43.

41 Baldwin-Ragaven et al. (1999).

42 Physicians for Human Rights/School of Public Health and Primary Health Care (2002), 5 . 
The project focussed on areas where human rights violations out of dual loyalty are most likely to happen: settings of forensic medicine, prisons, refugees and asylum seekers, the work floor and the military.

The working group identified a variety of situations where medical ethics and human rights were violated in the context of dual loyalty conflicts: using medical skills or expertise on behalf of the State to inflict pain, physical or psychological harm on an individual that is not a legitimate part of medical treatment, participating in torture and punishment, participation of health professionals in administration of the death penalty, participation in forced abortion, sterilization and contraception and other violations of reproductive health rights relating to bodily integrity, degrading physical examinations that violate human rights, such as virginity testing, female genital mutilation, use of chemical and physical restraints and intrusive examinations to enhance security interests of a prison, detention centre, or other institutions, subordinating independent medical judgment, in therapeutic or evaluative settings, to support medical conclusions favourable to the State, limiting or denying medical treatment or information related to treatment to an individual to effectuate policy of the State in a manner that violates the patient's human rights, denial of or restrictions on care based on gender, ethnic or racial discrimination, sexual orientation or immigration status, denial of care for political reasons and during armed conflicts, denial of appropriate care to prisoners, detainees, and institutionalized people, withholding information about health or health services, the special problem of hunger strikers, denial of care because of inequities in healthcare in society, disclosing confidential patient information to state authorities or powerful non-state actor, performing evaluations for legal or administrative purposes in a manner that implicate human rights, remaining silent in the face of human rights abuses committed against individuals and groups in the care of healthcare professionals. The working group has proposed a large number of general guidelines and guidelines tailored to the five fields mentioned above. The size of this article does not allow detailed mention of all guidelines. The working groups also provided institutional mechanisms, varying from national and international legal mechanisms, participation of health professionals in monitoring mechanisms such as shadow reporting to supervising bodies of international covenants, and stressing the importance of a well-functioning, independent, human rights oriented professional organization or association. 


\section{CONCLUSION}

\subsection{The Problem of Domain: What is the Definition of a »Healthcare Setting«?}

There is a number of questions in the struggle to end torture and illtreatment in healthcare settings, namely the definition of »healthcare settings « and »health worker«. In my view, the report of the Special Rapporteur seems to limit healthcare settings to »institutions«, while in reality many healthcare settings can be identified in the community and in private homes. The Special Rapporteur recommends replacement of institution-based care to community based care, but does not extend the prevention of torture and/or ill-treatment to the »non-institution« domain.

In his focus on torture and/or ill-treatment in healthcare settings, the Special Rapporteur writes:

»each State party should prohibit, prevent and redress torture and ill-treatment in all contexts of custody or control, for example, in prisons, hospitals, schools, institutions that engage in the care of children, the aged, the mentally ill or disabled, in military service, and other institutions as well as contexts where the failure of the State to intervene encourages and enhances the danger of privately inflicted harm. ${ }^{43}$ [emphasis added, A.v.E.]

What these »contexts « are, is not further elaborated. And on potential perpetrators of torture and/or ill-treatment, the Special Rapporteur writes:

»Indeed, the States obligation to prevent torture applies not only to public officials, such as law enforcement agents, but also to doctors, healthcare professionals and social workers, including those working in private hospitals, other institutions and detention centres $[\ldots]$. Here too, there is no elaboration as to whether volunteers and family members involved in healthcare are included in these categories. ${ }^{44}$

43 A/HRC/22/53, 1 February 2013, para. 23.

44 Ibid., 24. 
In his recommendations, the Special Rapporteur views a shift from »institutions« to »community« as a desirable goal. On compulsory drug detention centres, his recommendation is: »Close compulsory drug detention and >rehabilitation< centres without delay and implement voluntary, evidencebased and rights-based health and social services in the community «. ${ }^{45}$ For people with disabilities he recommends:

»Replace forced treatment and commitment by services in the community. Such services must meet needs expressed by persons with disabilities and respect the autonomy, choices, dignity and privacy of the person concerned, with an emphasis on alternatives to the medical model of mental health, including peer support, awarenessraising and training of mental health-care and law enforcement personnel and others. $\ll^{46}$

I welcome this recommendation wholeheartedly. However, I miss the next step: How to prevent torture and/or cruel or inhuman and degrading treatment in the recommended services in the community? If not specified precisely, the mention of »community services« may well be an empty phrase or a romantic irreality. Obviously, the recommended replacement is not in itself a guarantee for freedom from torture. In many countries such replacements from institutions to community are taking place, not in the least for financial reasons. The result is often home-based care, where healthcare professionals, but also volunteers and relatives are responsible for the (health)care. The question is: Can the torture and ill-treatment concept be applied in those situations as well?

Ill-treatment is often taking place »behind the front-door« of this homebased care. In my own experience as family doctor I have witnesses many cases of ill-treatment »at home« (some of which may even amount to torture) and I have been involved in training courses on awareness-raising of ill-treatment of the (frail) elderly is a prominent issue. I found that even among experienced health workers there is a huge under-estimation of illtreatment. Estimates in the Netherlands indicate that there are at least 160,000-200,000 cases of ill-treatment of elderly people. Ill-treatment may

45 A/HRC/22/53, 1 February 2013, para. 87(a).

46 Ibid., para. 89(c). 
be physical, psychological, sexual and financial by negligence and/or by deprivation of rights. Ill-treatment of the elderly is defined as

itreatment or neglect of by all persons having (repeated) a personal and/or professional relation with an elderly person, with the result of physical, psychological and/or material damage, and where the elderly is in a state of partial or total dependency ${ }^{47}{ }^{47}$ [translation A.v.E.]

The problem of ill-treatment is severely compounded by the fact that care is often informal (by family or volunteers). When it is a volunteer, or a family member who takes care (at home) of a person with a psychosocial disability, or (notably problematic) dementia, is overburdened and at a time loses his or her temper, this may be a form of »derailed care«, but is it also torture? In its appearance and/or outcome it may well be ill-treatment or even torture. The question then is whether the carer is a torturer, and if so, only in case of intent, or also in case of derailed care?

Is the torture and/or cruel or inhuman and degrading treatment framework applicable to this kind of situations? Does the Convention against Torture extend to the private homes of vulnerable, frail person, of persons with disabilities living at home? How does the urgently needed prevention of torture and ill-treatment relate to the right to privacy? These are, in my view, issues that warrant discussion urgently; they have largely been untouched by the report of the Special Rapporteur and the subsequent discussions.

\subsection{Prevention of Torture in Healthcare}

The report of the Dual Loyalty working group has published an extensive list of (institutional) mechanisms that can help to promote human rights in healthcare, and monitor human rights violations in healthcare. The mechanisms mentioned are (i.a.): employment relationships structured to avoid role conflicts and reduce interference with professional independence, administrative and legal arrangements to preserve professional independence, establishment of an ethos of peer review, professional credibility, support and inclusiveness in the profession that addresses the problem of dual loy-

47 Ministerie van Volksgezondheid, Welzijn en Sport. 
alty, monitoring, education and training, accountability, collective action by the profession. On monitoring mechanisms, the report stresses that:

»Independent oversight and reporting structures must be established to monitor and respond to practices in the health sector that threaten human rights. These structures should support audit activities undertaken by health professionals and should enable professionals to make independent reports of potential or actual violations of the human rights of patients or other victims. These structures would also have the capacity to refer appropriate cases to professional disciplinary structures $[\ldots] \ll .{ }^{48}$

Monitoring the complicity of health professionals in human rights abuses

$»[\ldots]$ should also be linked to monitoring the underlying human rights violations. Monitoring can take place at the local or national level (by national professional associations, statutory bodies, or human rights organizations) and may often be done as well by international bodies, including United Nations agencies, professional bodies, and human rights organizations. ${ }^{49}$

In order to make sure that health professionals are part of the struggle against torture and/or ill-treatment in healthcare setting, rather than (only) part of the problem, it is of utmost importance that national (and international) professional organizations are strong and independent, and have a high profile human rights agenda in place. Licensing bodies must also be independent and have human rights provision included in their program and mandate. The organized profession should be part of a larger coalition of organizations that monitors the defense and promotion of human rights. Such coalitions of organizations should provide input to and cooperate with UN Special Rapporteurs (e.g. on Torture and cruel or inhuman and degrading treatment, and on the right to the highest attainable standard of health), cooperate on the production and publication of parallel or shadow reporting to the supervising committees of UN Covenants.

48 Physicians for Human Rights/School of Public Health and Primary Health Care (2002), 88.

49 Ibid. 
An important role for monitoring human rights violations (in Europe) is the European Committee for the Prevention of Torture. In numerous reports the Committee has listed human rights violations.

Also the visits of the Subcommittee for the Prevention of Torture under the Optional Protocol to the Convention Against Torture have contributed to identifying human rights violations. The National Preventive Mechanisms, required under Optional Protocol to the Convention Against Torture, and which have been formed in OPCAT countries in different manners, play (or are supposed to play) an important role. A research project in the Netherlands by the University of Groningen with support of the International Federation of Health and Human Rights Organizations indicated that the National Preventive Mechanisms are still to be improved:

»In terms of mandate, the National Preventive Mechanisms appear to fulfil the requirements, however there are doubts about the independence. In addition, the National Preventive Mechanisms assignment to existing monitoring bodies have not (yet) led to organizational accommodation or change. $\aleph^{50}$ [translation A.v.E.]

My conclusion is that the prevention of torture in healthcare settings needs ongoing debate and elaboration both in international human rights law and in the health professional's domain. The application of medical expertise in the defence and promotion of human rights has achieved much, and should continue to be developed further. Existing mechanisms for monitoring human rights violations, including torture in healthcare setting should be utilized much more extensively, notably by health professionals.

50 University of Groningen (2013). 


\section{References}

Baldwin-Ragaven, Laurel/de Gruchy, Jeanelle/London, Leslie (1999): An Ambulance of the Wrong Colour. Health Professionals, Human Rights and Ethics in South Africa, Cape Town: University of Cape Town Press.

Brennan, Frank/Carr, Daniel/Cousins, Michael (2007): »Pain Management: A Fundamental Human Right«, in: Anesthesia \& Analgesia 105, 1 (2007), 205-221.

Centre for Human Rights \& Humantarian Law (2014): »Torture in Healthcare Settings: Reflections on the Special Rapporteur on Torture's 2013 Thematic Report«, Online: http://antitorture.org/wp-content/uploads/2014/03/PDF_Torture_in_Healthcare_Publication.pdf [17.10.2016].

FIGO (2012): »Ethical issues in obstetrics and gynecology, by the study of ethical aspects of human reproduction and women's health«, Online: http://www.figo.org/sites/default/files/uploads/wg-publications/ethics/English\%20Ethical\%20Issues\%20in\%20Obstetrics\%20and\%20Gynecology.pdf [17.10.2016].

Frewer, Andreas/Furtmayr, Holger/Krása, Kerstin/Wenzel, Thomas (Eds.) (2009): Istanbul-Protokoll. Untersuchung und Dokumentation von Folter und Menschenrechtsverletzungen. Medicine and Human Rights/ Medizin und Menschenrechte, Vol./Band 2, Göttingen: V \& R unipress.

Human Rights Watch (2009): »Please, do not make us suffer any more. Acess to Pain Treatment as a Human Right«, Online: https://www.hrw. org/report/2009/03/03/please-do-not-make-us-suffer-any-more/accesspain-treatment-human-right [17.10.2016].

Iacopino, Vincent/Xenakis, Stephen N. (2011): "Neglect of Medical Evidence of Torture in Guantánamo Bay: A Case Series«, in: Plos Medicine, published 26 April 2011, Online: http://dx.doi.org/10.1371/journal.pmed.1001027 [17.10.2016].

IASP (2010): »Declaration of Montreal. Declaration that Access to Pain Management is a Fundamental Right«, Online: http://www.iasp-pain. org/DeclarationofMontreal?navItemNumber=582 [17.10.2016].

IFHHRO (2011): »Foerced and/or coerced sterilisation«, Statement, 19 July 2011, Online: http:/www.ifhhro.org/images/stories/ifhhro/PositionState ments/ifhhro_position_statement_fs_def.pdf [17.10.2016]. 
IRCT (2012): IFEG: »Forcibly conducting virginity testing is a human rights violation and may constitute torture $«$, Statements \& Declarations, 16 December 2014, Online: http://www.irct.org/media-and-resources/irct-news/show-news.aspx?PID=13767\&NewsID=3943 [17.10.2016].

IRCT (2014): »IFEG doctor instrumental in Romanian ill-treatment ruling«, News 25 July 2014, Online: http://www.irct.org/media-andresources/irct-news/show-news.aspx?PID=13767\&NewsID=3894 [17.10.2016].

IRCT (2016): »IRCT joins the IFEG in condemning forced anal examinations as violations of the ban on torture and ill-treatment «, Statements \& declarations. 3 May 2016, Online: http://www.irct.org/media-andresources/irct-news/show-news.aspx?PID=13767\&-

Action $=1 \&$ NewsId $=4037$ [17.10.2016].

Levin, Aaron (2014): »UN Report says common psychiatric practices amount to >Torture«", Psychiatric News, published online 25 April 2014, Online: http://psychnews.psychiatryonline.org/doi/10.1176/appi.pn.2014.5a11 [17.10.2016].

Lohman, Diederik/Schleifer, Rebecca/Amon, Joseph (2010): »Access to pain treatment as a human right «, in: BMC Medicine 8, 8 (2010). doi: 10.1186/1741-7015-8-8.

Méndez, Juan E. (2014): »Letter from Juan E. Méndez (Special rapporteur on torture and other cruel, inhuman or degrading treatment or punishment) to Jeffrey Lieberman (President American Psychiatric Association), Pedro Ruiz, President (World Psychiatric Association), Saul Levin, CEO/Medical Director (American Psychiatric Association)«, Geneva, 22 January 2014, Online: http://www.wpanet.org/uploads/ Latest_News/News_from_WPA_Sections/attach\%2004.pdf [17.10.2016]. Ministerie van Volksgezondheid, Welzijn en Sport: »Ouderenmishandeling«, Dossier, Online: https://www.huiselijkgeweld.nl/ouderenmis handeling [06.06.2017].

Pearshouse, Richard (2016): »Why Asia`s Drug Dentention Centers Need to be Shuttered«, Human Rights Watch Blog, 18 April 2016, Online: https://www.hrw.org/blog-feed/rethinking-war-drugs [17.10.2016].

Physicians for Human Rights/School of Public Health and Primary Health Care (2002): »Dual Loyalty \& Human Rights in Health Professional Practice; Proposed Guidelines \& Institutional Mechanisms«, A Project 
of the International Dual Working Group, Online: https://s3.amazon aws.com/PHR_Reports/dualloyalties-2002-report.pdf [17.10.2016].

UNAIDS (2016): »Do no harm. Health human rights and people who use drugs«, Online: http://www.unaids.org/en/resources/documents/2016/do-no-harm [17.10.2016].

University of Groningen (2013): »Implementatie van het OPCAT: preventie van onmenselijke behandeling in Zorginstellingen«, Online: https://www.rug.nl/rechten/congressen/archief/2013/osi-project/rapportimplementatie-opcat.pdf [17.10.2016].

WHO (1998): »Action Programme on Essential Drugs. Collaboration between NGOs, Ministries of Health and WHO in Drug Distribution and Supply«, WHO/DAP/98.12, Online: http://apps.who.int/medicinedocs/ pdf/s2237e/s2237e.pdf [17.10.2016].

WMA (2011): „WMA Resolution on the Access to Adequate Pain Treatment $\ll$, adopted by the $62^{\text {nd }}$ WMA General Assembly. Montevideo, Uruguay, Online: http://www.wma.net/en/30publications/10policies/p2/ [17.10.2016].

WMA (2012): »WMA Statement on Forced and Coerced Sterilisation«, adopted by the $63^{\text {rd }}$ WMA General Assembly, Bangkok, Thailand, October 2012, Online: http://www.wma.net/en/30publications/10policies/s21/index.html [17.10.2016].

WMA (2013): »Letter from Otmar Kloiber (Secretary General) to Juan E. Méndez (Special rapporteur on torture and other cruel, inhuman or degrading treatment or punishment) «, Geneva, $3^{\text {rd }}$ May 2013, Online: http://www.wma.net/en/20activities/20humanrights/40torture/LetterJ_E_-Mendez--May-2013.pdf [17.10.2016]. 


\section{IMPLEMENTATION IN HeALTHCARE SyStemS}





\section{The Right to Health and the Post-2015 Health and Sustainable Development Goal Agenda}

Jonathan Mann's 1997 Call for a Paradigm Shift Remains Imperative

Claire E. BROLAN

\section{INTRODUCTION}

The Emerging Fields Initiative (EFI) Conference, » The right to health - an empty promise?«, held 14-16 September 2015 in Berlin, Germany, occurred one week before the General Assembly gathered together at United Nations (UN) headquarters in New York to vote on the post-2015 Sustainable Development Goal (SDG) agenda. At that high-level General Assembly plenary meeting, the »UN Sustainable Development Summit« of 25-27 September 2015, the UN member states collectively endorsed the General Assembly resolution, »Transforming our World: the 2030 Agenda for Sustainable Development «. ${ }^{1}$ This formative UN resolution on the post -2015 SDG agenda will be the global community's blueprint for development the »plan of action for people, planet and prosperity « ${ }^{2}$ - for the next 15 years. Consisting of a 35-page, 91-paragraph document, this important

1 A/Res/70/1, 25 September 2015.

2 Ibid. 
resolution contains much of the »unfinished business« of its precursor, the Millennium Development Goal (MDG) agenda.

Expiring on 31 December 2015, the eight MDGs were originally introduced to the world by former UN Secretary-General Kofi Annan in his »Road map towards the implementation of the UN Millennium Declaration report« (Road map report) of September 2001. ${ }^{3}$ Indeed, the MDGs have been described as the new global »super-norm « for poverty reduction. ${ }^{4}$ Much has been written on their rise, their benefits and deficits - including a myriad of critiques by global health analysts. Notwithstanding these, the MDGs have played a historic and transformative role in streamlining global attention, resource, and programmatic action onto three health and development priorities: the reduction of child mortality (MDG 4); the improvement of maternal health (MDG 5); and combatting HIV/AIDS, malaria and other diseases (MDG 6).

The 17 SDGs outlined in the September 2015 resolution extend the MDG agenda. ${ }^{5}$ This is mainly because the UN resolution on the post-2015 SDGs shifts the world's development focus from poverty eradication (as emphasised by the MDGs) to poverty eradication and sustainable development, while also reinforcing the inclusive nature of the new goals through its central principle, »that no one will be left behind «. ${ }^{6}$ Of added significance, the post-2015 agenda is a »new Universal Agenda $\ll{ }^{7}$ applicable to all, everywhere, in low-, middle- and high-income countries alike. As para. 5 of the post-2015 UN resolution powerfully states:

»This is an Agenda of unprecedented scope and significance. It is accepted by all countries and is applicable to all, taking into account different national realities, capacities and levels of development and respecting national policies and priorities. These are universal goals and targets which involve the entire world, developed and

3 Annan (2001).

4 Fukuda-Parr/Hulme (2009).

5 Full list of the 17 SDGs under http://www.un.org/sustainabledevelopment/ sustainabledevelopment-goals/ [24.02.2017].

6 Brolan (2016).

7 A/Res/70/1, 25 September 2015. 
developing countries alike. They are integrated and indivisible and balance the three dimensions of sustainable development. $\ll^{8}$

Global health was represented in the 17 SDGs in a single goal, SDG 3: Ensure healthy lives and promote well-being for all at all ages (table 1). While health was prominently featured in three of the eight MDGs (MDGs 4-6), the lone post-2015 global health and development goal, SDG 3, is no less »a win« for post-2015 health advocates. This is because SDG 3 and its nine targets and four means of implementation not only progress the unfinished business of the MDG health agenda through SDGs 3.1-3.3, but considerably expand this agenda to also include global prioritisation of noncommunicable diseases (SDG 3.4), the achievement of Universal Health Coverage (SDG 3.8) that explicitly includes universal access to sexual and reproductive healthcare services (SDG 3.7), the prevention and treatment of substance abuse (SDG 3.5), and reduction of global morbidity and mortality due to road traffic accidents (SDG 3.6) as well as poor ecological and environmental health (SDG 3.9).

Table 1: Post-2015 global health and development goal (SDG 3)

\section{Goal 3. Ensure healthy lives and promote well-being for all at all ages}

\section{Targets}

3.1 By 2030, reduce the global maternal mortality ratio to less than 70 per 100,000 live births

3.2 By 2030, end preventable deaths of newborns and children under 5 years of age, with all countries aiming to reduce neonatal mortality to at least as low as 12 per 1,000 live births and under-5 mortality to at least as low as 25 per 1,000 live births

\footnotetext{
8 UN General Assembly (2015a).
} 
3.3 By 2030, end the epidemics of AIDS, tuberculosis, malaria and neglected tropical diseases and combat hepatitis, water-borne diseases and other communicable diseases

3.4 By 2030, reduce by one third premature mortality from non-communicable diseases through prevention and treatment and promote mental health and well-being

3.5 Strengthen the prevention and treatment of substance abuse, including narcotic drug abuse and harmful use of alcohol

3.6 By 2020, halve the number of global deaths and injuries from road traffic accidents

3.7 By 2030, ensure universal access to sexual and reproductive healthcare services, including for family planning, information and education, and the integration of reproductive health into national strategies and programmes

3.8 Achieve universal health coverage, including financial risk protection, access to quality essential healthcare services and access to safe, effective, quality and affordable essential medicines and vaccines for all

3.9 By 2030, substantially reduce the number of deaths and illnesses from hazardous chemicals and air, water and soil pollution and contamination

\section{Means of Implementation}

3.a Strengthen the implementation of the World Health Organization Framework Convention on Tobacco Control in all countries, as appropriate

3.b Support the research and development of vaccines and medicines for the communicable and non-communicable diseases that primarily affect 
developing countries, provide access to affordable essential medicines and vaccines, in accordance with the Doha Declaration on the TRIPS Agreement and Public Health, which affirms the right of developing countries to use to the full the provisions in the Agreement on Trade-Related Aspects of Intellectual Property Rights regarding flexibilities to protect public health, and, in particular, provide access to medicines for all

3.c Substantially increase health financing and the recruitment, development, training and retention of the health workforce in developing countries, especially in least developed countries and small island developing States

3.d Strengthen the capacity of all countries, in particular developing countries, for early warning, risk reduction and management of national and global health risks

Source:http://www.un.org/sustainabledevelopment/sustainabledevelopm ent-goals/ [24.02.2017]

What is curious about the content of SDG 3, however, is that despite the UN member states having ratified one or more binding treaties that include »the right of everyone to the enjoyment of the highest attainable standard of physical and mental health « (the right to health), ${ }^{9}$ and this right otherwise expressed in over 100 national constitutions, ${ }^{10}$ these same countries in September 2015 unanimously voted for a single health goal bereft of clear and cogent right to health language. In other words, SDG 3 did not explicitly contain or reference the right to health originally introduced in the World Health Organization's constitution in 1946 and then codified in international law particularly by way of Article 12 of the International Covenant on Economic, Social and Cultural Rights (ICESCR) of 1966. Since that time, the right to health has been recognised in a wide array of other international and regional human rights instruments. ${ }^{11}$

Yet if the right to health in international law is the normative gold standard for global health that all UN member states have adopted (in some

9 Backman et al. (2008).

10 Kinney/Clark (2004); Perehudoff (2008).

11 E/C.12/2000/4, 11 August 2000. 
form) to respect, protect and fulfil, it is only right to ask why this human right did not translate into the overarching post-2015 global health umbrella goal, or was not sewn into one of the nine targets or, at very least, one of SDG 3's four means of implementation. In fact, close inspection of the content of the 17 SDGs and their 169 associated targets and means of implementation contained between pages 14 to 27 of the UN General Assembly resolution on the post-2015 SDG agenda highlights human rights' marginal presence. For instance, human rights' shortened version, »rights «, is explicitly found in six locations in the SDG metrics framework: in four targets and two means of implementation (Table 2). This ensures »rights« are expressed in only five of the 17 goals; less than a third of the SDGs. Further, where »rights« are referred to as »human rights « in the one standalone target, Target 4.7 (see Table 2), this phrase is inserted to affirm that the learning of human rights in educational settings is to be promoted. Of course, the learning and generation of human rights awareness is important; but in many ways this alone is insufficient to adequately and incrementally achieve the larger human right to education. ${ }^{12}$

Table 2: Rights in the post-2015 SDG framework

\begin{tabular}{|l|l|l|}
\hline \multicolumn{1}{|c|}{ Post-2015 Goal } & \multicolumn{1}{|c|}{ Target } & \multicolumn{1}{|c|}{$\begin{array}{c}\text { Means of } \\
\text { Implementation }\end{array}$} \\
\hline $\begin{array}{l}\text { Goal 1: End } \\
\text { poverty in all its } \\
\text { forms everywhere }\end{array}$ & $\begin{array}{l}\text { 1.4: By 2030, ensure } \\
\text { that all men and } \\
\text { women, in particular } \\
\text { the poor and the } \\
\text { vulnerable, have equal } \\
\text { rights to economic } \\
\text { resources, as well as } \\
\text { access to basic } \\
\text { services, ownership } \\
\text { and control over land } \\
\text { and other forms of } \\
\text { property, inheritance, } \\
\text { natural resources, } \\
\text { appropriate new }\end{array}$ & \\
\hline
\end{tabular}

12 Unterhalter (2014). 


\begin{tabular}{|c|c|c|}
\hline & $\begin{array}{l}\text { technology and } \\
\text { financial services, } \\
\text { including } \\
\text { microfinance. }\end{array}$ & \\
\hline $\begin{array}{l}\text { Goal 3: Ensure } \\
\text { healthy lives and } \\
\text { promote wellbeing } \\
\text { for all at all ages }\end{array}$ & & $\begin{array}{l}\text { 3.b Support the research } \\
\text { and development of } \\
\text { vaccines and medicines } \\
\text { for the communicable } \\
\text { and non-communicable } \\
\text { diseases that primarily } \\
\text { affect developing } \\
\text { countries, provide } \\
\text { access to affordable } \\
\text { essential medicines and } \\
\text { vaccines, in accordance } \\
\text { with the Doha } \\
\text { Declaration on the } \\
\text { TRIPS Agreement and } \\
\text { Public Health, which } \\
\text { affirms the right of } \\
\text { developing countries to } \\
\text { use to the full the } \\
\text { provisions in the } \\
\text { Agreement on } \\
\text { Trade-Related Aspects } \\
\text { of Intellectual Property } \\
\text { Rights regarding } \\
\text { flexibilities to protect } \\
\text { public health, and, in } \\
\text { particular, provide } \\
\text { access to medicines. }\end{array}$ \\
\hline $\begin{array}{l}\text { Goal 4: Ensure } \\
\text { inclusive and } \\
\text { equitable quality } \\
\text { education and } \\
\text { promote lifelong } \\
\text { learning }\end{array}$ & $\begin{array}{l}\text { 4.7: By } 2030 \text {, ensure } \\
\text { that all learners acquire } \\
\text { the knowledge and } \\
\text { skills needed to } \\
\text { promote sustainable } \\
\text { development and }\end{array}$ & \\
\hline
\end{tabular}




\begin{tabular}{|c|c|c|}
\hline $\begin{array}{l}\text { opportunities for } \\
\text { all }\end{array}$ & $\begin{array}{l}\text { sustainable lifestyles, } \\
\text { human rights, gender } \\
\text { equality, promotion of } \\
\text { a culture of peace and } \\
\text { non-violence, global } \\
\text { citizenship and } \\
\text { appreciation of cultural } \\
\text { diversity and of } \\
\text { culture's contribution } \\
\text { to sustainable } \\
\text { development. }\end{array}$ & \\
\hline $\begin{array}{l}\text { Goal 5: Achieve } \\
\text { gender equality } \\
\text { and empower all } \\
\text { women and girls }\end{array}$ & $\begin{array}{l}\text { 5.6: Ensure universal } \\
\text { access to sexual and } \\
\text { reproductive health } \\
\text { and reproductive rights } \\
\text { as agreed in accord- } \\
\text { ance with the Pro- } \\
\text { gramme of Action of } \\
\text { the International Con- } \\
\text { ference on Population } \\
\text { and Development and } \\
\text { the Beijing Platform } \\
\text { for Action and the out- } \\
\text { come documents of } \\
\text { their review confer- } \\
\text { ences. }\end{array}$ & $\begin{array}{l}\text { 5.a Undertake reforms } \\
\text { to give women equal } \\
\text { rights to economic } \\
\text { resources, as well as } \\
\text { access to ownership and } \\
\text { control over land and } \\
\text { other forms of property, } \\
\text { financial services, } \\
\text { inheritance and natural } \\
\text { resources, in accordance } \\
\text { with national laws. }\end{array}$ \\
\hline $\begin{array}{l}\text { Goal 8: Promote } \\
\text { sustained, } \\
\text { inclusive and } \\
\text { sustainable } \\
\text { economic growth, } \\
\text { full and productive } \\
\text { employment and } \\
\text { decent work for all }\end{array}$ & $\begin{array}{l}\text { 8.8: Protect labour } \\
\text { rights and promote } \\
\text { safe and secure } \\
\text { working environments } \\
\text { for all workers, } \\
\text { including migrant } \\
\text { workers in particular } \\
\text { women migrants, and } \\
\text { those in precarious } \\
\text { employment. }\end{array}$ & \\
\hline
\end{tabular}

Source: Brolan (2016) 
But there is an alternative argument that could be mounted that would submit the post-2015 SDG metrics framework is, or presents or is founded upon, a veritable human rights agenda. This is in light of the UN General Assembly's emphasis in the post-2015 outcome document's preamble and declaration on the interconnect between international human rights law and the post-2015 development action plan. This is notably expressed in both the content of the UN resolution's preamble and in paras. 8, 10, 19 and 20. Indeed, the post-2015 declaration envisages a world »of universal respect for human rights and human dignity, the rule of law, justice, equality and non-discrimination $\ll .{ }^{13}$ It outlines the new SDG agenda as:

»[g]uided by the purposes and principles of the Charter of the UN, including full respect for international law. It is grounded in the Universal Declaration of Human Rights, international human rights treaties, the Millennium Declaration and the 2005 World Summit Outcome. It is informed by other instruments such as the Declaration of the Right to Development. ${ }^{14}$

Despite such strong rhetoric for the integration of international human rights law in the post-2015 development goal agenda, in many respects these words on paper must be approached with caution. This is because, and if over ten years of MDG implementation by the global community is the litmus test, it is likely member state (and their development partners) focus will narrow to fixate on implementation of the SDG metrics framework; on achieving the 17 goals, their associated targets and means of implementation, and country-specific indicators only. This aligns with the potent adage in international development circles $->$ what gets measured gets done $<$ - and human rights are conspicuously absent from the language of SDG measurement. This includes not only the right to health in its express form, but also sexual and reproductive health and rights (SRHR).

It follows that SRHR as sexual and reproductive health and rights did not survive the political sieve of post-2015 negotiations. While access to universal sexual and reproductive healthcare services is sought to be achieved in SDG 3.7, this is not coherently framed as a matter of SRHR.

$13 \mathrm{~A} / \mathrm{Res} / 70 / 1,25$ September 2015.

14 Ibid., para. 10. 
Furthermore, although Target 6 of SDG 5, »Achieve gender equality and empower all women and girls«, appears laudable in its aim,

»[to] [e]nsure universal access to sexual and reproductive health and reproductive rights as agreed in accordance with the Programme of Action of the International Conference on Population Development and the Beijing Platform for Action and the outcome documents of their review conferences $«,{ }^{15}$

when the text is in fact examined in its minutiae it is evident SDG 5.6 is paradoxical, claiming these rights but implicitly diminishing them. SDG 5.6 cannot be »in accordance with the Programme of Action of the International Conference on Population Development $[\ldots] \ll$ as that document states sexual health is unequivocally part of reproductive health rights, whereas SDG 5.6 cleverly splits SRHR into "sexual and reproductive health and reproductive rights .

This chapter will consequently examine potential reasons why the express right to health - including SRHR - did not translate into the headline post-2015 global health goal for health, SDG 3: Ensure healthy lives and promote well-being for all at all ages, nor explicitly form part of the content of SDG 3's nine targets and four means of implementation. ${ }^{16}$

This chapter will now turn to examine the key post-2015 reports that informed the post-2015 SDG decision-making landscape and whether the right to health was explicitly present in SDG metrics proposals (i.e. the goals, targets and indicators). Six reasons as to why the right to health appeared marginal in emergent high-level post-2015 negotiations will be examined. This will be followed by reflection on what this all means for right to health advocates in a post-2015 world. By thinking about the future we

15 A/Res/70/1, 25 September 2015, SDG 5.6, 18.

16 This chapter's exploration will be based on the presentation at the EFI Conference in Berlin in September 2015, „Everywhere but not specifically somewhere«: Why is the right to health not explicit in post-2015 negotiations? A Qualitative Study. This presentation itself was grounded on the content of a peer-reviewed paper of the same name published in the scientific-journal, BMC International Health and Human Rights in 2015, co-authored by Dr. Claire E. Brolan, Dr. Peter S. Hill and Dr. Gorik Ooms, cf. Brolan et al. (2015). 
will then return to the past, and allow Jonathan Mann's inspirational words to echo through to the present.

\section{BACKGROUND TO THE FORMULATION OF THE SINGLE POST-2015 HEALTH GoAL}

Despite activism encouraging a right to health goal, particularly driven by the post-2015 Go4Health research consortium (among others), ${ }^{17}$ an explicit post-2015 health rights narrative did not gain effective traction in key post-2015 health goal proposals. Here, reference is made to four post-2015 goal proposals in particular, which incrementally emerged from UN-initiated and intergovernmental post-2015 forums. The first was the outcome report of April 2013 of the post-2015 Global Thematic Consultation on Health. ${ }^{18}$ This report synthesised the vast input into the post-2015 Global Thematic Consultation on Health (one of eleven global thematic consultations overseen by the UN Development Group) held between September 2012 and March 2013, and co-ordinated by UNICEF and the WHO with support from the governments of Sweden and Botswana. The consultation's objective was threefold: to stimulate broad discussion at all levels (global, regional, national) on MDG progress and lessons learnt from the health MDGs; to develop a shared understanding among key stakeholders (member states, UN agencies, civil society, and others) on health's positioning in the post-2015 development framework; and to propose health goals and associated targets and indicators for the post-2015 development agenda. The post-2015 Global Thematic Consultation on Health was farreaching and included 14 international meetings drawing over 1,600 people, submission of over 100 papers by an array of authors and organizations, as well as attracting more than 150,000 people to its respective website.

The post-2015 Global Thematic Consultation on Health culminated in a High-Level meeting in Botswana in early March 2013 to flesh out the content of the post-2015 Global Thematic Consultation on Health's final synthesis report. This latter document, released in April 2013, proposed one

17 Ooms et al. (2013).

18 UN System Task Team (2013). 
post-2015 health and development goal - »Maximising Healthy Lives« with three underlying interventions: accelerate the MDG agenda, reduce the non-communicable disease burden; and ensure Universal Health Coverage and access. ${ }^{19}$ The following month, May 2013, the second key post-2015 health goal proposal was released by the UN's post-2015 High-Level Panel of Eminent Persons on the Post-2015 Development Agenda (High-Level Panel), which was originally launched by UN Secretary-General Ban Ki-moon in July 2012 and co-chaired by the Presidents of Liberia and Indonesia, and the Prime-Minister of the United Kingdom. ${ }^{20}$ Similar to the post-2015 Global Thematic Consultation on Health's April 2013 report, the High-Level Panel presented one »illustrative« global health goal to the world, Goal 4: Ensure Healthy Lives, with five targets, which also included the unfinished business of the MDG health agenda, as well as reducing the disease burden of "priority" non-communicable diseases and neglected tropical diseases. In a departure from the post-2015 Global Thematic Consultation on Health, Universal Health Coverage was not identified by the High-Level Panel as an express target, though ensuring SRHR was. The right to health was not proposed in either report as a (or the) post-2015 headline health goal, nor progressive achievement of the right to health as an underlying global health goal target.

A week after the High-Level Panel released its report, in June 2013 another report proposing a framework for the post-2015 development agenda was offered by the Sustainable Development Solutions Network led by Professor Jeffrey Sachs. Similar to the High-Level Panel, UN Secretary-General Ban Ki-moon also launched the Sustainable Development Solutions Network in August 2012, which comprised scientific and technical expertise from academia and non-UN agencies. In contrast to the HighLevel Panel's twelve illustrative goals, the Sustainable Development Solutions Network suggested ten sustainable development priorities, the fifth of which was for global health (Goal 5: Achieve Health and Wellbeing at All Ages). ${ }^{21}$ Again, no express mention of progressively achieving the right to

19 UN System Task Team (2013).

20 UN Secretary-General's High-Level Panel of Eminent Persons on the Post-2015 Development Agenda (High-Level Panel) (2013).

21 Sustainable Development Solutions Network (2013). 
health as a possible headline post-2015 global health goal, or underlying target, was made.

Following the release of these three post-2015 reports between May and June 2013, leadership of the post-MDG discussion formally shifted from UN to member state auspice. This shift had already begun in early 2013 when the UN General Assembly proclaimed that Rio+20 Conference's Open Working Group would transform into the »Open Working Group on the Sustainable Development Goals «. ${ }^{22}$ In May-June 2014, the Open Working Group proposed a »zero draft« of 17 SDGs to be attained by the year 2030, with the proposed global health goal, SDG 3: Attain healthy life for all at all ages, with nine associated targets. ${ }^{23}$ The Open Working Group's final SDG proposal was then released over twelve months later in August 2015 in a draft UN General Assembly resolution. ${ }^{24}$

It was the content of this draft resolution that was finally voted on by UN member states at the September 2015 high-level summit in New York, where UN member states unanimously endorsed the draft resolution's content of 17 SDGs and 169 targets and means of implementation. ${ }^{25}$ However, the global health goal's content had altered from the Open Working Group's mid-2014 proposal: now, the global health SDG was titled, »Ensure health lives and promote well-being for all at all ages«. Thus the goal's language had changed from attaining to ensuring healthy lives and the promotion of well-being for all at all ages. Nine targets and four means of implementation were now incorporated (again, see Figure 2). When these nine targets and four means of implementation are placed under the normative-legal analytic microscope, the right to health in its express form appears absent.

22 A/67/L.48/Rev.1, 15 January 2013.

23 Open Working Group for Sustainable Development Goals (2014).

24 A/69/L.85, 12 August 2015.

$25 \mathrm{~A} / \operatorname{Res} / 70 / 1,25$ September 2015. 


\section{Why the Right to Health WAS NOt EXPLicit IN THE FINAL POST-2015 HEALTH GoAL (SDG 3)}

The BMC International Health and Human Rights article, upon which the EFI conference presentation was based, provides six reasons that may explain the right to health's marginalisation from the final post-2015 health and development goal framework. ${ }^{26}$ These reasons have an empirical base: they are founded on interview data collected in 2013 and 2014 by members of the Go4Health research team on the right to health's location in the unfolding post-2015 health goal negotiations. The team from the School of Public Health at The University of Queensland (Dr. Claire E. Brolan and Dr. Peter S. Hill), over a two year period, interviewed key informants from the multilaterals and inter-related agencies responsible for health in the post-2015 SDG agenda (or the formulation of the SDG agenda more broadly), whom were mainly based in New York, Washington DC, Paris and Geneva. ${ }^{27}$ Key informants frequently sat at the interface of UN and member state, as well as civil society, post-2015 discussion. Applying qualitative analytic techniques and aided by NVIVO 9 software, the interview data was subject to a discourse analysis and thematic analysis. The methodology is detailed not only in the BMC International Health and Human Rights article, ${ }^{28}$ but elsewhere. ${ }^{29}$ The remainder of the chapter will hence focus on the

26 Brolan et al. (2015).

27 Forty interviews were held in June-July 2013; 33 face-to-face interviews and seven by Skype with 57 participants, and two additional participants provided email responses. Participants were from a total of 31 agencies: 17 multilaterals, four academic institutes, three foundations, three non-government organisations (NGOs), two government agencies, and two development banks. In the second interview round held almost 12 months later in April-May 2014, the research team narrowed the second round interview question guide and participant sample; only interviewing participants working exclusively on the post-2015 health and development agenda in health related multilaterals or Global Health initiatives, and specialists from NGOs and academic institutes. Second round interviews comprised 14 face-to-face semi-structured interviews with 18 participants from a total of eight agencies (five multilaterals, two academics and one foundation). Nine participants had been interviewed in the first round.

28 Brolan et al. (2015). 
six cumulative reasons given by the high-level study participants as to why the right to health, in their view, lay at the periphery of post-2015 health goal negotiations.

\subsection{Reason 1: The Right to Health is on the Fringes of High-Level Post-2015 Health and Development Negotiation}

Key informants highlighted that, in short, the right to health (in its express form) was on the sidelines of post-2015 health and development negotiations; especially high-level discussion between the UN and member states. The right to health's lack of prominence on the post-2015 negotiation radar is reinforced by its lack of visibility in the key post-2015 reports that emerged in 2013 and 2014, which put forth to the global community potential health and sustainable development goals (and targets) for in-depth discussion. The marginalisation of the right to health in these formative reports is evidenced in our overview of the same above in Section 2.

\subsection{Reason 2: The Right to Health's Sidelining is Part of a Broader Human Rights Marginalisation}

Participants, however, considered the right to health was not alone being singled out and marginalised by high-level actors in emergent post-2015 global health dialogue. Rather, many key informants were of the view the right to health's relegation was part of the broader sidelining of human rights in wider post-2015 discussions. In fact, some key informants perceived human rights a potential and very real »fault line « to UN member state decision-making consensus on the SDG metrics. Therefore, many felt »pragmatics« would »prevail«. That is, that explicit inclusion of human rights would be effectively forfeited by governments worldwide so as to ensure the General Assembly could reach a collective decision on the post2015 goal framework.

Alternatively, some key informants considered that should human rights rhetoric indeed prevail in the final post-2015 SDGs, then this would be be-

29 Brolan/Hill (2014). 
cause UN member states had »compromised « on a post-2015 SDG framework that was weak or, in the words of one participant, »watered down«; or that the UN member states had opted for symbolism over much needed action. Most participants, however, considered human rights inclusion wholly unlikely. Several reasoned this was due to the alignment of an alliance of otherwise heterogeneous member states with a cultural relativist argument against human rights, related to deep and divisive geopolitical power-plays. As one key-informant stated:

»Some nations $[\ldots]$ are allergic to the term >human rights $\measuredangle$ They feel $[\ldots]$ it is the Western countries beating them around the head trying to impose Western cultures on them.«

\subsection{Reason 3: Member State Anxiety Around Potential Inclusion of SRHR}

In both interview rounds in 2013 and 2014, key informants were concerned that SRHR, as an express matter of rights, was in and of itself another very real »fault line« to post-2015 SDG decision-making consensus among member states. Indeed, this was in addition to »human rights« being perceived as a »fault line« threatening member state decision-making consensus. In the first interview round in mid-2013, participants predicted »an almighty fight « would likely arise over SRHR's incorporation in the post2015 SDG metrics framework. These participants anticipated this »fight» against SRHR's inclusion would be led by strong Catholic and Islamic nations.

However, when the second round of interviews were conducted almost one year later in April-May 2014, the discourse around SRHR had substantially migrated. By 2014, key informants now spoke of their concern that SRHR were being increasingly connected by countries to debate around post-2015 lesbian, gay, bi-sexual, transgender, queer and inter-sex (LGBTQI) rights. For these participants, government linkage of SRHR with advancement of LGBTQI rights only made the argument for SRHR's inclusion in the post-2015 SDGs, as one participant explained, "more and more difficult«. This seems to be the origins of the splitting of SRHR into Sexual and Reproductive Health and Reproductive Health Rights in the final SDG 5.6 wording, retaining reference to Reproductive Rights while precluding 
the inclusion of Sexual Rights and their potential to provide a platform for further, more inclusive, redefinition. Yet one participant from a UN agency suggested unfolding arguments for and against SRHR's inclusion among member states were not actually, at a de facto level, about sexual and reproductive health as a matter of rights. In this participant's view, this point of contention could not (again) be divorced from larger, deep-seated geopolitical power-plays:

»It's mostly a power play between the North and South, if I can put it crudely. For instance, the African Group has gone very conservative and that might be the use of SRHR as a bargaining chip within the North/South debates [...].«

\subsection{Reason 4: An Overarching Post-2015 Right to Health Goal is too Big to be Defined}

Despite a handful of participants acknowledging the right to health is articulated in Article 12 of the ICESCR, from immersion in the data it became clear that this definition of the right to health was unknown by a sizeable cluster of key informants. Many participants were vague with regards to the meaning of the right to health, and the source of this meaning; a number considered the »aspirational« right to health to be a »fuzzy«, broad imperative that was »too big« to be pragmatically condensed into a single, overarching post-2015 global health goal. Many considered that confusion around the right to health's definition was subsequently a key reason that precluded a serious and focused discussion on the right to health's potential to translate into the headline post-2015 health and development goal among the UN member states.

\subsection{Reason 5: Even If a Headline Right to Health Goal is Coherently Defined, it is too Difficult to Implement}

Participants in the second interview round were particularly emphatic that even if the right to health could be translated cogently into the post-2015 health and development goal, its broad elements were nonetheless too difficult to implement, to »measure«. This concern was best captured in the following statement by one participant: 
»For me, it's a very good principle, the right to health, but we need to materialise [it], really carry it out, how it spells out in different programs and different indicators. Because [...] it's very hard to conceptualise what exactly we should do to get there. [...] So people really want targets [...] if we don't have a target how do we manage our program?«

\subsection{Reason 6: The Right to Health would be Implicitly Captured in a Post-2015 Health and Development Goal}

Paradoxically, while many participants were unable to identify what the right to health's content included per Article 12 of the ICESCR, they nonetheless associated the aspirational nature of the right to health with the more tangible concepts of Universal Health Coverage, or health equity, or a >Healthy Lives across the Life Course` approach. And, what is more, all three concepts appeared to obtain more discursive coverage in the post2015 global health and development goal debate than the prima facie right to health in international law. In fact, seven participants in the second interview round viewed Universal Health Coverage as the tangible expression of the right to health, while others spoke of how the right to health would be inherently represented in the final health goal framework if words such as »equity« or »equality« were inserted into the text of the final SDG metrics:

$»$ When you unpack equity $[\ldots]$ you're talking about everyone having a right $[\ldots]$ it's often a presentation thing rather than a principle thing if you like.«

»The right to health, as far as I can see - it all seems to come down to how you address the inequalities in health in the world.«

\section{Reflection}

As noted at the beginning of this Chapter, the final SDG framework was voted on by the UN General Assembly in September 2015. And, as has been further contended, the right to health in its express form did not translate into the overarching post-2015 health and development goal, nor explicitly appear in the content of this goal's nine targets and four means of implementation (Figure 2). Through reviewing the six reasons given by this study's key informants as to why the right to health seemed to be on the 
fringes of evolving post-2015 health goal negotiations, the marginal presence of the right to health in the final post-2015 outcome document is unsurprising; and certainly anticipated by the majority of this study's participants. Moreover, participants' general prediction that broader human rights would likely be kept separate from final SDG metrics, in the interests of UN member state decision-making consensus, materialised. Thus, while the SDG framework that finally emerged was indeed a most broad and comprehensive plan of action for »people, planet and prosperity $«,{ }^{30}$ it appears this was at the expense of the member states affirming human rights' rich and intrinsic connect with development. ${ }^{31}$

It is therefore submitted that through the post-2015 SDGs of September 2015, the UN member states have perpetuated the schismatic relationship between international human rights law and global development policy and planning, which had been progressed in 2001 by the SDGs predecessor, the MDGs. ${ }^{32}$ Indeed, the high-level technocrats responsible for configuring the eight MDGs in the spring and summer of 2001 have been most forthright that rights and measureable goals and targets were not to intermingle; in their view, »development « and »rights « were incompatible. ${ }^{33}$ According to Jan Vandemoortele who was tasked by UN Secretary-General Kofi Annan to lead the small interagency team to devise those goals:

»The [MDGs] express targets that are feasible at the global level. They should not be seen as a normative statement of what is desirable in an ideal world, which is already embedded in the various human rights treaties that have been ratified by member states to varying degrees. There is no need to repeat or overlap with these instruments. $\ll^{34}$

As a number of participants in our study advised, and as with the MDG formulation process, metrics mattered foremost in post-2015 high-level negotiations (in addition to politics!). Thus if the respective post-2015 health goal and/or target being advocated for inclusion could be pragmatically de-

30 A/Res/70/1, 25 September 2015.

31 Alston (2005); Darrow (2012).

32 Alston (2005).

33 Murphy (2012).

34 Vandemoortele (2011), 14. 
fined, dissected and measured ideally through quantitative means, then it stood good chance of at least vying for member state attention in post-2015 negotiations. And, if the conceptual framing stood good chance of attracting member state (as well as multilateral and other) attention and discourse, then it stood some chance of being up-taken and included in the final post2015 health goal framework. Following this line of reasoning, it is of little wonder that during the recent post-2015 SDG formulation period the World Health Organization, in partnership with the World Bank, was ensconced in demonstrating how Universal Health Coverage could be measured at a country and global level. ${ }^{35}$

Nevertheless, it follows that this finding above points to a number of larger challenges for right to health advocates moving forward. The first is that even if the right to health had been successfully quantified and pitched to the post-2015 decision-makers, the conglomerate of member states, this still might not have been enough to ensure member state inclusion of the right to health expressly in the post-2015 health and development goal framework. This is because, as anticipated by the findings in our study, participants generally perceived it unlikely that a broader human rights agenda would be incorporated in post-2015 SDG metrics. Therefore, even if the right to health in its explicit form had been successfully repackaged and advocated to member states as a potential measurable goal and/or target, it would nonetheless arguably have been sacrificed in member states' broader sidelining of human rights language (and thus a human rights agenda) in the SDG goals, targets and indicators.

The second challenge for right to health advocates arising from this study is that it appears many high-level personnel in influential global health policy roles (and health and development policy roles more broadly), might not actually understand what the right to health means or, in other words, how the right to health is defined in international human rights law. It follows an array of these individuals (at least in our study) were uncomfortable with outright support of an explicit post-2015 right to health goal, and certainly not with lending such support directly on behalf of their respective organizations. However, this conservatism is inherently tied to the perceptible lack of prima facie knowledge among this study's key informants on what the right to health in fact is; and thus why its express incorpo-

$35 \mathrm{WHO} /$ World Bank (2014) and (2015). 
ration in the new development goal framework truly matters. In the view of many participants in our study, whatever the content of the right to health might be, it is for them aspirational and not pragmatically or tangibly applicable, nor measurable or politically palatable, so as to warrant prominence in the metrics of this formative global health policy endeavour.

Here, it is timely to remind why the right to health's incorporation in the post-2015 health goal framework is important. Among the mix of reasons, three will be highlighted. First, the right to health underpins global development policy, planning and implementation with a normative basis, allowing development to become a process by which people can progressively realise their human rights. Second, the right to health in international law, although not without its sceptics, ${ }^{36}$ is the normative gold standard for global health that all UN member states have adopted (in some form) to respect, protect and fulfil. ${ }^{37}$ Third, if the post-2015 health goal is to have any bite, it needs legal teeth: »Rights remove discretion from development and provide a framework of accountability «. ${ }^{38}$ Thus progressive and contextual achievement of the health SDG's content by the international community of states (and their array of partners) between 2016 and 2030 should not be based solely on state commitments engendered by a post- 2015 global health policy. Rather, UN member state commitment must be combined with states' obligations under international human rights law, and the consequential government accountability mechanisms and legal remedies that surround this. ${ }^{39}$

\subsection{Refocusing and Moving Forward in 2017 and Beyond}

Right to health advocates must return to the words of Jonathan Mann, the founder of the modern health and human rights movement, ${ }^{40}$ in their reflection on the liminal presence of the right to health in the post-2015 health goal framework:

36 Baumrin (2012).

37 Backman et al. (2008); Kinney/Clark (2004); Perehudoff (2008).

38 Sidibe/Buse (2013).

39 Yamin (2008).

40 Tarantola et al. (2006). 
$»[\ldots]$ Similarly, contemporary human rights, seeking to understand how to advance human well-being in diverse real-life settings, needs to draw upon a more sophisticated understanding of health, health status, and health realities [...]. Action is liberating: it can teach what cannot be learned nor imagined in the abstract. As much as we believe in the power of rhetoric [...] we need to see how and to what extent realising human rights and increasing respect for dignity can operate to diminish the societal contribution to disease, disability and death. While this work can draw upon traditional and well-developed modes of public health and human rights work, it will require innovation, experiment, and risk-taking. ${ }^{41}$

To this end, "the innovation, experiment, and risk-taking « must occur in multiple ways if it is to progress the right to health as "value added ${ }^{42}$ in the global health and development policy-making landscape.

Firstly, it is recommended that a serious conversation begins involving not only right to health advocates, but inter-sectoral human rights advocates, equally disappointed with the disconnect between human rights and the final post-2015 SDG metrics. This is because an urgent discussion must be initiated around how the bridge can be more effectively built between human rights and development in the post-2015 world. Insight from right to development advocates also needs to be elicited in this discussion. A conference or meeting of sorts might be a good starting point in facilitating such discourse.

Secondly, if the onus in contemporary, high-level development policy and planning is sall about the numbers « and results based management, then right to health advocates need to strategically splay the game <. Certainly, political realists would support this notion. It is therefore recommended right to health advocates consider how to insert more of the normative into the empirical, and more of the empirical into the normative. Working in partnership with communities, civil society, policy-makers, and global health colleagues from different disciplinary backgrounds, a flexible coherent framework with corresponding measures and targets for implementation for the right to health as espoused in international human rights law - particularly as elucidated and framed by the UN Committee on Economic, Social and Cultural Rights in its General Comment No. 14 of 2000 - could be

41 Mann (1997), 118-119.

42 Darrow (2012). 
developed. In collaboratively configuring such a tool, the right to health's content need not be detracted from or compromised. Here, right to health advocates can draw inspiration from related and already-developed scientifically-informed matrixes such as the EquiFrame. ${ }^{43}$ On this point, it is further recommended that right to health country-reporting matrixes are then linked to states' reporting obligations on the right to health with regards to UN treaty documents. In this way, the one innovative matrix (and its data) can be used by governments to serve two significant reporting purposes.

Thirdly, while a number of scholars from various disciplines consider the tension between cultural relativism and human rights an old and irrelevant debate, the findings from our study suggest otherwise. Indeed, our research indicates this tension remains an ongoing and real point of contention influencing and impacting member state decision-making consensus in the development field. Hence part of the serious conversation that must be had around the disconnect of the right to health from the post-2015 metrics framework, needs to examine this point. Health policy and related practitioners, especially in developing countries, are familiar with cultural relativist critique and related claims for regional exceptionalism: ${ }^{44}$ universalityrelativist tension emerges in a range of health issues particularly relating to women's and girls' health, and the health of LGBTQI individuals and communities. $^{45}$

Finally, right to health advocates need to work hard in a plethora of forums, explaining in plain, simple, and persuasive language what the right to health is and why and how this human right (as with all human rights) are necessarily part of sustainable development, and should therefore be clearly linked as such to development metrics. Of course, such efforts would be assisted if a right to health reporting matrix or measurement tool can be pointed to.

The four tasks identified above are enormous. At their heart, they implicate several paradigm shifts. One of these shifts involves repeatedly exposing those in elite positions who make decisions in the global health policy landscape, and who are frequently trained and educated in approaching that landscape through bio-medical and/or quantitative scientific methods

43 Amin et al. (2011).

44 Kirby (2011).

45 Murphy (2012); Tong (2012). 
and/or through an economic (neo-liberal) lens, to reframe their wholesale response to global health challenges by applying (and prioritising) normative health and human rights law. While human rights is not the only framing for the complex that is global health and foreign policy, ${ }^{46}$ more work needs to be invested in having human rights law not only merely understood and acknowledged, but prioritised by our rich diversity of global health and development peers. Of course, this fundamental reframing of what must be prioritised and respected in global health and development policy - that is, international human rights law, and member states obligations toward the same - must also be a message facilitated in tertiary educational settings, and especially directed toward public health, global health, international public health, public policy and social policy, and international development graduates.

Of course, the task before right to health advocates (who are in no way homogenous in their outlook and interpretation of the right to health), seems all too overwhelming: a lifetime of work is clearly on the horizon. However, commitment to the right to health vocation finds home in the words of Jonathan Mann:

»The health and human rights linkage, as seen from the public health side $[\ldots]$ provides a better guide for identifying, analysing and responding directly to critical societal conditions than any framework inherited from the biomedical or recent public health tradition. Thus, promoting and protecting health is proposed to depend upon the promotion and protection of human rights and dignity. The consequences of this line of thinking are nothing short of revolutionary for public health practice [...]. We share a confidence in the future - and in our ability to contribute - each in our own ways and yet together to the healing of the world [...]. This is our modesty, also our boldness, also our aspiration - and together we form a multitude. $\ll^{47}$

And, in working to slowly but incrementally achieve the above, Mann further cautions us to be reflexive, collegial and collaborative in so doing:

46 Labonte/Gagnon (2010); Stuckler/McKee (2008).

47 Mann (1997), 114 and 120. 
$»$ Avoid creating, inadvertently, an oppressive orthodoxy [...]. The fields of public health and human rights can learn much from each other [...]. A multiplicity of approaches, selected and designed locally by people directly concerned, is best. « ${ }^{48}$

Mann's above words were published in 1997. Twenty-years on, and in light of the side-lining of the right to health and international human rights law from the final post-2015 global health and development goal metrics, there is considerable work to be done by right to health advocates. We must continue to let Mann's words guide and inspire us.

\section{Acknowledgements}

The funding for Go4Health, a research project of which this analysis was part, was provided by the European Union's Seventh Framework Programme (grant HEALTH-F1-2012-305240) and by the Australian Government's NH \& MRC-European Union Collaborative Research Grants (grant 1055138). The author sincerely thanks her two co-authors on the $B M C$ International Health and Human Rights paper referred to in this chapter: Associate Professor Peter S. Hill, and Professor Gorik Ooms.

\section{REFERENCES}

Alston, Philip (2005): »Ships Passing in the Night: The Current State of the Human Rights and Development Debate seen through the Lens of the Millennium Development Goals«, in: Human Rights Quarterly 27, 3 (2005), 744-829.

Annan, Kofi (2001): »Report of the UN Secretary General: Road map towards the implementation of the United Nations Millennium Declaration«, A/56/326, Online: http:/www.un.org/documents/ga/docs/56/ a56326.pdf [17.10.2016].

Backman Gunilla/Hunt, Paul/Khosla, Rajat/Jaramillo-Strouss, Camila/ Fikre, Belachew Mekuria/Rumble, Caroline/Pevalin, David/Acurio Páez, David/Armijos Pineda, Mónica/Frisancho, Ariel/Tarco, Duniska/ Motlagh, Mitra/Farcasanu, Dana/Vladescu, Cristian (2008): »Health

48 Ibid., 116-118. 
systems and the right to health: an assessment of 194 countries «, in: The Lancet 372 (2008), 2047-2085.

Baumrin, Stefan Bernard (2012): »Why There is No Right to Health Care«, in: Rhodes et al. (2012), 91-96.

Brolan, Claire E. (2016): »A Word of Caution: Human Rights, Disability, and Implementation of the Post-2015 Sustainable Development Goals«, in: Laws 5, 22 (2016), 1-18.

Brolan, Claire E./Hill, Peter S. (2014): »Sexual and reproductive health and rights in the evolving post-2015 agenda: perspectives from key players from multilateral and related agencies in 2013«, in: Reproductive Health Matters 22, 43 (2014), 65-74.

Brolan, Claire E./Hill, Peter S./Ooms, Gorik (2015): ») Everywhere but not specifically somewhere $<$ a qualitative study on why the right to health is not explicit in post-2015 negotiations «, in: BMC International Health and Human Rights 15, 22 (2015). doi: 10.1186/s12914-015-0061-z.

Clapp, Jennifer/Wilkinson, Rorden (Eds.) (2010): Governance, Poverty and Inequality, London i.a.: Routledge.

Darrow, Mac (2012): »The Millennium Development Goals: Milestones or Millstones? Human Rights Priorities for the Post-2015 Development Agenda«, in: Yale Human Rights and Development Law Journal 15, 1 (2012), 55-127.

Fukuda-Parr, Sakiko/Hulme, David (2009): International Norm Dynamics and the End of Poverty<: Understanding the Millennium Development Goals (MDGs), Manchester Brooks World Poverty Institute (BWPI), University of Manchester.

Hulme David (2010): »Governing global poverty? Global ambivalence and the Millennium Development Goals«, in: Clapp/Wilkinson (2010), 135160.

Kinney, Eleanor D./Clark, Brian A. (2004): »Provisions for Health and Health Care in the Constitutions of the Countries of the World«, in: Cornell International Law Journal 37 (2004), 285-356.

Kirby, Michael (2011): »Health care and global justice«, in: International Journal of Law in Context 7, 3 (2011), 273-284.

Labonte, Ronald/Gagnon, Michelle L. (2010): »Framing health and foreign policy: lessons for global health diplomacy«, in: Globalization and Health 6, 14 (2010). doi: 10.1186/1744-8603-6-14. 
Mann, Johnathan (1997): »Health and Human Rights: If Not Now, When?«, in: Health and Human Rights 2, 3 (1997), 113-120.

Murphy, Timothy S. (2012) »Justice for Gay and Lesbian People in Health Care«, in: Rhodes et al. (2012), 289-298.

Ooms, Gorik/Brolan, Claire E./Eggermont, Natalie/Eide, Asbjørn/Flores, Walter/Forman, Lisa/Friedman, Eric A./Gebauer, Thomas/Gostin, Lawrence O./Hill, Peter S./Hussain, Sameera/McKee, Martin/Mulumba, Moses/Siddiqui, Faraz/Sridhar, Devi/van Leemput. Luc/Waris, Attiya/ Jahn, Albrecht (2013): »Universal health coverage anchored in the right to health«, in: Bulletin of the World Health Organization 91 (2013), 2-2A.

Open Working Group for Sustainable Development Goals (2014): »Open Working Group for Sustainable Development Goals: Introduction to the Proposal of the Open Working Group for Sustainable Development Goals«, Online: https://sustainabledevelopment.un.org/content/docu ments/4518SDGs_FINAL_Proposal\%20of\%20OWG_19\%20July\%20at $\% 201320$ hrsver3.pdf [17.10.2016].

Perehudoff, Katrina S. (2008): »Health, Essential Medicines, Human Rights and National Constitutions«, Geneva (Switzerland): World Health Organization, Online: http://cdrwww.who.int/medicines/areas/human_rig hts/Perehudoff_report_constitutions_2008.pdf [17.10.2016].

Rhodes, Rosamond/Battin, Margaret P./Silvers, Anita (Eds.) (2002): Medicine and Social Justice: Essays on the Distribution of Health Care, Oxford: Oxford University Press.

Sidibé, Michel/Buse, Kent (2013): „Global health governance after 2015 Authors' reply«, in: The Lancet 382 (2013), 1018-1019.

Stuckler, David/McKee, Martin (2008): »Five metaphors about global health policy«, in: The Lancet 372, 9633 (2008), 95-97.

Sustainable Development Solutions Network (2013): »An Action Agenda for Sustainable Development. Report for the Secretary General«, Online: http://unsdsn.org [17.10.2016].

Tong, Rosemarie (2012): »Gender Justice in the Health Care System: A Elusive Goal, in: Rhodes et al. (2012), 279-288.

UN Secretary-General's High-Level Panel of Eminent Persons on the Post2015 Development Agenda (High-Level Panel) (2013): »A New Global Partnership: Eradicate Poverty and Transform Economies through Sus- 
tainable Development«, Online: http://www.post2015hlp.org/wp-con tent/uploads/2013/05/UN-Report.pdf [17.10.2016].

UN System Task Team (2013): »Health in the Post-2015 Development Agenda: Report of the Global Thematic Consultation on Health«, Online: www.worldwewant2015.org/health [17.10.2016].

Unterhalter, Elaine (2014): »Measuring Education for the Millennium Development Goals: Reflections on Targets, Indicators, and a Post-2015 Framework«, in: Journal of Human Development and Capabilities 15, 2-3 (2014), 176-187.

Vandemoortele Jan (2011): »If not the Millennium Development Goals, then what?«, in: Third World Quarterly 32 (2011), 9-25.

WHO/World Bank (2014): »Monitoring progress towards universal health coverage at country and global levels. Framework, measures and targets«. Online: http://apps.who.int/iris/bitstream/10665/112824/1/WHO _HIS_HIA_14.1_eng.pdf [17.10.2016].

Yamin, Alicia E. (2008): »Beyond compassion: the central role of accountability in applying a human rights framework to health «, in: Health and Human Rights 10 (2008), 1-20. 


\title{
Mapping Constitutional Commitments on Sexual and Reproductive Health and Rights
}

\author{
A Global Survey
}

Lucía Berro Pizzaross A, KATrina S. PEREHUdofF ${ }^{1}$

\section{INTRODUCTION AND OVERVIEW OF THE LEGAL FRAMEWORK}

Sexual and reproductive health and rights (SRHR) have been increasingly recognized and developed in international human rights law. The UN human rights system has repeatedly confirmed that SRHR are human rights established in the core human rights conventions. Reproductive health was first enshrined under the right to health in the International Convention on Social, Economic and Cultural Rights (ICSECR) ${ }^{2}$ and - according to General Comment No. 14 - bestows on individuals the freedom to choose if, when, how, and with whom to engage in sexual activity, as well as the right to access to contraceptive methods, information, goods such as contraceptive devices, and sexual and reproductive healthcare. General Comment

1 Acknowledgements: The authors wish to thank Ms. Annabel Weijer for her research assistance.

2 The Convention on the Elimination of All Forms of Discrimination Against Women (CEDAW) in 1979 also made major contributions to protecting and promoting reproductive health and rights. 
No. 22 (GC) by the Committee on Economic, Social and Cultural Rights (CESCR) builds on these developments and states that the right to reproductive health entails both »the right to make free and responsible decisions and choices, free of violence, coercion and discrimination, over matters concerning one's body and sexual and reproductive health «, and the "unhindered access to a whole range of health facilities, goods, services and information, which ensure all people full enjoyment of the right to sexual and reproductive health $\ll .{ }^{3}$ Closely linked is the concept of sexual health, defined as »a state of physical, emotional, mental and social well-being in relation to sexuality ${ }^{4}{ }^{4}$

In 1994, the International Conference on Population and Development (the Conference) transformed the discourse at the time from reproductive health and rights as a strategy to meet demographic targets and control population growth to a more comprehensive and positive approach to sexuality and reproduction, free from coercion, discrimination and violence. ${ }^{5}$ The Conference forged the link between sexuality and health as human rights, where women's agency over their own bodies and sexuality was now intrinsically linked to their sexual and reproductive health. ${ }^{6}$ In 1995, the Beijing Platform for Action ${ }^{7}$ was the first declaration to embody the concept of sexual rights and expanded the definition to cover both sexuality and reproduction by upholding the right to exercise control over and make decisions about one's sexuality.

Furthermore, the Conference's Program of developed the notion of reproductive rights as embracing certain human rights that are already recognized in national laws, international human rights documents and other relevant UN consensus documents. Building on the notion that all human rights are indivisible, universal and interdependent - as noted at the World

3 E/C.12/GC/22, 2 May 2016, Context (I).

4 Ibid.

5 See generally Garita (2014), 1; Zampas/Gher (2008), 252.

6 Reichenbach/Roseman (2009), 11.

7 A/CONF.177/20 and A/CONF.177/20/Add.1, 1995. 189 governments at the Beijing Platform for Action recognized that social and cultural discriminations, gender inequalities, and the lack of information and services contribute to sexual and reproductive ill health. 
Conference on Human Rights in Vienna ${ }^{8}$ - the definition grounds these rights in binding international treaties that protect the right to life, liberty, security, health, self-determination, equality and non-discrimination, access to information, and the right to enjoy the benefits of scientific progress. Another of the many achievements of the Conference is the recognition of the responsibility of governments to legislate on the matter translating international commitments into national laws and policies. ${ }^{9}$

Earlier in the year 2016, the Committee of Economic, Social, and Cultural Rights (CESCR) extensively addressed states' legal duties to the right to sexual and reproductive health in its General Comment No. 22 in response to the continuing grave violations in practice and adopting a clear human rights based approach to matters of sexuality and reproduction. The General Comment affirms that the right to reproductive health is an integral part of the right to health ${ }^{10}$ that has enjoyed longstanding recognition based on already existing international human rights instruments. ${ }^{11}$ Among other issues, General Comment No. 22 recognizes abortions services as an integral part of the right to health (paras. 56-57) and notes that states have an obligation to repeal, eliminate laws, policies and practices that criminalize, obstruct or undermine an individual's or a particular group's access to health facilities, services, goods and information, including abortion (para. 35).

The legal obligations to respect, protect, and fulfil the right to sexual and reproductive health offered in General Comment No. 22 provide clear guidance to state parties using standardized terminology. According to the comment, the duty to respect requires states to refrain from interfering with individuals' right to exercise their sexual or reproductive health. Examples

\section{A/CONF.157/23, 12 July 1993.}

9 Cottingham et al. (2010), 551.

10 See also E/C.12/2000/4, 11 August 2000, paras. 2, 8, 11, 16, 21, 23, 34 and 36.

$11 \mathrm{E} / \mathrm{C} .12 / \mathrm{GC} / 22,2$ May 2016 the following documents as examples: Convention on the Elimination of All Forms of Discrimination against Women (CEDAW), 1979, Article 12; Convention on the Rights of the Child (CRC), 1989, Articles 17, 23-25 and 27; Convention on the Rights of Persons with Disabilities (CRPD), 2006, Articles 23 and 25; See also A/54/38/Rev.1, chap. 1, 19 January-5 February 1999 and 7-25 June 1999, paras 11, 14, 18, 23, 26, 29, 31(b); CRC/C/GC/15, 17 April 2013. 
include limiting or denying access to health services and information, such as laws or practices that criminalize abortion, limiting consensual sexual activities between adults, requiring third-party authorization for access to abortion or contraception, or excluding certain health services from publicly- or donor-funded programmes. ${ }^{12}$

Under the obligation to protect, states must protect individuals' right to sexual and reproductive health from interference by third parties. ${ }^{13}$ Examples include protecting against private health clinics, insurance or pharmaceutical companies that impose practical or procedural barriers to health services. ${ }^{14}$ States must introduce laws and policies that prohibit third parties from acting in a way that harms integrity or undermines the enjoyment of rights, such as ensuring adolescents have access to information about sexual and reproductive health, including family planning, that is appropriate for their age and regardless of their marital status. ${ }^{15}$

The responsibility to fulfil mandates states $»$ to adopt appropriate legislative, administrative, budgetary, judicial, promotional and other measures to ensure the full realization of the right to sexual and reproductive health $\ll .{ }^{16}$ States must take steps to ensure universal access to sexual and reproductive healthcare, and to guarantee care for survivors of sexual and domestic violence, including emergency contraception and access to safe abortion services. States are required to provide comprehensive education about sexual and reproductive health for all and to take measures to eradicate social barriers that prevent individuals from autonomously exercising their right to sexual and reproductive health. ${ }^{17}$

In spite of the development of the legal framework much progress must be made to realize SRHR in practice. ${ }^{18}$ One important step in this direction

12 E/C.12/GC/22, 2 May 2016, para. 40-41.

13 Ibid., para. 42.

14 Ibid., para. 42-43.

15 Ibid., para. 43-44.

16 Ibid., para. 45 .

17 Ibid., para. 47-48.

18 The Lancet Commission on Women and Health asserts that an estimated 225 million women have an unmet need for family planning, and every year, an estimated 75 million unintended pregnancies put women at risk of unsafe abortion. Furthermore, unsafe abortion is estimated to cause 47,000 maternal deaths 
is the removal of the legal barriers ${ }^{19}$ and to this end Gruskin demands »their identification, careful analysis and their subsequent modification - through laws, policies and regulations that are consonant with human rights «. ${ }^{20}$ Showcasing the importance of the legal arrangements, the Lancet Commission on Women and Health emphasizes the need for »an enabling social, legal, and regulatory environment « to respond to women and girls' health needs and rights, ${ }^{21}$ and the Commission on the Status of Women continues to demand that states strengthen their normative, legal and policy frameworks. $^{22}$ Both the removal of laws that obstruct the full realization of SRHR and the introduction of positive legal guarantees for these rights are needed.

Adopting domestic laws consistent with international standards is a demonstration of the government's commitment to realize SRHR. As a recognized indicator of such political will, legal codification may be the first step in improving the respect, protection and fulfilment of these rights in practice. Domestic constitutions are the most vital expressions of government responsibility and individual entitlements, and therefore one of the most deserving channels to endorse states' commitments to human rights. Constitutional law offers a frame for subsequent policies, programmes and services to be executed. In many jurisdictions, constitutional law supports enforcement and redress in case of violations, and is a key success factor in strategic litigation for reproductive health. ${ }^{23}$ Legal recognition in constitu-

and 5 million maternal disabilities annually. Maternal mortality claims the lives of 289,000 women annually while complications during childbirth result in 5.8 million serious injuries every year. See generally Langer et al. (2015).

19 Gruskin et al. (2008), 591; E/C.12/GC/22, 2 May 2016, para. 49(a). See generally Kismödi et al. (2015).

20 Gruskin et al. (2008), 591.

21 Langer et al. (2015), 1178.

22 E/2016/27-E/CN.6/2016/22, 14-24 March 2016.

23 See generally Roa/Klugman (2014). See generally Hogerzeil et al. (2006). Pivotal cases such as the Treatment Access Campaign vs. the South African Ministry of Health seeking access to essential medicines to prevent the transmission of HIV from mother to child during childbirth, illustrate how forceful a constitutional right to reproductive health can be. 
tions can endure changes in government administrations and survive economic or social strife and ensure a certain degree of consistency over time.

An estimated 20 nations replace or amend their constitution annually presenting the opportunity to strengthen state commitments to $\mathrm{SRHR}^{24}$ and, in this process, constitutional framers often seek inspiration from other jurisdictions or international law. ${ }^{25}$ Our objective is to survey the language and concepts used to describe SRHR in the domestic constitutions from around the globe.

\section{Methodology}

Our study investigates whether and how SRHR are introduced into domestic constitutional law. In March 2015 (updated in April 2016) we searched the constitutions of 195 WHO member states on the Comparative Constitutions Project webpage for the key words: >reproductive`, >reproduction<, >sexual $<$, family planning $<$, and `abortion $<.{ }^{26}$

After retrieving constitutional provisions, we excluded provisions concerning the use of genetic or reproductive material; the economy and reproduction of material and immaterial conditions; the reproduction of art, culture, or sound; the protection and reproduction of the (natural) environment; the delegation of competences or jurisdiction of authority; and proceedings for sexual harassment or crimes.

24 Ginsburg et al. (2009), 201.

25 See generally ibid.

26 One potential limitation of our study concerns the search scope. Although our search terms could be considered narrow by some, we intentionally chose SRHR terms clearly articulated in international law. With this approach, it is possible our search did not detect constitutions that implicitly govern or 'catch' SRHR in provisions for other, related rights. For example, constitutions enshrining a right to health could include reproductive health in their scope; however, our study did not include any related rights that are not expressly framed around SRHR. This is because the scope of our study was to understand how domestic constitutions address SRHR concepts elucidated under international law and recently affirmed by the CESCR in GC No. 22 (E/C.12/GC/22, 2 May 2016). 
As mentioned above, the international legal framework underpinning SRHR is complex and grounded in different instruments. We use the definitions and notions outlined in the Introduction and apply the tripartite typology of states' obligations (respect, protect and fulfil) to categorize constitutional provisions for SRHR. In addition, we report the constitutional provisions mentioning specific concepts in SRHR namely family planning, abortion, access to education and other interlinked human rights. Melton et al. suggest that the scope of the constitutional text, such as whether it is focused by topic rather than using complex cross-referencing, and the use of once-only words for clarity and brevity, are of most importance for clear interpretation. ${ }^{27}$ Therefore, we identify well-defined terminology and concepts in constitutional commitments in order to maximize their clarity and comparability between jurisdictions. ${ }^{28}$

\section{Results}

We retrieved 32 constitutions that met our inclusion criteria. 28 domestic constitutions enabled at least one aspect of SRH; these laws were most often found in the pan-American ( $\mathrm{n}=9$ constitutions) and African $(\mathrm{n}=8)$ regions. Seven constitutions restricted SRHR and these were found in the African ( $n=3$ constitutions), Western Pacific $(n=2)$, European $(n=1)$ and South-East Asian $(n=1)$ regions.

\subsection{Sexual Health and Rights}

The state duty to respect the right to sexual health and sexual rights is conceptualized in a positive sense as the right to make decisions about one's sexual life and orientation (Ecuador) and the right to exercise sexual rights (Bolivia), and in a negative sense as the right to sexual integrity (Belgium, Bolivia) or a right to sexual safety (Ecuador). Bolivia's constitutions states

27 Melton et al. (2013).

28 Constitutional law scholars Elkins, Ginsburg, and Melton note that a lack of conceptual clarity in constitutional language can impair comparisons across jurisdictions. We minimized this risk by using standard concepts in SRH and applying the tripartite typology. Elkins et al. (2011). 
»Women and men are guaranteed the exercise of sexual rights and their reproductive rights « ${ }^{29}$

The most frequent state duty is the protection against sexual exploitation (Ecuador, Egypt, Brazil, Cambodia, Zimbabwe), sexual abuse (Colombia, DRC, Guinea, Timor-Leste, Malawi, Somalia), and sexual violence (DRC, Dominican Republic, Ecuador) or an obligation to punish such acts (Bolivia, Brazil, DRC, Malawi). Guinea's constitution protects youth from sexual exploitation or abuse.

Notably, in terms of the state's duty to respect and protect sexual and reproductive rights, Ecuador's constitution recognizes and guarantees the

wright to freely take informed, voluntary, and responsible decisions on one's sexuality and one's sexual life and orientation. The State shall promote access to the necessary means so that these decisions take place in safe conditions. $\mu^{30}$ [emphasis added, L.B.P./S.K.P.]

This provision in Ecuador's constitution respects the right of individuals to make decisions about their sexuality, freely and voluntarily, implying without coercion. It obliges the government to fulfil this right by promoting access to safe conditions in which these decisions can be made. Finally, the constitution of Ecuador was the only constitution to protect confidentiality about one's sexual life.

\subsection{Reproductive Health and Rights}

Four constitutions require the state to respect the right to reproductive health through the right to make decisions concerning reproduction (Ecuador, South Africa, Zimbabwe), or the right to reproductive health (Nepal). Ecuador's constitution specifies the right to take free, responsible and informed decisions about one's health and reproductive life and to decide how many children to have and also guarantees respect for the reproductive health of all workers.

The constitutions of Ecuador and Nicaragua provide for the protection of sexual and reproductive health. Ecuador's law mandates the »elimination

29 Constitution of the Plurinational State of Bolivia of 2009, Article 66.

30 Constitution of Ecuador of 2008 (amended 2011), Article 66. 
of labour risks affecting reproductive health« and Nicaragua's law »grants special protection to the process of human reproduction«.

Eight constitutions include the explicit state duty to provide for reproductive healthcare. The constitutions of Fiji, Kenya, and South Africa indicate that everyone is entitled to access reproductive healthcare. In contrast, reproductive healthcare is limited in two instances to services and facilities »during reproductive phase $«{ }^{31}$ (Nepal) or to »citizens and permanent residents $«^{32}$ (Zimbabwe). Paraguay's constitution requires special plans for reproductive health care for people with scarce resources.

\section{3 »Family Planning» and Contraception}

Five constitutions address family planning in terms of individual rights and three constitutions approach family planning as an individual responsibility in relation to population control.

The constitution of Paraguay determines the obligation to respect the right to reproductive health referring specifically to family planning in an article with the same title, by stating »the right of persons to freely and responsibly decide on the number and frequency of the birth of their children «. ${ }^{33}$ The Brazilian constitution respects the right of couples to decide on family planning and prohibits sany coercion on the part of official or private institutions «. ${ }^{34}$ In the same line, the constitution of Venezuela also emphasizes the decision of the >couple<.

No constitution addresses the protection of the right to family planning. A state duty to fulfil family planning is described as a »right to access family planning education, information and capacity « ${ }^{35}$ (Ethiopia), and state guarantee of »full family planning services based on ethical and scientific values ${ }^{36}$ (Venezuela). Portugal's constitution offers a clear example

31 Constitution of Nepal of 2015, Article 51(j)3.

32 Constitution of Zimbabwe of 2013, Article 76(1).

33 Constitution of Portugal of 1976 (amended 2005), Article 67(2)d.

34 Constitution of Brazil of 1988 (amended 2015), Articles 226 and 7.

35 Constitution of Ethiopia of 1994, Article 35.

36 Constitution of the Bolivarian Republic of Venezuela of 1999 (amended 2009), Article 76. 
of state responsibility to fulfil access to family planning information and methods:

»In order to protect the family, the state shall particularly be charged with: (d) with respect for individual freedom, guaranteeing the right to family planning by promoting the information and access to the methods and means required therefore, and organizing such legal and technical arrangements as are needed for motherhood and fatherhood to be consciously planned «. ${ }^{37}$ [emphasis added, L.B.P./S.K.P.]

Portugal's constitution charges the state with guaranteeing family planning through access to information and the means to act on that information. Family planning resembles an individual obligation or duty in relation to national population control objectives in the constitutions of China, Vietnam, and Turkey.

\subsection{Abortion}

Three countries have specific constitutional provisions about abortion: Kenya, Swaziland and Somalia. Although the provisions frame abortion primarily in negative terms as $>$ unlawful $<,{ }^{38}>$ illegal $<{ }^{39}$ or $>$ not permitted $<,{ }^{40}$ all laws recognise various grounds on which abortion may be allowed. The Swazi Constitution provides exceptions for abortions performed on medical or therapeutic grounds to preserve life, physical health or mental health, in the case of rape, in the case of incest, or in the case of foetal impairment. Moreover, this is not an exhaustive list as the provision leaves room for the parliament to incorporate new grounds in which abortion would be allowed. The Kenyan constitution also contains similar grounds in which abortion is permitted when there is need for emergency treatment, or the life or health of the mother is in danger, or if permitted by any other written law. In the same line - but with a more restrictive approach - the Somalian Constitution states that abortion will be permitted in cases of necessity, especially to save the life of the mother.

37 Constitution of Portugal of 1976 (amended 2005), Article 67, para. 2.

38 Constitution of Swaziland of 2005, Article 15(5).

39 Constitution of Somalia of 2012, Article 15(5).

40 Constitution of Kenya of 2010, Article 26(4). 


\subsection{Indivisibility and Interdependence with other Human Rights}

The UN bodies have noted that SRHR are intimately linked to civil and political rights underpinning the physical and mental integrity of individuals and their autonomy, such as the rights to life; liberty and security of person; freedom from torture and other cruel, inhuman or degrading treatment; privacy and respect for family life; and non-discrimination and equality. ${ }^{41}$ In this regard, we mapped the constitutional commitments on SRHR looking for the explicit interlinkages between these rights and other human rights.

\subsubsection{Autonomy and Freedom from Coercion}

The Brazilian constitution recognizes that »couples are free to decide on family planning « and prohibits »any coercion on the part of official or private institutions $\ll{ }^{42}$ In the context of choices about family planning, Portugal's constitution introduces the duty to respect individual freedom when it comes to decisions on SRHR: »In order to protect the family, the state shall particularly be charged with: [...] respect for individual freedom ${ }^{43}{ }^{43}$ Ecuador has included the provisions on SRHR in Chapter 6 of the Constitution that enshrines »Rights to freedom« and recognizes both the right to decide freely and voluntary on matters of sexuality and sexual life and orientation and about one's health and reproductive life and to decide how many children to have. The Constitution of Paraguay and Venezuela also place emphasis on this element.

\subsubsection{Right to Benefit from Scientific Progress}

In this regard, three of the constitutions analysed contain provisions reflecting the importance of this element. The Brazilian constitution clearly mandates that the state must provide educational and scientific resources for the exercise of SRHR. Paraguay formulates in its constitution that the state recognizes the right of persons to receive »education, scientific orientation,

41 For a more extensive analysis see United Nations Population Fund et al. (2014); Center for Reproductive Rights (2008), (2009), (2010) and (2013).

42 Constitution of Brazil of 1988 (amended 2015), Article 226, para. 7.

43 Constitution of Portugal of 1976 (amended 2005), Article 67, para. 2. 
and adequate services «. ${ }^{44}$ The Venezuelan constitution notes that it is incumbent to the state to guarantee full family planning services based on ethical and scientific values. Furthermore, the constitutions of South Africa, Zimbabwe, and Ecuador enshrine the right of individuals not to be subjected to medical or scientific experiments without their informed consent.

\subsubsection{Right to Access to Information and Education on SRHR}

Several of the national constitutions have considered this element. The Brazilian constitution states that it is incumbent upon the state to provide educational and scientific resources for the exercise of these rights. The constitutions from Ecuador, Ethiopia, Paraguay, Portugal, and Venezuela recognize that education and information are sine qua non requisites for the effective enjoyment of SRHR. Notably, the constitution of Ethiopia innovates incorporating capacity.

\subsubsection{Budget Allocation}

Four of the constitutions have specific provisions related to budget allocation and all of them refer to reproductive healthcare. The Brazilian constitution states that the "government shall promote full health assistance programs for children, adolescents « and in order to do that there will be an allocation of a percentage of public health funds to assist mothers and infants. ${ }^{45}$ The Constitutions of Fiji, South Africa, and Zimbabwe establish that the state must take reasonable legislative and other measures, within the limits of the resources available to it, to achieve the progressive realization of the rights set out in this section (right to health including reproductive health). It should be noted that the constitution of Fiji demands that if the state claims that it does not have the resources to implement the rights, it is the responsibility of the state to show that the resources are not available.

44 Constitution of Paraguay of 1992 (amended 2011), para. 61. »The State recognizes the right of persons to freely and responsibly decide the number and the frequency of the birth of their children, as well as to receive, in coordination with the pertinent organs[,] education, scientific orientation, and adequate services in the matter $\ll$.

45 Constitution of Brazil of 1988 (amended 2015), Article 227, para. 1. 


\section{Discussion}

\subsection{Introducing the Sexual into Sexual and Reproductive Health and Rights}

Although our results suggest that, compared to other SRHR concepts, sexual rights/health were widely enshrined in 24 constitutions, the majority of these references are negative prohibiting discrimination on the grounds of sexuality and/or recognizing a negative right to sexual health (i.e. to be protected from sexual offences). Most references to sexual health were found in constitutions from the Americas and Africa.

As noted by the literature on the topic, prior to $1993^{46}$ sexuality - or the forbidden >s $<$ word - of any sort or manifestation was absent from human rights discourse. The Declaration of the World Conference on Human Rights in Vienna and the Declaration on Violence against Women represented a major turning point not only because they gained recognition of sexual violence as a human rights violation but also because they finally initiated >the sexual into human rights language. ${ }^{47}$ The term >sexual health has now been given equal recognition as >reproductive health CESCR.

Only two constitutions in our study embody positive references to sexual rights, such as to freely make decisions about one's sexual life or to have access to sexual healthcare. We use the term snegativer following Petchesky's observation that the emergence of the concept of sexual rights has only occurred from a negative approach, i.e. the abovementioned provisions expressing the right not to be the object of abuse or exploitation, in the corrective sense of combating violations. We concur with this opinion considering that the development of sexual rights needs to expand and move towards an affirmative concept. In this line, the WHO definition of

46 See generally Petchesky (2000); Girard (2007), Davis (2008). Petchesky ponders »why is it so much easier to assert sexual freedom in a negative way, and not in an affirmative, emancipatory sense? Why is it easier to reach a consensus on the right not to be abused, exploited, raped, trafficked or mutilated in one's body, but not the right to fully enjoy one's own body?« See Petchesky (2000), 88.

47 Petchesky (2000), 83. 
sexual health - adopted by General Comment No. 22 - that requires a positive and respectful approach to sexuality and sexual relationships can provide a good starting point. ${ }^{48}$

\section{2 »Couples « or »Individuals«? Universality and SRHR Right Holders}

Determining the holders of SRHR proved to be a controversial undertaking. Debates about the right holders have evolved from the first reference to the >family ${ }^{49}$ in the Declaration on Population, to »all couples and individuals« by the World Population Plan of Action following the Bucharest Conference, in $1974 .{ }^{50}$ Now, General Comment No. 22 clearly signals that »all

48 The WHO defines sexual health as »a state of physical, emotional, mental and social well-being in relation to sexuality; it is not merely the absence of disease, dysfunction or infirmity«. It also states that "Sexual health requires a positive and respectful approach to sexuality and sexual relationships, as well as the possibility of having pleasurable and safe sexual experiences, free of coercion, discrimination and violence.« And recognises that sexual health cannot be achieved and maintained without respect for, and protection of, certain human rights, that is, sexual rights. See WHO (2002).

49 One year later 18 more countries signed the declaration signalling the political acceptability of governmental policies to influence population control. This focus on restraining population growth grew out of widespread concern that the unprecedented pace and volume of population growth after 1950 was a serious threat to economic development, public health, and the environment. See generally Ashford (2001), 3.

50 The phrasing >couples and individuals $\triangleleft$ was not in the original draft but was inserted as a new principle in the working group of the WPPA. See United Nations World Population Conference, PN-AAH-494, 1974. Furthermore, in global debates, the Holy See has voiced its disagreement with the term >couples and individuals « and stated its own interpretation of the phrase as "married couples and the individual man and woman who constitute the couple«. According to the Holy See's position, no sexual and reproductive rights should be recognized and guaranteed to those outside the traditional heterosexual monogamous marriage. See for example Statement of the Holy See at the International Conference on Population and Development, A/CONF.171/13/ Rev.1, 5-13 September 1994. 
individuals and groups should be able [...] to exercise their rights to sexual and reproductive health without experiencing any discrimination «. ${ }^{51}$

The constitutions of Brazil and Venezuela afford the right to decide about family planning to >couples`, which restrict these to control procreation to two people in a heterosexual monogamous relationship. ${ }^{52}$ This concept fundamentally clashes with the universality of human rights as it makes exclusions based on marital status and sexual orientation.

\subsection{Decisional Autonomy and Freedom from Coercion in SRHR}

Furthermore, despite substantial international traction for the legal recognition of women's agency over their own sexuality and reproductive function, China and Vietnam continue to apply a controlling constitutional provision to procreation. Moreover, the constitution from Turkey states that

»the State shall take the necessary measures and establish the necessary organization to protect peace and welfare of the family, especially mother and children, and to ensure the instruction of family planning and its practice. ${ }^{53}$ [emphasis added, L.B.P./S.K.P.].

$51 \mathrm{E} / \mathrm{C} .12 / \mathrm{GC} / 22,2$ May 2016, para. 22. Where reproductive health is defined as including "access to a range of reproductive health information, goods, facilities, and services to enable individuals to make informed, free and responsible decisions about their reproductive behaviour« (ibid., para. 6).

52 The Brazilian constitution only affords protection to couples when it comes to their reproductive rights: »Based upon the principles of human dignity and responsible parenthood, couples are free to decide on family planning« and the constitutional definition of family specifically refers to the »stable union between a man and a woman«. Constitution of Brazil of 1988 (amended 2015), Article 226. In the same line, the Venezuelan constitution states that 》Couples have the right to decide freely and responsibly how many children they wish to conceive«. Constitution of Venezuela of 1999 (amended 2009), Article 76.

53 Constitution of Turkey of 1982 (amended 2002), Article 41. 
Provisions that subject the recognition of SRHR to its exercise in accordance with the government's demographic goals or in a manner that the government considers >responsible`, instrumentalizes human beings and their reproductive capacity as an object of population control. This approach has been widely criticized. ${ }^{54}$ Greater emphasis on the individual right to decide on contraception in national constitutions may help curb discriminatory practices in which, for example, male partners must give express permission for a women to obtain contraception. ${ }^{55}$

\subsection{Provision of Healthcare}

Ecuador's constitution is notable as it includes several provisions for the state's duty to fulfil access to both sexual and reproductive healthcare:

»The State shall guarantee this right by means of economic, social, cultural, educational, and environmental policies; and the permanent, timely and non-exclusive access to programs, actions and services promoting and providing integral healthcare, sexual health, and reproductive health. The provision of healthcare services shall be governed by the principles of equity, universality, solidarity, interculturalism, quality, efficiency, effectiveness, prevention, and bioethics, with a gender and generational approach. $\ll^{56}$ [emphasis added, L.B.P./S.K.P.]

This language is a positive innovation for the provision of healthcare for several reasons. First, numerous commentators from the both the legal and health disciplines maintain that the phrase >maternal health is insufficient to adequately address the core issue of healthcare tailored to women's health and needs. ${ }^{57}$ Instead, these commentators call for a holistic, lifecycle approach that addresses sexual and reproductive health - just as this provision in the Ecuadorian constitution has done - in order to capture the health needs of women at all life stages and regardless of whether they have born

54 Shalev (2000) 40. See also Aguirre/Wolfgram (2002).

55 See examples by Langer et al. (2015), 1173.

56 Constitution of Ecuador of 2008 (amended 2011), Article 32.

57 See generally Yamin/Boulanger (2013); Bustreo et al. (2013). 
children. ${ }^{58}$ Second, this provision considers the human rights elements of availability (>permanent, timely<), accessibility (>non-exclusiveく, >universality $<$ ), acceptability ( $>$ interculturalism $<$, >with a gender and generational

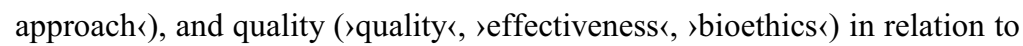
sexual and reproductive health programs and services.

\subsection{Reflections on Abortion}

Bearing in mind that restrictions on abortion were codified in three African constitutions, it is interesting to note that the African human rights system was the first to regulate explicitly on the issue of abortion in a binding instrument. The »Maputo Protocol« is the very first treaty to recognize abortion, under certain conditions, as women's human right which they should enjoy without restriction or fear of being prosecuted. ${ }^{59}$ Under Article 14 (2) (c) of the Maputo Protocol, states parties are called upon to take all appropriate measures to "protect the reproductive rights of women by authorizing medical abortion in cases of sexual assault, rape, incest, and where the continued pregnancy endangers the mental and physical health of the mother or the life of the mother or the foetus «. ${ }^{60}$

Both the constitutions from Kenya and Swaziland have placed such provisions in the Chapter that guarantees the right to life as a fundamental right. In Swaziland the provision on abortion is under Chapter III on Protection and Promotion of Fundamental Rights and Freedoms, Title15 on Protection of the Right to Life and in the Kenyan constitution it is regulated in Part 2 concerning Rights and Fundamental Freedoms, Article 26 on the right to life. This might be a reflection of the UN monitoring bodies' arguments that ground the discussion on abortion on the high rates of maternal mortality and a growing concern for the preventable deaths caused by unsafe abortions. ${ }^{61}$ Differently, the constitution of Somalia has placed the

58 See generally Yamin/Boulanger (2013); Bustreo et al. (2013); Langer et al. (2015).

59 Zampas/Gher (2008), 250. See also African Commission on Human and Peoples' Rights (2014).

60 »Maputo Protocol« or Protocol to the African Charter on Human and Peoples' Rights on the Rights of Women in Africa.

61 See more generally van Leeuwen (2007), 109-113. 
article regulating abortion under Title II on Rights, Basic Personal Liberties And Limitations, Article 15 Liberty and Security of the Person.

\subsection{Interdependence and Indivisibility}

This survey shows that various constitutions have drafted clear interlinkages between SRHR and other human rights. In 1993 in the World Conference on Human Rights in Vienna ${ }^{62}$ states agreed on the principles of indivisibility and interdependence among the different kinds of rights and their respective international conventions. The approach of the International Conference on Population and Development tying health outcomes to rights promotion and protection - is considered very innovative because it built on previously enshrined and widely accepted human rights, articulating >reproductive rights as already existing human rights applied to experiences related to reproduction. ${ }^{63}$ General Comment No. 22 has also insisted on these characteristics noting that $»[\mathrm{t}]$ he realization of the right to sexual and reproductive health requires that states parties also meet their obligations under other provisions of the Covenant $\ll .{ }^{64}$

It has been noted that no government argued the right to health should not constitute a right during the drafting of the WHO Constitution, the Universal Declaration of Human Rights, or the International Covenant on Economic, Social and Cultural Rights. ${ }^{65}$ However, the criticism stemmed from the fact that neither was it clear whose responsibility it was to realise the right to health, how this right would be realised, nor when this right had been satisfied. ${ }^{66}$ Undoubtedly, issues of budget availability and allocation of resources are crucial for the achievement of the right to health in general and particularly SRHR. The inability of countries to carry out the International Conference on Population and Development Program has been hampered by developing countries' financial constrains to meet their obligations but also by developed states not meeting theirs. ${ }^{67}$ Amnesty Interna-

62 Vienna Declaration and Programme of Action (1993).

63 Reichenbach/Roseman (2009), 9.

64 E/C.12/GC/22, 2 May 2016, paras. 9-10.

65 Davies (2010), 390.

66 Taylor (1992), 327.

67 Davies (2010), 394. 
tional reports that in the ICPD +5 many countries and civil society organizations stressed their concerns about the impact of the financial crisis on implementation at the national level because of budget limitations in developing countries and reduced development assistance from donor countries. ${ }^{6}$ Furthermore, it has been noted that funding shortfalls are a key factor explaining why most developing countries were unable to meet the health-related MDGs by $2015 .{ }^{69}$ However, the international community met in July 2015 to developed the Addis Ababa Action Agenda on Financing for Development (AAAA) that should guide governments in their decision making processes around guide wide range of development issues. ${ }^{70}$ Furthermore, the monitoring tools developed by the UNFPA and Centre for Reproductive Rights consider that an essential element to assess state compliance is the allocation of adequate budgetary resources. ${ }^{71}$

Furthermore, when austerity measures are adopted and states implement cuts in their budgets, evidence seems to indicate that SRHR - particularly SRHR of women - are the first ones to be adversely effected. ${ }^{72}$ Shalev cites the example of Croatia in which the first type of medication to be cut off from state funding was contraception and abortion was the first medical act to be removed from the free health care services. ${ }^{73}$ Legal recognition of SRHR and specific provisions regarding budget allocation contributes to these rights, endure changes in government administrations and survive economic or social strife and ensure a certain degree of consistency over time.

68 Amnesty International (2012), 9.

69 Singh et al. (2009), 7.

70 For a general overview of the financial aspects of SRHR see International Planned Parenthood Federation (2015).

71 See generally Centre for Reproductive Rights/United Nations Population Fund (2013).

72 Shalev (2000), 50.

73 Ibid. 


\subsection{A Gender Sensitive Approach}

General Comment No. 22 demands a gender sensitive approach to SRHR, specifically where $»[\mathrm{~g}]$ ender equality requires that the health needs of women, different from those of men, be taken into account and appropriate services provided for women in accordance with their life cycles ${ }^{74}{ }^{74}$ The Bolivian constitution states that both »women and men are guaranteed the exercise of sexual and reproductive rights ${ }^{75}$ and that $» e v e r y o n e$, in particular women ${ }^{76}{ }^{76}$ have the right to be free from sexual violence. The Ecuadorian constitution states that the state bears the responsibility to ensure SRHR actions and services, especially during pregnancy, childbirth and postpartum. Motherhood and maternal health are afforded special protection under the constitutions of Paraguay and Venezuela. The Constitution of Nicaragua provides for special protection to women during pregnancy and paid maternity leave.

The Ethiopian constitution places the regulation of SRHR under the $>$ Rights of women $<{ }^{77}$ The provision acknowledges a historical legacy of inequality and discrimination in the country and provides for affirmative measures to counter this. In this regard, it provides that »to prevent harm arising from pregnancy and childbirth and in order to safeguard their health women have the right of access to family planning, education information and capacity ${ }^{78}{ }^{78}$

Nepal's Constitution also adopts a similar approach and is notable in that it states: »Every woman shall have the right relating to safe motherhood and reproductive health ${ }^{79}{ }^{79}$ Among one of the most inclusive constitutions, Nepal's law does not limit the right to reproductive health to women of a certain age, reproductive capacity, marital or citizenship status as other constitutions have done. However, the abovementioned constitutional provisions fail to include men's right to reproductive health.

74 E/C.12/2000/4, 11 August 2000, para. 25.

75 Constitution of the Plurinational State of Bolivia of 2009, Article 66.

76 Ibid., Article 15.

77 Constitution of Ethiopia of 1994, Article 35.

78 Ibid., Article 35(6).

79 Nepal, PART 338, Rights of Women, para. 2. 
It's important to clarify that the adoption of a gender sensitive approach does not entail the recognition of rights exclusively for a particular group of individual, but to recognise the unavoidable gender specific challenges.

\subsection{Future Steps}

Although the global community has endorsed the interrelationship between sexual rights and health and rights in the Conference and Beijing Plan of Action, the development agenda has historically skirted around the issue of SRHR until now. ${ }^{80}$ Currently, considerable attention is given to reframing women's health around sexual and reproductive rights that consider a lifecycle approach independent of reproductive capacity. ${ }^{81}$ The most recently adopted 2030 Agenda for Sustainable Development also includes goals and targets to be achieved in the area of sexual and reproductive health. ${ }^{82}$ In a broader development perspective, SRHR is also among the key objectives of the Sustainable Development Goals (SDGs) and direct references to human rights treaties on SRHR are found in the targets themselves. The Global Strategy for Women's, Children's, and Adolescents' health (2016-2030) has as a key objective to »expand enabling environment« where the right to health and wellbeing can be achieved, specifically by removing barriers to the enjoyment of rights and by promoting gender equality. $^{83}$

80 The MDGs have been criticized for failing to address women's rights as a fundamental determinant of women's health, and deliberately focusing on maternal health rather than sexuality and reproduction. Yamin/Boulanger (2013) emphasize that initiatives inclusive of sexuality and reproduction are needed to address the core issue women's empowerment needed if sustainable progress is to be made in women's health.

81 See generally Langer et al. (2015).

$82 \mathrm{~A} / \operatorname{Res} / 70 / 1$, adopted by the UN General Assembly in September 2015, which contains Goal 3: Ensure healthy lives and promote well-being for all at all ages and Goal 5: Achieve gender equality and empower all women and girls.

83 See generally Kuruvilla et al. (2016). 


\subsection{Key Recommendations for Future Constitution Builders}

Constitutional law, as all domestic law, should conform to a human rights approach to protect and promote SRHR. Specifically, committed governments should expressly respect, protect, and fulfil SRHR for all individuals without discrimination.

First, barriers to the full enjoyment of SRHR should be removed from constitutional law. In line with General Comment No. 22, governments should end the codification of coercive practices in family planning and restrictive approaches to abortion in constitutional law. Second, the right to SHR should be framed in a manner that is sensitive to the different needs of men and women, and to their needs at different stages in their life cycles. Both sexual health and reproductive health deserve equal protection and promotion under constitutional law. This includes the right to make informed decisions free from coercion about one's sexuality and one's reproduction, and the right to access healthcare for sexual and reproductive needs, including contraception and safe abortion services. Furthermore, it is crucial to incorporate the paradigm of rights enshrining sexual and reproductive rights. This article provides examples of existing constitutional text that may be considered by future constitutional framers and governments truly committed to SRHR.

\section{REFERENCES}

African Commission on Human and Peoples' Rights (2014): »General Comment No. 2 on Article 14.1 (a), (b), (c) and (f) and Article 14. 2 (a) and (c) of the Protocol to the African Charter on Human and Peoples' Rights on the Rights of Women in Africa«, Online:http://www.achpr. org/instruments/general-comment-two-rights-women/ [25.06.2016].

Aguirre, Maria Sophia/Wolfgram, Ann (2002): »United Nations Policy and the Family: Redefining the Ties That Bind: A Study of History, Forces and Trends«, in: BYU Journal of Public Law 16, 2 (2002), Online: http://digitalcommons.law.byu.edu/jpl/vol16/iss2/2 [29.06.2016]. 
Amnesty International (2012): »Realizing Sexual and Reproductive Rights: A Human Rights Framework«, Online: https://www.amnesty.org/en/ documents/ACT35/006/2012/en/ [25.06.2016].

Ashford, Lori S. (2001): New population policies: advancing women's health and rights, Population Bulletin 56, 1, Washington: Population Reference Bureau.

Baksh, Rawwida/Harcourt, Wendy (Eds.) (2014): The Oxford Handbook of Transnational Feminist Movements, Oxford: Oxford University Press.

Bustreo, Flavia/de Zoysa, Isabelle/de Carvalho, Islene Araujo (2013): »Policy directions to improve women's health beyond reproduction«, in: Bulletin of the World Health Organization 91, 9 (2013). doi: http://dx. doi.org/10.2471/BLT.12.109785.

Center for Reproductive Rights (2008): »Bringing Rights to Bear: Abortion and Human Rights«, Online: http://www.reproductiverights.org/docu ment/bringing-rights-to-bear-abortion-and-human-rights [27.06.2016].

Center for Reproductive Rights (2009): »Twelve Human Rights Key to Reproductive Rights«, Online: http:/www.reproductiverights.org/sites/ crr.civicactions.net/files/documents/V4Repro\%20Rights\%20Are $\% 20 \mathrm{H}$ uman\%20Rights\%20-\%20FINAL.pdf [27.06.2016].

Center for Reproductive Rights (2010): »Briefing Paper: Reproductive Rights Violations a Torture and Cruel, Inhuman or Degrading Treatment or Punishment: A Critical Human Rights Analysis«, Online: http://reproductiverights.org/sites/crr.civicactions.net/files/documents/T CIDT.pdf [27.06.2016].

Centre for Reproductive Rights/United Nations Population Fund (2013): $»$ Reproductive Rights : A Tool for Monitoring State Obligations«, Online: http://www.reproductiverights.org/sites/crr.civicactions.net/files/ documents/crr_Monitoring_Tool_State_Obligations.pdf [29.06.2016].

Cottingham, Jane/Kismodi, Eszter/Hilber, Adriane Martin/Lincetto, Ornella/Stahlhofer, Marcus/Gruskin, Sofia (2010): »Using Human Rights for Sexual and Reproductive Health: Improving Legal and Regulatory Frameworks«, in: Bulletin of the World Health Organization 88 (2009), 551-555.

Davies, Sara E. (2010): »Reproductive Health as a Human Right: A Matter of Access or Provision?«, in: Journal of Human Rights 9, 4 (2010), $387-408$. 
Elkins, Zachary/Ginsburg, Tom/Leetaru, Kalev/Melton, James (2011): »Lessons from the decoding and coding of national constitution «, in: Comparative Democratization 9, 1 (2011), 2.

Garita, Alexandra (2014): »Moving toward Sexual and Reproductive Justice: A Transnational and Multigenerational Feminist Remix«, in: Baksh/Harcourt (2014), 271-294

Ginsburg, Tom/Elkins, Zachary/Blount, Justin (2009): »Does the process of constitution-making matter«, in: Annual Review of Law and Social Sciences 5, 5 (2009), 201-223.

Girard, Françoise (2007): Negotiating sexual rights and sexual orientation at the UN. Sex Politics: Reports from the Front Lines, Rio de Janeiro: Sexuality Policy Watch.

Gruskin, Sofia/Cottingham, Jane/Hilber, Adriane Martin/Kismodi, Eszter/ Lincetto, Ornella/Roseman, Mindy Jane (2008): »Using human rights to improve maternal and neonatal health: history, connections and a proposed practical approach «, in: Bulletin of the World Health Organization 86, 8 (2008), 589-593.

Hogerzeil, Hans V./Samson, Melanie/Vidal Casanovas, Jaume/ Rahmani-Ocora, Ladan (2006): »Is access to essential medicines as part of the fulfilment of the right to health enforceable through the courts? «, in: The Lancet 368 (2006), 305-311.

International Planned Parenthood Federation (2015): »Financing Demystified «, Online: http://www.ippf.org/sites/default/files/ippf_financing demystified.pdf [19.10.2016].

Kismödi, Eszter/Cottingham, Jane/Gruskin, Sofia/Müller, Alice M. (2015): "Advancing sexual health through human rights: The role of the law«, in: Global public health 10, 2 (2015), 252-267.

Kuruvilla, Shyama/Bustreo, Flavia/Kuo, Taona/Mishra, CK/Taylor, Katie/ Fogstad, Helga/Gupta, Geeta Rao /Gilmore, Kate/Temmerman, Marleen/Thomas, Joe/Rasanathan, Kumanan/Chaiban, Ted/Mohan, Anshu/ Gruending, Anna/Schweitzer, Julian/Dini, Hannah Sarah/Borrazzo, John/Fassil, Hareya/Gronseth, Lars/Khosla, Rajat/Cheeseman, Richard/ Gorna, Robin/McDougall, Lori/Toure, Kadidiatou/Rogers, Kate/ Dodson, Kate/Sharma, Anita/Seoane, Marta/Costello, Anthony (2016): »The Global strategy for women's, children's and adolescents' health (2016-2030): a roadmap based on evidence and country experience«, in: Bulletin of the World Health Organization 94, 5 (2016), 398-400. 
Langer Ana/Meleis, Afaf/Knaul, Felicia M./Atun, Rifat/Aran, Meltem/ Arreola-Ornelas, Héctor/Bhutta, Zulfiqar A./Binagwaho, Agnes/Bonita, Ruth/Caglia, Jacquelyn M./Claeson, Mariam/Davies, Justine/Donnay, France A./Gausman, Jewel M./Glickman, Caroline/Kearns, Annie D./ Kendall, Tamil/Lozano, Rafael/Seboni, Naomi/Sen, Gita/Sindhu, Siriorn/Temin, Miriam/Frenk, Julio (2015): »Women and Health: the key for sustainable development«, in: The Lancet 386, 9999 (2015), 1165-1210.

Mattar, Laura Davis (2008): »Legal recognition of sexual rights: a comparative analysis with reproductive rights«, in: Sur. Revista Internacional de Direitos Humanos 5, 8 (2008), 60-83.

Melton, James/Elkins, Zachary/Ginsburg, Tom/Leetaru, Kalev (2013): »On the interpretability of law: Lessons from the decoding of national constitutions«, in: British Journal of Political Science 43, 2 (2013), 399423.

Office of the High Commissioner for Human Rights (2012): »Human Rights Indicators: A Guide to Measurement and Implementation«, Online: www.ohchr.org/Documents/Publications/Human_rights_indicators _en.pdf [28.06.2016].

Parker, Richard/Barbosa, Regina Maria/Aggleton Peter (Eds.) (2000): Framing the Sexual Subject: The Politics of Gender, Sexuality, and Power, Berkley i.a.: University of California Press.

Petchesky, Regina Maria (2000): »Sexual Rights. Inventing a Concept, Mapping an International Practice«, in: Parker et al. (2000), 81-103.

Reichenbach, Laura/Roseman, Mindy Jane (2009): Reproductive health and human rights: the way forward, Philadelphia: University of Pennsylvania Press.

Roa, Mónica/Klugman, Barbara (2014): »Considering strategic litigation as an advocacy tool: a case study of the defence of reproductive rights in Colombia«, in: Reproductive health matters 22, 44 (2014), 31-41.

Roseman, Mindy Jane/Reichenbach, Laura (2009): »Global Reproductive Health and Rights: Reflecting on ICPD «, in: Reichenbach/Roseman (2009), 3-20.

Shalev, Carmel (2000): »Rights to Sexual and Reproductive Health: The ICPD and the Convention on the Elimination of All Forms of Discrimination Against Women«, in: Health and Human Rights Journal 4, 2 (2000), 38-66. 
Singh, Susheela/Darroch, Jacqueline E./Ashford, Lori S./Vlassoff, Michael (2009): »Adding It up: The Costs and Benefits of Investing in Family Planning and Maternal and Newborn Health«, New York: Guttmacher Institute and United Nations Population Fund, Online: https://www. guttmacher.org/sites/default/files/report_pdf/AddingItUp2009.pdf [29.06.2016].

United Nations Population Fund/Office of the United Nations High Commissioner for Human Rights/Danish Institute for Human Rights (2014): »Reproductive Rights Are Human Rights: A Handbook for National Human Rights Institutions«, Online: http:/www.ohchr.org/Documents/Publications/NHRIHandbook.pdf [29.06.2016].

van Leeuwen, Fleur (2007): »Woman's Right to Decide-The United Nations Human Rights Committee, Human Rights of Women, and Matters of Human Reproduction«, in: Netherlands Quarterly of Human Rights 25, 1 (2007), 97-116.

WHO (2010): »Sexual and Reproductive Health«, Geneva: WHO, Online: http://www.who.int/reproductivehealth/topics/sexual_health/sh_definiti ons/en/ [24.06.2016].

Yamin, Alicia/Boulanger, Vanessa M. (2013): »Embedding sexual and reproductive health and rights in a transformational development framework: lessons learned from the MDG targets and indicators «, in: Reproductive Health Matters 21, 42 (2013), 74-85.

Zampas, Christina/Gher, Jamie M. (2008): „Abortion as a human right international and regional standards«, in: Human Rights Law Review 8, 2 (2008), 249-294. 


\section{Emergency Treatment after Potential HIV-Exposure}

A Neglected Right to Healthcare?

MATHIAS WIRTH

In Western countries it is commonly assumed that quick emergency treatment is absolutely guaranteed. This, however, does not hold true for cases of possible acute HIV infection, particularly for men and transgender women who have sex with men. This is because an overwhelming majority of people are still unaware of the option of HIV post-exposure prophylaxis (HIV-PEP). Consequently, those who could have been infected with HIV through high-risk sex behaviours often do not consider their situation a medical emergency. As such, patients who could otherwise have begun a course of PEP after risk assessment fail to visit a clinic within the recommended 2 to 48 hours after exposure. Patients who do take the antiretroviral drugs for one month reduce their risk of HIV infection by around $80 \%$.

\section{INTRODUCTION: A DISTURBING OBSERVATION IN THE ॥WESTERN WORLD॥}

It is difficult to understand that in the so-called »Western World «, a severe medical emergency may arise that can result in a life-threatening situation if not treated, or in the chronic infection of a virus, without affected individuals and those around them recognizing it as an emergency and obtaining access to immediate medication that could prevent the individual from 
becoming infected. ${ }^{1}$ This scenario, however, reflects the possible failure to obtain the HIV post exposure prophylaxis (HIV-PEP). ${ }^{2}$ This paper discusses the problem of the ignorance surrounding HIV-PEP as a serious issue concerning the right to healthcare. The reasons for the low distribution of PEP will be investigated and ethically classified.

The available statistical data reveals a fairly poor adherence among patients to an initiated HIV-PEP ${ }^{3}$ due to possible side-effects. No further research upon the question of HIV-PEP-knowledge in the population in general has been conducted. We have some results from specific research into particular target groups, such as men who have sex with men (MSM). ${ }^{4}$ These results do not, however, extend to trans and inter individuals who may also belong to specific risk groups. However, there is reason to believe that with the exception of medical students, the younger generation of physicians, and doctors of infectiology, most people, at least in Germany, are not aware that there is a medication that can be used to prevent HIV-infection immediately after exposure.

My intention here is not primarily to focus on the question of who is responsible for the lack of knowledge regarding PEP amongst the majority of individuals. A mixture of medical, political, and economic reasons are behind the current state of general ignorance. The most disturbing explanation concerns the idea that certain actors could have a vested economic interest in avoiding HIV-PEP in order to benefit from the profit of lifelong drug therapy for HIV-infected individuals. What is for sure, however, is that $»\left[\right.$ t] he fight against HIV/AIDS is, above all, an economic issue. $\iota^{5}$

An important preliminary mark must be made when discussing strategies to prevent HIV and AIDS. This severe virus and disease requires a life-

1 Doyal/Doyal (2013).

2 Whelehan (2009).

3 Ford et al. (2014).

4 The survey by Jochen Drewes and Martin Kruspe on behalf of the Deutsche AIDS-Hilfe of homosexual men and their sexual behaviour includes also a chapter on HIV-PEP. Although one special risk group, younger men, are underrepresented, the study collects and summarizes useful statistical data about the knowledge and use of HIV-PEP amongst MSM and detects fairly poor knowledge and usage of the treatment. See Drewes/Kruspe (2013).

5 Leoni (2010), ix. 
long regimen of drugs while imposing a higher risk of contracting other diseases, such as Leukoencephalopathy or AIDS-related lymphomas. ${ }^{6}$ In this connection, it must be stressed that the severity of the disease does not mean that already infected people are judged to be in a deficient state of human life. The struggle against sickness does not necessarily entail fighting against sick people, although the history of medicine provides plenty of examples to the contrary. ${ }^{7}$ A sharp distinction between ethically permissible efforts against sickness and ethically not permissible efforts against sick people stems from the following philosophical observation: Diseases, according to traditional philosophy, are considered to be a natural evil (malum physicum). This is to say that diseases cause a "too much", which occurs in pain, for instance, that individuals desire to overcome. ${ }^{8}$ Thus, launching programmes against diseases does not constitute an assault against those infected, because the programmes seek to obtain the same situation for both groups (infected and non-infected). The goal is to prevent both groups from having to suffer from the "too much« of severe sickness through a) avoiding infection or b) through medication enabling a person to live like someone who is not infected. The »not being infected «, notably, applies to both groups. The human right to healthcare means both: Preventing people from being infected ${ }^{9}$ and treating the infected, in the best scenario, so that they can live as if they had not been infected.

6 Wyen et al. (2004) and (2012).

7 Schmiedebach (2012).

8 Wirth (2015a); Wirth/Hurwitz (2016).

9 The Universal Declaration of Human Rights states in Article 25 that not only health care in the sense of treatment, but also in the wider sense, which includes prevention as the means of a certain standard of living, is a human right: »Everyone has the right to a standard of living adequate for the health and well-being of himself and of his family, including food, clothing, housing and medical care $[\ldots] \ll$. 


\section{OVERVIEW OF HIV POST EXPOSURE PROPHYLAXIS}

HIV-PEP is an antiretroviral treatment that reduces the risk of HIV-infection after potential exposure, both occupational and through sexual intercourse, by approximately $80 \%$ when treatment with drugs is initiated within 48 hours after potential exposition to the HI-virus. ${ }^{10}$ A 28 -day-treatment is recommended. Medication may be necessary to manage side-effects that occur among a number of users and include nausea, fatigue, diarrhea, and headache and that are often an issue affecting adherence. ${ }^{11}$ These sideeffects and possible effects on liver and kidney are usually reversible. All guidelines agree that HIV-PEP is indicated in cases of anal or vaginal sexual intercourse when one partner is HIV-positive and not on sufficient antiretroviral-medication or when men have unprotected anal sex with men, because this specific group is considered to have a higher prevalence of HIV than individuals exclusively practicing heterosexual sex. ${ }^{12}$ Comparable use of antiretroviral medication occurs with pre-exposure prophylaxis and prevention of mother-to-child-transmission. ${ }^{13}$

The World Health Organizations' (WHO) Guidelines on HIV-PEP begin with mentioning the astonishing fact that since 1989, HIV-PEP has been prescribed after occupational exposure to HIV. ${ }^{14}$ This guideline also mentions the failures of HIV-PEP and stresses that complete protection is

10 Jensen (2011).

11 Jones, S. G. (2009).

12 Benn et al. (2011); Deutsch Aids-Gesellschaft (2013). It is rather unclear how women who may have sexual risk contact with the one-fifth of MSM who also have heterosexual contact can be protected. Their number seems to be on the rise, cf. Drewes/Kruspe (2013). Concerning those 11\% of MSM who have sexual relations with a woman, newer empirical work stresses the unlikelihood that these men are a bridge for HIV; although such studies admit that a closing result cannot be given on the question, cf. Sekuler et al. (2014). This is especially interesting, insofar as only a minority of women who have sexual relations with a bisexual man, as indicated by a German survey, are aware of their situation, cf. Drewes/Kruspe (2013).

13 Baggaley et al. (2015).

14 Drewes/Kruspe (2013). 
impossible, and that therefore, sexual intercourse involving a high risk factor is still to be avoided. The WHO explicitly states that HIV-PEP should be easily accessible to all those who have been exposed to potential HIV-transmission, and also mentions children and their specific need for HIV-PEP, especially following incidents of rape. The WHO's guideline on HIV-PEP suggests training teachers, counsellors, police officers, and frontline healthcare workers on this topic. ${ }^{15}$ The overall evaluation of HIV-PEP by the WHO is very positive: »Post-exposure prophylaxis [...] is currently the only way to reduce the risk of the development of HIV infection in an individual who has been exposed to the virus «. ${ }^{16}$ In addition, newer studies on the early use of antiretroviral therapy stress the overall benefit for the individual and society. ${ }^{17}$ All in all, the WHO adheres to »strong ethical arguments support providing PEP for HIV infections $«{ }^{18}$ and the guidelines' overall assumption puts HIV-PEP explicitly in the area of human rights by generally stating that $»$ HIV-PEP can preserve life and health $\ll .{ }^{19}$ Unfortunately, the strategy of a widened distribution of knowledge about HIV-PEP has not been successful, although a major goal of HIV-prevention is to inform about means of prevention. ${ }^{20}$ This strategy should include the topic of HIV-PEP as well, which is not the case in all current works on HIV-prevention. $^{21}$ One of the most significant findings to emerge from the study by

15 World Health Organization (2007).

16 Ibid.,2.

17 Cohen et al. (2011).

18 World Health Organization (2007), 2.

19 Ibid., 5.

20 Corsten/von Rüden (2013).

21 One example is the work of Rolf Rosenbrock, a prominent voice in the academic approach to the HIV challenge during the last decades in Germany. In his work, HIV-PEP plays no crucial part. In a recent paper on societal and medical challenges surrounding AIDS prevention, HIV-PEP is not mentioned at all, although he quotes a campaign in Germany (»Ich weiß, was ich tu«), which focuses on PEP and other gay-related health issues, cf. Rosenbrock/Schmidt (2012). This is especially astonishing as Rosenbrock has dedicated much of his work to the politics and prevention of HIV and one of his first, still fundamental works is about how AIDS can be overcome more efficiently, cf. Rosenbrock (1987). Although his book was written before HIV-PEP, it is still unclear why 
Drewes and Kruspe is that even special risk groups for HIV, such as MSM, either do not know about PEP at all or do not feel well informed about it. ${ }^{22}$ Younger people are especially prone to being unaware that after a risk contact an HIV infection can be prevented, ${ }^{23}$ while younger MSM show an increased vulnerability for HIV infection (see chapter 4). More broadly, an important implication of this is that so far, HIV prevention has failed to establish HIV-PEP widely, and consequently the right to healthcare of MSM and other risk groups is not fully taken into account. Thus, there is a definite need for tackling this issue as a serious human rights issue.

HIV-PEP never became a crucial topic in the prevention strategies of the last decades.

22 Drewes/Kruspe (2013). In 2007, only 17\% of MSM knew about the option of a combination therapy - see Cohen et al. (2011) - that helps to prevent HIV infection after risky behaviour. Though the weakness of that study was that the term PEP was not mentioned, follow-up studies also revealed poor knowledge of HIV-PEP. These findings suggest in general that information politics since the beginning of HIV-PEP in 1989 have failed to reach the intended audience. Drewes and Krusper summarize the German situation and the knowledge about HIV-PEP as being differentiated and rather deflated: »Only a minority of the participants [of the survey] feel well informed about PEP, and amongst those participants who know about PEP, only a minority say that they know where to obtain PEP in case of an emergency. Although the probability of being familiar with PEP increases with the probability of needing it, gay men and other MSM who have sex with risky partners or with a high number of partners are, as a whole, rather poorly informed about PEP and where to find it. [...] Although the number of gay men and MSM with PEP-knowledge is visibly increasing in Germany, knowledge about PEP must be judged as bad overall.« Drewes/ Kruspe (2013), 241-242. This observation throws up many questions in need of further investigation, including the question of the need for general knowledge in society about HIV-PEP, which would not only be a support for MSM health but also for the currently rarer HIV risk for heterosexual individuals.

23 Drewes/Kruspe (2013). 


\section{Human Rights AND HIV-PEP}

Access to healthcare is the bare minimum of the human right to health, as expressed in Article 25 of the Universal Declaration of Human Rights. ${ }^{24}$ This is especially true in cases of medical emergency. ${ }^{25}$ However, access to healthcare is dependent on knowledge of one's personal situation, of possible treatment and where to go when needed. In the case of HIV-PEP this is more easily said than done. The situation amounts to an offence under Article 27 of the Declaration of Human Rights, which is dedicated to "sharing $[\ldots]$ scientific advancement and its benefits. ${ }^{26}$

Another relevant international document concerning human rights and healthcare is the United Nation's Committee on Economics, Social and Cultural Rights' (CESCR) document entitled The right to the highest attainable standard of health. General Comment No. 14 (GC No. 14) and its para. 2 include what is known as the triple $» \mathrm{~A} «$ and $» \mathrm{Q} \ll{ }^{27}$ This AAAQ stands for availability, acceptability, accessibility, and quality of healthcare. Concerning accessibility for the purpose of evaluating HIV-PEP leads to a complete failure. According to GC No. 14, accessibility means, in detail, non-discrimination, accessibility of information, and physical and economic accessibility. ${ }^{28}$ None of these fourth goals are reached, an observation which in some aspects also holds true for general HIV treatment. ${ }^{29}$ HIV-PEP regulations tend to discriminate against people who are possibly infected but who are not in target groups. Access to information is also poorly managed. It is necessary to be aware that PEP exists in order to be able to search for further information in cases of HIV emergency. Since many people probably have a rather vague idea that a certain period of time is required before HIV can be detected in the blood, they would not see the need for immediate action. Physical access is also not sufficient because only specialized hospitals are able to offer expertise and treatment with

24 Farmer (2003); Lisk (2010).

25 Asher (2010).

26 Farmer (2003), 215-216.

27 Jones, P. S. (2009).

28 E/C.12/2000/4, 11 August 2000.

29 Jones, P. S. (2009); Lisk (2009). 
HIV-PEP. In addition, economic accessibility is insecure where there is uncertainty as to whether health insurance covers treatment with HIV-PEP.

What is worth mentioning is that GC No. 14 puts special emphasis on vulnerable groups. Men who have sex with men might be considered a vulnerable group in the sense of GC No. 14 and need to be addressed specifically. ${ }^{30}$ The General Comment also states that providing education and access to information is a core obligation in healthcare (GC No. 14, para. 44). ${ }^{31}$ This again makes HIV-PEP-policies appear in rather a negative light.

Health is one of the unachievable but undeniable values people desire. It is a very fragile state that will be weakened over time and that can be lost in the case of chronic and severe sickness. Therefore, healthcare is a basic human right and implementing the right to healthcare is a political act. Thus, the human right to healthcare implies the right to timely and appropriate professional help. It is clear that if an individual does not know about the existence of HIV-PEP, recognizing the individual's need for timely and appropriate medicine is impossible and thus a human rights issue. ${ }^{32}$

\section{Ethically Debating HIV-PEP}

The desirability of a widespread administration of HIV-PEP is medically and ethically debatable. The aim of this contribution is to stress the fundamental right to information regarding one's health and the means to prevent diseases. Having discovered that there is a lack of knowledge concerning HIV-PEP - which, as indicated, needs further statistical evaluation - medical ethics can participate in overcoming a hesitancy to promote the only existing and therefore ultimate therapy to prevent the HI-virus from infecting an individual after potential exposure.

When examining the ethical debate on the withholding of HIV-PEP in some parts, which can also, in this specific HIV-context, be understood as »structural violence«, as Paul Farmer did explicitly, ${ }^{33}$ two items should be

30 Doyal/Doyal (2013).

31 Santelli et al. (2010).

32 White (2009).

33 Farmer (2003), 230; White (2009). 
considered in more detail: First, the quest for medical paternalism or maternalism in the debate over HIV-PEP; secondly, the question of proportionality between risk and administering drugs.

First and foremost, the argument is that the knowledge of HIV-PEP could promote high-risk sexual behaviour. This has not only been emphatically refuted, it also seems to be a paternalistic argument exhibiting low regard for an individual's autonomy. Medical paternalism or maternalism more generally alludes to the conviction that individuals without academic medical education are unable to entirely understand their circumstances and therefore need professional guidance. A recurring theme of implicit paternalism is the conviction that popular knowledge about HIV-PEP could weaken behavioural discipline in terms of sexual intercourse, which is considered to be the best strategy to prevent HIV or any sexually transmitted infection. The efficacy of the entire abstinence strategy is highly debatable $;^{34}$ even in a theological perspective, since control over one's behaviour appears to be a never entirely accomplishable good. Religions and ethics deal with the torment of always being unable to overcome the juxtaposition of will and deed. ${ }^{35}$ Humans are known for notoriously failing to realize possible moral convictions, while other people do not have any moral convictions (regarding their sexual practice) at all. Hence the »rational choice paradigm « in HIV-prevention ${ }^{36}$ appears to be a fairly weak approach due to the weakness of rational choices, especially in the area of sexual desire. If HIV-prevention is to become more successful, medical aid without paternalistic or maternalistic judgment about patients is highly required, as these judgments are not a medical task in any way. Any cultural or sublime religious reason for hindering wide access of PEP therefore needs further and critical inspection. ${ }^{37}$ Hence, the learning strategy aspect in HIVprevention ${ }^{38}$ should incorporate the issue of HIV-PEP, especially in terms of risk group-oriented approaches ${ }^{39}$ also because the gap between that

34 Altman (2010); Kovara (2012).

35 Wirth (2015b).

36 White (2009); Vollmann (1991).

37 Doyal/Doyal (2013); Lisk (2010); Jones, P. S. (2009).

38 Corsten/von Rüden (2013); Rosenbrock/Schmidt (2012).

39 Herrn (1999); Herrn et al. (2002). 
which has been learned and that which is performed is especially evident in the domain of sexual pleasure.

Another core issue regarding HIV-PEP and medical ethics is the question of proportionality. The ethical means of appreciation of conflicting values (»Güterabwägung«) must also be conducted for the usage of HIVPEP. ${ }^{40}$ Since HIV is still an incurable and severely chronic disease, ${ }^{41}$ much effort has been put into the attempt to find vaccines or medication that not only helps infected people to survive, but also seeks to cure HIV-infected individuals in the future. ${ }^{42}$ Until such a cure is found, HIV-PEP should be administered widely, as side-effects are reversible and not as intolerable as they used to be. The cost of approximately 1.500 Euros for the 28 days of therapy with antiretroviral medicine is not astronomical, as well as being in line with the human right to basic good healthcare. Due to the severity of an HIV infection and the physician's mandate to cure, HIV-PEP should be prescribed whenever there is any danger of HIV-infection.

At least in Germany, one reason for the observable hesitancy on both the physician's and the patient's side is the unclear financial situation, as insurance companies could possibly refuse to cover the cost for HIV-PEP. Experiences seem to differ depending on the state and the concrete practice within the institution where PEP is administered. Although an unclear situation is likely to hinder patients from receiving adequate treatment, it seems as if compulsory insurance companies (»Gesetzliche Krankenkassen «) do generally cover costs for HIV-PEP, when the treatment is administered according to the aforementioned German-Austrian Guidelines. These differentiate between circumstances in which HIV-PEP should be »suggested « (e.g. anal or vaginal intercourse with a person with a known HIV-infection) and circumstances in which it should be »offered « (e.g. receptive or inserting anal sexual intercourse amongst men, especially when occurring in places visited by MSM seeking sexual intercourse). Although the likelihood of transmission is different, both indication groups are in what German insurance companies consider to be situations where an infection is very likely and thus cost should be covered. ${ }^{43}$ There are other medi-

40 Whelehan (2009).

41 DiClemente et al. (2009); Whelehan (2009).

42 Ibid.

43 Marcus/Stellbrink (2013). 
cal circumstances where there is no hesitancy to administer medication to potential patients without knowing beyond all reasonable doubt that they are needed. An example is meningoencephalitis. If a young child is suspected to have contracted the virus, acyclovir is immediately administered. Side effects are tolerated since avoiding a disease would be worth the mild discomfort occasioned by them.

Another aspect that might arise from the argument from proportion is that of the rather low risk of HIV infection and the relatively low number of new infections each year. For example, there were 3.525 registered HIV cases in 2014 in Germany, ${ }^{44}$ and the argument claims that new PEP politics in medicine is too much effort for such a small amount of people, though infected people do not know their status early (late presenter). ${ }^{45}$ Although it may be of minor importance compared to other diseases, the HIV prevalence amongst MSM in Germany is around 4,9-6,7\%. ${ }^{46}$ Moreover, HIV is still so severe that is it important to be prepared for every eventuality, also because the disease can affect any social group in society. ${ }^{47}$ To underline this with an analogy: Anyone who boards a plane will be confronted with safety instructions pertaining to the well-known »unlikely event« of an accident. What's striking is that less than 30 individuals in Germany were involved in serious plane accidents in 2016. In other words, there is a notion that possible extremely harmful but rather unlikely situations need constant preparation through the distribution of information. A similar requirement should be in place for information on HIV-PEP, since contracting HIV in the territory of Germany is more likely than being involved in a plane crash.

\section{Conclusion}

The ethical debate about HIV-PEP indicates that much more information about HIV-PEP should be provided. Key players are policy makers, teachers, and healthcare professionals. A new HIV-PEP-strategy could begin

44 Robert Koch Institute (2015).

45 Whelehan (2009); Rosenbrock/Schmidt (2012).

46 Drewes/Kruspe (2013).

47 Whelehan (2009). 
with the revision of biology books that are used in schools and would fall under the General Comment (GC No. 14, para. 44). ${ }^{48}$ At present, the sexual education sections of biology books in Western countries generally contain detailed information regarding the prevention of unwanted pregnancies and emergency contraception, but there is no information about emergency post-exposure prophylaxis. This is despite the fact that the information on HIV prevention would appear to be the most important amongst other kinds of prophylaxis, for instance against hepatitis. The strategy of communicating the possibility of HIV-PEP in biology classes and sexual education would be especially important to the group of young men who have or will have sex with other men. ${ }^{49}$ Perhaps surprisingly, the rates of infection and unprotected sexual intercourse among young men who have sex with men seem to be relatively high compared to those among older men,${ }^{50}$ whereas studies also show that about one third of MSM usually do not practice risky sexual interaction. ${ }^{51}$ However, an open and unpretentious introduction to

48 Santelli et al. (2010). It is worth mentioning, that letter »b« of GC No. 14, para. 44 stresses the need to spread information when it is understood as an obligation »to provide education and access to information«

49 Newer infection rates in East Europe, however, indicate that heterosexuality may not necessarily provide protection against HIV. Statistical data indicates that there has been a slow but constant increase in HIV infection rates amongst the heterosexual general public in the last decade, cf. Rosenbrock/Schmidt (2012). The question regarding to what extent bisexual men are a bridge for transmission is not fully resolved, but on the basis of the available data, they do not seem to play a key part in transmitting HIV.

50 DiClemente et al. (2009); Vollmann (2001). Admittedly, it must also be considered that in actuality, men who have sex with men who are HIV-positive tend to be older, live in urban or metropolitan surroundings, more often define themselves as homosexual and judge their general health condition to be poorer than that of general populations, cf. Drewes/Kruspe (2013). However, $90 \%$ of those who know about their HIV-infection undergo antiretroviral therapy and $80 \%$ are not infectious any more, as the HI-virus in their blood is below the limit of determination, cf. ibid.; Cohen et al. (2013). Amongst older HIV-positive men, the tendency that they undergo successful treatment is higher than amongst younger MSM, as implied by the quoted study by Drewes and Kruspe.

51 Rosenbrock/Schmidt (2012). 
the specific healthcare issues of MSM within school education, including information about HIV-PEP, could also help to normalize the selfawareness of young men who have or will have sexual relationships with other men. This is especially urgent as internalized homo-negativity is still widespread. Internalized homo-negativity refers to taking negative assumptions about homosexuality held by parts of society to be true, which leads to an (unconscious) negative self-picture. This again increases the susceptibility of MSM to healthcare issues. ${ }^{52}$ The fear of informing one's general practitioner (GP) or another physician about same-sex intercourse will hinder a homosexual or bisexual man from obtaining adequate healthcare, including means of prevention. ${ }^{53}$ There is also evidence that family and peer support help MSM to deal constructively with idiosyncratic needs, including a higher adherence to HIV-testing. ${ }^{54}$ Treating special healthcare issues covering not only heterosexual concerns during school education is of paramount importance and can lead to a more open handling of specific needs that may otherwise be hindered by internalized homo-negativity. Discrimination and stigmatization not only lead to psychological harm but can also cause, apart from direct violence, severe physiological conditions, especially when MSM are too afraid to take sufficient care of themselves. ${ }^{55}$

Not only men who have sex with men, along with their friends and families, need to be informed about HIV-PEP. Women can also be exposed to situations where it is important that they be informed about HIV-PEP, as currently one heterosexual person in every 10.000 has tested positive for HIV. The number is increasing, especially in Eastern Europe. ${ }^{56}$ Although bisexual men don't appear to be a »bridge« for HIV-transmission, ${ }^{57}$ their role cannot be entirely disregarded.

52 Drewes/Kruspe (2013).

53 Ibid.

54 Ibid. Also due to the stigma of an HIV infection or expressed anxiety, the majority of MSM generally have a weak adherence to HIV testing. A recent German study revealed that only one third of MSM test their status regularly, although amongst the group of MSM who do it only once a year or never, many state that they engage in risky behaviour (ibid.).

55 Drewes/Kruspe (2013).

56 Rosenbrock/Schmidt (2012).

57 Sekuler et al. (2014). 
Finally, in order to draw a more general lesson from the debates concerning HIV-PEP, the stereotype that in highly developed countries highly undeveloped areas in high-tech and medicine domains would not persist has been proven to be incorrect. The need for further developing HIV prophylaxis is obvious and should be addressed.

\section{References}

Aggleton, Peter/Parker, Richard (Eds.) (2010): Routledge Handbook of Sexuality, Health and Rights, London/New York: Routledge.

Altman, Dennis (2010): »Exporting Moralities«, in: Aggleton/Parker (2010), 193-201.

Asher, Judith (2010): The Right to Health. A Resource Manual for NGOs, Leiden/Boston: Martinus Nijhoff Publishers.

Baggaley, Rachel/Doherty, Meg/Ball, Andrew/Ford, Nathan/Hirnschall, Gottfried (2015): »The Strategic Use of Anti-retrovirals to Prevent HIV Infection: A Converging Agenda«, in: Clinical Infectious Diseases 60 (2015), 1-3 [supplement 3].

Benn, Paul/Fisher, M./Kulasegaram, Richard. (2011): »UK guideline for the use of post-exposure prophylaxis for HIV following sexual exposure«, in: International Journal of STD \& AIDS 22 (2011), 695-708.

Biggs, Nalini A. (Ed.): Education and HIV/AIDS. Education as a Humanitarian Response, London/New York: Continuum.

Brinkschulte, Eva/Gadebusch-Bondio, Mariacarla (Eds.) (2015): Norm als Zwang, Pflicht oder Traum. Normierende versus individualisierende Bestrebungen in der Medizin. FS Heinz-Peter Schmiedebach, Frankfurt/M.: Peter Lang.

Cohen, Myron S./Chen, Ying Q./McCauley, Marybeth S./Gamble, Theresa/ Hosseinipour, Mina C./Kumarasamy, Nagalingeswaran/Hakim, James G./Kumwenda, Johnstone/Grinsztejn, Beatriz/Pilotto, Jose H.S./ Godbole, Sheela/Mehendale, Sanjay/Chariyalertsak, Suwat/Santos, Breno R./Mayer, Kenneth H./Hoffman, Irving F./Eshleman, Susan H./ Piwowar-Manning, Estelle/Wang, Lei/Makhema, Joseph/Mills, Lisa A./ de Bruyn, Guy/Sanne, Ian/Eron, Joseph/Gallant, Joel/Havlir, Diane/ Swindells, Susan/Ribaudo, Heather/Elharrar, Vanessa/Burns, David/ Taha, Taha E./Nielsen-Saines, Karin/Celentano, David/Essex, Max/ 
Fleming, Thomas R./HPTN 052 Study Team (2011): »Prevention of HIV-1 Infection with Early Antiretroviral Therapy«, in: The New England Journal of Medicine 365 (2011), 493-505.

Corsten, Claudia/von Rüden, Ursula (2013): »Prävention sexuell übertragbarer Infektionen (STI) in Deutschland. Von der HIV- zur STI-Prävention «, in: Bundesgesundheitsblatt 56 (2013), 262-268.

Deutsche Aids-Gesellschaft (2013): »Deutsch-Österreichische Leitlinien zur postexpositionellen Prophylaxe der HIV-Infektion«, Online: http://www.aidshilfe.de/sites/default/failes/Deutsch-Osterrechische_Leitlinien_zur_Postexpositionellen_Prophylaxe_der_HIV-Infektion.pdf [23.03.2015].

DiClemente, Ralph J./Crittenden, Colleen P./Rose, Eve S./Sales, Jessica M. (2009): »A Social Contextual Perspective to Optimize the Prevention and Control of STIs/HIV among Adolescents«, in: Pope et al. (2009), 215-226.

Doyal, Lesley/Doyal, Len (2013): Living with HIV and Dying with AIDS. Diversity, Unequality and Human Rights in the Global pandemic, Ashgate: Farnham.

Drewes, Jochen/Kruspe, Martin (2013): »Schwule Männer und HIV/AIDS 2013. Schutzverhalten und Risikomanagement in den Zeiten der Behandelbarkeit von HIV « (= AIDS Forum Deutsche AIDS-Hilfe 61), Online: https://www.aidshilfe.de/sites/default/files/documents/2016_05_11_schwule_maenner_und_hiv_aids_2013.pdf [10.12.2016].

Fangerau, Heiner/Polianski, Igor J. (Eds.) (2012): Medizin im Spiegel ihrer Geschichte, Theorie und Ethik: Schlüsselthemen für ein junges Querschnittfach, Stuttgart: Franz Steiner.

Farmer, Paul (2003): Pathologies of Power. Health, Human Rights, and the New War on the Poor. With a Foreword by Amartya Sen, Berkeley: University of California Press.

Ford, Nathan/Irvine, Cadi/Shubber, Zara/Baggaley, Rachel/Beanland, Rachel/Vitoria, Marco/Doherty, Meg/Mills, Edward J./Calmy, Alexandra (2014): »Adherence to HIV post exposure prophylaxis: a systematic review and meta-analysis«, in: AIDS 28 (2014), 2721-2727.

Harman, Sophie/Lisk, Franklyn (Eds.) (2009): Governance of HIV/AIDS. Making Participation and Accountability Count, London \& New York: Routledge. 
Herrn, Rainer (1999): Schwule Lebenswelten im Osten: Andere Orte, andere Biographien, Berlin: Deutsche Aids-Hilfe.

Herrn, Rainer/Kohler, Robert/Rosenbrock, Rolf (2002): »Defizite der AidsPrävention in Ostdeutschland«, in: Rosenbrock/Schaeffer (2002), 157110.

Jensen, Lawrence T. (2011): Responding to HIV/AIDS: National Strategies, Plans and Programs, New York: Nova Science Publishers.

Jones, Peris S. (2009): AIDS Treatment and Human Rights in Context, New York: Palgrave Macmillan.

Jones, Sande G. (2009): »Looking Inside the Pill Bottle: The Evolution of HIV Antiretroviral Combination Drug Therapy«, in: Pope et al. (2009), 149-163.

Kovara, David (2012): »The Politics of the President's Emergency Plan for AIDS Relief (PEPFAR)«, in: Biggs (2012), 53-74.

Leoni, Patrick L. (2010): Economic Challenges in the Fight against HIV/AIDS, New York: Nova Science Publishers.

Lisk, Franklyn (2009): »Conclusion: Challenge and innovation in governance of HIV/AIDS «, in: Harman/Lisk (2009), 180-185.

Lisk, Franklyn (2010): Global Institutions and the HIV/AIDS Epidemic. Responding to an international crisis, London/New York: Routledge.

Maio, Giovanni/Bozzaro, Claudia/Eichinger, Tobias (Eds.) (2015): Leid und Schmerz. Konzeptionelle Annäherungen und medizinethische Implikationen, Freiburg/München: Karl Alber.

Marcus, Ulrich/Stellbrink, Hans-Jürgen (2013): »Neue Leitlinien zur Postexpositionsprophylaxe«, in: HIV\&more 3 (2013), 30-35.

Pope, Cynthia/White, Renee T./Malow, Robert (Eds.) (2009): HIV/AIDS. Global Frontiers in Prevention/Intervention, New York/London: Routledge.

Robert Koch Institute (2015): »HIV-Diagnosen und AIDS-Erkrankungen in Deutschland. Bericht zur Entwicklung im Jahr 2014«, in: Epidemiologisches Bulletin 27 (2015), 239-260.

Rosenbrock, Rolf (1987): AIDS kann schneller besiegt werden: Gesundheitspolitik am Beispiel einer Infektionskrankheit, 3rd edition, Hamburg: VSA-Verlag.

Rosenbrock, Rolf/Schaeffer, Doris (Eds.) (2002): Die Normalisierung von Aids: Politik - Prävention - Krankenversorgung, Berlin: edition sigma. 
Rosenbrock, Rolf/Schmidt, Axel J. (2012): »Aids. Neue Herausforderungen für die soziale und medizinische Prävention«, in: Bundesgesundheitsblatt 55 (2012), 535-542.

Santelli, John S./Schleifer, Rebecca/Melnikas, Andrea. J. (2010): »Sexuality Education, US federal abstinence policies and young people's right to health information«, in: Aggleton/Parker (2010), 339-350.

Schmiedebach, Heinz-Peter (2012): »Seuchen und ihre Spuren in Gesellschaft, Kultur und Politik«, in: Fangerau/Polianski (2012), 235-257.

Sekuler, Todd/Bochow, Michael/von Rüden, Ursula/Töppich, Jürgen (2014): »Are bisexually active men a >bridge the 'general population' in Germany? Data from the European MenWho-Have-Sex-With-Men Internet Survey (EMIS)«, in: Culture, Health \& Sexuality 16 (2014), 113-1127.

Vollmann, Jochen (1991): »Ethische Implikationen von Hans Jonas' >Prinzip Verantwortung ^ für die AIDS-Problematik«, in: Medizin, Mensch, Gesellschaft 16 (1991), 53-60.

Vollmann, Jochen (2001): »HIV-Prävention bei jungen schwulen Männern. Eine medizinethische Herausforderung«, in: Gesundheitswesen 63 (2001), 392-397.

Whelehan, Patricia (2009): The Anthropology of AIDS. A Global Perspective, Gainesville: University Press of Florida.

White, Reneet T. (2009): »HIV, Public Health, and Social Justice: Reflections on the Ethics and Politics of Health Care«, in: Pope et al. (2009), 269-278.

Wyen, Christoph/Hoffmann, Christian/Schmeisser, Norbert/Wöhrmann, Andrej/Qurishi, Nazifa/Rockstroh, Jürgen/Esser, Stefan/Rieke, Ansgar/ Ross, Birgit/Lorenzen, Thore/Schmitz, Karina/Stenzel, Werner/Salzberger, Bernd/Fätkenheuer, Gerd (2004): »Progressive multifocal leukeoncephalopathy in patients on highly active antiretroviral therapy: survival and risk factors of death «, in: Journal of Acquired Immune Deficiency Syndrome 37, 2 (2004), 1263-1268.

Wyen, Christoph/Jensen, Björn/Hentrich, Marcus/Siehl, Jan/Sabranski, Michael/Esser, Stefan/Gillor, Daniel/Müller, Markus/van Lunzen, Jan/ Wolf, Timo/Bogner, Johannes R./Wasmuth, Jan C./Christ, Hildegard/ Fätkenheuer, Gerd/Hoffmann, Christian (2012): »Treatment of AIDSrelated lymphomas: rituximab is beneficial even in severely immunosuppressed patients«, in: AIDS 26 (2012), 457-464. 
Wirth, Mathias (2015a): »Brompton-Cocktail gegen Sinnschmerz? Anmerkungen zur palliativen Tiefensedierung bei existentieller Not im Gespräch mit Albert Camus und Emmanuel Lévinas«, in: Maio et al. (2015), 312-331.

Wirth, Mathias (2015b): »Es lebe die Erbsünde?! Schnittstellen zwischen Degenerationstheorie und Erbsündendoktrin«, in: Brinkschulte/ Gadebusch-Bondio (2015), 79-102.

Wirth, Mathias/Hurwitz, Brian (2016): »Awareness and Dying. The Problem of Sedating >Existential Suffering «, in: Ethical Perspectives 23 (2016), 307-326.

World Health Organization (2007): »Post-Exposure Prophylaxis to Prevent HIV Infection. Joint WHO/ILO guidelines«, Online: www.who.int/ iris/bitstream/10665/43838/1/9789241596374_eng.pdf [23.03.2016]. 


\section{The Case Law on the Right to Health as an Example and as a Problem}

The Distortive Effects of Litigation Reconsidered

LAURA ClÉRICO, Leticia Vita

\section{INTRODUCTION: THE CASE LAW ON THE RIGHT TO HEALTH AS AN EXAMPLE AND AS A PROBLEM}

One of the aims of this book is to discuss the question of whether the right to health is an empty promise or not. More precisely it is alleged that

"while even highly developed countries have come to realize that expensive health technologies may not be affordable for everyone under all circumstances, the absence of an adequate healthcare infrastructure in some developing countries renders the universal right to health hopelessly utopian - or so it may seem. « ${ }^{1}$

The answer is: the right to health is not an empty promise. The evidence of the case law demonstrates that the right to health is justiciable. Empirical studies show that the right to health is not any more a matter of concern because of the lack of constitutional recognition: approximately $70 \%$ of constitutions worldwide contain health-related guarantees, and the right to

1 See: http://archiv.efi.fau.de/projekte/human-rights-in-healthcare/stand-150715_ efi-conference-programm_the-right-to-health-berlin.pdf [19.06.2017]. 
health is justiciable in approximately $40 \%{ }^{2}$ Accordingly, it is more than a promise. It entails a normative aspiration that imposes negative and positive obligations for the states. The case law shows in general that these obligations enable the individuals to bring a claim against the state or other agencies of the healthcare system before a court. ${ }^{3}$

What lessons can be learned from the case law on the right to health? To address the question, we highlight two uses ${ }^{4}$ of the case law on the right to health: 1) the case law as an example to analyse the structure of the right to health and to address some objections regarding the determination of the content of the right and 2) the case law as a problem of inequality.

The first use is found in different types of documents (articles, books, handbooks, factsheet No. 31 of the UN about the right to healthcare, general comments and general recommendations), in which the content of the right to healthcare is developed. The case law helps to sustain an idea with an example. ${ }^{5}$ In these documents the case law is not a problem. It is a matter of inspiration or illustration. The authors of these works do not pick up some examples while excluding others. The case law is used to illustrate: type of obligations (positive-negative obligations; definitive-principle obligations; core obligations, »obligations of comparable priority ( $\left.^{6}\right)$, type of defendant (state, social security agencies, private pre-pay healthcare com-

2 Jung et al. (2015), 1043-1094.

3 Abramovich/Pautassi (2008), 53-65 and 261-282.

4 The case law can also be used as indicator. Although it exceeds the objective of our work, we have to point out that case law can be analyzed as an expression of factual and judicial issues that those entitled to the right to health have to deal with when they need to enforce their right. The importance of the information extracted from case law is highlighted to evaluate the compliance of the state as regards the right to medical care, as outlined by the Committee on Economic, Social and Cultural Rights (CESCR) of the United Nations on its Final Considerations on the Third State Report of Argentina: E/C.12/ARG/CO/3, 14.12.2011, para. 6, 7; especially when the lack of inclusion of case law on social rights is observed. See Abramovich (2005), about the use of courts to monitor public policies in Argentina.

5 About the uses of examples and illustrations in the practical argumentation see Perelman/Olbrechts-Tyteca (1969), 350-362.

6 Forman (2015), 43. 
panies), type of plaintiff (individuals, individuals, NGOs, consortiums of NGOs, public defenders, indigenous communities), subject of the claims (access to medicaments and treatments covered by the law or plan or basket and not-covered by the law, these include claims to have access to expensive new drugs or the use of expensive health technologies; lack of social determinants of the right to healthcare like access to clean water, sanitation, housing, education, protection of the environment), standards to evaluate the violation of the right to health (minimal core obligations, procedural review, reasonableness, proportionality review, equality review, multidimensional equality test), type of reparative measures (material, symbolic; individual, collective), among others. ${ }^{7}$ To sum up: case law presents powerful examples of the right to health and is rich enough to promote further reconstruction on the rationality of legal argumentation on the right to health.

The second use of the case law supposes that the great majority of individual health rights actions are successful. Then it asks whether this can reinforce or produce inequality, »if limited public resources are diverted to those with the means and ability to litigate their right to health, as has been argued is the case in, for example, Colombia and Brazil.$^{8}$ In the debate on the distortive effects of litigation in the healthcare sector in Latin America, a considerable portion of the literature assumes that both actors and the requested services represent the middle and upper classes of the population, whereas vulnerable, low-income sectors would be left out of this litigation universe. ${ }^{9}$ However, recently it has also been pointed out that these effects depend on the concrete context in which litigation is brought about, and the importance of this tool is highlighted as guarantee the right to health of the most vulnerable. ${ }^{10}$ Our work aims to analyse this theme concerning Argentina, based on the studies on local litigation in healthcare issues of the Province of Buenos Aires. ${ }^{11}$ The question is simple: Does litigation favour and protect the wealthy ones at the expense of the most vulnerable population in

7 See, for example, in general, Langford (2011).

8 Flood/Gross (2014), 62-72.

9 Ferraz (2011), 1643-1668; Da Silva Virgilio et al. (2011), 825-853; Yamin et al. (2011); Reveiz et al. (2013), 213-222.

10 Biehl et al. (2016).

11 As we explain in the next section, the local case law is not object of inquiry of the mainstream of the research about the right to health. See Biehl et al. (2016). 
countries with high inequalities in healthcare systems? The results of the analysis challenge the distorting effects thesis and points out case law that may enable a more robust debate on equitable access to health.

While the first use of the case law promotes jurisdiction on the right to health, the second one claims to use the litigation of the right to health with caution. The second one challenges the legitimacy of judicialization as a whole. If it is right, then it could undermine the legitimacy of the first one. This cannot be the case for two reasons. On the one hand, the first use is vital for developing the doctrine of fundamental social rights, which is underdeveloped in comparison to the »traditional civil and political rights «. ${ }^{12}$ On the other hand, in countries with high inequalities in healthcare systems, litigation is one way »to advance health equity, although this too requires a judiciary willing to enforce it effectively $\ll{ }^{13}$

\section{The Distortive Effects of Litigation RECONSIDERED FROM A BOTTOM UP Perspective: The INCLUSION OF THE LOCAL DIMENSION}

One of the recurring diagnoses of specialized literature regarding litigation in the healthcare sector in Latin America is its distorting or unfair effects. It has been suggested that litigation in healthcare brings about more inequality, due to the fact that the people who go into litigation generally come from the middle and upper classes and have healthcare plans, and at the same time judges tend to grant any type of claims, even those that are not covered by law and irrespective of its appropriateness. ${ }^{14}$ We name this

12 See Ferrajoli (2002), 13.

13 Forman/Singh (2015), 317; Flood/Gross (2014), 62-72; and related to Colombia: »tutela actions [judicial claim] have been central to a constitutional transformation that has permeated every sphere of state activity to include the concern with human rights, and to put courts at the reach of ordinary citizens. Tutelas have thus produced unprecedented implications for the redistribution of goods and services in this dramatically unequal society.« Young/Lemaitre (2013), 186 [emphasis added, L.C./L.V.] .

14 See a systematization of the literature by Reveiz et al. (2013), 213-222. 
diagnosis the »distorting effect thesis«, it has also been used to describe Argentina's case. ${ }^{15}$

However, according to parts of the specialized literature, although there actually are specific contexts, institutional designs ${ }^{16}$ and types of decisions that allow us to predict the regressive and unfair effects of judicial health protection, it is also possible to identify other factors that would provide this judicial protection with democratic and redistributive potential. ${ }^{17}$ In other words, the distorting effect thesis does not necessarily materialize in all cases. But then, which are the factors that could facilitate this inclusive and redistributive effect?

This question is the starting point of this chapter. Our aim is to find out whether the distorting effect thesis is applicable when considered in the local sphere of litigation rather than in the higher sphere of the judicial branches and supreme courts. For instance, in Argentina most publications on the issue take as a starting point the analysis of decisions made by Argentina's Supreme Court. ${ }^{18}$ Therefore, it is also relevant to include studies on local cases, due to the health systems' particular functioning in a federal state. ${ }^{19}$ This line of research is not the mainstream on the right to health. However, there are pioneering studies such as the one from Biehl, Sokal and Amon. They used a systematic sample of 1,262 lawsuits for access to

15 Gotlieb et al. (2016).

16 In this sense, our work inscribed in the recent line of work that analyzes litigation in relation to the particularities of national health system: »[T]he right to health plays different roles in different types of health systems $[\ldots]$ in middleincome countries with big gaps between a poor public health system and a rich private one [...] In some of these countries, constitutional rights were included as $[\ldots]$ an attempt to address huge inequities within society. Here the scale of health inequities suggests that courts need to be bolder in their interpretation of healthcare rights. We conclude that in adjudicating health rights, courts should scrutinize decision-making through the lens of health equity and equality to better achieve the inherent values of health human rights«. Flood/Gross (2014), 62.

17 Uprimny/Durán (2014), 60; Krennerich (2013); Suárez Franco (2009).

18 For instance, the work of Abramovich/Pautassi (2008), 261-282; Bergallo (2005); Cano (2005), 111-120.

19 On federalism and the right to health in Argentina see, among others: Arballo (2013), 1621-1652; Vita (2013), 17-63. 
medicines filed against the southern Brazilian state of Rio Grande do Sul, and showed that

»the majority of patient-litigants are in fact poor and older individuals who do not live in major metropolitan areas and who depend on the state to provide their legal representation, and that the majority of medicines requested were already on governmental formularies. $\ll^{20}$

They concluded that judicialization »may serve as a grassroots instrument for the poor to hold the state accountable ${ }^{21}{ }^{21}$

In our work we choose as case study the cases filed in local courts of the Buenos Aires province, for two reasons. Firstly, Buenos Aires has a socioeconomically heterogeneous population. In Buenos Aires, considerable proportion of the population from low-income homes and neighbourhoods coexist with people from middle income and high income homes and neighbourhoods. ${ }^{22}$ Therefore, it is best suited to analyse the access of people in situation of poverty to the Courts. Secondly, as explained above, because we are interested in highlighting the local case law to the specialized debate on the healthcare sector.

For our research we focused on a qualitative and quantitative analysis concerning litigation in the healthcare sector. There is no official information as regards the total amount of claims (generally injunctions) about the sector in the province, but we managed to get databases published by the courts (especially the province's Supreme Court), the Argentine System of Judicial Information (Sistema Argentino de Información Jurídica) and judicial reviews to make our sample. ${ }^{23}$ Likewise, our research focuses on

20 Biehl et al. (2016), 1; Clérico/Vita (2015), 70-85.

21 Biehl et al. (2016), 1.

22 According to the Permanent Homes Survey (Encuesta Permanente de Hogares) and the Basic Food Basket calculated by INDEC in 2010.

23 The sample consists of 172 solved cases between 1995 and 2014 found searching in the Supreme Court of Justice of the Province of Buenos Aires' database (www.scba.gov.ar), the Argentine System of Judicial Information (Sistema Argentino de Información Jurídica) (www.infojus.gov.ar) and La Ley's database (www.laleyonline.com.ar). In all cases the keywords »derecho a la salud« 
the actors, claims and decisions taken in the rulings, which include first district courts, courts of appeal and the province's Supreme Court. We make some references to Supreme Court of Justice of Argentina's case law (from now on, the »National Supreme Court «), but only to the claims initiated in the province.

The results, as we will see, show that litigation in the healthcare sector in Argentina confirms only partially the distorting effect thesis. It is possible to identify several rulings, some of them in leading cases, in which the plaintiffs belong to vulnerable groups, such as women, children, people with disabilities and the elderly people. In several occasions these are not only individual claims, ${ }^{24}$ but rather seek a collective impact, because notwithstanding the fact that they were initiated by one plaintiff, they involve groups of affected people or also seek the implementation of a health care program or agenda or the adoption of public policies for a group of people. There is also a significant tendency in jurisprudence to use a wider conception of the right to health that includes »social determinants of health «.

We will lay out herein below a brief outline of the healthcare mechanism in the province and the different factors that must be taken into account to understand its dynamics and the context in which the local cases are set. Then we will outline the main results of our research on litigation in the province's healthcare sector. Lastly, we will discuss those results in the light of the ongoing debate on litigation and lay out some hypothesis on the possible factors that allow a certain degree of redistributive or democratic effect of litigation in this specific case.

(»right to health «) were used as search criteria, providing as a result approximately 200 files, which in some instances referred to the same cases.

24 Most of the claims are from individuals. Nonetheless, evidence shows that decisions in individual cases are used to solve similar cases. For instance, this is the case of Campodónico de Beviacqua, the Supreme Court in Argentina ordered the State to ensure the continued provision free of charge of a drug against bone disease in the case of a child with disability. Abramovich/Pautassi (2008) sustained that the case of Campodónico de Beviacqua impact direct in the ruling on several cases about medical coverage to persons with disabilities, among others. 


\section{The Healthcare System in the Province of Buenos Aires: THe Local Context}

Health as a human right issue enjoys robust constitutional and legislative protection in the province. Indeed, the provincial Constitution, as amended in 1994, recognizes the right to health in Article $36 .{ }^{25}$

Nevertheless, the real functioning of the healthcare system replicates that of its national counterpart. The health system in Argentina is one of the most fragmented systems. ${ }^{26}$ For instance, such as the national healthcare system, the province's is made up of three subsectors (public, ${ }^{27}$ private $^{28}$ and social security or social insurance system $^{29}$ ) that, due to the govern-

25 These constitution can be interpreted as part of the trend highlighted - for example by Flood/Gross (2014) - that includes countries in Latin America and Southern Africa, which have created (or reform) constitutions to include health and other social rights »as part of a strategy to accelerate an equity and equality agenda in the aftermath of legacies of dictatorship and apartheid resulting in enormous disparities between rich and poor.« (Ibid., 64)

26 Health System in Argentine is one of the most fragmented system, »with more than 500 private health-care insurers, national social insurance organizations, and provincial health insurance organizations regulated by provinces, which are responsible for health service provision. Argentina has almost 16,000 healthcare providers, including 3000 with inpatient facilities«. Atun (2014), 12301247.

27 Public subsystem, under public administration - national, provincial, and municipal - is formed by the network of free-access healthcare providers across the country (hospitals).

28 Private agencies are composed of a complex network of commercial diagnostic institutions, clinics, and pre-pay healthcare systems. This subsystem is funded by private contributions, paid from the users.

29 Social Security, composed of the »obras sociales«, compulsory-membership healthcare plans for salaried workers. The most number of the social security insurances are organized and administrated by labor unions. »Both the most vulnerable groups and salaried workers, are precisely those who are most affected, with these groups demonstrating greater heterogeneity, segmentation, and employment conditions that do not ensure health care equity.« Abramovich/ Pautassi (2008), 274. 
ment's federal scheme, coexist in the province with the federal subsystems. That is to say, we can be dealing with a national or provincial public subsystem, a private national or provincial subsystem and provincial or national social security systems.

Buenos Aires has 15,625,084 inhabitants. According to official data resulting from census 2010 almost half of them (47.7\%) has social security coverage, approximately $15 \%$ has private health insurance $(5 \%$ of them can access it through their social security coverage) $)^{30}$ and only a $1.28 \%$ has some type of state health plan coverage. This means that the rest $(35.37 \%)$ can only count on the national or provincial public subsystem. ${ }^{31}$

The significance of social security coverage in the province is clear. Its origins are both at the national and provincial level. ${ }^{32}$ Within the provincial social security medical coverage, I.O.M.A. ${ }^{33}$ is the most important. Its beneficiaries are divided in two groups: members and voluntaries. The first group includes provincial state personnel and public administration employees, teachers, retirees and pensioners from the province's Institute of Social Prevision as well as other state departments. Voluntaries can be individuals, groups, relatives of deceased members, transitory agents, officials with elected posts, judges from the Judicial Branch and state personnel under unpaid leave rights. Also, Malvinas War ex-combatants residing in the province have been incorporated. Nowadays, the total amount of beneficiaries is approximately two million.

The public subsystem includes the network of provincial and municipal hospitals with the main headquarters in the province as well as the provin-

30 On the complex link between private providers and unions' medical care see, among others, Fidalgo (2008).

31 Source: Table P12-P. Buenos Aires Province. Population in private homes by type of medical coverage, according to sex and age, year 2010. Online: http://www.censo2010.indec.gov.ar/resultadosdefinitivos.asp [17.02.2016].

32 Conference given by I.O.M.A.'s President, Antonio La Scaleia, in »Presente y futuro de las obras sociales provinciales«, Asociación de Magistrados del Departamento Judicial de La Matanza. Online: http://www.ioma.gba.gov.ar/archivos/ futuro_obras_sociales.html [12.06.2017].

33 Instituto de Obra Médico Asistencial de la Provincia de Buenos Aires (provincial social security medical coverage), see Online: http://www.ioma.gba.gov.ar/ index.html [12.06.2017]. 
cial health programs. ${ }^{34}$ Also, the province has a Public Health Insurance (Seguro Público de Salud, SPS) created in 2005. This insurance aims to provide health care for $»$ scarce economic resources population that has got no other type of coverage « (Section 2, Law No. 13.413) and in practice has widened the subsystem's coverage in real terms, with a tendency towards a sanitary model based in the essential concepts of primary health attention, promotion and prevention. ${ }^{35}$ Nevertheless, the option of public insurance does not seem to have strengthened the provincial public system. As the Institute of Statistics and Census's (INDEC) statistics show, more than 35\% of the population depends exclusively on the public health system. The SPS has had positive effects, but it still benefits a low portion of the population when compared to resources destined to free medical attention in hospitals and regional medical attention centers. ${ }^{36}$

Finally, a last factor to be taken into account is the decentralization process undergone by first level health care services (the primary health attention centers, »CAPS $\ll^{37}$ ), now under municipal orbit. While this process has had a positive impact on the primary attention at the national level, several

34 On the province's critical situation of public hospitals see Crojethovich (2013), 2411-2433.

35 Maceira (2008).

36 Yavich et al. (2013), 26-34. This research's objective is to evaluate whether the Province's Public Health Insurance had strengthened its first level medical attention and enhanced the access and integrity of the attention. Towards that objective home surveys were made in eight municipalities $(2,413$ individuals in all). This allowed them to access information on the use of services among beneficiaries of the Public Health Insurance in individuals younger than eight years. According to the results, more than $95 \%$ of beneficiaries received medical care using the insurance and other services. They affirm that the insurance varied among municipalities. They point out that beneficiaries that used the insurance and other services achieved higher attention integrity and access to medical consults than those who used the Insurance exclusively. In the same way, the use of hospitals was significantly lower among users of the insurance. They conclude that the insurance "was more effective while being articulated with the network of municipal services«. And as regards accessibility to health attention in Bahía Blanca through the SPS, see Moscoso Nebel et al. (2010).

37 Centros de Atención Primaria de la Salud. 
investigations show that it has had specific negative consequences in terms of equality in the region. Inequality is present among municipalities in the province, due to the disparities in the levels of public spending in the health sector per uncovered inhabitant, which are especially detrimental to residents from the Buenos Aires metropolitan area. ${ }^{38}$

\section{Litigation in the Health Sector Before Provincial Courts and THE NATIONAL SUPREME COURT}

The results of the analysis of the decisions taken at the provincial first circuit courts, courts of appeals, the Supreme Court of the Province of Buenos Aires and some cases taken by the National Supreme Court can be read from different angles: the content of the claim, the profile of the defendant or the profile of the plaintiff.

As to the content of the claim, most of them are related to medical treatments and the delivery of medicines. As to medicines, most part of the claims focus on different cancer ${ }^{39}$ and HIV treatments. ${ }^{40}$ Therefore, diseases for which treatments are included in the Mandatory Medical Plan (Plan Médico Obligatorio, PMO), and therefore guaranteed by law. In only one case we found a request for a high-cost medicine to treat a low-incidence

38 Lago et al. (2012), 263-274. In the same sense: Chiara et al. (2009), 97-128; Lago et al. (2013), 40-54.

39 For instance: »A.B.M. c/I.O.M.A.«, Juzgado de 1ra. Instancia en lo Contencioso Administrativo Nro. 1 de La Plata, 20/02/2004; »García, Juan Adolfo c/Medicus S.A.«, Juzgado en lo Correccional Nro. 4 de Mar del Plata, 26/03/2008; »Beccaceci, Mónica Noemi c/MANO SALUD S.A. s/amparo«, Cámara de Apelaciones de Morón, 21/03/2006 y »Alba Eduardo Vicente c/O.S.P.R.E.R.A. S/amparo«, Cámara de Apelación de San Nicolás, 19/6/2007.

40 For instance: »G., E. L. c/I.O.M.A.«, Juzgado de 1ra. Instancia en lo Contencioso Administrativo Nro. 1 de La Plata, 06/09/2004; »B., G. S. c/I.O.M.A.«, Juzgado de 1ra. Instancia en lo Contencioso Administrativo Nro. 1 de La Plata, 12/12/2005; »P., C. H. c/P. d. B. A. y o. s/Demanda contencioso administrativa«, Suprema Corte de Justicia de la Provincia de Buenos Aires, 22/08/2012. 
disease. ${ }^{41}$ In this same line, in addition to specific treatments and medicines, we found claims to request hearing aid objects, wheelchairs and different kinds of prosthetics. ${ }^{42}$

The second place in terms of amount of requests is connected in one way or the other to what is called »social determinants of health «. This means, the right to health includes an ample variety of socioeconomic factors that promote the conditions through which people can access it, including feeding and nutrition, housing, access to drinking water and adequate sanitary conditions, safe and healthy working conditions and a healthy environment. ${ }^{43}$

In this way, in some cases the State is compelled to guarantee not only medical coverage for individuals or a family but also to address housing emergency situations ${ }^{44}$ and the lack of a monthly income. ${ }^{45}$ The accessi-

41 »A., A. A. c/M. S. d. A. M. y C. s/Amparo«, Suprema Corte de Justicia de la Provincia de Buenos Aires, 19/02/2015.

42 For instance in: »González de Ricci, María Cristina c/I.O.M.A.«, Cámara 1a de Apelaciones en lo Civil y Comercial de Bahía Blanca, sala II, 12/04/2007; »Divita, Virginia Daniela c/I.O.M.A. s/amparo«, Cámara de Apelación en lo Contencioso Administrativo con asiento en San Martín, octubre de 2010; »H., E. c. Instituto de Obra Médico Asistencial«, Juzgado en lo Correccional Nro. 4 de Mar del Plata, 22/12/2008 y »Ferrari, María L. c. Instituto de Obra Médico Asistencial (I.O.M.A.)«, Juzgado de 1ra. Instancia en lo Contencioso Administrativo de San Martín, 18/06/2004.

43 See E/C.12/2000/4, 11 August 2000, par. 11; Berlinguer (2007), 1; Lema Añón (2009).

44 About the judicialization of the right to housing at the local level to advance equality in favor of the most vulnerable people, see Cardinaux et al. (2013), 3374.

45 »A., G. C. c/Fisco de la Provincia de Buenos Aires y otra s/amparo«, Cámara de Apelación en lo Contencioso Administrativo con asiento en La Plata, marzo de 2011; »M. A. C. c/Provincia de Buenos Aires«, Juzgado Contencioso Administrativo No 1 , La Plata, 05/2006; »R., J. O. c/Municipalidad de San Fernando s/amparo«, Cámara de Apelación en lo Contencioso Administrativo con asiento en San Martín, 12/2010; »Correa, Sandra Dolores c/Ministerio de Infraestructura viv. y serv. s/amparo«, Cámara de Apelación en lo Contencioso Administrativo con asiento en La Plata, 11/2011; »Duarte, Iris Paola c/Fisco de la Provincia de 
bility to a home as a precondition to physical access to medical establishments ${ }^{46}$ and families' socioeconomic conditions have also been laid out as a protection in a context of high vulnerability and exposition to epidemics such as Hantavirus. ${ }^{47}$

All referred cases detailed descriptions of the individuals' states of vulnerability and the clear correlation between this situation and access to health. In this same regard we need to mention certain cases taken by the National Supreme Court, mostly close to the December 2001 Argentine crisis, ${ }^{48}$ where the right to adequate food is directly connected to health. We refer to the rulings in cases such as $» \operatorname{Ramos} \aleph^{49}$, $»$ Rodríquez ${ }^{50}$, »Quiñone $\ll^{51}$ and »Esquivel $\aleph^{52}$, all of them families with young children living in Buenos Aires Province and women, mothers, who are either the sole or primary breadwinners for the family. ${ }^{53}$

The connection between access to health and social determinants of health appear also in several cases which deal with environmental pollution

Buenos Aires s/amparo«, Juzgado Contencioso Administrativo Nº 1 , La Plata, 12/2008; »A., G.C. Amparo. R.E.N.-R.I.L.«, Suprema Corte de Justicia de la Provincia de Buenos Aires, 30/10/2013.

46 For instance in »M. A. C. c/Prov. De Bs As.«, Juzgado Contencioso Administrativo $\mathrm{N}^{\circ}$ 1, La Plata, 5-2006.

47 »García, Juan C. y otra c/Municipalidad de Zárate«, Juzgado de 1ra. Instancia en lo Contencioso administrativo Nro. 1 de Zárate-Campana, 28-5-2004.

48 See Maurino/Nino (2014), 299-333.

49 National Supreme Court (from now on CSJN), »Ramos, Marta R. y otros c/Ministerio de Desarrollo Social y Medio Ambiente y otros«, 12/03/2002.

50 CJSN, »Rodríguez, Karina Verónica c/Estado Nacional y otros s/acción de amparo«, 7/3/2006.

51 CSJN, »Quiñone, Alberto Juan c/Buenos Aires, Provincia de s/amparo«, 11/07/06.

52 CSJN, »Esquivel, Roberto y otro c/Buenos Aires, Provincia de y otros s/amparo«, 07/03/2006.

53 The other significant case relating to the violation of right of housing and healthcare is »Q. C.« decided by the National Supreme Court, 24/04/2012, see Clérico et al. (2015). 
connected to construction ${ }^{54}$ and industrial activities. ${ }^{55}$ There are also several cases that dealt with access to drinking water and sanitation. ${ }^{56}$ In some of them, the Provincial Supreme Court ordered a municipality to adjust the supply of water to legally established quality standards, ${ }^{57}$ also ordering the provider to adjust to such standards for the provision of drinking water in homes. $^{58}$

We found some cases linked to the prevention of affection of health through social determinants of health, such as in a case in which the court

54 »Carrasco, Juan A. y otros c. Delegación Puerto Paraná Inferior, Dirección Provincial de Actividades Portuarias y otros«, Juzgado de 1ra. Instancia en lo Contencioso administrativo de San Nicolás, 16/06/2004; „Guzmán, Juan José c/ Telecom Personal S.A. y Otra s/Interdicto de obra nueva«, Suprema Corte de Justicia de la Provincia de Buenos Aires, 07/05/2014.

55 »Fundación Ecosur, Ecología, Cultura y Educación para los Pueblos del Sur c/Municipalidad de Vicente López y otro, s/Recurso extraordinario de inaplicabilidad de ley«, Suprema Corte de la Provincia de Buenos Aires, 28/12/2010.

56 Asociación para la Protección del Medio Ambiente y Educación Ecológica ' 18 de Octubre' c/Aguas Argentinas SA y Otros, Cámara Federal de Apelaciones (La Plata) 3156/02, RDAmb 2004-0-193, Online: http://www.ecolex.org:8984/ server2neu.php/libcat/docs/COU/Full/En/COU-143728S.pdf [13.06.2017]: collective claim about the violation of the right to health and a healthy environment of the inhabitants who live near the coast of the River Plate in Quilmes, because of the rise of the groundwater level produced by the activities undertaken by a private water company (under a public concession contract), that were not monitored by the competent public authorities.

57 »Boragina, Juan Carlos, Miano, Marcelo Fabián y Iudica, Juan Ignacio c/ Municipalidad de Junín. Amparo«, Suprema Corte de Justicia de Buenos Aires, 15/07/2009.

58 »Conde, Alberto J.L. c/Aguas Bonaerenses S.A. (A.B.S.A.). Amparo-Recurso extraordinario de inaplicabilidad de ley«, Suprema Corte de Justicia de Buenos Aires, 11/2011. In the same sense in »Florit, Carlos Ariel y otro c/Provincia de Buenos Aires y Aguas Bonaerenses S.A. (A.B.S.A. S.A.). s/Amparo. Recurso extraordinario de inaplicabilidad de ley«, Cámara de Apelación en lo Contencioso Administrativo con asiento en La Plata, abril 2011. See Faierstein/ Levenzon (2013), 1233-1275. 
ordered a provincial road to be repaired so as to prevent accidents, ${ }^{59}$ or another in which the court ordered the restriction of gambling games legally promoted by the province, highlighting its link to the promotion of health. ${ }^{60}$

In the same line of claims that contemplate the link among conditioning factors and access to health there finally appears an interesting set of considerations in which some of the structural flaws of the Province's system are highlighted: cases which concern the discussion of public hospitals' conditions, either because the demands focus in the conditions of the buildings' infrastructure ${ }^{61}$ or because they focus in the appointment of doctors or nurses in one of the province's pediatric hospital, ${ }^{62}$ or also because what is demanded is the cancellation of an x-ray service until the security measures to protect hospital personnel and patients' are met. ${ }^{63}$ A common characteristic of these judicial claims is that they do not necessarily respond to the individualistic feature that is predominant in the distorting effect thesis. Indeed, although several of these claims do not reach the level of a structural litigation questioning the inequality of the whole healthcare system, they do present a claim that exceeds the problem of a particular individual or family and that needs a broad type of answer from the State. ${ }^{64}$

59 »O., H. G. c/Dirección de Vialidad de la Provincia de Buenos Aires y otros«, Juzgado de 1ra. Instancia en lo Contencioso Administrativo Nro. 1 de Mercedes, 10-8-2009, see also: WaterLex/Wash United (2014); Winkler (2008).

$60 »$ Juzgado de Faltas $2^{\circ}$ (Juzgado de Defensa del Consumidor)«, Juzgado de Faltas Nro. 2 Defensa del Consumidor de la Municipalidad de La Plata, 04/05/2010.

61 »Gutierrez Griselda Margarita y otro/a c/Hospital Zonal A. Korn y otro/a«, Cámara de Apelación en lo Contencioso Administrativo con asiento en La Plata, september 2010.

62 »Gaviot, María Cecilia y otros c/Fisco de la Provincia de Buenos Aires«, Juzgado de 1ra. Instancia en lo Contencioso Administrativo Nro. 1 de La Plata, 29/5/2008.

63 »Espolsin, Miryam E. y otros c. Hospital Bocalandro y otra«, Juzgado de 1 ra. Instancia en lo Contencioso Administrativo de San Martín, 14/06/2004.

64 »Florit, Carlos Ariel y otro c/Provincia de Buenos Aires y Aguas Bonaerenses S.A. (A.B.S.A. S.A.). s/Amparo«, Cámara de Apelación en lo Contencioso Administrativo, La Plata, April 2011; »Asesoría Nº1 c. Fiscalía de Estado - 
In the third place, by amount of claims according to their object, appear cases linked to membership to social security coverage or private health care providers. In most of these claims the discussions focus on waiting periods before the patient can request a service ${ }^{65}$ or also the admission of a spouse or partner in an equal set of conditions as those of the actor. ${ }^{66}$

Fourthly, we find a set of judicial decisions that address the lack of execution of certain provincial health programs. For instance, regarding the provincial system of haemotherapy, which had not been implemented in the province for more than eight years ${ }^{67}$ the Provincial Growth Hormone Deficit Program ${ }^{68}$ suspended without any reason the delivery of medicines for the year 2007. Likewise, a similar situation occurred with the delivery of medicines in connection with the $» \mathrm{PROFE}$ « provincial programme,${ }^{69}$ which

Prov. de Buenos Aires s/Art. 250 del CPCC«, Cámara de Apelaciones en lo Contencioso Administrativo de Mar del Plata, 30/09/2014; Asociación para la Protección del Medio Ambiente y Educación Ecológica '18 de Octubre' c/ Aguas Argentinas SA y Otros [2003] Cámara Federal de Apelaciones (La Plata) 3156/02, RDAmb2004-0-193. Online: http://www.ecolex.org/server2.php/ libcat/docs/COU/Full/En/COU-143728S.pdf [13.06.2017].

65 Por ejemplo en »González Bonorino M. c/Ministerio de Salud - I.O.M.A. s/amparo«, Cámara de Apelación en lo Contencioso Administrativo con asiento en Mar del Plata, junio 2012; »Benigni Maria Luisa c/I.O.M.A. s/amparo«, Cámara de Apelación en lo Contencioso Administrativo con asiento en La Plata, octubre 2011.

66 »S.L.N. c/I.O.M.A.«, Juzgado en lo Criminal y Correccional Nro. 1 de Transición de Mar del Plata, 12/03/2002; »M, A. G. c. Instituto de Obra Médico Asistencial«, Cámara de Apelaciones en lo Contencioso Administrativo con asiento en La Plata, 26/11/2004 y »Benítez Roque c/I.O.M.A.«, Juzgado en lo Criminal y Correccional Nro. 1 de Transición de Mar del Plata, 12/9/2005.

67 »Fundación Hematológica Sarmiento c/Instituto de Hemoterapia de la Provincia de Buenos Aires. Hospital Interzonal Especializado s/Amparo«, Suprema Corte de Justicia de la Provincia de Buenos Aires, 03/2005.

68 »Asociación Civil Creciendo c. Ministerio de Salud«, Juzgado de 1ra. Instancia en lo Contencioso Administrativo Nro. 1, La Plata, 14/05/2007.

69 See, for example, »Ramírez Susana c/Ministerio de Salud y otro/a s. amparo«, Cámara de Apelación en lo Contencioso Administrativo de Mar del Plata, 12/2012 and National Supreme Court, »González Fabiana Lucía«, 26/06/2012 y 
aims to guarantee access to the right to health for persons with disabilities. What is interesting in this group of cases is that, as in other cases which center on health social conditioning factors, these are not always individual claims that demand the implementation of the provincial programme for a singular person. Rather, in some of these cases, we find collective injunctions (amparos colectivos) referring to the Province's lack of compliance and the corresponding impairment of the population's health.

Finally, we could identify a fifth group of cases linked to reproductive and sexual health. In some of them the plaintiffs request abortion of an anencephalic foetus, ${ }^{70}$ artificial insemination currently treatments not covered by the law, ${ }^{71}$ and two cases in which women with low-income backgrounds request tubal ligation medical procedures, both cases initiated before the passing of Law No. 26.862 of surgical contraception. In one of the cases the focus is put on the severe health consequences undergone by a person after having a not-safe abortion. ${ }^{72}$ Neither in these nor in other cases have we found an approximation to the right to health from a gender perspective.

Additionally, it is important to mention that not many cases have risen in which the object of the claim is the non-intervention of the state. For instance, the one case on blood transfusions to children belonging to a religious group that prohibits them, ${ }^{73}$ a case in which parents of a child in its first years deny its right to vaccination ${ }^{74}$ and another in which an 84

CSJN, »Insfrán, Alberto - en representación de su hija P. M. I. F. -/c PROFEBA Ministerio de Salud de la Provincia de Buenos Aires«, 11/09/2012.

70 »Parisotti, Fátima Viviana s/Amparo«, Suprema Corte de la Justicia de la Provincia de Buenos Aires, 05/05/2004.

71 Ronconi (2010), 17-28.

72 »N. d. Z., M. V. c/F. S. S. p. 1. F. s/Reclamo contra actos de particulares«, Suprema Corte de la Provincia de Buenos Aires, 8/8/2007, see Bergallo (2014), $143-165$.

73 »Hospital Interzonal General de Agudos Dr. Oscar Alende (HIGA)«, Juzgado en lo Criminal y Correccional Nro. 1 de Transición de Mar del Plata, 09/05/2005.

74 CSJN, »N.N. o U.,V. s/Protección y guarda de personas«, 12/06/2012; Suprema Corte de la Provincia de Buenos Aires, 6/10/2011. 
years old woman requests that her right to a death with dignity be respected. ${ }^{75}$

Now, as regards the profile of the defendants, I.O.M.A. is the defendant with most cases against it. To a much lesser extent appear other agencies/providers of the social security coverage system, »mutuals« or medical insurance providers. After I.O.M.A., the provincial state and municipalities occupy the second place, most times with demands initiated concurrently. It can be identified as a case-law rule that the state providers' heterogeneity (national state, province or municipality; social security agencies) does not matter at all when facing the disease's diagnosis severity or the person's state of need; in general terms the most effective provider is the one which was already bound to render the services and threatens to interrupt them. This means that the complexity and fragmentation of the system is no excuse for the provider not to render the services it should provide under the light of the right to health. A transversal analysis of this case-law allows us to affirm that it is not the person affected with a health problem the one who should bear the burden of the lack of effective coordination among the different subsystems.

One of the most interesting results of this research can be seen in the plaintiffs' profiles. Contrary to what the distorting effect thesis postulates, the predominant profile is not that of high-income individuals. In effect, in several cases the plaintiffs' social and economic vulnerability is highlighted. ${ }^{76}$ Plaintiffs are mostly I.O.M.A. members, what means that for the most part they are state employees of the province or volunteers, which implies a wide variety of profiles. A considerable portion of these plaintiffs belong to vulnerable socioeconomic sectors: the elderly, persons with disabilities,

75 »B., I. N. Causa n ${ }^{\circ}$ 4033«, Juzgado en lo Correccional Nro. 4 de Mar del Plata, 3/10/2014.

76 For instance in: »Torres, Leonardo E.«, Juzgado en lo Criminal y Correccional Nro. 1 de Transición de Mar del Plata, 02/04/2004; "Álvarez, Cristian A. c/Ministerio de Salud«, Juzgado de 1ra. Instancia en lo Contencioso Administrativo Nro. 1 de La Plata, 20/02/2004; »E., C. E. c/Provincia de Buenos Aires y otros«, Juzgado de 1ra. Instancia en lo Contencioso Administrativo Nro. 1 de La Plata, 11/10/2005, apart from the cases already mentioned and many other in which it is mentioned that the plaintiff has the »right to litigate for free«, which means that it cannot afford to pay for the legal services rendered. 
women and children living in a state of poverty. Generally speaking, the claimants bringing up a case against I.O.M.A. (or the provincial State) is not a wealthy individual nor do they request expensive or high-tech treatments. As we said before, for the most part requests focus on simple treatments, mainly covered by law.

\section{Final Considerations}

The main aim of our chapter was to challenge the distorting effect thesis taking seriously the bottom up perspective, the analysis of case law initiated and produced at the local level, not the high court's federal level.

Firstly, the content of the claims is not focused on complex judicial matters or unusual medical treatments not covered by the law. The claims are related to medicaments or treatments covered in general by the law. This confirms what evidence shows, that

»[...] the legal structure of the health care system itself - with its emphasis on a defined package of benefits that are part of contract insurance - frequently provides the conditions conductive to litigation of health care rights. ${ }^{77}$

There are clear cases, where the defendant's breach is obvious and in which the obligation to perform and provide cannot be put off. If the provider does not fulfil its obligations, it is not only impairing the effective right to medical care but also - in a great amount of cases - the survival of the individual.

Secondly, we have observed that do not exclusively arise from an individualistic pattern of violation of the right to health. In several cases these health demands are linked to access to social conditions that enable the exercise of the right, like sanitation and clean water, or to the critical situation of provincial hospitals. They may not be the most numerous, but their existence and variety force us to seek more complex diagnoses.

Thirdly, most cases are against the agency of the provincial social security system I.O.M.A. In regard to the plaintiffs' profiles, the results of our inquiry show that they are not part of the better-off sector of society. In

77 Flood/Gross (2014), 460. 
several cases there also appear individuals that belong to the most vulnerable population of society. And while they directly demand the province, they are not only requesting access to healthcare in a restricted way, but also in an ample one, that contemplates social conditions that make the exercise of the right to health possible, such as access to housing, food and education.

In all, these conclusions do not imply that at the provincial level we do not find cases in which middle and high-income individuals demand a private medical company to access some high-complexity treatment that the provider refuses to provide. ${ }^{78}$ Or demands granted by judges without taking into account the impact it may have on the state budget. These cases exist, but they are neither the rule nor the most part of case law related to the right to health in the province of Buenos Aires.

That is the reason why we do not take the distorting effect thesis for this local research as an unquestionable truth. Therefore, we present some hypothesis on the factors that contribute to the result that this thesis does not completely materialize in the province of Buenos Aires. Evidently, public law defender services play an important role in specific cases in which the plaintiff could have not otherwise have brought a judicial case. ${ }^{79}$ This access to justice is undoubtedly insufficient and requires to be widened with structural claims that addressed the right to health violation from an overall health system perspective.

78 See a. o., Clérico et al. (2013), 1417-1495.

79 Evidence shows that the access to right health litigation for poor people increased when the cases are litigated by the public defense office (Defensoría Pública, publicly funded legal services), which offers legal services for free to people who cannot afford lawyers. Informal interviews with professionals from the public defense office from the City of Buenos Aires revealed the existence of case law at the local level to access to housing as a material condition for the right to health. The plaintiffs are homeless women with children with severe disabilities. Regarding the judicialization of the right to housing at the local level to advance equality in favour of people in vulnerable situation, see Cardinaux et al. (2013), 33-74; Aisenstein (2013), 1845-1869; Pucciarello (2013), 24552475 ; and in connection with judicialization the right to education, Blanck (2013), 40-87. 
A second hypothesis deals with a case-law tradition that has been long present as regards the right to medical care in Argentina. Already in the nineties and in a context of a state structural adjustment, the National Supreme Court advanced in consolidating a clear line of guarantees regarding the right to medical care that establishes that if the omission or insufficient action on the part of the state affects the individual's subsistence, then we are clearly in front of a violation against the right to medical care. ${ }^{80}$ This line of reasoning follows a case-law sequence from the National Supreme Court that starts with the »Campodónico ${ }^{81}$ case and partially consolidates with »Orlando $\ll^{82}$, »Sánchez ${ }^{83}{ }^{83}$, »Passero $\ll^{84}$, »Floreancig $\varkappa^{85}$ and »Reyes Aguilera ${ }^{86}{ }^{8}$ cases, and which we see reflected in the province's courts' analysed decisions.

It is true that the Supreme Court's rulings have not even questioned structural factors ${ }^{87}$ of Argentina's healthcare system. ${ }^{88}$ There are no cases in which the existence of three coverage subsystems or the forced inequality brought about by the national variable and the resource distribution among the provinces has been questioned. It may be possible that such demand is not something that the argentine society (better said, the privi-

80 It is the urgency argument, which among others was dealt with by Arango (2005).

81 CSJN, »Campodónico de Beviacqua, Ana Carina«, ruling dated 24/10/00.

82 CSJN, »Orlando, Susana Beatriz c. Provincia de Buenos Aires y otros s/amparo«, ruling dated 24/05/2005.

83 CSJN, »Sánchez, Norma Rosa c/Estado Nacional y otro s/amparo«, ruling dated 20/12/2005.

84 CSJN, »Passero de Barriera, Graciela Noemí c/Estado Nacional s/amparo«, ruling dated 18/09/2007.

85 CSJN, »Floreacing, Andrea C. y otro por sí y en representación de su hijo menor H., L. E. c. Estado Nacional«, ruling dated 11/07/2006.

86 CSJN, »Reyes Aguilera, Daniela c/Estado Nacional«, ruling dated 04/09/2007.

87 See this hypothesis in Abramovich/Pautassi (2008); Clérico (2010), 93-118, among others, and confirmed in Gotlieb et al. (2016).

88 In contrast to the Colombian Constitutional Court's ruling T-760 of 2008 that ordered government to address the systemic factors driving right to health litigation. See Yamin et al. (2011). 
leged part of it ${ }^{89}$ that can push the political agenda) is actually willing to put forward. Therefore, for people living in situation of vulnerability, litigation is the only way they could raise their voices to demand their rights to access to healthcare.

\section{References}

Abramovich, Víctor/Courtis, Christian (2002): Los derechos sociales como derechos exigibles, Madrid: Trotta.

Abramovich, Víctor/Pautassi, Laura (2008): »El derecho a la salud en los tribunales: Algunos efectos del activismo judicial sobre el sistema de salud en Argentina«, in: Salud Colectiva 4, 3 (2008), 261-282 [Abramovich, Víctor/Pautassi, Laura (2008): »Judicial activism in the Argentine health system: recent trends«, in: Health and Human Rights 10, 2 (2008), 53-65.]

Abramovich, Víctor (2005): »Líneas de Trabajo en Derechos Económicos, Sociales y Culturales: Herramientas y Aliados«, in: SUR, Revista Internacional de Derechos Humanos 2, 2 (2005), 194-232.

Aisenstein, Mariela (2013): »El papel de los Asesores Tutelares en la exigibilidad del derecho a la salud de los niños, niñas y adolescentes en el ámbito local«, in: Clerico et al. (2013), 1845-1869.

Arango, Rodolfo (2005): El concepto de los derechos sociales fundamentales, Bogotá: Legis.

Arballo, Gustavo (2013): »Localizando el derecho a la salud«, in: Clérico et al. (2013), 1621-1652.

Atun, Rifat (2014): »Health-system reform and universal health coverage in Latin America«, in: The Lancet 385, 9974 (2014), 1230-1247.

89 There are different theories that try to explain the structural problems of the health system in Argentina. From a human rights perspective, the main concern must be the problem of inequality to the detriment of people who are in vulnerable situations. Like Tittor, among others, explains in the case of Argen-tina: the structures of the health sector reflect social structures: the influential groups have "privileges «, which they defended for decades, while the poorest groups, especially those that are unorganized, have far less access and quality of healthcare, see Tittor (2012), 49. 
Bergallo, Paola (2005): »Justicia y experimentalismo: la función remedial del poder judicial en el litigio de derecho público en Argentina«, in: SELA Seminario en Latinoamérica de Teoría Constitucional y Política, paper 45.

Bergallo, Paola (2014): »The Struggle Against Informal Rules on Abortion in Argentina«, in: Cook et al. (2014), 143-165.

Berlinguer, Giovanni (2007): »Determinantes sociales de las enfermedades«, in: Revista Cubana de Salud Pública 33, 1 (2007), 1-17.

Biehl, João/Socal, Mariana P./Amon, Joseph J. (2016): »The Judicialization of Health and the Quest for State Accountability: Evidence from 1,262 Lawsuits for Access to Medicines in Southern Brazil«, in: Health and Human Rights 18, 1 (2016), 209-220.

Blanck, Ernesto (2013): Desigualdad educativa en la Ciudad de Buenos Aires: un análisis estructural de las politicas educativas desde un enfoque de derechos humanos, Buenos Aires: Eudeba.

Cano, Luisa Fernanda (2005): »El litigio estructural en salud: un estudio comparado con base en casos de Sudáfrica, Argentina, India y Colombia«, in: Revista Facultad Nacional de Salud Pública 33, 1 (2005), 111-120.

Cardinaux, Nancy/Vita, Leticia/Aldao, Martín/Clérico, Laura (2013) »Condiciones de posibilidad para la exigibilidad judicial del derecho a la vivienda en el ámbito local«, in: Revista Argentina de Derecho Administrativo, 5 (2013), 33-74.

Chiara, Magdalena/Di Virgilio, María Mercedes/Moro, Javier (2009): »Inequidad(es) en la atención de la salud en el gran Buenos Aires: Una mirada desde la gestión local«, in: Postdata 14, 1 (2009), 97-128.

Clérico, Laura (2010): „¿El argumento del federalismo vs. el argumento de igualdad? El derecho a la salud de las personas con discapacidad«, in: Revista Jurídica de Palermo 11 (2010), 93-118.

Clérico, Laura/Ronconi, Liliana/Aldao, Martín (Eds.) (2013): Tratado de Derecho a la Salud, Buenos Aires: Abeledo Perrot.

Clérico, Laura/Ronconi, Liliana/Scioscioli, Sebastián/Aldao, Martín/ Mendizábal, Gonzalo (2013): »El subsistema privado de salud en Argentina. Notas y preguntas sobre el marco regulatorio de la medicina prepaga«, in: Clérico et al. (2013), 1417-1495. 
Clérico, Laura/Vita, Leticia (2015): »Der Rechtsstreit um Gesundheit in Argentinien. Gerechtigkeit für alle?«, in: Zeitschrift für Menschenrechte 2, 36 (2015), 70-85.

Clérico, Laura/Ronconi, Liliana/Aldao, Martín (2016): »Equality«, in: González Bertomeu/Gargarella (2016), 1-18.

Cook, Rebecca J./Erdman, Joanna N./Dickens, Bernard M. (Eds.) (2014): Abortion Law in Transnational Perspective. Cases and Controversies, Pennsylvania: University of Pennsylvania Press.

Crojethovich, María (2013): »Claves para pensar la Dinámica del Hospital Público«, in: Clérico et al. (2013), 1339-1357.

Crojethovich, María (2013) »Microcosmos hospitalario. Redefiniendo las reglas en los hospitales del Gran Buenos Aires«, in: Clérico et al. (2013), 2411-2433.

Da Silva Virgilio, Afonso/Terrazas Vargas, Fernanda (2011): »Claiming the Right to Health in Brazilian Courts: The Exclusion of the Already Excluded?«, in: Law \& Social Inquiry 36, 4 (2011), 825-853.

Faierstein, Carolina/Levenzon, Fernanda (2013): »Apuntes sobre el reconocimiento e implementación del derecho humano al agua y al saneamiento, in: Clérico et al. (2013), 1233-1275.

Ferrajoli, Luigi (2002): »Prólogo«, in: Abramovich/Courtis (2002), 9-14.

Ferraz, Octavio (2011): »Harming the Poor Through Social Rights Litigation: Lessons from Brazil«, in: Texas Law Review 89, 7 (2011), 16431668.

Fidalgo, Maitena (2008): Adiós al derecho a la salud. El desarrollo de la medicina prepaga, Buenos Aires: Espacio.

Flood, Colleen/Gross, Aeyal (2014): »Litigating the Right to Health: What Can We Learn from a Comparative Law and Health Care Systems Approach?«, in: Health and Human Rights 16, 2 (2014), 62-72.

Flood, Colleen/Gross, Aeyal (Eds.) (2015): The Right to Health in a Globalized World, Cambridge: Cambridge University Press.

Forman, Lisa/Singh, Jerome (2015): »The role of rights and litigation in assuring access to health care in South Africa«, in: Flood/Gross (2015), 288-318.

Forman, Lisa (2015): „Can Core Obligations under the Right to Health Achieve their Ambitions? « in: Zeitschrift für Menschenrechte 2, 36 (2015), 43-48. 
González Bertomeu, Juan/Gargarella, Roberto (Eds.) (2016): The Latin American Casebook. Constitution, Courts and Rights, Ashgate: Farnham U.K.

Gotlieb, Verónica/Yavich, Natalia/Báscolo, Ernesto (2016): »Litigio judicial y el derecho a la salud en Argentina«, in: Cadernos de Saúde Pública 32, 1 (2016), February 16, 2016. doi: https://dx.doi.org/ 10.1590/0102-311X00121114.

Jung, Courtney/Hirschl, Ran/Rosevear, Evan (2015): »Economic and Social Rights in National Constitutions«, in: American Journal of Comparative Law 62, 4 (2015), 1043-1094.

Krennerich, Michael (2013): Soziale Menschenrechte. Zwischen Recht und Politik, Schwalbach/Ts: Wochenschau Verlag.

Lago, Fernando Pablo/Moscoso Nebel, Silvana/Elorza, María Eugenia/ Vanini Ripari, Nadia (2012): »Descentralización y equidad: el gasto público en salud en los municipios de la provincia de Buenos Aires«, in: Salud colectiva 8, 3 (2012), 263-274.

Lago, Fernando Pablo/Elorza, María Eugenia/Nebel-Moscoso, Silvana/ Vanina-Ripari, Nadia (2013): »Equidad en el acceso a los servicios de Atención Primaria de Salud en sistemas de salud descentralizados: el caso de la provincia de Buenos Aires, Argentina«, in: Revista Gerencia y Politicas Salud 12, 25 (2013), 40-54.

Langford, Malcolm (2011): Social Rights Jurisprudence, Emerging Trends in International and Comparative Law, Cambridge: Cambridge University Press.

Lema Añón, Carlos (2009): Salud, justicia, Derechos. El derecho a la salud como derecho social, Madrid: Dykinson.

Maceira, Daniel (2008): »Evaluación del Programa de Seguro Público de Salud de la Provincia de Buenos Aires«, CIPPEC, Online: https:/www.cippec.org/publicacion/evaluacion-del-programa-de-seguro -publico-de-salud-de-la-provincia-de-buenos-aires/ [15.06.2017].

Maceira, Daniel/Kremer, Pedro (2008): »Evaluación de una experiencia de aseguramiento social en la Provincia de Buenos Aires: Impacto sobre el modelo de atención. Asociación Argentina de Economía Política«, Online: http://www.cedes.org/publicaciones/documentos/Salud/2008/ 7717.pdf [15.06.2017]. 
Maurino, Gustavo/Ezequiel, Nino (2014): »Economic and social rights and the Supreme Court of Argentina in the decade following the 2001-2003 crisis«, in: Nolan (2014), 299-333.

Moscoso Nebel, Silvana/Gullace, Maria E./Elorza, Maria E./Ripari, Nadia (2010): »Implementación del seguro provincial de salud en la ciudad de Bahía Blanca: Condiciones de acceso en el período 2004-2009« (paper presented in XLV Reunión Anual de la Asociación Argentina de Economía Política, Ciudad de Buenos Aires, 2010), Online: http://www.aaep.org.ar/anales/works/works2010/moscoso.pdf [17.02.2016].

Nolan, Aoife (Ed.) (2014): Economic and Social Rights After the Global Financial Crisis, Cambridge: Cambridge University Press.

Perelman, Chain/Olbrechts-Tyteca, Lucie (1969): The new rhetoric: A treatise on argumentation, Notre Dame: University of Notre Dame Press.

Pucciarello, Mariana (2013): »El derecho a la salud en la Ciudad Autónoma de Buenos Aires«, in: Clérico et al. (2013), 2455-2475.

Reveiz, Ludovic/Chapman, Evelina/Torres, Rubén/Salgado, Osvaldo (2013): »Litigios por derecho a la salud en tres países de América Latina: revisión sistemática de la literatura«, in: Revista Panamericana de Salud Pública 33, 3 (2013), 213-222.

Ronconi, Liliana (2010): $¡$ ¿Debe el Estado satisfacer los tratamientos de fertilización asistida? Un análisis a la luz del principio de proporcionalidad«, in: La Ley, Suplemento de Derecho Constitucional, 22 (2010), 17-28.

Suárez Franco, Ana María (2009): Die Justiziabilität wirtschaftlicher, sozialer und kultureller Rechte, Frankfurt/M.: Peter Lang.

Tittor, Anne (2012): Gesundheitspolitik in Lateinamerika. Konflikte um Privatisierung in Argentinien und El Salvador, Baden-Baden: Nomos.

Uprimny, Rodrigo/Durán, Juanita (2014): Equidad y protección judicial del derecho a la salud en Colombia, Santiago de Chile, Naciones Unidas: División de Desarrollo Social, CEPAL.

Vita, Leticia (2013): »Modelos de Estado y Derecho a la Salud en Argentina, in: Clérico et al. (2013), 17-63.

WaterLex/Wash United (2014): »The Human Rights to Water and Sanitation in Courts Worldwide. A Selection of National, Regional and International Case Law«, Geneva: WaterLex. Online: http://www.sus 
ana.org/_resources/documents/default/3-2159-7-1423501950.pdf [03.06.2016].

Winkler, Inga (2008): »Judicial Enforcement of the Human Right to Water: Case Law from South Africa, Argentina and India«, in: Law, Social Justice and Global Development Journal 11 (2008), Online: www2.war wick.ac.uk/fac/soc/law/elj/lgd/2008_1/winkler [06.06.2016].

Yamin, Alicia/Gloplen, Siri (Eds.) (2011): Litigating Health Rights: Can Courts Bring More Justice to Health?, Cambridge, Harvard University Press.

Yamin, Alicia Ely/Parra, Oscar/Gianella, Camilla (2011): „Colombia. Judicial Protection of the Right to Health: An elusive promise?« in: Yamin/Gloplen (2011), 103-131.

Yavich, Natalia/Báscolo, Ernesto Pablo/Haggerty, Jeannie (2013): »Evaluación del componente infantil del Seguro Público de salud de la Provincia de Buenos Aires«, in: Salud Pública de México 55, 1 (2013), 26-34.

Young, Katharine/Lemaitre, Julieta (2013): »The Comparative Fortunes of the Right to Health: Two Tales of Justiciability in Colombia and South Africa«, in: Harvard Human Rights 26 (2013), 186-216. 



\section{THERAPISTS AS ADVOCATES THE EXAMPLE OF HELEN BAMBER}





\title{
Human Rights in Practice
}

\author{
The Life and Work of Helen Bamber
}

RACHEL WITKIN

\section{INTRODUCTION}

From 1945 until her death in 2014, Helen Bamber worked therapeutically with thousands of displaced and traumatised people who had suffered torture, human trafficking, slavery and war. She learned from the individual circumstances of each person, adapting her unique Model of Integrated Care to meet their needs. Her approach to her work and methods of practice are discussed in the lecture paper: >Therapists as Advocates: A Conversation with Helen Bamber ${ }^{l}$ which is taken from an interview conducted in 2002 by Freihart Regner.

I first met Freihart Regner at the Memorial for Helen Bamber at St Martin-in-the-Fields Church in London on the $26^{\text {th }}$ of January 2015. We discussed working together on the transcript of the interview to create a lecture from her words. This was an exciting opportunity to capture Helen Bamber's own voice in some detail on the practice of her work. As a charismatic speaker and campaigner she had fought tirelessly for recognition of the rights of people who are traumatised and also forced to seek asylum. Most of her own writing about her work is contained in thousands of confidential reports and letters and therefore remains unpublished. These reports and letters intricately document the histories, injuries, health and circumstances of individual survivors she worked with. She was well known for

1 See the contribution by Freihart Regner and Rachel Witkin in this volume. 
her persuasive eloquence in describing her clients\& needs to people who could help them, and for her calm, determined persistence in cases that were initially met with refusal.

Those who worked with Helen Bamber knew she was always to be found in her office, sitting at a small, circular table with refugees who were struggling to cope with the uncertainty of their daily lives. Each of her clients was met with the same warm welcome. Her room, set out with flowers, photographs and pebbles, provided a quiet place of safety for people who had lost everything that was familiar to them. Despite the intense daily activity of Helen Bamber and her team, there was always a sense of stillness there, and time enough to be given. In the year before her death she said: »It is the continuation of this work that matters, not remembering the personality.« However, for all those who knew Helen, her work was infused with her character, her strength, her wisdom and often mischievous sense of humour. Her example demonstrated to professionals of all fields who come into contact with survivors, that they should not be afraid of extending a personal level of kindness and connectedness to their work.

Overview: Helen Bamber's life and work is illustrated on a wall at the Helen Bamber Foundation, which maps her work with survivors of atrocity throughout the last century:

Soviet Union 1930-1960; World War II 1939-1945; Palestine 1948present; Korea 1950-1953; Kenya 1950-1962; China 1951; Tibet 1950present; Algeria 1954-1962; Eritrea 1961-1999; Brazil 1964-1977; Guatemala 1968-1996; Northern Ireland 1968-1998; Bangladesh 1971; Burundi 1972-1993; Chile 1973-1990; Cambodia 1975-1979; East Timor 1975-1999; Angola 1972-2002; Argentina 1976-1983; Ethiopia 19771978; El Salvador 1979-1992; Iran 1979-present; Iraq 1979-present; Nicaragua 1981-1990; Sri Lanka 1983-present; Turkey 1984-present; Uganda 1986; Tiananmen Square 1989; Liberia 1989-1996; Somalia 1991; Sierra Leone 1991-2002; Bosnia and Herzegovina 1991-1995; Rwanda 1994; Kosovo 1998-1999; Congo 1998-2003; Chechnya 19992009; Zimbabwe 2000; Afghanistan 2001-present; Guantanamo Bay 2002-present; Nigeria 2005-present

As these events move into history, they are documented and obtain a level of international recognition. However, at the time when Helen Bamber was 
working with survivors, their recent experiences were often not widely known or cared about. She supported people from all political and cultural backgrounds, often years before their causes had gained a fuller understanding in law and practice. These included survivors of violence because of their gender or sexual identity, people who had been trafficked and held in slavery, women who had suffered female genital mutilation (FGM), ${ }^{2}$ child soldiers, people subjugated through the use of Juju ceremonies, ${ }^{3}$ victims of local community violence, and those who were persecuted for their political or religious beliefs.

Even in cases where the plight of survivors is better understood, there will always be a clamour against asylum seekers and refugees from politicians, the media and the general public. One of the greatest challenges they face is being viewed as a general category or stype their >foreignness and their uncertain immigration status. As we see from

2 Female Genital Mutilation (FGM) is an illegal, extremely harmful practice. It is a form of child abuse and violence against women and girls. It describes all procedures involving partial or total removal of the external female genitalia or other injury to the genital organs for cultural or other non-medical reasons. There are estimated to be $100-140$ million women in Africa alone who have experienced FGM, and three million girls who are at risk of the procedure in Africa. Although it is mainly an African phenomenon it is also prevalent in parts of the Middle East and Asia, and is seen in Western countries (e.g. Somalia, Guinea, Dijbouti, Egypt: $>90 \%$ women with FGM). Different regions perform FGM at different parts of a woman's life cycle varying from birth through to marriage. Girls born within practising communities are at risk of FGM both abroad and in the UK, cf. WHO (2017).

3 The Helen Bamber Foundation works with victims of human trafficking from West Africa who have been subjected to ritualised violence in ,Juju' ceremonies which are performed by traffickers. These ceremonies utilise cultural beliefs in the ancient and omnipotent power of Juju to terrorise victims, instilling deep fears in order to subjugate them in preparation for exploitation and to prevent them from telling anyone about their experiences. Rituals which threaten victims and their loved ones with illness and death are an effective form of long-term coercion. An enduring psychological bond is formed between the trafficker and the victim that is not dependent upon their physical proximity. See Witkin on behalf of the Helen Bamber Foundation (2013). 
events currently and throughout history, terms like sasylum seekerı, >illegal immigrant and >refugee can swiftly become negative in the public mind and stereotypes may be applied to all the many and various individuals who are categorised in this way. This is one reason why Helen Bamber worked collaboratively with each client to consider their own specific circumstances, needs and opinions and importantly, to rediscover their individuality, resilience and creativity. In >Therapists as Advocates she explains that the need to protect traumatised and exiled people in practical ways is of equal significance to the intricate, therapeutic work which is required for their sustained recovery.

\section{Helen Bamber's Career}

Helen Bamber began her career working with the Jewish Relief Unit at the Bergen Belsen Concentration Camp in Germany from 1945-1947. There, she learned that >compassion has a short life lations are fully recognised. There was international condemnation of the crimes committed during the holocaust, which caused shock and outrage. She saw the immediate outpouring of sympathy for camp inmates who were left barely alive having been tortured, starved and enslaved. Despite their suffering, thousands of these survivors were forced to remain in camps until the early 1950 s, because no country was willing to accept them. Helen said of this time:

»They began to be referred to differently, no longer known as >victims〈 or >survivors $\measuredangle$ but $>$ displaced persons $\measuredangle$. As time went on this was shortened simply to $\gg \mathrm{DPs} \varsigma$. I learned that given certain circumstances, quite ordinary people can become perpetrators. Caring organisations can bend under criticism and hostility directed against the people they are there to help. It was at Bergen-Belsen that I vowed never to be a bystander.«

In 1947 she was appointed to the Committee for the Care of Children from Concentration Camps. This was a scheme sponsored by the British Government to bring 732 orphaned child survivors to the UK and introduce them to a new life. 
»The children had been forced into the torments of the ghettos, concentration camps, slave labour camps and death marches, often witnessing at first-hand the death of their parents and siblings."

In contrast to the rather authoritative and disciplinarian response to these children at the time, Helen Bamber offered them a sympathetic, listening ear. She was able to tolerate and understand their anger, and to allow them space to talk about their memories and dreams. She understood why the boys wanted to be physically tough in order to reclaim their bodies after they had been so brutally abused. She did not expect them to forget about the past as so many survivors are urged to do, and this insight would inform her later work with torture victims. In her interview with Freihart Regner she said that, »Justice comes in many forms of acknowledgement, not only >forgiveness $<$, or >moving on««.

Helen Bamber continued to work with people who had suffered torture throughout ongoing world crises, campaigning consistently for the principles of the Universal Declaration of Human Rights. In 1961, she began working with Amnesty International to publicise cases of disappearances in Chile and other countries, focusing on the complicity of some doctors and other medics in torture. This work led to her to chairing the first Amnesty International Medical Group, where dedicated GPs, surgeons, psychologists and psychiatrists collated individual testimony and documented evidence of state torture for submission to the UN Rapporteur on Torture. Speaking at her Memorial in 2013, Jim Welsh of Amnesty International said:

»Half a century ago in the 1960s, human rights may have been universal but they were not universally known, and were regarded with suspicion in some sectors in society, including the medical profession. Few organizations systematically monitored human rights. Helen Bamber came to believe that a fusion of ethical medicine and political change was desperately needed; the Amnesty Medical Group was the result.«

Helen Bamber knew that doctors, who were trying to treat torture survivors arriving in the UK, experienced serious difficulties because of the specialised nature of this work. She recognised the need to provide multi-faceted practical support and advocacy. 
»One $\mathrm{GP}^{4}$ said to me, >I have a group of exiles from Chile living in South London. They have all been tortured. I do not have the time to address their physical and psychological problems, I do not have the time to look at marriages which have been broken by torture, the sexuality which has been compromised, to listen to the children because no-one can hear them - I do not have time to listen to their silences««.

In 1985 she founded the Medical Foundation for the Care of Victims of Torture, which began its life in two rooms of an abandoned hospital in London and grew into a world-renowned organisation. Helen Bamber remained at the Medical Foundation as its Clinical Director for the next twenty years. Her human rights work was recognised with many awards, including the OBE in 1997, and honorary degrees from 11 universities.

Throughout her life Helen Bamber was concerned to help all survivors of human rights violations, not only those who had suffered state torture. In 2005 she established the Helen Bamber Foundation in order to provide the Model of Integrated Care to a wider remit of clients including survivors of war, torture, human trafficking/slavery, identity-based violence, community and familial violence.

»I believe that all people who have suffered extreme inter-personal violence, experience the same psychological and physical symptoms and enduring trauma. The individual should not be defined by the identity of the perpetrator, but, instead by the deprivation, loss and damage suffered. I have learned that victims of extreme human cruelty remain vulnerable to further harm and trauma. We need to think in terms of sustained recovery rather than cure.«

Today, HBF's multi-disciplinary team of clinicians, therapists and other specialists continue to deliver the Model of Integrated Care which is based on Helen Bamber's pioneering work. It is continuously developed, monitored and evaluated to ensure that clinical methods and therapeutic techniques are evidence-based, effective for each individual client, and shared as widely as possible through HBF's training and publications.

In an ever-changing landscape of world events and crises, Helen Bamber's words resonate, never more so than now: »I find heroism in our cli-

4 This refers to a General Practitioner (medical doctor). 
ents[']: despite all they have been through they find the remnants of resilience and courage to face continuing adversity.«

At the end of her life her main concern was, »There is so much left to do.«

\section{References}

Organization for Security and Cooperation in Europe (2013): »Trafficking in Human Beings. Amounting to Torture and other Forms of Illtreatment«, Vienna, Online: https:/www.osce.org/cthb/103085?down load=true [03.07.2017].

Witkin, Rachel on behalf of Helen Bamber Foundation (2013): »Clinical Links Between Human Trafficking and Torture«, Part II, in: Organization for Security and Cooperation in Europe (2013), 45-117.

WHO (2017): »Female genital mutilation«, Fact Sheet, updated February 2017, Online: http://www.who.int/mediacentre/factsheets/fs241/en/ [03.07.2017]. 



\section{Therapists as Advocates}

\section{A Conversation with Helen Bamber ${ }^{1}$}

FREIHART REGNER, RACHEL WITKIN

\section{INTRODUCTION}

Helen Bamber began her career in 1945 at the age of 20, working with survivors of the Nazi Holocaust in the former concentration camp of Bergen Belsen. She dedicated the rest of her life to people who have experienced torture, human trafficking, slavery and other forms of extreme human cruelty. She was renowned for her energetic compassion, helping thousands of men, women and children to confront the horror and brutality of their experiences, and supporting them in their pursuit of dignity and human rights.

Helen Bamber's intricate focus on the individual needs of each person she worked with gave her the ability to navigate the complexity of trauma and human responses to it. She pioneered methods to enable her clients to achieve what she termed >Creative Survival which is delivered within an individually tailored Model of Integrated Care. This includes psychological therapy, medico-legal documentation of injuries, medical advice and access to healthcare services, legal, welfare and housing support, a therapeutic community for parents and children and a creative arts and skills programme to support the challenges of integration through further education. These methods are in practice today at the Helen Bamber

1 First published in »Menschenrechte und Gesundheit«, see www.amnestygesundheit.de (16.06.2017). The version in this paper has been re-edited. 
Foundation (HBF), the London human rights charity which she founded in 2005.

An interview with Helen Bamber was conducted by Freihart Regner as part of his doctoral thesis on »normative empowerment «. ${ }^{2}$ The interview took place at the Medical Foundation for the Care of Victims of Torture in London on 18 September 2002 and at the Evangelische Akademie, Bad Boll, Germany on 2 October 2002. ${ }^{3}$ The lecture paper 'Therapists As Advocates' was presented at the International EFI Conference in Berlin at the Berlin-Brandenburg Academy of Sciences in September 2015 together with a retrospective on the life and work of Helen Bamber and the ongoing work of the Helen Bamber Foundation. ${ }^{4}$ Here, the conversation from Regner's interview has been organised to form a lecture which is in keeping with Helen Bamber's spoken words.

\section{ACKNOWLEDGEMENT THROUGH DOCUMENTATION OF SURVIVORS' EXPERIENCES}

»An important task for a therapist is to recognise what a person has suffered through the careful documentation of their experiences, as well as verbal affirmation. There is no acceptance by perpetrators that torture has been inflicted, so there is a climate of denial. It is such a shameful and difficult subject for people that they repress their feelings about what has happened to them. Therefore the first thing that I do is talk to them about

2 »Normative Empowerment describes a basic conceptual attitude for psychosocial and therapeutic practice with politically traumatised persons based on the values of human rights. The main theme is that of empowering people who have experienced traumatogenic powerlessness and injustice and supporting them in claiming their rights. Therapeutic efforts should be made within the framework of and permeated by this political and legal conceptualisation. « cf. Regner (2006).

3 Client cases that are described in the course of this interview have been adjusted where necessary to ensure that confidentiality is protected.

4 By invitation from the Germany Health Professional Network of Amnesty International. 
their experience, acknowledge it and document their story, their injuries and their psychological difficulties.

The taking of history, the taking of testimony, the documentation of a person's suffering by doctors, therapists and others, whether there are physical signs of injury or not, is significant. It provides acknowledgement and validation of survivors' experiences. It can support their claim for asylum, and it also becomes a historical document which could eventually be used in the International Criminal Court at The Hague or other legal forums where perpetrators are brought to justice.«

\section{The Therapist as Advocate}

»I am talking about the therapist as an advocate, not solely as a therapist. When a person sees that the therapist is part of their search for justice, and is not only working with their internal world, a different relationship is formed. As therapists who work with survivors of human rights violations we are operating within a political arena, so it is important that we declare this through our work and through documentation of our clients' experiences.

Survivors present to us with many physical and practical problems that need to be addressed. As an advocate the therapist will take up the practical and legal issues of a client's case, as well as looking at the clinical treatment that they need. I recommend a combination of therapy, practical skills and adaptations. You cannot begin to treat a person appropriately if they are desperately concerned about their future, about the past, and about the present. What your client brings to you from the refugee world are the practical things: lack of housing, lack of money, not being able to work or study, being separated from their families. I help them to register with good NHS (National Health Service) doctors and we will take up the case at various levels: housing, welfare, health, asylum, education, occupation and the legal procedures for family reunion.

The question of justice then becomes one for your own society: do they have, for example, the right to access appropriate medical care? Will they be treated with the same respect as other people? If not, their sense of injustice may be carried on from the country of origin to the country in which they find themselves. Many of them have a sense of injustice not 
only about what has happened to them and the political dilemma from which they came, but also about their situation now. Their backgrounds are often disbelieved by government officials, and they may be refused registration at NHS medical practices due to a reluctance to accept them, and the challenges integral to working with them, for example the need to use interpreting services.

Then of course there is their claim for asylum. They usually have to face many legal obstacles before they can, if they are lucky, be granted leave to remain in the UK. Many are initially refused protection by the Government due to a stated disbelief about their case, so their sense of injustice becomes magnified. They feel that they have come to a country in hope of receiving justice and recognition and have found that there is none. I am sure it is the same in Germany and throughout Europe.«

\section{The Sense of Injustice of Political Activists in Exile: The ChILEAN Group}

»I am working with a group of middle-aged Chileans who took part in the political struggle against Pinochet's regime in the 1970s. They lost that struggle, they were tortured and some of their relatives were >disappeared When they arrived in the UK, I was working on Chile for Amnesty International and we documented their cases at the Amnesty International Medical Group.

Many of them had been university students or trade union leaders in Chile, but they had not found a rightful place for their skills in our society. They said they wanted me to run a group for them because they were finding it difficult. They still had one foot in Chile, one foot in this country and their children did not always understand what had happened to them and why they had come to the UK. When I first went to the community centre that they had set up in the North of England, they sat me down at a table with a pen and paper. Everyone had bits of paper and it was like a trade union or a political meeting. I went along with this and I didn't change it. We just talked about what was worrying them. So I think the group I ran was a mixture of a political meeting and a therapeutic group, although they never saw themselves as a therapeutic group at first. They just wanted an understanding of how to go forward. 
When Pinochet was arrested in London in $1998,{ }^{5}$ these Chileans had been living in the UK for over 20 years and about one year before his arrest, I had begun to work with the group once again, this time as a therapist.

I found that they had crushed and submerged a great deal of their longing for justice. They had not acknowledged it, they did not know it existed anymore. They were struggling in a fairly hostile society to find a way to bring up their children, to battle with the schools about remarks made about their children, to keep alive something that was very special in their own culture. They cried a lot, they were grieving, and I said to them, >Do you understand that you have never really grieved? This is why you are finding it so difficult. You have never cried, you have never grieved for all your losses and you have never grieved communally. You have fought each other about your political views and your different political positions in Chile, but you haven't grieved`. So the group had re-started in this way.

We had kept the group going over a period of a year and one day a man said, >This is a therapeutic group!^ He said it, I didn't say it. So one aspect of the process was their grief, and saying goodbye to Chile, realising that they would not go back, that there was no place for them there. They knew that they would now be called >gringos` in Chile and they would not feel at home there. They did not feel at home in England really either. I think therapy is always about reality and here it was about coming to terms with who they were, what they had, and how to speak to their children. The main problems that they brought to me were about their children. What they often say is >I live only for the children`, and that is dangerous.

5 »General Augusto Pinochet was indicted for human rights violations committed in his native Chile by Spanish magistrate Baltasar Garzón on 10 October 1998. He was arrested in London six days later and held for a year and a half before finally being released by the British government in March 2000. His arrest in London made the frontpage of newspapers worldwide as not only did it involve the head of the military dictatorship that ruled Chile between 1973 and 1990, but it was the first time that several European judges applied the principle of universal jurisdiction, declaring themselves competent to judge crimes committed by former heads of state, despite local amnesty laws." See en.wikipedia.org/wiki//Indictment_and_arrest_of_Augusto_Pinochet [08.04.2015]; Amnesty International (2013). 
Another aspect of this process was to give them back a sense of their resilience and to reflect upon whether they could accept their situation. One woman who was teaching Spanish part-time at the university, cried a lot about her child. She said >I can't even speak English as well as my child does $\prec$ I asked her, >But how many languages does your child speak?« She said, >Well she speaks English<. I said, >And how many languages do you speak? She spoke about four! I didn't say anything else but everybody laughed of course, and she laughed. There were tears and laughter. So you can do quite small interventions in a group, it was charming, she is actually a very intellectual woman.

The man who had first called it a therapeutic group had realised that they were dealing with their feelings rather than their political concepts. He understood this because he had cried a lot in the group, and it was something that I have rarely seen in a communal setting, except at a catastrophic event where you get sobbing and screaming and crying. Here you got sustained, uncontrollable sobbing by everybody there, and it was a releasing process. All of this happened before Pinochet was arrested, it was nothing to do with him, it was to do with the beginning of the therapeutic group. It was not easy to run that group because of their political positions. Just imagine starting a group with everybody with pens and papers, to a point where it became understood that we were dealing with our feelings.«

\section{Pinochet's ARREst in London, 1998-2000}

»When Pinochet was arrested in London, the Chileans mobilised. They had always maintained a community centre where they put on Chilean activities, taught their children Spanish and so forth. Now they formed themselves into a committee with computers and telephones. I managed this situation from the therapeutic point of view by being very open with them. I had known them first when they were on hunger strike, when they had been tortured and needed our help. Now, instead of being victims upon whom we called for assistance, they became active in trying to bring Pinochet to justice.

The early documentation of their cases had become highly significant: if we had not documented the cases of these Chilean exiles when they first 
came to the UK, we would not have been in a position to take part in the legal case against Pinochet. The group gathered new information from Chile and asked Chileans who were living in other countries to come to us so that we could document their cases.

Our aim has always been to advocate using evidence that we have produced. In other words, we do not just speak, we speak only if we have the evidence, and we had a good deal of evidence against Pinochet. We had many documented cases of torture and we had people with us who had been tortured. I think that sometimes therapists lose the capacity to see their client as a person who has potency and strengths and resilience, and we have to work with that, as well as with victimhood. I had worked for a long time with the victimhood in this Chilean community, and I saw the possibility of something else. We began to work together, joining with Amnesty International and human rights lawyers in order to provide evidence.

The Chilean group was invigorated by this event. Although Pinochet was not brought to full trial, their sense of injustice was alleviated to some extent because they were able to see him appear in a magistrates' court in London to hear the allegations against him. They felt he had been shamed and reduced, and that was very important for them. The whole world, and the world's media, was speaking and writing about Pinochet's crimes. People do not generally use the word >justice`, but they did in the Pinochet context because the word >justice place: >Bring Pinochet to justice, bring the torturers to justice and it is still being used because torturers are being pursued now in Chile. Suddenly Chilean people who had submerged their feelings in order to survive within family and work settings in the UK began to feel potent.

I asked those who felt able to speak if they were prepared to take part in interviews. I think that one has to use people's own sense of advocacy when it is appropriate and if they feel able to do it. You have to be open with them about what an interview means though: it has expectations, you want change to come from it and change does not always come. You have to be very honest, but you are also speaking to people who have been politically active and have not lost their capacity to be realistic and understand the limitations. I accompanied them to all the interviews that took place - CNN, BBC, the World Service. For them, being able to speak to the media was empowering. I was with them during the interviews and I was interviewed many times myself. 
It was a very difficult thing for them to do. They spoke about their dreams, their shattered dreams and their torture. I am not keen on the word >healing therapeutic aspect came in, because it was upsetting and it brought back many memories and a lot of pain. It was important that we had the time and space to talk about what it was doing to them and to be open about whether they'd had enough, and if they felt that what they had done was sufficient.

I accompanied the group in the role of therapist and advocate. I have never been able to separate the two because I find that advocacy is part of the therapeutic process. Whilst I dealt with a lot of their tears, their pain and their anger, I was also able to accompany them to speak publicly, to go to the House of Lords, to go out on the streets and see the public interest in the case. So there had been preparation for Pinochet, and I suppose, I have to be honest, I am a political activist as well as a therapist. It is a double act which you have to be very careful about and you have to be honest about it. In any case, everybody was prepared for the interviews, and the whole group did very well.«

\section{The Pinochet Event in Retrospect}

»The dynamics of the group changed after the Pinochet event: immediately afterwards there was a sense of realism. They were politically aware enough to know that there was not going to be a full trial in the UK despite enormous efforts. However, they felt that something of a victory had been obtained because they had been acknowledged and they now felt there was a future for justice. They knew that some torturers in Chile had become frightened and fled South, and Pinochet had been humiliated.

After Pinochet left the UK the group still had many of the same problems that they had before. But had there been a change? We looked afterwards at what had happened: did they have more sense of justice? I think they did. They personally had more sense of justice and recognition. They had been able to speak publicly about being tortured and persecuted, they had been interviewed in the media, they had spoken and been heard, acknowledged by politicians on all sides. It's true they had to go back to being cleaners, or teaching Spanish or living off benefits - and many had been seriously damaged physically and psychologically by the torture they 
had suffered. ${ }^{6}$ However, there is something about political and legal justice that recognises what has happened to you. This is what we see refugees suffer every day: a total lack of acknowledgement. So it is to do with justice in emotional terms.

Speaking to their children had formed the essence of the therapeutic group from its beginning, because they felt they had lost contact with them. They were keeping many of their Chilean characteristics going, but the children were not so interested in what their parents had to say: they wanted to integrate, to be like every other child, to play football. This changed when Pinochet was arrested in the UK, because the children saw their parents in a different light, and we were able to work with the issues that emerged.

I suppose what also came out of the group concerned their differences from each other. Some were originally from very simple backgrounds and others from far more sophisticated backgrounds. Their politics had varied depending on which political organisation they had belonged to, which always matters terribly to them of course. So they had other difficulties in being thrown together as a community, which we ought to understand. Had they remained in their own environment they would have kept within their own social structure, whereas this group, because they were Chilean exiles, stayed together. They had enormous differences, so this was something else we needed to think about in the group: the differences between them which they had never thought about because they had always seen themselves collectively as Chilean politicos. This also touches on the question of justice, because there was envy in the group, and we had to acknowledge it. As we got deeper into the therapeutic content, we began to talk about the anger and envy that existed within the group and the feelings that members had towards each other. There was also a >hierarchy of suffering<, as to who had suffered the most. So there was injustice within the group and we were able to resolve some of this together.«

»I do not think that we could have achieved all that we did without the opportunity presented by Pinochet coming to London. It was such an extraordinary event, Pinochet being arrested by policemen in London,

6 See https://en.wikipedia.org/wiki//Indictment_and_arrest_of_Augusto_Pinochet [08.04.2015]; Amnesty International (2013). 
which is crazy, which is wonderful! I do believe that the work we did in the group - hard, grinding work - was good preparation. They had become more mature, I would say. Who knows how they would have reacted if his arrest had happened earlier? It could have been a negative experience with the group and their difficult feelings with each other.

We spoke a lot in the group about being defeated and what >defeat< means. One day a man said, II'm not going to be able to go back to Chile to live. I will visit, I will be called a 'gringo' and I will come back again. My dream of Chile has gone.< So they were able to let go of a dream. However, he said something interesting: >There was a defeat but it wasn't 'mine' or 'our' defeat<. He meant that in losing them, Chile had lost something good, but they had each kept their integrity. This is what the group really achieved: the sense that there was integrity in the group and within each individual. It had not been lost and this helped them in quite a profound way.«

\section{RECOGNISING LACK OF JUSTICE: TURKISH-KURDS}

"Of course we see many people in this country who have not had the opportunity of the Chilean group. Sometimes you need to recognise with a client that they may never get the justice they want, and that their country may not move towards the progress that they wanted to see happen. It is a difficult job for the therapist but it is important. I see Turkish-Kurdish people who have been persecuted since they were children. Their villages were ransacked, their cattle were killed, they were persecuted in the schools and not allowed to speak their Kurdish language. They have a long history of persecution and tragedy and they find living in exile very difficult. Some go on hunger strike when there is a protest in Turkey or when people are killed. It is a collective sense of injustice and they carry it with them like a flag, a kind of emblem.

Many of them make a living here. Once they are established, they set up their workshops and their kebab shops and they become quite competitive. They do very well sometimes, although not always. We are also working with impoverished Turkish-Kurds, many of whom face enforced return to Turkey. I am fighting their cases. 
I think that the people I work with carry a sense of loss and injustice that they will always carry. It is not the only thing that they bring to the therapy room, but it's an inevitable part of it. Having their histories acknowledged means a great deal to them. They are impressed that there is a file with their history - not only their injuries, not just their suffering and the medication that their doctor prescribes for them, but their history, their story. They know that there may be a time when this can be used, when torturers from Turkey are brought to trial. We cannot be sure of that, but we have to work for it together.«

\section{Moving from a Political Struggle TO A HuMAN RightS StRUgGLE: A Woman fRom the Middle EAst}

»Making an issue of the sense of injustice is, in a way, therapeutic too. It can be quite empowering. I am working with a woman from a Middle Eastern country who was very political and had joined a hardline, militant opposition group. She was tortured, raped, all of it. She is now beginning to realise that their way of trying to fight while they are here in exile is not changing anything in her home country, it is just hurting them a great deal. I think many people move from a more militant political struggle to a human rights struggle once they are living in exile. They need to think in terms of establishing their rights under the various UN Conventions. I believe it is our job to help them to do this, to understand that there are international Conventions that are there to protect them.

It is not that she is giving up her political beliefs - I would be the last person to expect that - but we have looked at how she can empower her community here to get what they need; to be able to speak their original language, to teach the children that language so they do not lose it, to have a community that keeps alive many of the things that are important to them. These are not just the political issues, but can be food, music, fun, anything. We helped this woman to get asylum eventually, and now she is taking up a childcare course so that she can empower fellow women here to do other things while their children are being taken care of. They do not have to just be a servant in their home, but they too can learn English, go and study, or engage in other activities. 
It has given her a tremendous sense of justice for women. She does not use the word justice, and I am not sure she considers it that way, but she thinks about women becoming more creative, and having a place and a voice in their society. It is not just about women being able to join a political struggle anymore, because many women of her ethnic group have played a strong role in that. She will always feel part of that struggle, but she is doing something now which is giving her the courage to see herself in a much broader way, continuing with her studies and doing challenging things on her course. At the moment it is the men who go to the coffee house and into the community and the women who stay at home. This way she is doing something quite imaginative for the future of her community here, which is actually about justice.«

\section{Injustice in Family, Culture and Politics: A WOMAN FROM EUROPE}

»I think it is a mistake to only consider the political arena. I have clients who bring a sense of injustice which originates from their home life, so the therapist needs to consider their childhood, to go through the experience of their family home, their school and - only then - their political life. I am not sure you can simply separate each of these out, or look only at political injustice.

I am working with a European woman who was abducted and raped by soldiers during a war in her home country. Such was the tragedy of her experience of the war that she has never been able to disclose it to anyone. She says that because of her community's patriarchal culture she could be rejected, or possibly even killed. Now there are two areas of injustice here: one is the terrible tragedy of war, in which innocent people can be taken and abused. Another is the fact that, after having experienced this tragedy, she cannot receive the normal sympathy, care and understanding from her community that one would hope for, quite the contrary. We must look at this as well, and explore it with our client.

This woman also experienced injustice in her family home from childhood: she was not allowed to do the things she wanted, not permitted to study, and she was treated as a kind of servant in the household. She had to be extremely obedient, any sign of deviation from expected behaviour 
would result in a beating. Dancing, singing, all the things that young people like to enjoy were denied to her. Then there was an arranged marriage imposed upon her. So it would be a mistake to look only at the political scene and the tragedy that happened to her. Did she think that it was unjust that because she is a woman she had to be obedient, that she had to take off her father's coat and serve him? She just said to me >This is how it is in my home country<.

My work then was in finding out how she felt about it. Without using the word >injustice`, how did this make her feel as a young person? What did she feel then about her parents, about her home, about her society? I think she feels that the situation for women in her country and in other countries is terrible, but she is not looking for political justice for herself. She has grown up in a system which was imposed upon her by her own community, quite apart from the brutality of the war. She had felt that there was no one to help her in her predicament. I find that people do not use the word sjustice< very much, there is not always an expectation of justice in the region that they were brought up in, but they do seek it in different ways. I would use the word >right it was right? What was wrong in that situation, for her?

I wanted her to be able to express her feelings, because she has two children and she does not believe that she can be a good role model for them. My great concern is about generational perpetuation of trauma, so I explored with her how she felt when her needs were not acknowledged by her family members, and how we can begin to change how she reacts to her own children; how she feels about herself and about them. She loves her children very much, but she would shrug and say, >Well that's how it is I might then say to her, >Well do you think we can change that, and if so, how?« >Do you want to change things for your children or do you want to go on in the same way that you knew before? I would not rush to look at how we can make changes, but rather allow her to express herself, and enable her to do it herself, without guilt feelings. Every person has feelings for their parents, no matter how questionable their actions may be. I always work with clients who have suffered this kind of injustice within their communities on the understanding that their parents did not know anything else. They were born into a situation in which everything they did was simply what everyone else did, and it was acceptable. There is no need to blame her parents or even her community, that is just >how it is.< However 
now she is in a different situation, in a new country, how does she feel about what she wants to do?

She is an extremely bright woman, very clever. It would give her a tremendous sense - whether it is justice, it may be - to fulfil her dream to go to university. This is possible for a mother in a Western society. I do not know whether her husband would allow it, but I believe it would be recognition of all that she lost in the course of her early childhood when she was forbidden to study. I hope that by working with both the husband and the wife there may eventually be recognition on his part that she should go to university. This does not put right the early injustice in her family or the terrible injustice of the war which assaulted her so badly, but it is one way of looking at how she can achieve something that was absolutely denied to her. She was told by her community and by the events of the war itself that she was nothing, deserved nothing. So in this case working with the inner world is not enough, certain practical things need to be put in place. It is worth considering that there is an Open University ${ }^{7}$ which enables people to study at home. There are many other things that are needed for her, but being able to pursue her education would give her a sense of recognition.

Change - and this is a political word really - change can be made. She is excited by the idea of change. Although she does not feel she can get justice for herself, she might be able to provide more justice for her children. She is interested in looking at the ways I have been able to work with her in relation to her husband. When she married him she was very young and she wasn't able to assert herself. Now she has told him - not asked him, but told him - that she is coming to see me because she thinks it will help her with her asylum claim, her poor health and her future. She also believes that it helps her to manage her children better. This did not happen overnight, it took time. I go very slowly and it's difficult. You could not put on paper what you have achieved in one session because it is so small. However, there are little areas of change, and recently she has brought her children to a session with me for the first time."

7 The Open University is a public distance learning and research university, and one of the biggest universities in the UK for undergraduate education: www.open.ac.uk. 


\section{The Concept of Justice}

»I think my irritation towards the concept of justice when we started with this interview was really to do with the fact that as therapists working in Europe with people who have been tortured, abused, who have been war victims, misused as slaves - we are ourselves working in an atmosphere of injustice towards our clients. I mean the injustice of the rhetoric that is used politically and publicly against them, the asylum legislation that becomes more and more punitive, the harsh decisions to send people back to their countries when we know perfectly well that they are likely to be tortured or >disappeared . So the question of justice applies to us as much as it does to our client, and it forces us into the role of being an advocate for them. It is irritating because it brings out the advocate in us, the sense of injustice on behalf of our client and on behalf of ourselves.

I have never really been preoccupied with what my father called sthe enemy<. He once said to me, >Don't waste your hatred and your time with the enemy. You'll recognise the enemy, you'll work against the enemy, so don't waste your energy. Attend to the bystander, attend to the people who allow these things to happen! I think that in a way my anger and my irritation about injustice is most definitely towards my own Government and government policy. What the client brings to me in many cases - not all, I am not going to generalise here - is the injustice of the system in which they now find themselves, and the final disappointment and disillusion from believing that the United Kingdom is a country where they will be given a full and fair hearing. This is a final piece of the destruction in their belief system.

I believe that a sense of justice becomes applicable only when people are more settled and stabilised. They may have obtained their safety in the country, which is something, they may still be fighting for housing and the right to work and to be accepted, but they will be in a better position now to look back upon their original tragedy. It is then that you are able to unravel some of the most difficult feelings that people have about what is, very often, their lost political cause. Most refugees have lost the political battle, the change that they wanted to bring about in their country. This is a good point to talk and listen, to flush out and try to disentangle the complicated feelings that people have about lack of justice. 
So justice is an essential component of therapy in such cases, perhaps the most important component, but we do not verbalise it very much. I think we should try to explore it more. [...] We do not often see the original search for justice, but I believe that this search goes on with people in some way. With the Chilean group for instance, they do not expect to have justice in the way that they wanted it originally. They have had a success with the Pinochet event, they saw him humiliated and they got a lot from that, above all a sense of recognition. However, justice is also about the public, the host community, about an understanding of who they are and what they are. For example, there is an >Artists in Exile< group, which has exhibitions, music, art and theatre. This is one way of expressing to the public whatever they want to express. Public recognition is terribly important: it is the denial of public interest that accentuates the sense of injustice. It is difficult for some therapists to see themselves as advocates and it is important to recognise this. It goes against their training and it can cause a conflict. There is a jump to be made: you need to accept that we are working in a political and social environment which not only affects the lives of our clients, but our own lives as well. We can acknowledge their suffering but often we cannot bring the justice that would make the difference. We can be part of the pursuit of justice though. It is important for therapists not to feel powerless as they often do, but to think a little bit >side-laterally<, to see whether there is a way in which they can use documented evidence of injuries and work more with the legal justice system for their client as well as working through feelings. This way we can be more powerful as therapists.« 


\section{References}

Amnesty International (2013): How General Pinochet's detention changed the meaning of justice, News, 16 October 2013, Online: https:/www.amnesty.org/en/latest/news/2013/10/how-general-pinochetsdetention-changed-meaning-justice/ [19.04.2015].

Regner, Freihart (2006): »Normatives Empowerment. Das Unrechtserleben bei politisch Traumatisierten aus der Sicht von Unterstützern im Therapieumfeld - Möglichkeiten psychosozialer und stherapeutischer` Bearbeitung«, Online: http://www.diss.fu-berlin.de/diss/receive/ FUDISS_thesis_000000001964?lang=en [22.11.2016]. 



\section{Authors}

\section{Lucía Berro Pizzarossa, LLM}

Global Health Law Groningen Research Centre

Department of International Law, Faculty of Law

University of Groningen

Oude Kijk in't Jatstraat 26

9712 EK Groningen (Netherlands)

\section{Prof. Dr. phil. Dr. h.c. Heiner Bielefeldt}

Chair in Human Rights and Human Rights Politics

University of Erlangen-Nuremberg

Kochstraße 4

91054 Erlangen (Germany)

Dr. Claire E. Brolan. MA, LLB, BA

Dalla Lana School of Public Health

155 College St, Toronto

ON M5T 3M7 (Canada)

PD Dr. med. Walter Bruchhausen, M.Phil., Dipl.-Theol.

Department for History of Health/Global Health

Institute for Hygiene and Public Health

University of Bonn

Sigmund-Freud-Str. 25

53127 Bonn (Germany) 


\section{Luljeta Caraoshi}

Rr. Bilal Golemi

Pall-33. H-5. Apt-7

Njesia Bashkiake Nr-5

Tirana 1060 (Albania)

Audrey R. Chapman, Ph.D.

UConn Health Center

University of Connecticut School of Law

55 Elizabeth Street

Hartford, CT 06105-2290 (USA)

\section{Prof. Dr. phil. Laura Clérico}

Faculty of Law

University of Erlangen-Nuremberg

Bismarckstraße 12

91054 Erlangen (Germany)

\section{Adriaan van Es, MD}

Regentesselaan 32

3818 HJ Amersfoort (Netherlands)

\section{Veronika Flegar, LLM}

Faculty of Law

University of Groningen

Oude Kijk in 't Jatstraat 26

9712 EK Groningen (Netherlands)

Prof. Dr. med. Andreas Frewer, M.A.

Professor for Medical Ethics

University of Erlangen-Nuremberg

Glückstraße 10

91054 Erlangen (Germany) 


\section{Prof. Lisa Forman, BA, LLB, MA, SJD}

Canada Research Chair in Human Rights and Global Health Equity

Dalla Lana School of Public Health

155 College Street,

Toronto, Ontario, M5T 3M7 (Canada)

Tessy Huss, Ph.D.

Centre for Global Health \& School of Psychology

Trinity College Dublin

7-9 Leinster Street South

Dublin 2 (Ireland)

\section{Dipl.-Pol. Sabine Klotz}

Chair in Human Rights and Human Rights Politics

University of Erlangen-Nuremberg

Kochstraße 4

91054 Erlangen (Germany)

\section{PD Dr. phil. Michael Krennerich}

Chair in Human Rights and Human Rights Politics

University of Erlangen-Nuremberg

Kochstraße 4

91054 Erlangen (Germany)

\section{Everaldo Lamprea}

Los Andes Law School

Los Andes University,

Carrera 1 No. 18A-12

Bogotá (Colombia)

\section{Prof. Malcolm MacLachlan, Ph.D.}

Department of Psychology

National University of Ireland Maynooth

Newtown Road, Kilcock,

Maynooth Co. Kildare (Ireland) 


\section{Dr. phil. Amrei Müller}

School of Law

Queen's University Belfast,

University Road

Belfast BT7 1NN (United Kingdom)

\section{Katrina Perehudoff}

Global Health Unit, Department of Health Sciences

University Medical Centre

University of Groningen

Antonius Deusinglaan 1

9713 AV Groningen (Netherlands)

\section{Dr. phil. Freihart Regner}

INTER HOMINES e.V.

Stargarder Str. 47

10437 Berlin (Germany)

\section{Prof. Brigit Toebes}

Associate Professor and Rosalind Franklin Fellow

Faculty of Law, University of Groningen

Oude Kijk in 't Jatstraat 26

9712 EK Groningen (Netherlands)

\section{Dr. phil. fac. theol. Martina Schmidhuber}

Institute for History of Medicine und Medical Ethics

University of Erlangen- Nuremberg

Glückstraße 10

91054 Erlangen (Germany)

\section{Marie-Noëlle Veys, LLM}

Mechelsesteenweg 103

2018 Antwerpen (Belgium) 


\section{Leticia Vita}

Instituto de Investigaciones Juridicas y Sociales Ambrosio Lucas Gioja Av. Figueroa Alcorta 2263

Primer Piso (C1425CKB)

Ciudad Autonoma de Buenos Aires (Argentina)

Dr. phil. Mathias Wirth

Feodor Lynen Postdoc

Yale Divinity School

409 Prospect St

New Haven, CT 06511 (USA)

\section{Rachel Witkin}

Helen Bamber Foundation,

Bruges Place

15-20 Baynes Street

Camden, London, NW1 0TF (England) 
